Portland State University

PDXScholar

Spring 6-8-2018

\title{
Composition and Dispersal Dynamics of Vegetation Communities in Urban Riparian Forests
}

Christa von Behren

Portland State University

Follow this and additional works at: https://pdxscholar.library.pdx.edu/open_access_etds

Part of the Botany Commons, and the Environmental Sciences Commons Let us know how access to this document benefits you.

\section{Recommended Citation}

von Behren, Christa, "Composition and Dispersal Dynamics of Vegetation Communities in Urban Riparian Forests" (2018). Dissertations and Theses. Paper 4409.

https://doi.org/10.15760/etd.6293

This Dissertation is brought to you for free and open access. It has been accepted for inclusion in Dissertations and Theses by an authorized administrator of PDXScholar. Please contact us if we can make this document more accessible: pdxscholar@pdx.edu. 
Composition and Dispersal Dynamics of Vegetation Communities in Urban Riparian Forests

by

Christa von Behren

A dissertation submitted in partial fulfillment of the requirements for the degree of

\author{
Doctor of Philosophy \\ in \\ Environmental Sciences and Resources
}

Dissertation Committee:

J. Alan Yeakley, Chair

Sarah Eppley

Martin Lafrenz

Joe Maser

Angela Strecker

Portland State University

2018 
(C) 2018 Christa von Behren 


\begin{abstract}
In urban riparian areas, vegetation composition may be affected by urban land use changes at both the stream reach and the watershed scale. Moreover, the mechanisms by which seeds disperse may be affected both by reduction in seed sources due to vegetation removal and by the urban stream syndrome that produces flashier hydrographs and incised channels. I hypothesized that vegetation communities with high cover of native and hydrophilic species would be found in watersheds with high forest cover, while more limited cover of these species would be found in highly developed watersheds. Additionally, to examine the dispersal mechanisms contributing to these patterns, I hypothesized that 1) more seeds would be deposited in riparian areas by water than by wind; 2) the number of seeds deposited by streams would decrease as watershed urbanization increased; and 3) seeds deposited in the most urbanized sites would be primarily from species with traits favoring deposition by water, including large seed size and presence of a dispersal appendage.

To investigate relationships between urban land cover types and riparian vegetation, I surveyed 30 randomly-selected riparian forests in the Portland-Vancouver metro area and related vegetation assemblages to watershed land cover. Vegetation was mapped to the nearest $1 \mathrm{~cm}$ along three transects in each site. Land cover was characterized both within a 500m buffer around each site, and within the entire watershed. Relationships between land cover and vegetation assemblages were investigated using nonmetric multidimensional scaling and classification trees. To
\end{abstract}


investigate the effect of watershed urbanization intensity on riparian seed deposition, I collected seeds deposited in nine riparian sites along a gradient of watershed total impervious area (TIA). I used a stratified-random approach to select sites. In each site, wind-deposited seeds were collected in funnel traps three times, and water-deposited seeds were collected in turf traps four times, over a 15-month period, spanning both wet and dry seasons.

Consistent with my first hypothesis, communities dominated by native understory species were found exclusively in watersheds that were at least $15 \%$ forested by evergreen canopy. These findings suggest that native understory communities can persist in urban areas if adequate surrounding forest cover is maintained. Regarding my second major hypothesis, significantly more seeds were deposited by water than by wind ( $\mathrm{p}<$ 0.05; mean of 155 seeds per turf trap; mean of 30 seeds per funnel trap). For shrubs, for species primarily dispersed by animals, and for species under $15 \mathrm{~m}$ tall, hydrochory significantly increased delivery to riparian areas over the background seed delivery rate measured in funnel traps. There was a significant reduction in the number of seeds deposited by streams as TIA increased (adjusted $\mathrm{R}^{2}=0.74 ; \mathrm{p}<0.01$ ). Deposition of shade-tolerant seeds decreased significantly, while deposition of non-native seeds increased significantly $(\mathrm{p}<0.05)$ with watershed TIA and with development within 500m from the site, likely due to alterations of seed source pools of these species.

Findings indicate that in an urban setting, small streams have the capacity to act as dispersal vectors, connecting fragmented populations that may otherwise be seedlimited. Riparian forests with diverse understory assemblages maintained by ongoing 
seed deposition may persist in urban areas with sufficient watershed forest, as well as with low development cover, in both the whole watershed and the near-stream area. Total seed deposition by streams, as well as deposition of shade-tolerant species, can be expected to decrease with increased watershed development. Results suggest that passive approaches to restoration of riparian forest understories in urban watersheds will only likely be successful with sufficiently high forest cover and with restricted development. 


\section{Acknowledgements}

I would first like to thank my advisor, Alan Yeakley, for encouraging me to pursue this work in the first place, and for providing the ongoing guidance and expertise that made this dissertation possible. I would also like to thank my dissertation committee members, Angela Strecker, Sarah Eppley, Joe Maser, and Martin Lafrenz for their thoughtful feedback and support. I am very grateful for the GK-12 Cascades to Coast Teaching Assistantship and Fellowship for providing much of the funding for this research. I am also grateful for the following funding sources: American Reinvestment and Recovery Act grant from the US Forest Service Pacific Norwest Research Station (to Alan Yeakley), Native Plant Society of Oregon research grant, Portland Garden Club Scholarship, GK-12 mini-grant, and Bushby Award. I am also grateful to Portland Parks and Recreation, Portland Bureau of Environmental Services, Oregon State Parks, Metro, Tualatin Hills Parks and Recreation Department, and Clackamas Water Environment Services for allowing me access to riparian areas under their management. Thank you also to the many private property owners who allowed me to access to riparian areas on their property.

The participation of so many people at various stages has made this work possible. I am especially grateful to Ed Guerrant and Kris Freitag for allowing me access to the seed lab, as well as the wonderful conversation that always came with it. I have been very fortunate to have many wonderful research assistants, including Jose Herrera, Ben Burton, Stephanie Zhao, Megan Mao, William Kerney, Laura Miller, Bobby 
Nuvolilni, Neal Robinson, Kristen Miller, Kristen Purdy, Kirsten Wright, and Troy McKinlay. I am thankful to for the encouragement and wisdom from members of the Yeakley lab: Sarah Kidd, Denisse Fisher de Leon, Ted Hart, Gunnar Johnson, Micelis Doyle, Robbie Lascheck, and especially my partner in crime for Chapter 2, Andrew Dietrich.

This work would not have been possible without the unwavering support from friends, and family, and coworkers. Thank you to Mark Davis for getting me interested in plants in the first place, and to Andrea Raven and Ed Guerrant for introducing me to the fascinating world of seeds. I would like to thank my BES coworkers for their support, ideas, and flexibility with my crazy schedule. Thank you to my parents, Jon and Barbara von Behren, for providing endless encouragement. Thank you to my mom as well for assistance in the field. I am particularly grateful to my partner, Ben Pollak, for keeping me fed and caffeinated, being my default field and lab assistant, providing support, and for making me laugh.

Finally, I would like to acknowledge the Chinook, Clackamas, and Tualatin people, on whose unceded land this research took place. 


\section{Table of Contents}

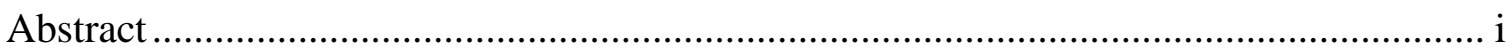

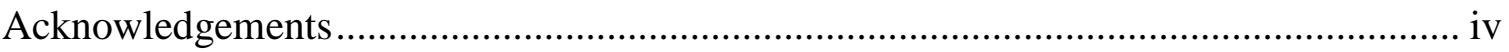

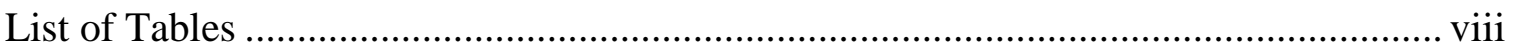

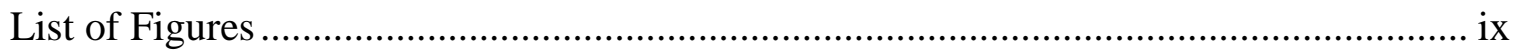

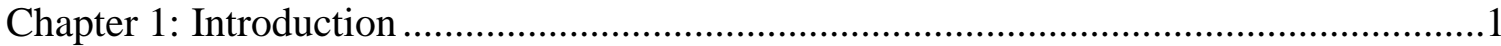

Ecosystem Functions of Riparian Forests .............................................................

Small Streams and Riparian Forests of the Pacific Northwest ................................... 3

Vegetation Patterns in Riparian Forests on Small Streams .......................................

Dispersal Limitation in Riparian Vegetation Community Formation ......................8

Urban Stream Syndrome..................................................................................

Response of Riparian vegetation to Urban Development........................................14

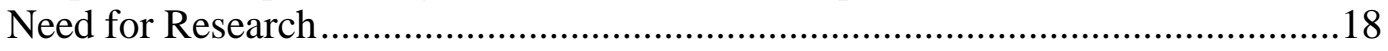

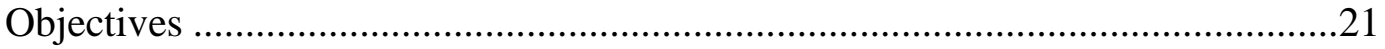

Chapter 2: Riparian Vegetation Assemblages and Associated Landscape Factors Across an Urbanizing Metropolitan Area ......................................................................23

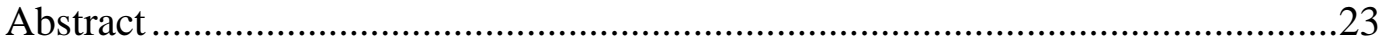

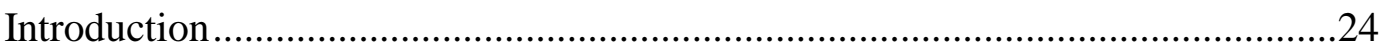

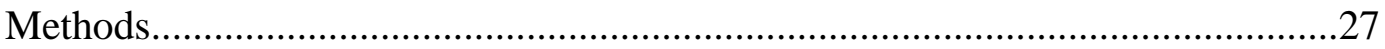

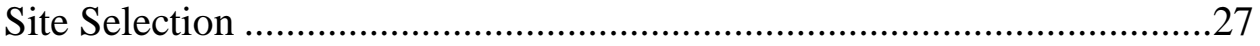

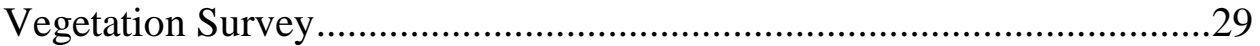

Watershed Characteristics......................................................................30

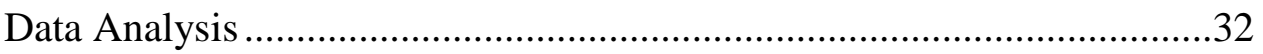

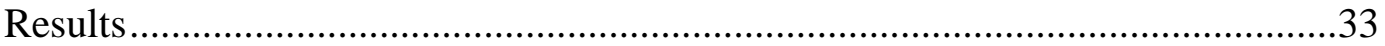

Cover by Vegetation Type ....................................................................

Watershed Characteristics and Association with Riparian

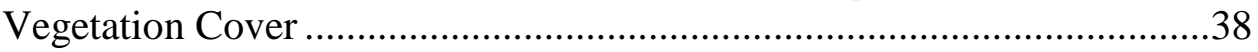

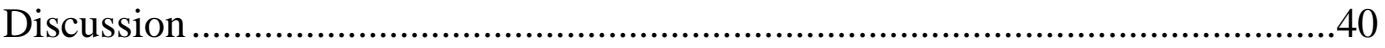

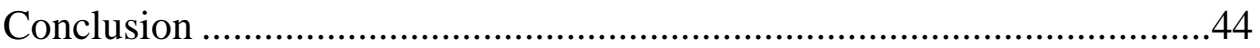


Chapter 3: Seed Deposition by Water and Wind in Riparian Forests Across an Urban Gradient

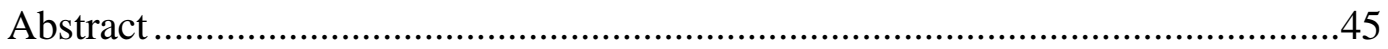

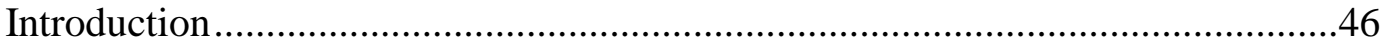

Urban Forest Fragmentation and Dispersal Limitation ..........................48

The Importance of Hydrochory for Urban Riparian Forests ....................49

Study Purpose and Hypotheses ..........................................................54

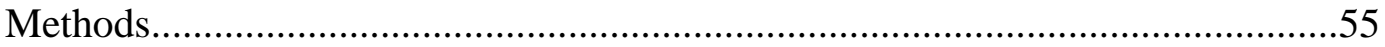

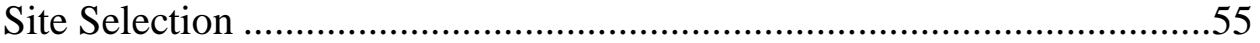

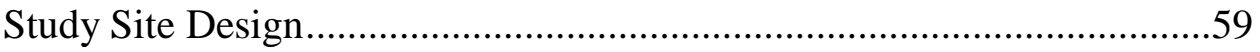

Seed Rain Sampling ......................................................................6

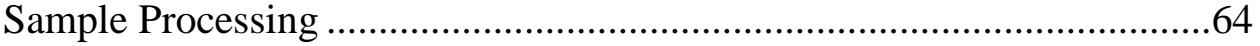

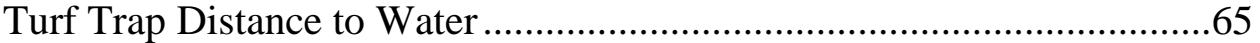

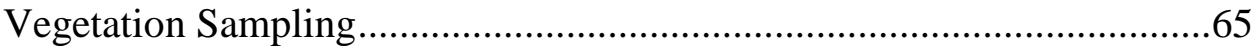

Landscape Analysis ...................................................................66

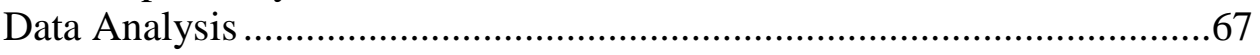

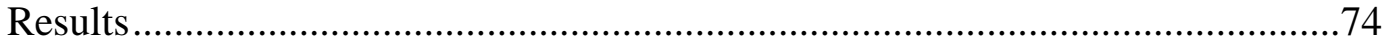

Land Use Composition of Study Watersheds .........................................74

Rainfall and Stream Hydrology across Study Sites .................................74

Site Standing Vegetation.................................................................8

Deposition Patterns in Turf and Funnel Traps .......................................85

Functional Group Patterns in Turf and Funnel Traps .............................98

Differences across the TIA Gradient: Deposition in Funnel Traps .........115

Differences across the TIA Gradient: Deposition in Turf Traps .............115

NMDS Results .....................................................................123

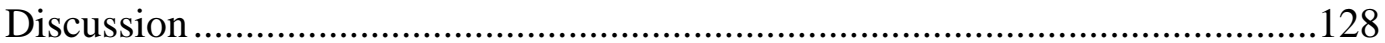

TIA, Land Use Patterns, and Hydrology .........................................128

Seed Deposition by Different Vectors in Urban Riparian Areas .............128

Changes in Seed Deposition by Hydrochory across an Urban

Gradient.....

Chapter 4: Conclusions and Management Implications ...........................................142

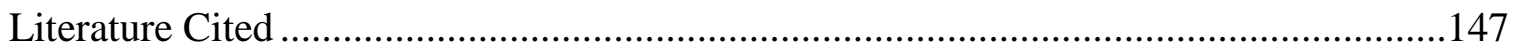

Appendix A: Functional Groups of Taxa Found in Seed Traps ...................................162

Appendix B: Water-to-Turf Distance and Total Seed Deposition................................166 


\section{List of Tables}

Table 2.1: Landscape variables measured within a 500m buffer and within the entire watershed

Table 2.2: Significant indicator species for cluster groups...............................................36

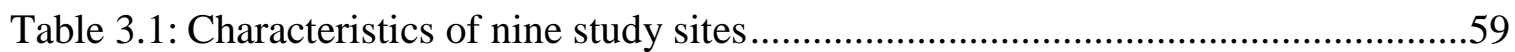

Table 3.2: Functional groups of taxa found in seed traps ................................................70

Table 3.3: Landscape cover by four densities of development and forest in watershed cones at three spatial scales from each site ......................................................77

Table 3.4: High pulse events during four collection periods at each site ..........................82

Table 3.5: Vegetation metrics in three strata across the nine study sites............................85

Table 3.6: Turf and funnel traps recovered in each site during the four collection periods

Table 3.7: Average aerial density of seeds per trap in each collection period across sites

Table 3.8: Forward selection of fixed effects in GLMM's explaining total number of seeds and species caught in seed traps.

Table 3.9: Parameters for selected models explaining total number of seeds caught in turf and funnel traps

Table 3.10: Parameters for selected models explaining species richness in turf and funnel traps

Table 3.11: Deposition patterns of different functional groups in turf traps .113

Table 3.12: Deposition patterns of different functional groups in funnel traps 114 


\section{List of Figures}

Figure 1.1: Rural and urban streams in NW Oregon ................................................11

Figure 2.1: Thirty study sites in the Portland-Vancouver metro area............................28

Figure 2.2: NMDS plot of study sites with associated landscape vectors .......................34

Figure 2.3: ( $\mathrm{a}$ and b) Native and non-native cover by cluster group; (c, d, and e) tree, shrub, and herb cover by cluster group..............................................38

Figure 2.4: Classification of sites by land cover variables .........................................40

Figure 3.1: Seeds with different primary dispersal mechanisms .................................53

Figure 3.2: Nine study sites in the Portland, Oregon metropolitan area..........................58

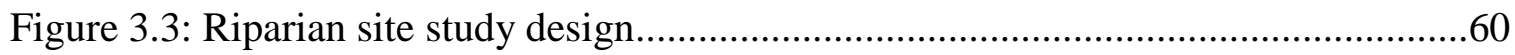

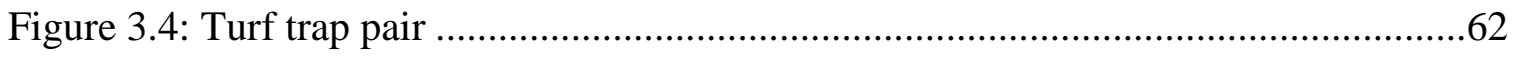

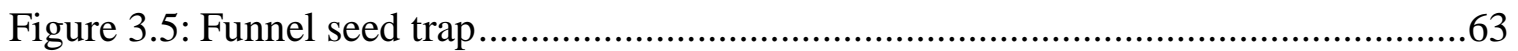

Figure 3.6: Cover by total development and forest in watersheds of study sites (top) and within a $250 \mathrm{~m}$ cone from each site (bottom) .....................................76

Figure 3.7: Water depth measured in study sites during p1 (January - March 2015) .......78

Figure 3.8: Water depth measured in study sites during p2 (March - July 2015) ............79

Figure 3.9: Water depth measured in study sites during p3 (July - November 2015) .....80

Figure 3.10: Water depth measured in study sites during p4 (November 2015 - March 2016)

Figure 3.11: Shrub and herbaceous cover in the understory at nine study sites .84

Figure 3.12: Cover by all shrub species and by Rubus spp. at nine study sites

Figure 3.13: Aerial density of Whole seeds in turf and funnel traps across four collection periods 
Figure 3.14: Species richness of Whole seeds in turf and funnel traps across four collection periods

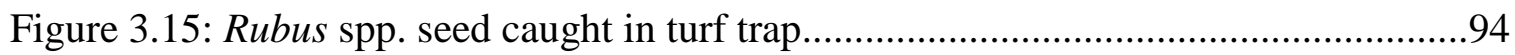

Figure 3.16: Whole Rubus spp. seeds caught in turf and funnel traps across four collection periods

Figure 3.17: Alnus rubra seed found in funnel trap.................................................96

Figure 3.18: Carex leptopoda seed caught in turf trap ............................................97

Figure 3.19: Top 20 taxa found in turf traps across the study period ...........................97

Figure 3.20: Top 20 taxa found in funnel traps across the study period.........................98

Figure 3.21: Density of Whole seeds by weight class on a log scale across all collection

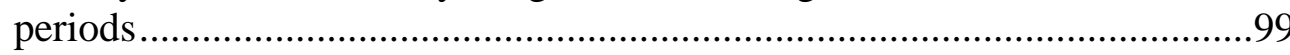

Figure 3.22: Density of New seeds by weight class on a log scale across all collection periods

Figure 3.23: Density of Whole seeds by length class on a log scale across all collection periods

Figure 3.24: Density of New seeds by length class on a log scale across all collection periods

Figure 3.25: Density of Whole seeds by growth form on a log scale across all collection periods. .105

Figure 3.26: Density of Whole seeds by primary dispersal vector on a log scale across all collection periods

Figure 3.27: Density of Whole seeds by height class on a log scale across all collection periods

Figure 3.28: Density of Whole seeds by seed output class on a log scale across all collection periods

Figure 3.29: Mean Whole seed density in turf traps in four collection periods across the TIA gradient ............................................................................... 116

Figure 3.30: Cumulative Whole seed density in turf traps across the TIA gradient........117 
Figure 3.31: Mean species richness of Whole seeds in turf traps in four collection periods across the TIA gradient

Figure 3.32: Density of Whole Rubus spp. seeds in turf traps in four collection periods across the TIA gradient.

Figure 3.33: Whole Rubus spp. seeds per trap in the four high TIA and four low TIA sites

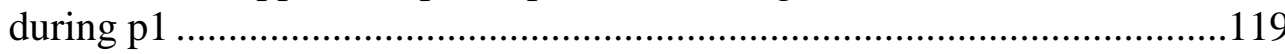

Figure 3.34: Mean Whole seed density of output class 4 seeds in turf traps during p3 and $\mathrm{p} 4$

Figure 3.35: New non-native seeds in turf traps in four collection periods across the TIA gradient

Figure 3.36: NMDS of sites based on composition of Whole taxa in turf traps, p1 through $\mathrm{p} 4$

Figure 3.37: NMDS of sites based on composition of New taxa in turf traps, p1 through $\mathrm{p} 4$

Figure 3.38: Cumulative mean density of New shade-tolerant taxa in turf traps along a gradient of development within a 500m cone, on a log scale 


\section{Chapter 1: Introduction}

Ecosystem Functions of Riparian Forests

Riparian areas are zones adjacent to streams and other water bodies where terrestrial and aquatic systems interact. There are many definitions of riparian areas and corresponding techniques to determine their boundaries, e.g., based on the area contributing energy and matter to the stream, or the zone where vegetation is affected by a high water table, or simply a fixed distance from the stream (Richardson 2005). Regardless of the precise definition used, riparian areas are characterized by interfaces and physical gradients, resulting in high biological diversity and unique habitat. For human societies, riparian areas provide many valued functions, including flood buffering, water filtration, and wildlife habitat, among many others. In urban areas, these functions are particularly important, but also at high risk from development pressures. A better understanding of the drivers of riparian dynamics in urban areas can improve management efforts to maintain these functions to the greatest extent possible.

Many of the riparian functions and ecosystem services that we value depend on the resident vegetation. Live and dead vegetation can either obstruct or facilitate movement of water above and below ground, exerting large control over the hydrologic regime of a riparian area. The resistance to water flow provided by vegetation can contribute to the dissipation of energy from floods (Tabacchi et al. 2000). Riparian forests also play a major role in regulating the supply of nutrients and materials to streams (Naiman and Decamps 1997). Nutrients from upland areas accumulate in riparian zones, where they are transformed by biological uptake, microbial processes, or 
remineralization (Naiman et al. 2005). The generally high productivity of riparian areas means that vegetation typically takes up a large quantity of nutrients compared to vegetation in other ecosystem types (Gregory 1991; Tabacchi et al. 2000). This vegetation then contributes important nutrients to the stream, largely in the form of leaf fall, forming the base for stream food webs (Naiman et al. 2005). In addition to nutrient regulation, riparian vegetation is important for regulating stream temperatures. Maintaining sources of cold water for rivers is of high priority in the Pacific Northwest for protecting habitat for ecologically and culturally important salmon (Yeakley 2014a). Vegetation affects stream temperatures, both directly by shading the stream, and through evapotranspirative cooling (Tabacchi et al. 1998). Vegetation removal and modelling studies have shown that streamside vegetation is a major controlling factor for water temperature in small streams (Johnson and Jones 2000; Sun et al. 2015).

Riparian forests also provide important habitat for many wildlife species. High microsite diversity in riparian areas due to dynamic hydrological regimes leads to a high diversity of vegetation types (Gregory et al. 1991). Many animal species make use of this heterogeneous environment for breeding, foraging, movement, and shelter (Richardson et al. 2005). In addition to riparian obligate species, riparian forests provide habitat for species that seek forest edges and early-successional plant communities (Naiman et al. 2000). The composition of the wildlife community in a riparian forest is determined to a large degree by the size of the stream and successional stage of the forest. Fish, and wildlife that prey on them, are often not found in smaller streams and their riparian areas. Likewise, bird species that require large patches of deciduous forest are 
more often found adjacent to larger streams with broad riparian areas (Naiman et al. 2000). Smaller streams and riparian areas with no fish are often crucial habitat areas for amphibians (Miller et al. 1997). In riparian areas on both large and small streams, large woody debris can provide crucial habitat for birds and small mammals. Use of riparian areas by some wildlife species, like beaver and deer, can have large impacts on the vegetation community and nutrient cycling in the riparian area (Naiman et al. 2000).

\section{Small Streams and Riparian Forests of the Pacific Northwest}

Small streams have historically received less attention in research and management communities than larger rivers, in part because they are often too small to support fish (Benda et al. 2005). However, these small streams make up the majority of the length of any given drainage. Headwater streams, defined as $1^{\text {st }}$ or $2^{\text {nd }}$ order streams (King et al. 2009) can make up $80 \%$ or more of the channel length in a stream network (Downing et al. 2012), so understanding dynamics of small streams and headwaters is crucial for any comprehensive understanding of the overall stream system. Small streams can also provide habitat for a different suite of species than large streams (Richardson et al. 2005; Miller et al. 1997).

Small streams and their riparian areas in the Pacific Northwest are highly unique systems, with processes and features that distinguish them from other habitat types.

Forests of the Pacific Northwest are highly productive and species rich due to the high precipitation in the area (Naiman et al. 2000). Adjacent to small streams, steep slopes make these forests particularly dynamic. Steep slopes are the major features driving 
many of the processes of headwater streams and associated riparian forests. Hillslope processes are tightly linked to processes in the stream channel (Gomi et al. 2002). These steep hillslopes restrict the development of alluvial areas along streams, leaving the true riparian area very narrow. Often, upland forest can even extend all the way to the stream margin (Richardson 2005). Steep hillslopes mean that headwater systems frequently lack the water storage capacity of large floodplains and broad U-shaped valleys found along large streams (Wohl 2017). With this low storage capacity, as well as small contributing areas and short pathways from upland areas where rain falls to stream channels, the hydrology in small streams can be much more temporally variable than in large streams (Naiman and Decamps 1997; Gomi et al. 2002; Wohl 2017).

Steep slopes also make headwater systems very dynamic compared to larger streams and riparian areas. Large-scale disturbances, like landslides, are fairly common adjacent to small streams. Frequent landslides and other disturbances in headwaters are major sources of sediment and nutrients for stream systems (Gomi et al. 2002). Debris flows are especially common adjacent to small streams after heavy rains. The frequency and importance of debris flows depends on the geology, topography, and soils of a particular watershed. In very steep basins they can be the primary processes that deliver sediment and wood to streams (Montgomery and Buffington 1998; Naiman et al. 2000).

\section{Vegetation Patterns in Riparian Forests on Small Streams}

Along small streams in western Oregon, there are several major drivers of forest vegetation patterns, including hillslope topography, soil moisture, disturbance frequency, 
and shade. Studies have found tree species to be strongly associated with the topographic gradient from the stream edge up the hillslope. Along this gradient, soil moisture decreases, while conifer cover increases (Sarr and Hibbs 2007). Pabst and Spies (1998) found that, in riparian areas across three subregions of western Oregon, basal area of conifer species increased moving upslope from the stream edge, while basal area of hardwoods decreased. In another study, Pseudotsuga menziesii (Douglas fir) was most prevalent on steep slopes and was almost always located at least $1 \mathrm{~m}$ above the stream. In contrast, Alnus rubra (red alder) was most prevalent on flat areas closer to the stream, preferring mineral soils (Hibbs and Bower 2001).

Disturbances, associated with both hillslope processes and flooding, are also major drivers of vegetation patterns and forest succession adjacent to small streams. Woody material delivered by debris flows can have large influences on the succession of riparian vegetation (Fetherston et al. 1995). Shade-intolerant Alnus rubra and Pseudotsuga menziesii often establish after large disturbances and tend to dominate the canopy near the stream (Nierenberg and Hibbs 2000). On steep hillslopes, frequent soil disturbances favor understory species that are tolerant of moderate disturbances, including Oplopanax horridus (devil's club), and Rubus spectabilis (salmonberry; Pabst and Spies 1999). Disturbances to vegetation can also come from flooding. Flooding can destroy vegetation patches, create new habitat patches for colonizing vegetation, and alter competitive dynamics among plant species (Naiman et al. 2000). Pabst and Spies (1999) found that within a few meters of a stream, understory communities were dominated by species, including Urtica dioica (stinging nettle), Carex obnupta (slough sedge), and 
Holcus lanatus (velvetgrass), that either could tolerate high stormflows, or could quickly colonize mineral soils after these high flows subsided.

Frequent disturbances and high microsite diversity mean that riparian forests are often very species-rich. In the Pacific Northwest, riparian forests often have twice the number of plant species as upland forests. However, it is common for many of the species present to be quite rare, often leaving upslope and riparian forests with similar levels of Shannon diversity, though riparian forests have much higher species richness (Gregory 1991). For both upland and riparian forests, species richness and evenness will vary with successional stage, with greater richness typically seen in earlier seral stages than in later stages (Burton et al. 2013). The high frequency of disturbances in riparian forests compared to upland forests means that the successional stage is more frequently reset. This maintenance of early seral stages is a mechanism through which frequent disturbances promote high species richness in riparian forests (Tabacchi et al. 1998).

Shade is another major driver of vegetation patterns in riparian areas, particularly in the understory. In riparian forests where soil water and nutrients are typically not limiting resources (Naiman and Decamps 1997), the tree canopy exerts major control over understory vegetation through regulation of light levels. A study of riparian forests in Southern France found that the height and biomass of understory plants, including herbaceous plants and semi-woody brambles, were significantly and positively correlated with canopy openness. The authors determined that in tree gaps adjacent to streams, understory vegetation can provide considerable amounts of shade and litter to streams, functions that are usually attributed to canopy species (Lecerf et al. 2016). 
In Pacific Northwest riparian forests, conifer canopy is associated with dense shade, while hardwood canopy allows more light through to the forest floor, particularly in the springtime (Pabst and Spies 1999). It is thus not surprising that Hibbs and Bower (2001) found that understory cover, including both shrub and herbaceous species, was higher under hardwood canopy than under conifer canopy. Interestingly, they also found higher understory diversity found under conifer canopy cover. Rubus spectabilis preferred riparian areas with hardwood canopy, though it was also the shrub species with the greatest cover in conifer patches. Sambucus racemosa (elderberry) was also most common under hardwood canopy, while Corylus cornuta (hazel) and Berberis aquifolium (tall Oregon grape) preferred coniferous canopy. Among herbaceous plants, some species, like Polystichum munitum (sword fern) and Oxalis oregana (Oregon wood sorrel) were ubiquitous in riparian forests under all canopy types. Other species, like Tolmiea menziesii (piggyback plant), Athyrium filix-femina (lady fern), and Stachys mexicana (Mexican hedgenettle) increased in cover with hardwood basal area (Hibbs and Bower 2001). Light to the understory also increases when gaps are created by treefall events. These disturbances have been found to be important for some riparian shrub species, like Ribes sanguineum (red-flowering currant) and Rubus spectabilis (Sarr and Hibbs 2007).

A riparian forest study in British Columbia found that light transmission was the environmental variable most strongly correlated with understory species composition. Consistent with Sarr and Hibbs (2007), they found that Rubus spectabilis increased in cover as light levels increased. Circaea alpina (enchanter's nightshade) also preferred 
high light levels, while Oplopanax horridus and Osmorhiza berteroi (mountain sweet cicely) were associated with lower light levels. Overall, shrub cover was significantly correlated with light levels, while herbaceous cover was not. The authors suggested that low light areas provide refuges for understory plants that are poor competitors with the dominant shrub species, but that can tolerate higher shade levels (Giesbrecht et al. 2017).

Several studies have reported particularly dense shrub understories in riparian forests in the Pacific Northwest (e.g. Pabst and Spies 1998; Pabst and Spies 1999; Wimberly and Spies 2001; Hibbs and Bower 2001). Rubus spectabilis can be particularly dominant, especially on transition slopes (Pabst and Spies 1999). This dense shrub understory in northern riparian forests may be partially responsible for the low numbers of conifers observed in the regeneration layer in several studies (e.g. Pabst and Spies 1998, Wimberly and Spies 2001). It is also likely that a lack of ample seed sources of shade-tolerant conifers contributes to this pattern (Wimberly and Spies 2001).

\section{Dispersal Limitation in Riparian Vegetation Community Formation}

Successful recruitment is a basic requirement for the existence of any plant in a given location, and is a fundamental process involved in community assembly. Recruitment of any plant requires the availability of a propagule, often a seed. Seeds, like water, sunlight or other resources, can be limiting factors for plant establishment. A plant species is considered to be dispersal-limited (a.k.a. seed-limited) if its distribution is primarily limited by seed availability in the landscape (Münzbergová and Herben 2005). The degree to which species are dispersal-limited depends on the presence of plants in the 
surrounding landscape (the species pool; Pätel et al. 1996), as well as their ability to disperse seed to suitable microsites.

In forest environments, dispersal limitation has been shown to interact with site availability to contribute to local vegetation patterns (Hughes and Fahey 1988; Erikkson and Ehrlen 1992; Ehrlen and Erikkson 2000, Ettinger et al. 2017). For example, in lightlimited forest systems, treefall gaps often provide critical establishment opportunities for understory species. When a gap forms, however, the plants that establish there will be constrained to the species in the local seed pool (Dalling 2002). Dispersal characteristics can affect the dispersal limitation of species in their environments. In a study in a Michigan forest, McEuen and Curran (2004) found that some forest species, particularly those with heavy seeds or animal-dispersed seeds, were strongly limited by seed availability (McEuen and Curran 2004). Disturbance dynamics that affect seed dispersal can also affect dispersal limitation of different plant species. The disturbance dynamics in riparian zones have been shown to affect dispersal limitation in riparian plant communities. In one riparian study, Fraaije et al. (2015) found a strong relationship between seed arrival and the presence of that species in the standing vegetation, indicating the presence of dispersal limitation. Similarly, in a study of riparian forests on seven streams in Sweden, Herberg and Sarneel (2017) found that dispersal limitation interacted with environmental conditions limiting establishment to determine seedling dynamics. 


\section{Urban Stream Syndrome}

Urban development has many impacts on streams and their riparian areas. There are a handful of stream features that tend to change consistently across regions as urbanization increases. Collectively, these changes are often referred to as the urban stream syndrome (Walsh et al. 2005). They include flashy stream hydrographs, increased nutrient and pollutant concentrations, incised channels and altered bank stability, reduced biotic richness, and dominance by disturbance-tolerant species (Groffman et al. 2003; Morse et al. 2003; Walsh et al. 2005). Impervious surfaces, including roads, sidewalks, and rooftops, are major features of urban areas, and are primarily responsible for the symptoms of urban stream syndrome (Walsh et al. 2005; Yeakley 2014b). Under natural conditions, much of the rain that falls in a watershed is intercepted by plants and stored in the soil, draining slowly to streams. With the addition of impervious surfaces and pipe networks, water does not infiltrate into the soil, but becomes surface runoff that flows much more quickly to streams after rainfall, causing the stream hydrograph to peak quickly. The duration of peak flows also decreases more quickly after storms due to the lack of water storage in soils. The resulting tall, narrow peak in the hydrograph is referred to as stream flashiness and is a key signature of urban streams (Arnold and Gibbons 1996; Konrad and Booth 2005; Walsh 2005; Yeakley 2014b). These large peak flows can lead to channel incision and downcutting, resulting in V-shaped streams with very steep banks (Figure 1.1; Henshaw and Booth 2000; Konrad and Booth 2005). 


\section{Rural}

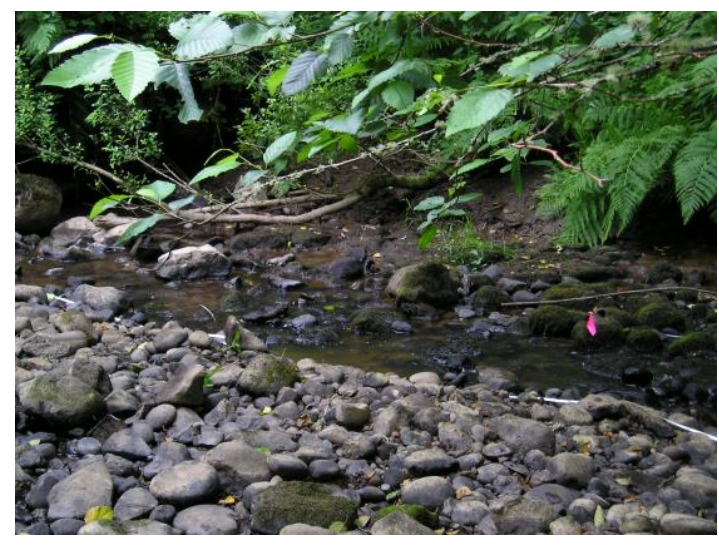

Urban

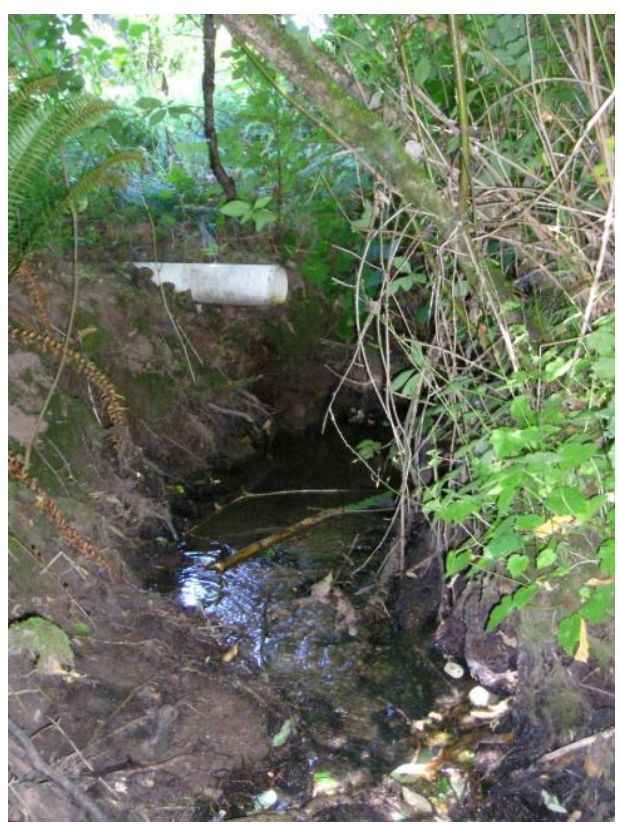

Figure 1.1: Rural and urban streams in NW Oregon. The stream on the left is in a rural location outside of the Portland metro area. Though the terrain is fairly steep, the stream banks are not deeply incised. The stream on the right is in Lake Oswego, Oregon, in a dense residential area. The stream banks are deeply incised.

The effects of urbanization on stream baseflow are less straight forward than the effects on peak flow. Impervious surfaces reduce infiltration and groundwater levels, which may decrease baseflow in streams. However, landscape irrigation and leaky pipes may contribute extra water to streams, thus increasing baseflow in some urban areas (Paul and Meyer 2001; Walsh et al. 2005). A nation-wide study of stream responses to land use showed that stream baseflow responds differently to urbanization across the United States. In the Pacific Northwest, the authors found that baseflows generally decrease with urban development (Poff et al. 2006). This pattern is typical of regions 
with Mediterranean climate and precipitation patterns (Walsh et al. 2005; Cooper et al. 2013).

High pollutant loads are also typical of urban streams. Specific land use types within a watershed will determine what types of pollutants and nutrients are found in streams. It is quite common, though, for urban streams to have high nitrogen and phosphorous loads that originate from fertilizer applications to golf courses, gardens, and lawns, as well as from wastewater treatment plants. Pesticides, pharmaceuticals, plastics, and metals are also common occurrences in urban streams (Arnold and Gibbons 1996; Sonoda et al. 2001; Cooper et al. 2013). Chadwick et al. (2006) suggested that there is a strong relationship between watershed imperviousness and levels of some pollutants. In their Florida study, they found high concentrations of nitrogen, phosphorous, and metals in headwater streams with high watershed impervious surface cover (Chadwick et al. 2006). In addition to receiving higher nutrient loads, urban riparian areas may be less effective at filtering those nutrients than riparian areas in more natural settings. The lower water table, resulting from urban impervious surfaces, means that pollutants, particularly nitrates in groundwater, are less likely to come into contact with the microbes and plant matter in the near-surface soil that can remove them before the water reaches the stream (Gold et al. 2001; Groffman et al. 2003).

There are many consequences of these urban alterations for biota living in and around streams. Fish communities often have lower diversity and are dominated by more generalist species that are tolerant of disturbances and higher pollutant loads (Morse et al. 2003; Walsh et al. 2005). Macroinvertebrate assemblages can be particularly sensitive to 
urbanization, often showing larger responses to urban development than to agricultural land use (Cooper et al. 2013). Like fish, macroinvertebrate communities often become dominated by pollution-tolerant species, while sensitive species disappear (Morse et al. 2003; Walsh et al. 2005; Cooper et al. 2013). Amphibians may be particularly susceptible to urban development because they rely on both aquatic and terrestrial habitats. Ficetola et al. (2011) found that landscape-level features that directly affect adult salamander upland habitat, and indirectly affect instream juvenile habitat were better predictors of salamander populations than environmental features measured at more local scales. Similarly, Dietrich (2012) found that within an urban area, riparian forest cover, as well as high forest cover within the entire watershed, was related to the presence of amphibians in small streams and their riparian areas. Moderate to high cover by urban development precluded native amphibians from riparian areas (Dietrich 2012).

Compared to larger streams, small streams and their riparian areas may be particularly susceptible to changes from urban development. Even with the ever-growing knowledge of the importance of small streams and their riparian areas in the landscape, they still often receive fewer protections than larger streams and are highly affected by surrounding land use (Roy et al. 2009; Wohl 2017). The response of small streams to urban development has received less study than responses of larger streams, even though the cumulative effect of small-stream impacts can result in major changes downstream (Stanfield and Jackson 2011). The tight coupling of small streams to terrestrial areas means that they can be very quickly altered by nearby development (Richardson and Danehy 2007; Stanfield and Jackson 2011). Stanfield and Jackson (2011) found that 
along an urbanization gradient, headwater streams in the most urban areas had the highest relative change in stream discharge in response to storm events.

\section{Response of Riparian Vegetation to Urban Development}

Urbanization can cause physical changes to riparian areas in addition to the streams themselves, which can have consequences for vegetation assemblages. Major losses in riparian vegetation cover have been documented in response to urban development, even in places where policies are in place to protect natural resources (Ozawa and Yeakley 2007; Newham et al. 2011). The combination of incised stream channels and reduced groundwater infiltration due to surrounding impervious surfaces can lead to drought-like conditions in riparian areas (Groffman et al. 2003). Drier riparian soils can have enormous implications for the function of the riparian zone. Numerous studies have documented a shift from riparian communities dominated by wetland-adapted species to communities dominated by upland species in response to urbanization. A Baltimore study found more than twice the number of upland species in lower floodplains of urban streams than of non-urban streams (Groffman et al. 2003). Similarly, a study in Georgia showed that the woody regeneration layer in urban riparian sites was dominated by upland and generalist species, instead of riparian specialists (Burton and Samuelson 2008). Turner et al. (2015) demonstrated direct relationships between channel incision and shifts in vegetation communities from wetland-adapted to upland species in ground-layer vegetation in floodplains of low order streams in the Alabama Piedmont region. Ground-layer vegetation assemblages were dominated by 
hydrophytic species in locations with low bank incision and shallow depth to groundwater. As incision and depth to groundwater increased, vegetation assemblages became increasingly dominated by species intolerant of flooding (Turner et al. 2015).

In addition to the shift to upland assemblages, there can be other changes in vegetation communities in response to urban development. Burton and Samuelson (2008) found that urbanization can lead to the simplification of riparian forest structure. A mid-canopy layer, common to eastern deciduous forests, was present in riparian sites surrounded by unmanaged forest, but virtually absent from agricultural or urban sites (Burton and Samuelson 2008). There may also be shifts in dominant life-history strategies with urbanization. One study showed that annual herbaceous and woody species were found with much higher frequency in urban riparian sites, while perennial herbaceous species were more prevalent in rural sites (Moffatt and McLachlan 2004). Brice et al. (2017) found that for herbaceous assemblages in riparian forests in Quebec, increased urbanization led to a decrease in species richness. At the same time, changes in the flooding regime from urbanization led to new microhabitat types, resulting in high rates of species turnover. Overall, these processes led to differentiation among riparian sites in herbaceous community composition, resulting in a decreased likelihood of finding species in common between two forest patches in urban areas (Brice et al. 2017).

Some studies have suggested that while herbaceous species may respond quickly to urban development, there is often a temporal lag in the response of plants in the woody strata. Moffatt and McLachlan (2004) found that the herbaceous layer differed in urban and rural riparian forests more than any other forest stratum. In their study, perennial 
herbaceous species were present in rural riparian forest fragments in Manitoba but were infrequent in suburban and urban patches. Similarly, while Turner et al. (2015) found a strong relationship between herbaceous vegetation composition and stream channel incision, there was no such relationship observed with shrub or canopy species. Pennington et al. (2010) found that while metrics for both canopy and understory layers responded to increased landscape imperviousness, a much stronger response was exhibited by the understory than the canopy layer. It is likely that the shorter life cycle and faster turnover rate of herbaceous species compared to woody species explains why urbanization effects can be observed in this layer first (Pennington et al. 2010; Turner et al. 2015).

Urban forest fragmentation can lead to increased dispersal limitation for forest species in both upland and riparian areas. Several studies have shown that forest species are more seed-limited when forests exist in fragmented patches than in a continuous tract (Ehrlen and Erikkson 2000; Honnay et al. 2002; McEuen and Curran 2004). Mendoza et al. (2009) found that in forests in southern Spain, human impacts that reduced adult plant density strongly increased dispersal limitation of those species, but there was no similar increase in establishment site limitation. In Seattle, Ettinger et al. (2005) found that the lack of tree regeneration in forest fragments was largely due to a lack of seed availability.

The alteration of local source pools is one way that urbanization can alter dispersal patterns and lead to dispersal limitation of some species. Roy et al. (1999) found that the proportion of non-native species in the landscape doubled moving from no urbanization to complete urbanization in several regions of Britain. They found that in 
general, native source pools did not change with increasing urbanization, except for woodland species, which decreased as urbanization increased (Roy et al. 1999). In riparian forests, streams can be effective seed dispersal vectors. By acting as corridors that connect plant populations, they can allow for some species in the landscape, which would otherwise be disconnected from seed sources, to overcome dispersal limitation (Hérault and Honnay 2005; Moggridge and Gurnell 2010; Fraaije et al. 2017). However, with urban alterations to streams, their capacity to act as effective seed dispersal vectors in urban settings is unclear.

There are many examples of riparian vegetation communities being substantially altered by urbanization, but there is also some evidence that, in certain cases, riparian vegetation communities can be quite resistant to the pressures of urbanization. In a study of headwater streams in Orange County, California, Oneal and Rotenberry (2008) found that geographic variables like stream order and elevation were much stronger predictors of riparian vegetation composition than amount of surrounding urban development. In another study, Schwoertzig et al. (2016b) found an increase in species richness in urban riparian areas that was not explained by the presence of non-native species, suggesting that some native species are resilient to urban pressures. More research is needed to determine why riparian vegetation assemblages are heavily altered by surrounding development in some cases, but more resilient in others. 


\section{Need for Research}

In urban landscapes, streams and their riparian areas may play a disproportionate role in providing habitat for wildlife, as well as ecosystem services on which human societies depend. Bennett et al. (2014) found that for birds, riparian forest patches provided better habitat in an urban matrix than remnant forest patches in upland areas. This was true even for birds that associate with upland forests. The authors concluded that within a developing urban matrix, the relative stability of forests in riparian buffers contribute disproportionately to landscape-scale biodiversity (Bennett et al. 2014). For some species, the narrow vegetation strips around streams may serve as the only connection to larger habitat areas outside of the urban region (Parker et al. 2008). Even though riparian vegetation composition and dynamics are often heavily altered by urbanization, what riparian vegetation remains has been shown to buffer streams from some of the impacts of urban development (Newham et al. 2011). Because it plays such an important role in urban landscapes, it is important to improve understanding of the dynamics of riparian vegetation.

Because of their high value in urban areas, riparian forests are frequently targeted for restoration. Often instream work involves removing fish passage barriers, increasing channel complexity, installing large woody debris, and regrading stream banks. In riparian areas, emphasis is typically on restoring canopy (Briggs 1992; Matzek et al. 2016). Weed management often accompanies planting of trees and shrubs. Often a passive approach is used for restoration of the understory, allowing it to return on its own after hydrological and canopy conditions have been restored (Hilderbrand et al. 2005; 
Gornish et al. 2017). There are many examples of successful riparian restoration projects, but sometimes restoration fails to restore desired vegetation conditions. Passive approaches, in particular, may fail to restore desired species to a site (Hilderbrand et al. 2005; Gornish et al. 2017). A better understanding of riparian vegetation dynamics in relation to features at multiple spatial scales could help to improve restoration techniques, and to determine when passive restoration might be successful.

While much has been learned in recent decades about how urban development affects stream networks in general, and riparian vegetation communities in particular, understanding the main drivers of changes to riparian vegetation communities remains an important research goal. Most studies on urbanization effects have been conducted along rural-to-urban gradients (e.g. Moffatt and McLachlan 2004; Oneal and Rotenberry 2008; Burton et al. 2009). These studies have effectively demonstrated general impacts of urban development on riparian vegetation assemblages, but have provided little information on how different types of land cover within an urban matrix affect vegetation patterns. Pennington et al. (2010) shed some light on the effects of different urban cover types in their study in Cincinnati, Ohio. They demonstrated that within $250 \mathrm{~m}$ of a riparian forest, impervious surfaces, buildings, roads, and railroads all have different relationships with riparian vegetation, and natural land cover types in the urban area, like grass and forest, are also related to riparian vegetation metrics. While native canopy cover was negatively associated with impervious surface cover in general, it was positively associated with buildings. The authors noted that most buildings in the study area were residential, and suggest that this type of development, which maintains some 
surrounding vegetation for aesthetic purposes, could be less detrimental for riparian vegetation than other types of urban land use (Pennington et al. 2010). However, it is unclear how residential land use and other urban land cover types may be important at a broader spatial scale. There have been some studies exploring the importance of local vs landscape variables for urban riparian vegetation. In an investigation of land cover and soil properties, Schwoertzig et al. (2016a) found that landscape factors within $500 \mathrm{~m}$ of a riparian area explained more variation in species composition than soil properties. In another study, urban matrix features within a 500m buffer explained more variation in riparian vegetation properties than riparian buffer width (Schwoertzig et al. 2016b). While these studies indicated the importance of landscape-level development factors compared to site-level features, the importance of these variables for riparian vegetation at broader scales, such as the entire watershed, are unclear. Several non-urban studies have shown that in forested landscapes, environmental variables from the local scale, to the several hundred meter scale, to the regional scale influence riparian vegetation (Pabst and Spies 1999; Sarr and Hibbs 2007). In an urban context, White and Greer (2006) studied the effect of impervious surface cover in a watershed on riparian vegetation. They found a significant relationship between total watershed impervious cover and riparian vegetation assemblages in their Southern California study (White and Greer 2006). More research is needed to determine if, beyond total imperviousness, different types of urban land cover might also affect riparian vegetation assemblages at the watershed scale. 
It is also unclear to what extent changes to riparian vegetation communities are driven by changes in the physical environment that inhibit plant establishment and growth, or if dispersal limitation plays a prominent role. It is clear that drier soils predominate in urban riparian areas and may provide unsuitable habitat for many riparian specialists (Groffman et al. 2003; Turner et al. 2015). In addition, fragmented forests and altered hydrology may mean that urban riparian species become dispersal-limited. For riparian forests, the stream may serve as an important corridor for seed dispersal, connecting forest fragments that would otherwise be isolated from each other. However, with urban modifications to streams, their ability to carry out this role in dispersal is unclear. The degree to which propagule limitation contributes to the changes observed in riparian vegetation assemblages in response to urban development has not been made clear.

\section{Objectives}

My first objective was to determine what broad-scale urban landscape characteristics are related to riparian forest vegetation assemblages (Chapter 2). I hypothesized that assemblages composed of native and hydrophilic species would be positively associated with the amount of forest cover in a watershed, and negatively with urban development cover types. I surveyed riparian vegetation along 30 first- to thirdorder streams in the Portland-Vancouver metropolitan area and used multivariate techniques to determine relationships between these assemblages and land cover type measured at three spatial scales. 
My second objective was to characterize seed dispersal patterns in forested riparian areas across an urbanization gradient, and to examine the potential for streams to connect fragmented vegetation patches in urban settings (Chapter 3). In nine riparian forests along an urbanization gradient in the Portland metropolitan area, I collected seeds deposited by wind and by water over a 15 -month period. I hypothesized that the overall number of seeds deposited in riparian forests would decrease along the urbanization gradient. I also expected that in the most urban sites, seeds deposited by streams would mostly be from species with traits favoring water dispersal, including large seed size and presence of a dispersal appendage, while a broader range of traits would be represented in seeds collected from the least urban sites. 


\title{
Chapter 2: Riparian Vegetation Assemblages and Associated Landscape Factors across an Urbanizing Metropolitan Area
}

This is the author's accepted manuscript of an article published as the version of record in Écoscience in 2013: https://www.tandfonline.com/doi/abs/10.2980/20-4-3635.

von Behren, C., J.A. Yeakley and A. Dietrich. 2013. Riparian vegetation assemblages and associated landscape factors across an urbanizing metropolitan area. Écoscience

\begin{abstract}
While diverse, native riparian vegetation provides important functions, it remains unclear to what extent these assemblages can persist in urban areas, and under what conditions. I characterized forested riparian vegetation communities across an urbanizing metropolitan area and examined their relationships with surrounding land cover. I hypothesized that native and hydrophilic species assemblages would correlate with forest cover in the landscape. For each of 30 sites in the Portland-Vancouver metro area, I recorded vegetation at $1 \mathrm{~cm}$ intervals along 3 transects using the line-intercept method. Land cover was characterized at 2 scales: within $500 \mathrm{~m}$ of each site; across the entire watershed. Multivariate analyses were used to evaluate relationships between species composition and land cover patterns. A classification tree was created to determine landscape predictors of riparian community type. Results indicated a strong relationship between watershed land cover and vegetation diversity and structural complexity. My hypothesis of native species association with landscape forest cover in urban riparian areas was supported, but I found no clear relationship between land cover and wetland
\end{abstract}


indicator status. My results suggest that high watershed forest cover (at least 15\%) may allow the persistence of functionally diverse, native riparian vegetation communities in urban landscapes.

\section{Introduction}

The vegetation of riparian forest communities provides many critical functions in urban areas (Groffman et al. 2003; Newham et al. 2011). These assemblages modulate runoff from uplands, provide flood buffering capacity (Tabacchi et al. 2000), pollution amelioration (Sweeney et al. 2004), energy for stream organisms (Nakano and Murakami 2001), and stream temperature regulation (Johnson and Jones 2000). They also offer unique habitat (Gregory et al. 1991; Naiman and Decamps 1997) and recreation opportunities. Diverse, native riparian assemblages, however, are disappearing from urban areas (Moffatt et al. 2004; Loewenstein and Loewenstein 2005; Ozawa and Yeakley 2007). It is unclear to what extent these assemblages can persist in urban settings, and under what conditions. My goals were to characterize variation among forested riparian vegetation assemblages across the Portland, Oregon and Vancouver, Washington metro area, and to identify relationships between these assemblages and different urban watershed land cover types. A better understanding of these relationships can help improve restoration and maintenance of these ecosystems.

Unlike in rural forests, urban understory communities are often dominated by woody, annual, and animal-dispersed species (Moffatt and McLachlan 2004). Flood- and shade-intolerant species are also common in these areas (Groffman et al. 2003; Burton et 
al. 2009), as are non-natives (Cadenasso and Pickett, 2001; Duguay et al. 2007). While these vegetation types are more common in urban than rural riparian forests, it is unclear how their prevalence varies across an urban environment in response to different types of land cover.

Habitat fragmentation is one potential driver of riparian vegetation patterns in urban areas. Urban habitat patches are often highly fragmented (Irwin and Bockstael 2007), potentially reducing seed dispersal among patches (Ehrlen and Erikkson 2000; McEuen and Curran 2004) and altering habitat conditions within patches. The prevalence of shade-intolerant species in urban forest fragments is likely due to the great extent of surrounding open habitat and lack of forest interior (Moffatt et al. 2004). Forest fragmentation can also facilitate establishment by non-native species common to the surrounding landscape (Lin et al. 2006).

Landscape urbanization can also cause numerous changes throughout the watershed, affecting stream hydrology, water quality, stream and riparian habitat, and ultimately riparian vegetation assemblages. (Allan 2004; Meek et al. 2010). Soil alteration affects transport of water and sediment to streams, altering stream flows, sediment loads, and erosion (Cooper et al. 2013). Urban impervious surfaces can lead to channel down-cutting, infrequent overbank flow, reduced infiltration, and higher pollutant loads (Groffman et al. 2003; Walsh et al. 2005; Cooper et al. 2013). While irrigation and sewage treatment can increase summer flows in some areas, urban surfaces typically enhance the seasonality of stream flow in Mediterranean and similar climates, resulting in higher winter peak flows and even lower dry season flows (Konrad and 
Booth 2005; Cooper et al. 2013). Because of these changes, many urban riparian areas support very different vegetation assemblages than rural riparian areas (Groffman et al. 2003; Burton et al. 2009).

While many studies report strong effects of urbanization on vegetation (Moffatt and McLachlan 2004; Loewenstein and Loewenstein 2005; Burton and Samuelson 2008), others suggest that native, diverse riparian areas can exist in urban settings. Oneal and Rotenberry (2008) found that riparian community composition did not vary substantially along a development gradient in California. Likewise, Guntenspergen and Levenson (1997) and Porter et al. (2001) found no predictable patterns in vegetation composition related to land use. Others have shown equal (Hutmacher et al. 2013), or higher (Wania et al. 2006; McKinney 2008; Meek et al. 2010) species richness in urban areas than rural. Tabacchi and Planty-Tabacchi (2005) found high riparian richness in a human-dominated landscape at all scales considered. These studies suggest that some native, diverse vegetation assemblages are resilient to urban development.

While there is evidence that land cover immediately adjacent to a riparian area affects vegetation (Pennington et al. 2010; Fernandes et al. 2011), it is unclear how urban cover types at broader scales affect these assemblages. Riparian species are thought to be influenced by a mix of landscape and local variables (Sarr and Hibbs 2007; Baker and Wiley 2009), so considering urban influences at a broad scale is important. I sought to gain insight into what broad-scale urban landscape characteristics were needed to maintain diverse native riparian forest assemblages. I hypothesized that riparian assemblages with high cover by native and hydrophilic species would be associated with 
high forest cover and low development cover in the surrounding landscape. My analysis focused on the community composition of riparian areas. Better understanding of how landscape factors correspond to the maintenance of diverse and native riparian vegetation assemblages can inform urban land use planning and policy development that will help conserve these ecosystems.

\section{Methods}

\section{Site Selection}

This study took place in the Portland, Oregon and Vancouver, Washington metro area. Portland and its metropolitan area have a strong history of conservation of parks and natural areas, with a regional government that maintains an urban growth boundary and works to conserve the region's natural areas (Metro 2013). The metro region has an average annual temperature of $12.5^{\circ} \mathrm{C}$, with an August average of $20.8^{\circ} \mathrm{C}$ and a December average of $4.7^{\circ} \mathrm{C}$. Annual rainfall is $92 \mathrm{~cm}$ per year, with over $70 \%$ of rain occurring November through April (Rockey 2012). Thirty forested riparian sites were randomly selected for study in the summer of 2011 (Figure 2.1). In the Portland metro area in Oregon I defined all sites within the urban growth boundary as urban. In the Vancouver, Washington area riparian sites were considered for study if they were within 30 minutes driving from downtown Portland and within Clark County, the county that contains the city of Vancouver. All sites considered for selection had perennial flow, first to third stream order, at least a $100 \mathrm{~m}$-long accessible stream segment, and canopy cover along the $100 \mathrm{~m}$ segment. ArcGIS version 9.3.1 (ESRI 2009) was used to identify qualified 
sites. I used stream layers from the National Hydrography Dataset (nhd.usgs.gov) for the Portland metro area and Vancouver, and land cover layers from the Metro 2007 Regional Land Information System (Metro Data Resource Center).

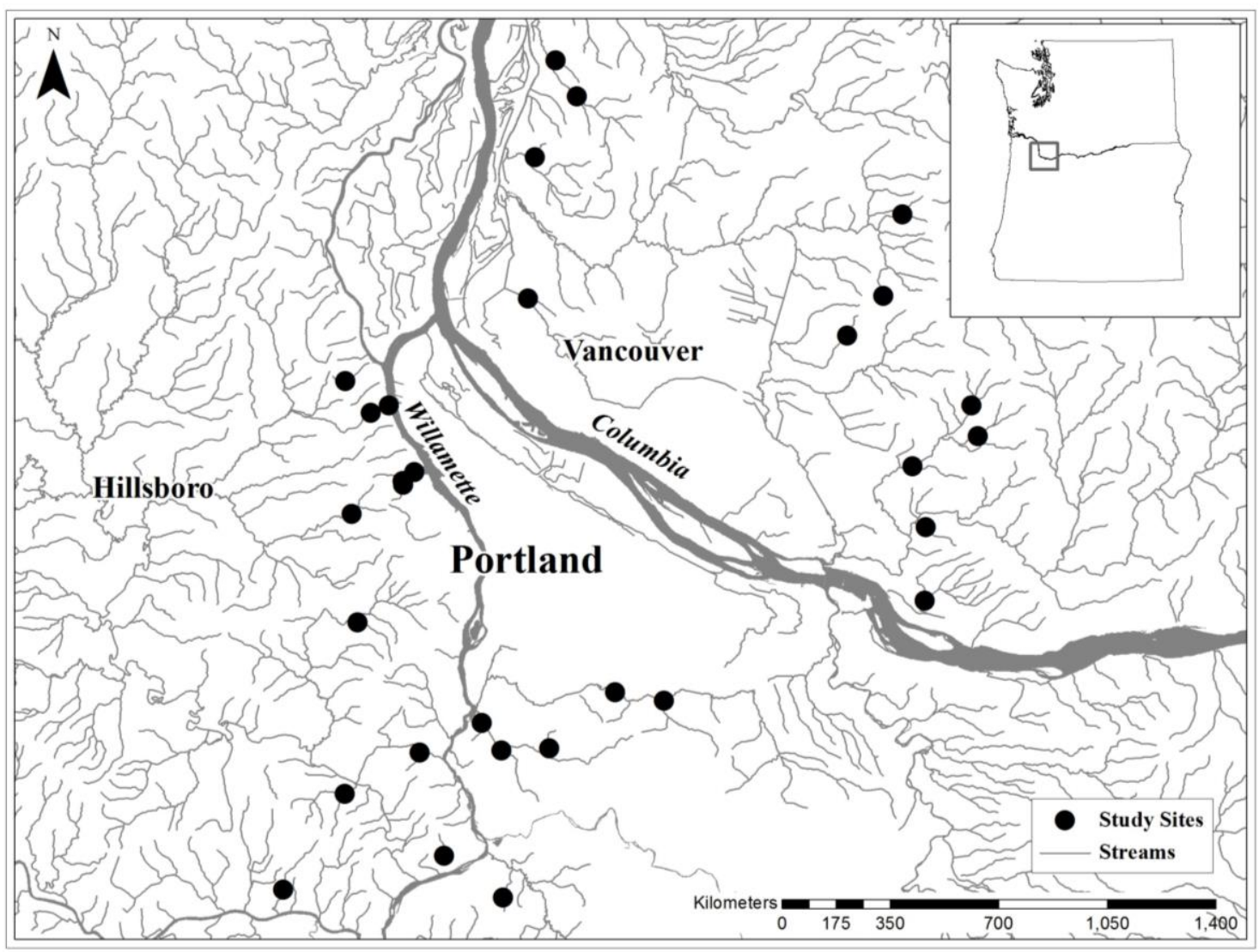

Figure 2.1: Thirty study sites in the Portland-Vancouver metro area. Riparian sites were randomlyselected on public and private property on both the Oregon and Washington sides of the Columbia River. All sites were on first- to third-order streams, had some canopy cover, and had not been actively managed. Map center is at $45^{\circ} 35^{\prime} 46^{\prime \prime} \mathrm{N}, 122^{\circ} 36^{\prime} 10^{\prime \prime} \mathrm{W}$.

I used a robust randomization procedure to assure good representation of streams typical to the metro area. Random numbers were assigned to each stream that met selection criteria, and 40 stream sites were selected, including sites on both publicly- and privatelyowned land. In field visits I determined that 9 of those 40 sites had active restoration 
projects, and were therefore not suitable for study. Additionally, I removed 1 site due to insufficient canopy cover. Data were collected from the remaining 30 sites.

\section{Vegetation Survey}

I used the line-intercept method to sample vegetation. Three transects were established in each site on 1 stream bank, spaced 25 meters apart and perpendicular to the stream reach. The first transect was placed at the midpoint of the site. Transects were at least $5 \mathrm{~m}$ in length and spanned from the top of the stream bank to the smaller of either the termination of accessible riparian area or $60 \mathrm{~m}$ measured laterally across the slope. Vegetation in all strata was identified along the transects. The length of transect covered by each plant species was recorded to the nearest centimeter. We identified vegetation to the species level based on Pojar and MacKinnon (1994) and Hitchcock and Cronquist (1973). Species richness and Shannon diversity were calculated for each site (Shannon and Weaver 1949). Species were categorized by native status, structural class (tree, shrub, herb), and wetland indicator status (WIS). WIS categories used were Obligate Upland (UPL), Facultative Upland (FACU), Facultative (FAC), Facultative Wetland (FACW), and Obligate Wetland (OBL). The USDA PLANTS database (USDA, NRCS 2013) was used to determine WIS categories for each species. Species with no WIS listing (NL) in the PLANTS database were considered unlikely to occur in wetlands and grouped with UPL species for analysis. These vegetation metrics were recorded as percent cover, which ranged from $0 \%$ to well over $100 \%$ due to the dense, multi-layered nature of the vegetation. 


\section{Watershed Characteristics}

Watershed boundaries were delineated using ArcGIS (ESRI 2009) from a point $500 \mathrm{~m}$ downstream from the study site. Land cover data from 2006 in the National Land Cover Database (Fry et al. 2011) were used to determine composition of cover types in the landscape. The percentages of each cover type defined in the NLCD were recorded at 2 scales, within a $500 \mathrm{~m}$ buffer around each site and in the entire watershed. Land cover types included different urban development intensities, agricultural land, and forest cover, among other types (Table 2.1). At the watershed level total impervious surface area, also provided in the NLCD, derived from Landsat imagery at a resolution of $30 \mathrm{~m}$ (Table 2.1), was calculated. 
Table 2.1: Landscape variables measured within a 500m buffer and within the entire watershed. "W" in the variable code indicates the variable was measured at the watershed scale, "B" indicates that it was measured at the $500 \mathrm{~m}$ buffer scale. All land cover data are from the 2006 National Land Cover Database. The land cover classification is based on Landsat satellite data and has $30 \mathrm{~m}$ resolution (NLCD; Fry et al. 2011). Mean, minimum, and maximum cover recorded at the watershed level is reported. Development density variables are based on percentage impervious surface area. Total impervious surface area (TIA) within the watershed is also shown.

\begin{tabular}{|c|c|c|c|c|}
\hline $\begin{array}{c}\text { Variable } \\
\text { Code }\end{array}$ & Variable Description & $\begin{array}{l}\text { Mean } \\
\text { Cover }\end{array}$ & $\begin{array}{c}\text { Min } \\
\text { Cover }\end{array}$ & $\begin{array}{c}\text { Max } \\
\text { Cover }\end{array}$ \\
\hline $\begin{array}{l}\text { W.Water, } \\
\text { B.Water }\end{array}$ & $\begin{array}{l}\text { Open water }- \text { areas of open water with } \leq 25 \% \\
\text { soil or vegetation }\end{array}$ & $0.01 \%$ & $0 \%$ & $0.28 \%$ \\
\hline $\begin{array}{l}\text { W.Open, } \\
\text { B.Open }\end{array}$ & $\begin{array}{l}\text { Open development - some construction, } \\
\text { mostly vegetation, }<20 \% \text { total impervious } \\
\text { cover }\end{array}$ & $8 \%$ & $0.01 \%$ & $26 \%$ \\
\hline $\begin{array}{l}\text { W.Lo, } \\
\text { B.Lo }\end{array}$ & $\begin{array}{l}\text { Low density development - } 20 \% \text { - } 49 \% \\
\text { impervious cover, often single-family housing }\end{array}$ & $20 \%$ & $0 \%$ & $60 \%$ \\
\hline $\begin{array}{l}\text { W.Md, } \\
\text { B.Md }\end{array}$ & $\begin{array}{l}\text { Medium density development - 50\% - 79\% } \\
\text { impervious cover, often single-family housing }\end{array}$ & $8 \%$ & $0 \%$ & $40 \%$ \\
\hline $\begin{array}{l}\text { W.Hi, } \\
\text { B.Hi }\end{array}$ & $\begin{array}{l}\text { High density development - } 80 \%-100 \% \\
\text { impervious cover - apartments, commercial } \\
\text { and industrial areas }\end{array}$ & $2 \%$ & $0 \%$ & $17 \%$ \\
\hline $\begin{array}{l}\text { W.Dec, } \\
\text { B.Dec }\end{array}$ & $\begin{array}{l}\text { Deciduous forest }- \text { trees }>5 \mathrm{~m} \text { tall make up } \geq \\
20 \% \text { vegetation, } \geq 75 \% \text { of trees are deciduous }\end{array}$ & $5 \%$ & $0 \%$ & $19 \%$ \\
\hline $\begin{array}{l}\text { W.For, } \\
\text { B.For }\end{array}$ & $\begin{array}{l}\text { Evergreen forest - trees }>5 \mathrm{~m} \text { tall } \geq 20 \% \\
\text { vegetation, } \geq 75 \% \text { of trees are evergreen, } \\
\text { canopy is never without green foliage }\end{array}$ & $18 \%$ & $0 \%$ & $65 \%$ \\
\hline $\begin{array}{l}\text { W.Mix, } \\
\text { B.Mix }\end{array}$ & $\begin{array}{l}\text { Mixed forest - trees }>5 \mathrm{~m} \text { tall } \geq 20 \% \\
\text { vegetation, neither deciduous nor evergreen } \\
\text { trees make up } \geq 75 \% \text { trees }\end{array}$ & $16 \%$ & $0 \%$ & $57 \%$ \\
\hline $\begin{array}{l}\text { W.Shrub, } \\
\text { B.Shrub }\end{array}$ & $\begin{array}{l}\text { Scrub/shrub - shrubs }<5 \mathrm{~m} \text { tall } \geq 20 \% \\
\text { vegetation }\end{array}$ & $6 \%$ & $0 \%$ & $39 \%$ \\
\hline $\begin{array}{l}\text { W.Herb, } \\
\text { B.Herb }\end{array}$ & $\begin{array}{l}\text { Grassland/herbaceous - graminoid or } \\
\text { herbaceous vegetation }>80 \% \text { of vegetation }\end{array}$ & $2 \%$ & $0 \%$ & $12 \%$ \\
\hline $\begin{array}{l}\text { W.Pas, } \\
\text { B.Pas }\end{array}$ & $\begin{array}{l}\text { Pasture/hay - grasses or legumes planted } \\
\text { grazing or hay }>20 \% \text { vegetation }\end{array}$ & $12 \%$ & $0 \%$ & $58 \%$ \\
\hline $\begin{array}{l}\text { W.Crop, } \\
\text { B.Crop }\end{array}$ & $\begin{array}{l}\text { Cultivated crops - crop vegetation }>20 \% \\
\text { vegetation }\end{array}$ & $1 \%$ & $0 \%$ & $12 \%$ \\
\hline $\begin{array}{l}\text { W.Wet, } \\
\text { B.Wet }\end{array}$ & $\begin{array}{l}\text { Woody wetlands }- \text { forest/shrubland }>20 \% \\
\text { vegetation, soil or substrate periodically } \\
\text { saturated with water }\end{array}$ & $1 \%$ & $0 \%$ & $5 \%$ \\
\hline $\begin{array}{l}\text { W.Emer, } \\
\text { B.Emer }\end{array}$ & $\begin{array}{l}\text { Emergent herbaceous wetlands - perennial } \\
\text { herbaceous vegetation }>80 \% \text { vegetation, soil } \\
\text { periodically saturated or covered with water }\end{array}$ & $0.1 \%$ & $0 \%$ & $1 \%$ \\
\hline W.imp & $\begin{array}{l}\text { Total impervious surface area - measured as } \\
\text { percent cover }\end{array}$ & $15 \%$ & $12 \%$ & $54 \%$ \\
\hline
\end{tabular}




\section{Data Analysis}

Data analysis was completed using R version 2.15.2 (R Development Core team 2012). Because of the large number of both explanatory (land cover) and response (vegetation characteristics) variables, I decided to use a multivariate approach. I used non-metric multidimensional scaling (NMDS) to characterize riparian vegetation community similarity among sites. The ordination was based on rank-similarity of sites using the Bray-Curtis index. Species cover data were square-root transformed to reduce NMDS stress. The square root transformation was used to preserve the information in species of low abundance in the transects (e.g. Magee et al. 2008). Because of the apparent arrangement of sites in distinct clusters, sites were divided into three groups for further analysis. Partitioning around medoids (PAM) was used to classify sites into 3 groups based on riparian community similarity (e.g. Hanzlik and Gerowitt 2011; Puşcaş and Choler 2012). PAM partitioned data set objects into clusters by searching in an iterative process for $\underline{\mathrm{k}}$ representative objects, which are the medoids for the clusters. Data objects were then assigned to the nearest representative object, creating $\underline{\mathrm{k}}$ clusters (Kaufman and Rousseeuw 1990). I created final cluster groups for further analysis by combining the results of PAM with patterns visible in the NMDS plot. Analysis of similarity (ANOSIM) was used to verify that these 3 groups differed from each other in species composition.

Indicator analysis was conducted using the "indval" function in the package "vegan," (Oksanen et al. 2012) to determine species characteristic of each cluster group. The most appropriate indicator species were those found primarily in a single group, and 
were present in most of the sites in that group. The indval method created an index of indicator values, ranking species on specificity and fidelity to group (Dufrêne and Legendre 1997). A randomization procedure with 1000 permutations was used to determine significant $(\mathrm{p}<0.05)$ indicator values. Differences among cluster groups in cover by native and non-native species, wetland indicator classes, and structural classes were identified using Kruskal-Wallis and pairwise Wilcoxon rank-sum tests with the Bonferroni correction for multiple tests.

Relationships between land cover and riparian vegetation were identified by fitting landscape vectors to the NMDS ordination. The R function "envfit" was used with 1000 permutations to fit landscape vectors to the NMDS ordination and determine which vectors were significantly ( $\mathrm{p}<0.05)$ associated with NMDS space (Strohbach et al. 2009). I then created a classification tree using the package "rpart" (Therneau et al. 2012) to determine the best landscape predictors of a site's cluster group affinity.

\section{Results}

Across all 30 sites mean transect length was $16.8 \pm 15.3 \mathrm{~m}$ (mean $\pm \mathrm{SD})$. A total of 82 vegetation types were identified to species level, including 65 native and 17 nonnative species. Site species richness ranged from 10 to 42 , with a mean of $20 \pm 8$. Shannon diversity ranged from 1.79 to 2.62 with a mean of $2.24 \pm 0.22$.

The NMDS plot showed a wide distribution of sites based on species composition (Figure 2.2), indicating variation in riparian vegetation composition among sites. NMDS stress was 0.21 , and because a third dimension did not substantially improve the stress 
value, I used only the first two dimensions. PAM broke sites into 3 groups roughly

matching their location on the NMDS ordination. Three of the sites were poorly matched

by PAM and were re-assigned to more appropriate groups according to their position in

NMDS space. ANOSIM results confirmed that these final 3 cluster groups differed

significantly $(\mathrm{p}<0.05)$ in species composition.

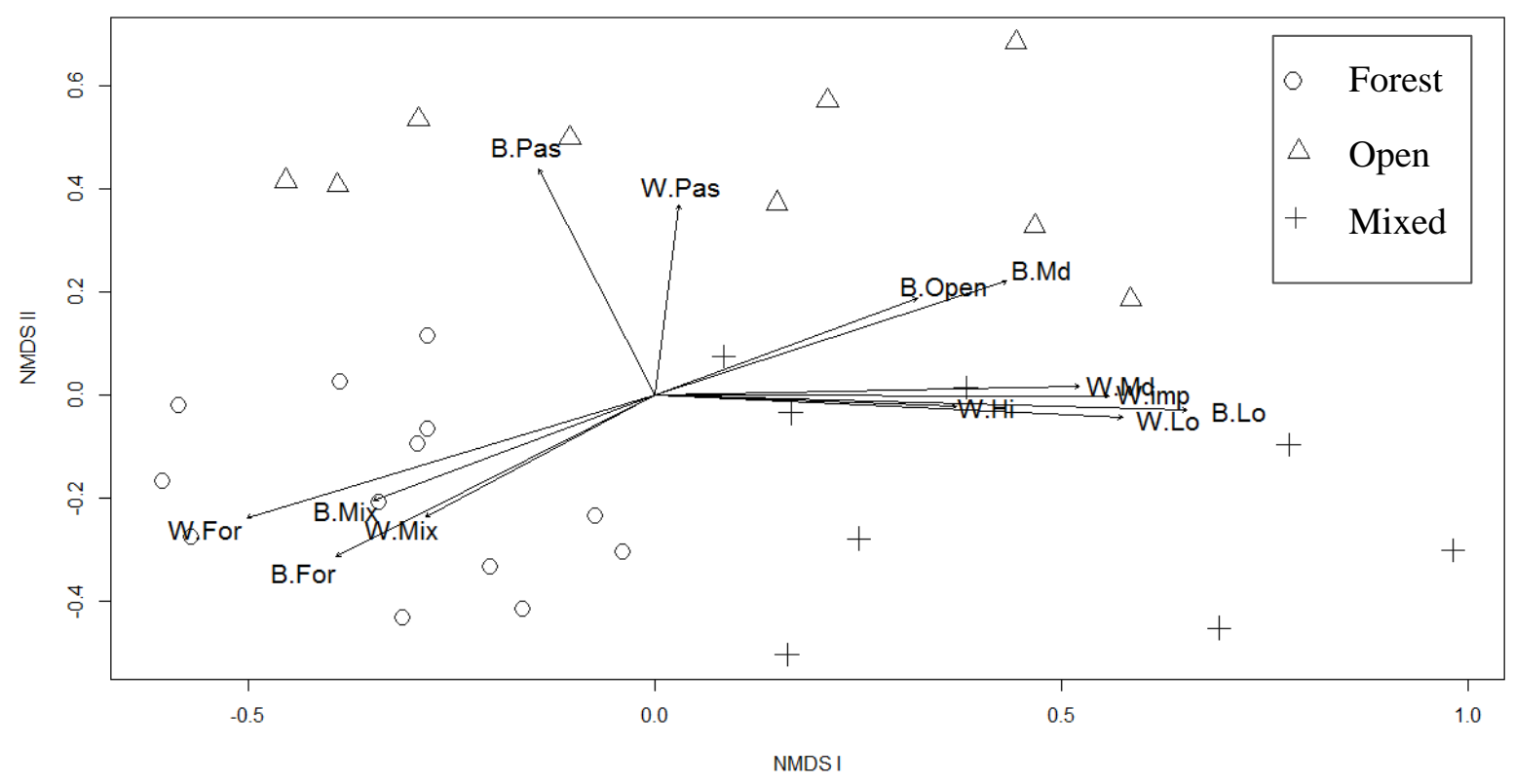

Figure 2.2: NMDS plot of study sites with associated landscape vectors. The ordination of sites was based on riparian vegetation similarity. Symbols indicate the cluster group to which each site belongs, determined by partitioning around medoids (PAM) and position in NMDS space. Overall, there is a wide distribution of sites in NMDS space, indicating variation in riparian vegetation composition. Forest sites (circles) clustered a bit more tightly than sites in Open (triangles) and Mixed (crosses). Vectors represent the association of landscape variables with distribution of sites in ordination space. Only landscape vectors significantly associated with the ordination $(\mathrm{p}<0.05)$ are shown. Forest sites are associated with high landscape forest cover. Open sites appear to be associated with agricultural cover and urban development at the $500 \mathrm{~m}$ buffer scale (B.Open, B.Md). Mixed sites are associated with urban development and watershed impervious surface area. NMDS stress $=0.21$. Definitions of landscape variables are shown in Table 2.1.

Between 2 and 11 species with significant $(\mathrm{p}<0.05)$ indicator values were found for each of the 3 cluster groups (Table 2.2). The first group was termed the "Forest" group, and had a mean species richness of $27( \pm 7)$. Indicator species for this group 
included Tsuga heterophylla (western hemlock), a mature forest species, as well as the subcanopy species Acer circinatum (vine maple). Three fern and 3 lily species were also indicators for the Forest group, in addition to other herbs and shrubs typical of forest understory. The second group had a mean species richness of $14( \pm 3)$, and was characterized by the native tree Alnus rubra (red alder) and non-native grass Phalaris arundinacea (reed canarygrass). Both of these species occur in open areas, so this group was termed the "Open" group. Two native trees, evergreen Thuja plicata (western redcedar) and deciduous Fraxinus latifolia (Oregon ash), and 2 non-native shrubs, Hedera helix (English ivy) and Ilex aquifolium (English holly) were indicators for the third group. Due to the mixture of native and non-native species, shade tolerances, and moisture requirements in this group, it was termed the "Mixed" group. Mixed had a mean species richness of $17( \pm 3)$. 
Table 2.2: Significant indicator species for cluster groups. A minimum of two species with significant $(\mathrm{p}<0.05)$ indicator values were found for each cluster group. Species with the highest values were the best indicators. The native tree $T$. heterophylla, subcanopy species A. circinatum, and species typical of a forest understory were Forest indicators. The fast-growing tree A. rubra and non-native $P$. arundinaea were indicators for Open. Two native trees and 2 non-native shrubs were Mixed indicators. Wetland indicator status codes: $\mathrm{FAC}=$ facultative, $\mathrm{FACU}=$ facultative upland, $\mathrm{FACW}=$ facultative wetland, $\mathrm{NL}=$ not listed (treated as upland). Wetland indicator status classifications from the USDA PLANTS database (USDA, NRCS, 2013).

\begin{tabular}{|c|c|c|c|c|c|}
\hline Species & Native Status & Structure & $\begin{array}{c}\text { Wetland } \\
\text { indicator } \\
\text { status }\end{array}$ & $\begin{array}{l}\text { Indicator } \\
\text { Value }\end{array}$ & p-value \\
\hline \multicolumn{6}{|l|}{ Forest } \\
\hline Acer circinatum & Native & Tree & FAC & $88 \%$ & 0.00 \\
\hline Polystichum munitum & Native & Herb & FACU & $73 \%$ & 0.00 \\
\hline Vaccinium parvifolium & Native & Shrub & NL & $63 \%$ & 0.00 \\
\hline Gaultheria shallon & Native & Shrub & FACU & $54 \%$ & 0.01 \\
\hline Adiantum aleuticum & Native & Herb & FAC & $53 \%$ & 0.00 \\
\hline Trillium ovatum & Native & Herb & FACU & $52 \%$ & 0.01 \\
\hline Vancouveria hexandra & Native & Herb & NL & $48 \%$ & 0.04 \\
\hline Prosartes hookeri & Native & Herb & NL & $48 \%$ & 0.03 \\
\hline Maianthemum racemosum & Native & Herb & FAC & $44 \%$ & 0.01 \\
\hline Tsuga heterophylla & Native & Tree & FACU & $44 \%$ & 0.01 \\
\hline Polypodium glycyrrhiza & Native & Herb & NL & $44 \%$ & 0.04 \\
\hline \multicolumn{6}{|l|}{ Open } \\
\hline Alnus rubra & Native & Tree & FAC & $51 \%$ & 0.01 \\
\hline Phalaris arundinaceae & Non-native & Herb & FACW & $48 \%$ & 0.01 \\
\hline \multicolumn{6}{|l|}{ Mixed } \\
\hline Fraxinus latifolia & Native & Tree & FACW & $57 \%$ & 0.00 \\
\hline Hedera helix & Non-native & Shrub & NL & $53 \%$ & 0.01 \\
\hline Thuja plicata & Native & Tree & FAC & $47 \%$ & 0.05 \\
\hline Ilex aquifolium & Non-native & Shrub & NL & $47 \%$ & 0.02 \\
\hline
\end{tabular}

\section{Cover by Vegetation Type}

Kruskal-Wallis tests indicated significant differences $(\mathrm{p}<0.05)$ among cluster groups in diversity metrics, native and non-native cover, and cover by different WIS and structural categories. Wilcoxon tests showed that Forest sites had significantly higher species richness than Open and Mixed sites, and higher Shannon diversity than Open sites $(\mathrm{p}<0.05)$. Forest sites also had significantly higher native cover than Open and Mixed $(\mathrm{p}<0.001)$ sites and significantly lower non-native cover than Mixed sites $(\mathrm{p}<$ 
0.05; Figure 2.3a, 2.3b). Sites in Open and Mixed groups did not differ significantly from each other in diversity metrics or native and non-native cover.

Cover by 3 wetland indicator classes, FACU, FAC, and FACW varied among cluster groups. There were no significant differences in cover by UPL species, and too few occurrences of OBL species to analyze. Forest sites had significantly higher FACU cover $(\mathrm{p}<0.001)$ and significantly lower FACW cover $(\mathrm{p}<0.05)$ than Open sites. Forest sites also had higher FAC cover than Mixed sites ( $\mathrm{p}<0.05)$.

The structural composition of Forest differed from the composition of Open and Mixed. Forest sites had significantly higher tree cover than Open sites $(\mathrm{p}<0.05$, Figure 2.3c), and significantly higher herbaceous cover than Mixed sites ( $\mathrm{p}<0.001$, Figure 2.3e). Shrub cover appeared to be lower in Forest than Mixed sites (Figure 2.3d), but the difference between the 2 groups was not statistically significant. 
a)

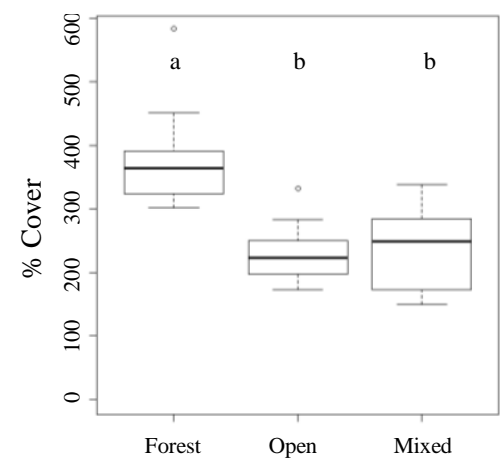

c)

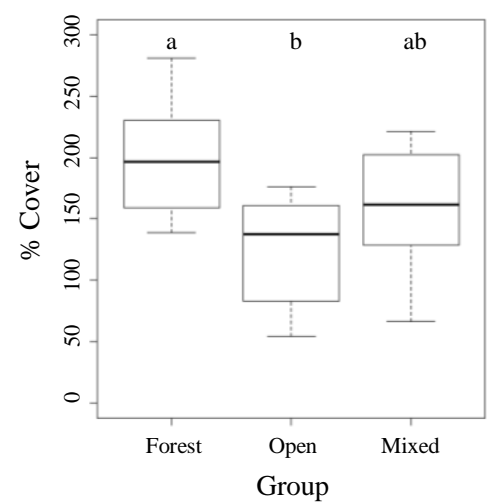

b)

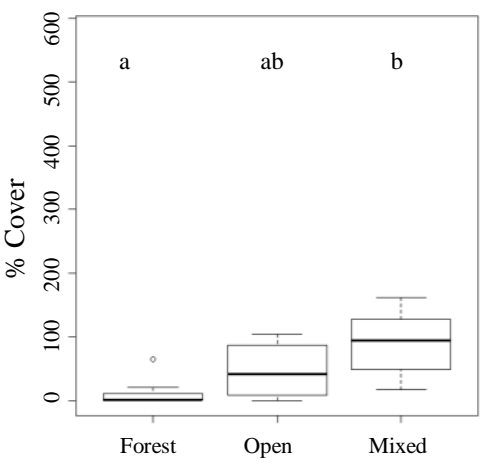

d)

Group

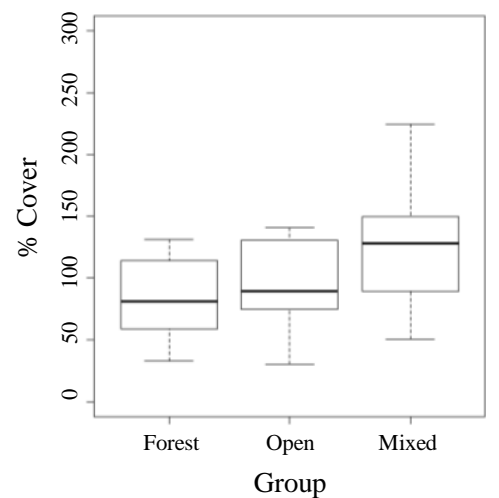

e)

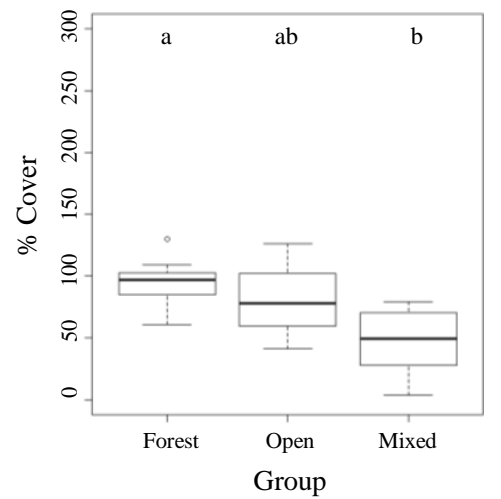

Figure 2.3: (a and b) Native and non-native cover by cluster group; (c, d, and e) Tree, shrub, and herb cover by cluster group. Letters indicate significant $(p<0.05)$ differences between groups in pairwise Wilcoxon tests. a) Forest had significantly higher native cover than Open and Mixed. b) Mixed had significantly higher non-native cover than Forest. Open was not significantly different in non-native cover from Forest or Mixed. c) Forest had significantly higher tree cover than Open. d) Forest had the lowest shrub cover and Mixed the highest, although differences were not statistically significant $(p>0.05)$. e) Forest had significantly higher herb cover than Mixed.

\section{Watershed Characteristics and Association with Riparian Vegetation Cover}

A total of 13 land cover variables had significant $(\mathrm{p}<0.05)$ relationships with NMDS space, indicating a relationship with vegetation composition in the sites (Figure 2.2). Variables measured at both the watershed and $500 \mathrm{~m}$ buffer scales were significant. At the watershed scale 3 of the 4 urban development levels (low-, medium-, highintensity), evergreen forest, mixed forest, pasture/hay, and impervious surface cover were significant $(\mathrm{p}<0.05)$. At the $500 \mathrm{~m}$ buffer scale open-, low-, and medium-intensity 
development, evergreen forest, and pasture/hay were significant $(\mathrm{p}<0.05)$. Forest group sites were strongly associated with high landscape forest cover, both at the watershed scale and within the $500 \mathrm{~m}$ buffer. Open and Mixed sites were positively associated with urban, agriculture, development and impervious surface in the landscape and negatively with forest cover. Wilcoxon tests confirmed differences between Forest and the other cluster groups in surrounding landscape composition. While Wilcoxon tests did not show significant differences between Open and Mixed sites for landscape metrics, landscape vectors fit to the NMDS by 'envfit' suggested that at least some Open sites were surrounded by more agriculture than Mixed sites (Figure 2.2).

The classification tree confirmed the importance of watershed forest cover (Figure 2.4), indicating it as the strongest predictor of cluster group affinity. All 13 Forest sites were distinguished from Open and Mixed sites by watershed forest cover of at least $15 \%$. Open and Mixed sites all had watershed forest cover lower than $15 \%$ and were distinguished from each other by watershed-level open development and $500 \mathrm{~m}$ bufferlevel low-intensity development. 


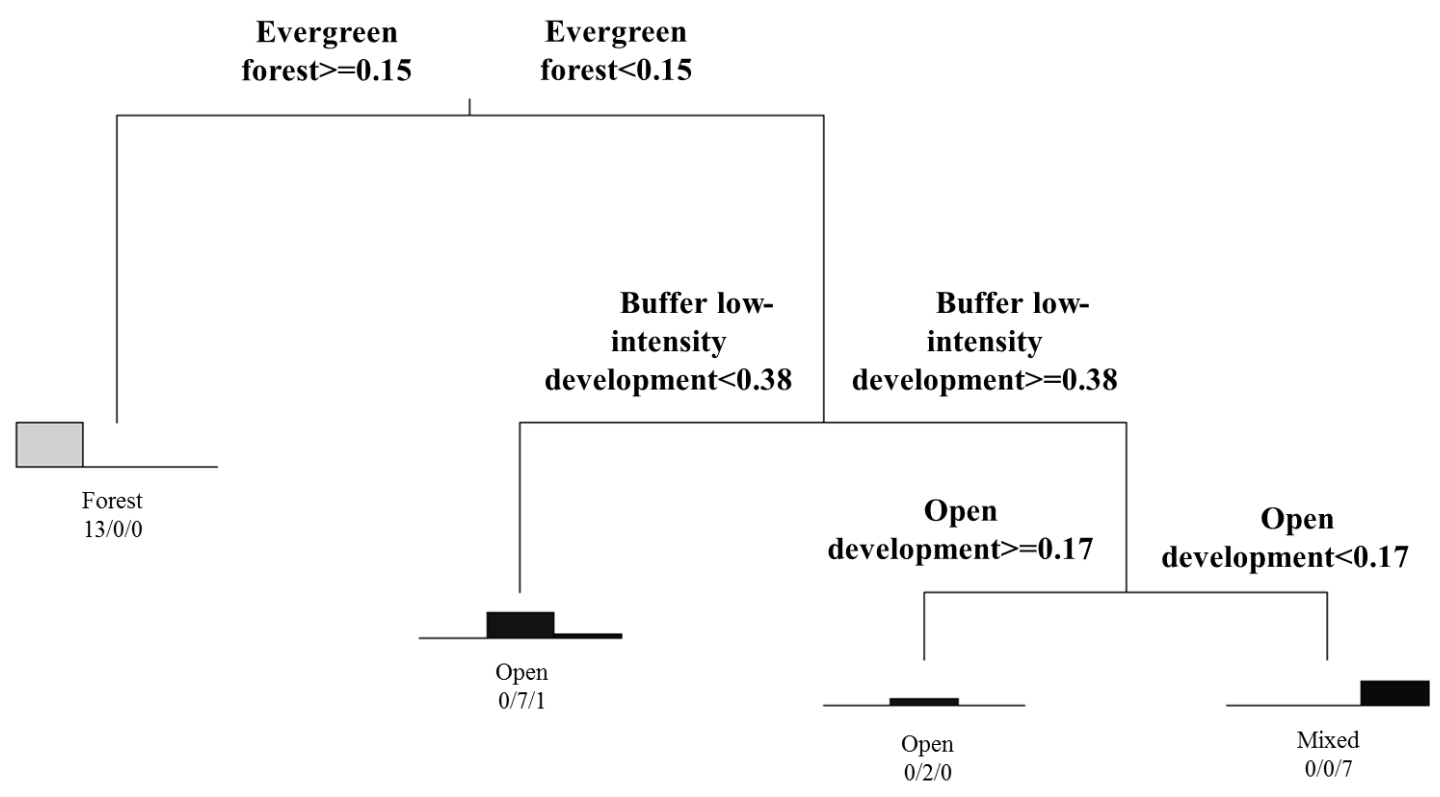

Figure 2.4: Classification of sites by land cover variables. The classification tree had a misclassification rate of 3.3\%, with 1 Mixed site classified as an Open site. Bar charts indicate the number of sites classified in each group by the tree (Forest/Open/Mixed). Watershed evergreen forest was the first predictor of cluster group, separating out all 13 Forest sites with cover of at least $15 \%$. Open and Mixed sites were distinguished from each other by low-intensity development within the $500 \mathrm{~m}$ buffer and open development within the watershed.

\section{Discussion}

Landscape forest cover played a significant role in predicting vegetation community type in urban riparian areas in this study. Similar to other studies (Lowenstein and Lowenstein 2005; Burton and Samuelson 2008), I found the most species rich Forest communities in sites with high surrounding forest cover. The classification tree indicated that at least $15 \%$ watershed forest cover was the determinant of Forest communities. These sites had higher native cover and greater structural complexity than Open or Mixed sites, and very low or no non-native cover. The high mean native cover in these assemblages (Figure 2.3a) is not surprising given the shade- 
tolerant nature of these forest species. These sites were characterized by species representative of forest interior habitat, including several lily and fern species and shadetolerant shrubs. Forest cover may promote the persistence of these species by maintaining low understory light levels, inhibiting encroachment by faster growing, shade-intolerant species (Everson and Boucher 1998; Angiolini et al. 2011). Forest understory species are also generally poor dispersers over a long-distance and are likely to be affected by habitat fragmentation (Honnay et al. 2002; Kolb and Diekmann 2005; Pearson and Dawson 2005). Forest connectivity may be a requirement for viable populations of these understory species; forest discontinuities within $1 \mathrm{~km}$ of a patch have been found to affect forest specialist species (Herault and Honnay 2005). Likewise, my results suggest that at the scale of the entire watershed, forest continuity affects these species. However, while some other studies have found weaker relationships between riparian vegetation and land cover at broad scales than at local scales (Allan et al. 1997; Fernandes et al. 2011), my results suggest that watershed-level land cover patterns are correlated with riparian vegetation patterns. Studies of stream organisms and water quality have also found watershed-level land cover patterns to be important variables (Houser et al. 2005; Lorenz and Feld 2013), and it appears from this study that those relationships may extend to riparian vegetation assemblages as well. These findings are consistent with Nucci et al. (2012), who concluded that a multiscale perspective is appropriate when considering the controls on riparian vegetation.

My hypothesis of largely native riparian assemblages in watersheds with high forest cover was supported by results. Native cover was strongly and positively 
associated with landscape forest cover and negatively with watershed development and agriculture. Non-native cover was positively associated with surrounding development and negatively with forest cover. Magee et al. (2008) also found lowest cover by alien species in watersheds with closed forest compare to other rural land cover types, however, urban riparian areas and land cover types were not included in their Eastern Oregon study. My results are also consistent with findings of high non-native cover in riparian areas immediately surrounded by development, but these urban studies have generally not considered the effects of land cover at broader watershed scales (Cadenasso and Pickett 2001; Lin et al. 2006; Duguay et al. 2007).

Contrary to my expectations, high FACW cover was found in Open and Mixed sites, positively associated with agriculture and development and negatively with forest cover in the landscape. These results vary from findings of greater prevalence of floodintolerant species in more urban sites in other studies (Groffman et al. 2003; Burton et al. 2009). It is important to note, however, that the 2 most abundant FACW species, $P$. arundinacea and F. latifolia, indicator species for Open and Mixed respectively, have medium and low shade tolerance, and are not typical of dense forest (USDA NRCS 2013). It is possible that the high cover by these hydrophilic species in Open and Mixed sites is driven by the light environment in these more urban and agricultural watersheds, rather than moisture regime. It is also possible that the expected trends would emerge in a study including watersheds with more cover by high-intensity development. The low amount of surrounding cover by high-intensity development is also likely the reason that, 
as with Hutmacher et al. (2013), I found no relationship between the density of urban development and non-native riparian cover.

My results suggest that local and landscape factors associated with minimal riparian cover by $H$. helix and other non-native shrubs are necessary for protecting structural diversity in riparian areas. Forest, with highest watershed forest cover, was the only group to have indicator species representative of all 3 structural groups. Higher tree cover in Forest than in Open and Mixed groups (Figure 2.3a) is consistent with Salinas and Casas (2007), who found lower woody cover and diversity in riparian areas with increasing human impacts. However, the significantly higher herbaceous cover in Forest than Mixed (Figure 2.3e) is in sharp contrast to Guntenspergen and Levenson (1997), who found no difference in understory herbaceous composition along a rural-urban gradient in Wisconsin. In my study, it is possible that the difference between Forest and Mixed sites in herbaceous cover reflects a tradeoff between understory herb and nonnative shrub cover. Mixed sites had high cover by invasive $H$. helix, an indicator species for this group. H. helix is a moderately fast-growing vine (USDA NRCS 2013) that can smother native, herbaceous species on the forest floor (Dlugosch 2005). Similarly, Vidra et al. (2006) found that non-native vines were negatively correlated with the presence of native forest herbaceous species in Northern California. H. helix may be contributing to reduced species richness and structural complexity in Open and Mixed sites compared to Forest sites, as was found in Seattle parks (Dlugosch 2005). Structural complexity is an important habitat component (Banville and Bateman 2012), and results suggest that control of $H$. helix and other non-native shrubs is required for its maintained presence. 
My results indicate that cover by non-native shrubs is lowest where there is highest watershed forest cover. Riparian sites in such watersheds with significant forest cover should be prioritized for conservation.

\section{Conclusion}

My results show that functionally diverse, native riparian forest assemblages can exist in urban landscapes in certain situations. Watershed forest cover appears to be the most important condition for these assemblages, with structurally diverse, native, forest understory species present in urban riparian areas with at least $15 \%$ watershed forest cover. While the relationship between diverse, native riparian assemblages and landscape forest cover is not surprising, as far as I know this is the first study to suggest that, even for sites within an urban area and subject to urban disturbances, forest cover at the watershed scale can serve to protect these assemblages. Within the urban environment, riparian management and research has largely focused on near-stream variables and buffer strips (Richardson et al. 2012), but my results indicate that to maintain diverse riparian forest assemblages and corresponding functions and services, land cover at the broader watershed level should also be considered. As urbanization continues to increase, maintaining as much forest cover as possible in watersheds should be emphasized. Prioritization of large parks, natural areas, and undeveloped forests in watersheds at urban edges may allow cities to better sustain the substantial ecosystem services provided by natural, functionally diverse riparian areas. 


\title{
Chapter 3: Seed Deposition in Riparian Forest Fragments Along a Gradient of Watershed Urbanization
}

\begin{abstract}
Riparian forests are valuable ecosystems, but the composition of their vegetation is often greatly altered in urban environments. While local riparian habitat alterations, including altered hydrology and disturbance regimes are known to affect plant establishment and survival in urban areas, the mechanisms of seed dispersal in urban riparian areas are unclear. Urban habitat fragmentation could inhibit seed exchange among sites by wind, while stream channel incision and altered flooding patterns could affect the ability of streams to deposit seeds on stream banks. I hypothesized that, 1) more seeds overall would be deposited by water than by wind across study sites; 2) there would be a reduction in the overall number of seeds deposited by water as watershed urbanization increased; and 3) in the most urban watersheds, seeds deposited by water would be predominantly from species with traits favoring dispersal in general, including tall stature and high seed production, and favoring deposition by water in particular, including large seed size and the presence of a structure or appendage to facilitate water dispersal. Nine riparian forests, selected with a stratified random approach, were studied along a gradient of watershed impervious surface area in the Portland, Oregon metropolitan region. Seeds deposited by wind were collected three times, and seeds deposited by water were collected four times over a 15-month period to span both wet and dry seasonal conditions. Across all sites, seed deposition by wind and gravity into
\end{abstract}


funnel traps was compared to seed deposition by water into turf traps. Regression analysis was used to examine the relationship between watershed urbanization and seed deposition. Over the course of the study, a total of 15,688 potentially viable seeds were collected from 78 taxa. A significantly higher density of seeds was found in turf traps than in funnel traps $(\mathrm{p}<0.05$; cumulative mean of 155 seeds per turf trap and cumulative mean of 30 seeds per funnel trap). Significantly more seeds were deposited by water during the winter than during the summer $(\mathrm{p}<0.05)$, but there were no significant seasonal differences in total number of seeds deposited by wind. Overall riparian deposition of shrub species, species primarily dispersed by animals, and species under $15 \mathrm{~m}$ tall was significantly increased by hydrochory. Along the urbanization gradient, there was a significant decrease in the total number of seeds deposited by hydrochory ( $\mathrm{y}$ $=-2.87 \mathrm{x}+191.95$; adjusted $\left.\mathrm{R}^{2}=0.74 ; \mathrm{p}<0.01\right)$. Deposition of shade-tolerant and native taxa by water decreased as surrounding urbanization increased $(\mathrm{p}<0.05)$. Overall, results show that urban streams can act as dispersal vectors, connecting riparian populations that may otherwise be dispersal-limited due to forest fragmentation. The reduction in overall seed deposition, and in deposition of shade-tolerant species as urbanization increased suggests that passive restoration approaches will be less likely to succeed in highly urbanized watersheds, particularly for restoration of the riparian forest understory. 


\section{Introduction}

Riparian forest vegetation provides many valued functions in urban areas, including flood dissipation, nutrient buffering (Tabbachi et al. 2000), and habitat for many species (Naiman and Decamps 1997). Urban structures and processes can drastically change riparian areas however, altering their ability to support native riparian vegetation. Large differences in species composition between urban and non-urban riparian communities have been observed (Moffatt et al. 2004, White and Greer 2006, Burton and Samuelson 2008, Burton et al. 2009, Pennington et al. 2010). Several studies have identified local and landscape-level variables that are correlated with riparian vegetation composition (e.g. Metzger 2000; Schwoertzig et al. 2016b; Chapter 2). The physical mechanisms through which these variables act to affect riparian vegetation, however, are not entirely clear. On the one hand, land use that alters the local, physical properties of a site, such as soil moisture and light level, can alter the site's suitability for growth of different plant species. On the other hand, land use may affect the regional process of dispersal; the ability of propagules to arrive at a riparian site from the surrounding landscape. There has been much work on how local habitat features of riparian areas are altered by urban land use, and how vegetation communities respond (e.g. Groffman et al. 2003; White and Greer 2006; Burton et al. 2009). Following the assumption that local processes are the main drivers of vegetation change, riparian restoration in urban areas typically seeks to restore hydrology and canopy conditions, while allowing much of the vegetation community, particularly understory vegetation, to reestablish on its own. While sometimes successful, restoration goals are not always met 
with this passive approach (Hilderbrand et al. 2005; Gornish et al. 2017). There have also been recent studies suggesting that urban land use alters the dispersal processes of forest plant species, particularly those dispersed by animals (e.g. Alados et al. 2010). It is less clear how hydrochory (water dispersal) might be affected by urban land use in the landscape. While dispersal is crucial to the restoration process (Suding et al. 2004), it is unclear how dispersal properties may constrain species distributions in urban riparian areas.

\section{Urban Forest Fragmentation and Dispersal Limitation}

Altered dispersal success due to forest fragmentation may be a driver of change in urban riparian vegetation communities. Studies have shown that forest vegetation communities in fragmented landscapes are seed-limited due to reduced colonization success. Honnay et al. (2002) found that for numerous forest species, successful dispersal to suitable habitat occurred less frequently in a landscape of highly fragmented forest patches than in a network of patches connected by hedgerows. In a seed-sowing experiment, Ehrlen and Erikkson (2000) found evidence of seed limitation in seven perennial herbs in isolated forest patches in Sweden. McEuen and Curran (2004) found that only four of 17 woody species dispersed seeds among temperate forest fragments in Michigan.

Not all species are equally affected by habitat fragmentation. Species that mainly disperse seeds over small ranges and colonize landscapes slowly are highly susceptible to fragmentation (Alados et al. 2010). Brunet and Von Oheimb (1998) found that as habitat 
fragmentation increases, the relative importance of a plant's dispersal mode for colonization also increases. A survey of habitat patches varying in connectivity to seed sources demonstrated this phenomenon. Large seeds and seeds without specialized dispersal structures were found infrequently in highly isolated patches, as were seeds from plants of small stature (Kolb and Diekmann 2005). Short plants typically can't disperse seeds as far as taller plants can (Muller-Landau et al. 2008, Thomson et al. 2011) and are likely disadvantaged in fragmented landscapes (Pearson and Dawson 2005). Alados et al. (2010) found that vertebrate-dispersed shrubs were limited in very fragmented patches, likely due to limited visits by seed-dispersing animals. Pearson and Dawson (2005) concluded that species with poor dispersal abilities have decreased migration success and are less likely to survive in fragmented arrangements of habitat patches than species that are capable of long-distance dispersal.

Studies have produced conflicting results on the success of wind-dispersed species in forest fragments. McEuen and Curran (2004) found that light weight, winddispersed species were most likely to be capable of saturating forest fragments with seeds. Similarly, Lin et al. (2006) concluded that wind-dispersed species are most likely to be capable of invading forest fragments. In contrast, others have found wind brings very few seeds into forest patches. Forest edges can act as seed filters, preventing some wind-dispersed seeds from reaching the forest interior (Cadenasso and Pickett 2001). Takahashi and Kamitani (2004) also found very slow migration rates of wind-dispersed species to new forest patches. 


\section{The Importance of Hydrochory for Urban Riparian Forests}

Riparian forests differ from upland forests and may respond differently to fragmentation. In riparian forests, water is a key influence on community dynamics (Naiman et al. 1993). Studies have found hydrochory (water dispersal) to be a major factor shaping riparian vegetation communities (Honnay et al. 2001, Merritt et al. 2010, Moggridge and Gurnell 2010, Nilsson et al. 2010, Fraaije et al. 2015). Jansson et al. (2005) found that riparian plots that were flooded and subject to deposition of propagules from the stream had 40-200\% higher species richness than plots that were unflooded. Hérault and Honnay (2005) found hydrochorous species to be better colonizers of fragmented riparian forests than anemochorous (wind-dispersed) or zoochorous (animaldispersed) perennials.

In Mediterranean-type climates, hydrochory is likely the most important dispersal vector in the winter time when flows are high (Gurnell et al. 2008, Moggridge and Gurnell 2010, Fraaije et al. 2017), while wind dispersal may be more important in the summer (Moggridge and Gurnell 2010). A seed barrier created by forest structure (Cadenasso and Pickett 2001) may prevent entry into a patch by wind and make hydrochory a particularly important vector in riparian forests. Hydrochory has in fact been shown to connect otherwise fragmented habitats by depositing seeds in sites that could not be reached through wind dispersal alone (Vogt et al. 2004, Merritt et al. 2010). Parendes and Jones (2000) found that streams act as dispersal corridors, similar to roads, in forest systems. In their study in the H.J. Andrews Experimental Forest in western Oregon, 21 ruderal non-native plants were generally rare, even in disturbance areas such 
as landslides. These species were present, however, along many of the streams and roads surveyed, suggesting that streams and roads serve as corridors for species that are otherwise dispersal-limited in the forest environment (Parendes and Jones 2000).

Hydrochory is a complex process that involves multiple steps, with the potential for seeds to be sorted based on size and shape at each step (Chambert and James 2009). First, seeds must reach the stream. They can be released directly into the stream from an overhanging plant or be washed in after initially falling to the ground. Seeds can wash in from overland flow during a storm event or be picked up by high stream flows that overtop the banks (Chambert and James 2009). Life-history traits of riparian species contribute to the likelihood of their seeds making it to the stream. For riparian species, Boedeltje et al. (2003) found that seed production rate was the most important predictor of a species' ability to disperse downstream by hydrochory. Plant height has also been hypothesized to relate to a plant's ability to disperse seeds to streams. Generally, seeds released from taller plants should be more likely to travel by wind (Muller-Landau et al. 2008; Thomson et al. 2011), and thus reach a stream, than seeds released from shorter plants (Willson and Travaset 2000; Boedeltje et al. 2003).

Transport by the stream and deposition are the two other steps in the hydrochory process, after seed arrival at the stream (Chambert and James 2009). Once a seed has reached the stream, seed size and morphology can affect the likelihood of long-distance travel by the stream, as well as deposition on a stream bank. The buoyancy of a seed can facilitate transport and deposition by water (Boedeltje et al. 2003; Fraaije et al. 2017). Hairs, wings, or other appendages can increase adhesion to the water surface and so may 
facilitate hydrochory. However, even seeds that don't float can be transported and deposited by streams, similarly to sediment and organic material (Goodson et al. 2003; Chambert and James 2009). Seeds of most species can be dispersed by water, Nilsson et al. (2010) concluded, even those without specific adaptations for water dispersal. High seed weight and the presence of an appendage have been shown to encourage deposition on the stream bank (Samuel and Kowarik 2013).

The ability of urban streams to connect fragmented patches, however, is unclear. Samuel and Kowarik (2010.) found that an urban river effectively transported Acer spp. (maple) and Ailanthus altissima (tree of heaven) seeds, although they evaluated seed transport while seeds were in the water and did not look at deposition on the stream bank. Urban streams are often incised and have infrequent overbank flow (Groffman et al. 2003, Walsh et al. 2005); reduced overbank flow could potentially reduce opportunities for seeds to be deposited on stream banks. Additionally, features that increase the complexity of stream morphology, including meanders, riffles, and bars provide greater opportunities for seed deposition (Cunnings et al. 2015). The urban stream syndrome, which often includes channel straightening and reduced complexity (Walsh et al. 2005), may decrease opportunities for seed deposition.

It is unclear if, and to what extent, dispersal of seeds of species with different lifehistory traits may be differentially affected by watershed urbanization and urban stream syndrome. It is possible that seeds adapted for dispersal by different dispersal vectors might vary in their abilities to travel along and be deposited by streams with altered hydrology and morphology. Animal- or wind-dispersed seeds that have wings, hooks, or 
other similar structures (Figure 3.1), may have enhanced floating ability, as well as an increased likelihood of catching on leaves, twigs, or other objects along stream banks, facilitating deposition. These features that favor stream travel and deposition may allow these species to disperse through urban systems more effectively than species with ballistic dispersal or no special adaptation for dispersal, which generally lack these traits.

a)

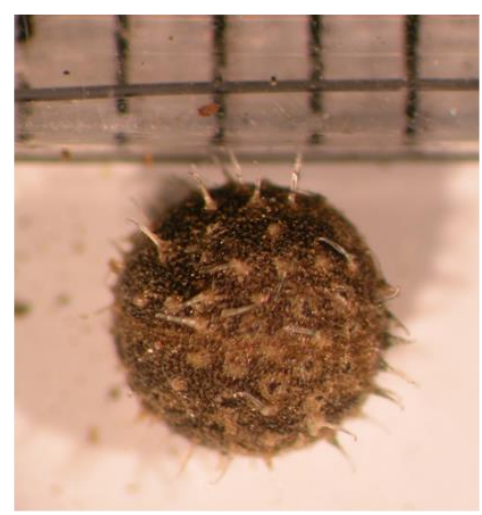

d)

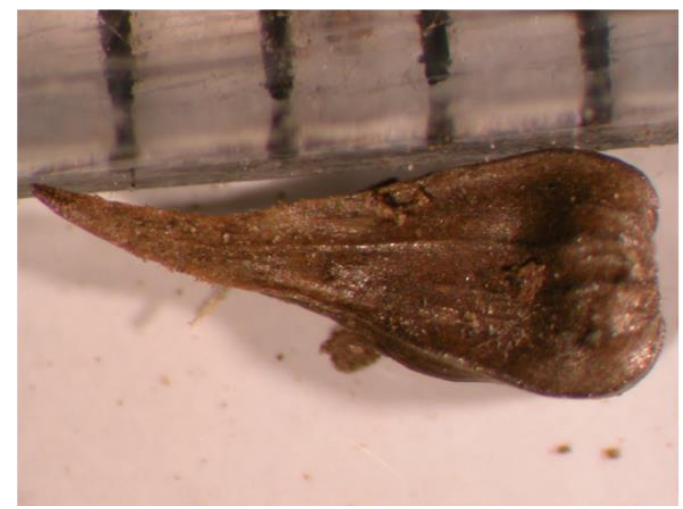

b)

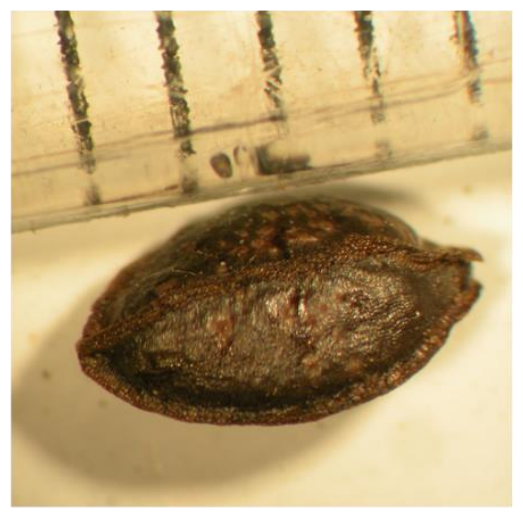

e) c)
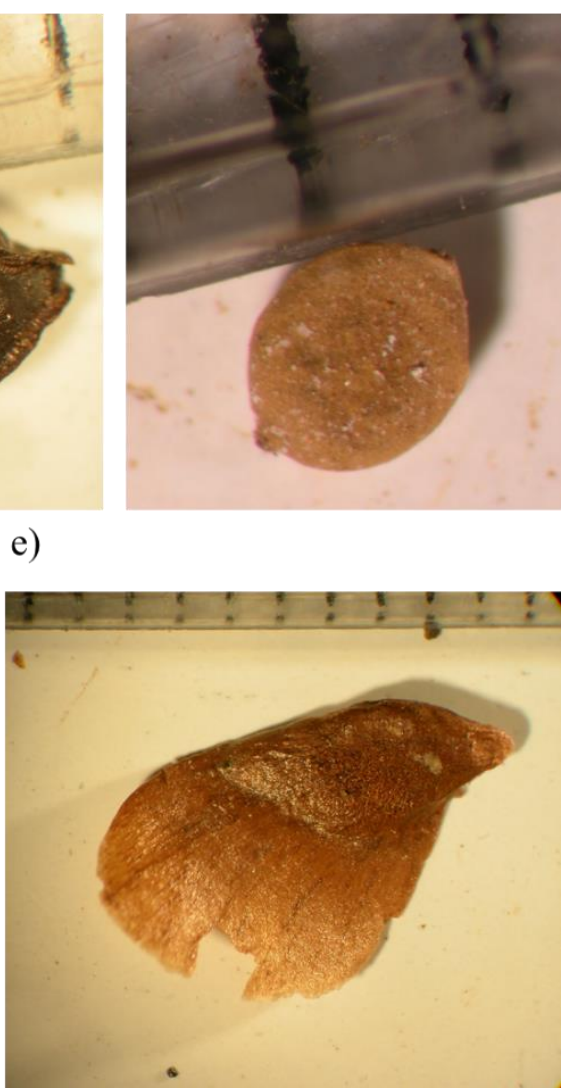

Figure 3.1: Seeds with different primary dispersal mechanisms. a) Animal-dispersed seed Galium aparine (cleaver) has hooks that attach to animal fur; b) Ballistically-dispersed Impatiens capensis (jewelweed); c) No specialized dispersal mechanism, Urtica dioica (stinging nettle); d) Water-dispersed Carex stipata (awl-fruit sedge) with inflated perigynium which increases buoyancy; e) Wind-dispersed Pseudotsuga menziesii (Douglas fir) with large wing to facilitate travel through the air. It is unclear if the presence of a structure that enhances dispersal (a, d, e) may facilitate dispersal by streams in urban systems. 
This study will add significantly to the body of knowledge on riparian seed dispersal in general, and on hydrochory in particular, by characterizing deposition patterns on multiple streams across a broad urban region, and by examining relationships between these patterns and landscape features to infer mechanisms that act on seed dispersal in urban areas. To date, most studies of hydrochory have typically involved heavy monitoring at sites on two to three streams to evaluate seasonal deposition patterns and relationships with stream hydrology (e.g. Merritt and Wohl 2002; Gurnell et al. 2008; Moggridge and Gurnell 2010; Fraaije et al. 2017), or releasing seeds or artificial seeds to investigate relationships between seed traits and travel and deposition patterns (e.g. Engstrom et al. 2009; Samuel and Kowarik 2013; Cunnings et al. 2016). These studies have provided detailed information on relationships between seasonal hydrology patterns, sediment deposition, and seed deposition by hydrochory, as well as relationships between seed characteristics and stream travel and deposition patterns. However, few studies have evaluated relationships between landscape-level features and seed dispersal by hydrochory. Beodeltje et al. (2003) quantified relationships between seed presence in instream seed traps and distance to source population, but did not consider other landscape factors. By investigating how deposition patterns by hydrochory may be affected by changing landscape patterns, this study will provide knowledge that can be used to improve the designs of conservation and restoration projects. 


\section{Study Purpose and Hypotheses}

The first goal of this study was to characterize patterns of seed deposition by aerial vectors, primarily wind and gravity, and by water, in forested riparian areas along small streams across an urban landscape. The second goal was to determine how seed deposition patterns change with increasing levels of development throughout the watershed, as a way of inferring mechanisms at work in dispersing seeds in urban riparian areas. I hypothesized that 1) more seeds overall would be deposited by water than by wind across study sites, and in particular more "new" species to a microsite (species not in the standing vegetation) would be deposited by water than wind;2) there would be a reduction in the overall number of seeds deposited by water as watershed urbanization increased; and 3) in the most urban watersheds, seeds deposited by water would be predominantly from species with traits favoring dispersal in general, including tall stature and high output of seeds per individual, and favoring deposition by water in particular, including large seed size and the presence of structure or appendage to facilitate water dispersal. I expected that in less urban watersheds a greater variety of life-history strategies and seed morphologies would be represented.

\section{Methods}

\section{Site Selection}

Nine forested riparian areas were selected in the Portland metropolitan area along a gradient of watershed total impervious surface area (TIA) using a stratified random approach. Other studies examining urban to rural gradients have used watershed 
imperviousness as a metric of urbanization (e.g. Morse et al. 2003, Chadwick et al. 2006). To initially be considered for selection, sites had to be within $5 \mathrm{~km}$ of the urban growth boundary of the Portland metro area, had to be on permanent streams of second to fourth order, and had to have at least 1 ha of forested area, with 0.5 ha of that area accessible for study. The USGS National Hydrography Dataset (NHD; nhd.usgs.gov) and Metro Regional Land Information System (Metro Data Resource Center 2013; www.oregonmetro.gov) datasets were used to select all permanent second-order through fourth-order streams in this region. Stream order was manually delineated in ArcGIS version 10.4 (ESRI 2014) from USGS NHD flowlines and verified using data from the Intertwine Alliance (www.theintertwine.org). Data on land cover and impervious surface area from the 2011 National Land Cover Database (NLCD; Homer et al. 2015) were used to identify sites along these streams with at least 1 ha forest cover. From these potential sites, watersheds were delineated using the USGS Streamstats tool (streamstats.usgs.gov). These watersheds were then imported into ArcGIS. The TIA (total impervious area) of these delineated watersheds was calculated by clipping the NLCD impervious surface area raster layer to the watersheds imported from Streamstats. Potential sites were then assigned the following TIA categories: 0-5\%, 5-15\%, 15-30\%, and $>30 \%$. The TIA categories were established based on evidence of thresholds of impact at different levels of TIA (May and Horner 2000; Booth et al. 2002; Randhir and Ekness 2009). The target for selection was two sites in each category, with one additional site below $15 \%$ TIA (in either the $0-5 \%$ or the $5-15 \%$ category), and one additional site above $15 \%$ TIA (in either the $15-30 \%$ or $>30 \%$ category). GIS analysis determined that 
27 sites met selection criteria. After site visits and conversations with land managers, 15 sites remained that met study criteria and where access would be allowed. For TIA categories with more than two possible sites, two sites were randomly selected, giving eight study sites. One additional site with greater than $15 \%$ TIA was available and included, and an additional site below 15\% TIA was selected from the three remaining viable sites. Of the 10 selected study sites, one was lost to beaver activity after site setup, leaving nine sites (Figure 3.2; Table 3.2). 


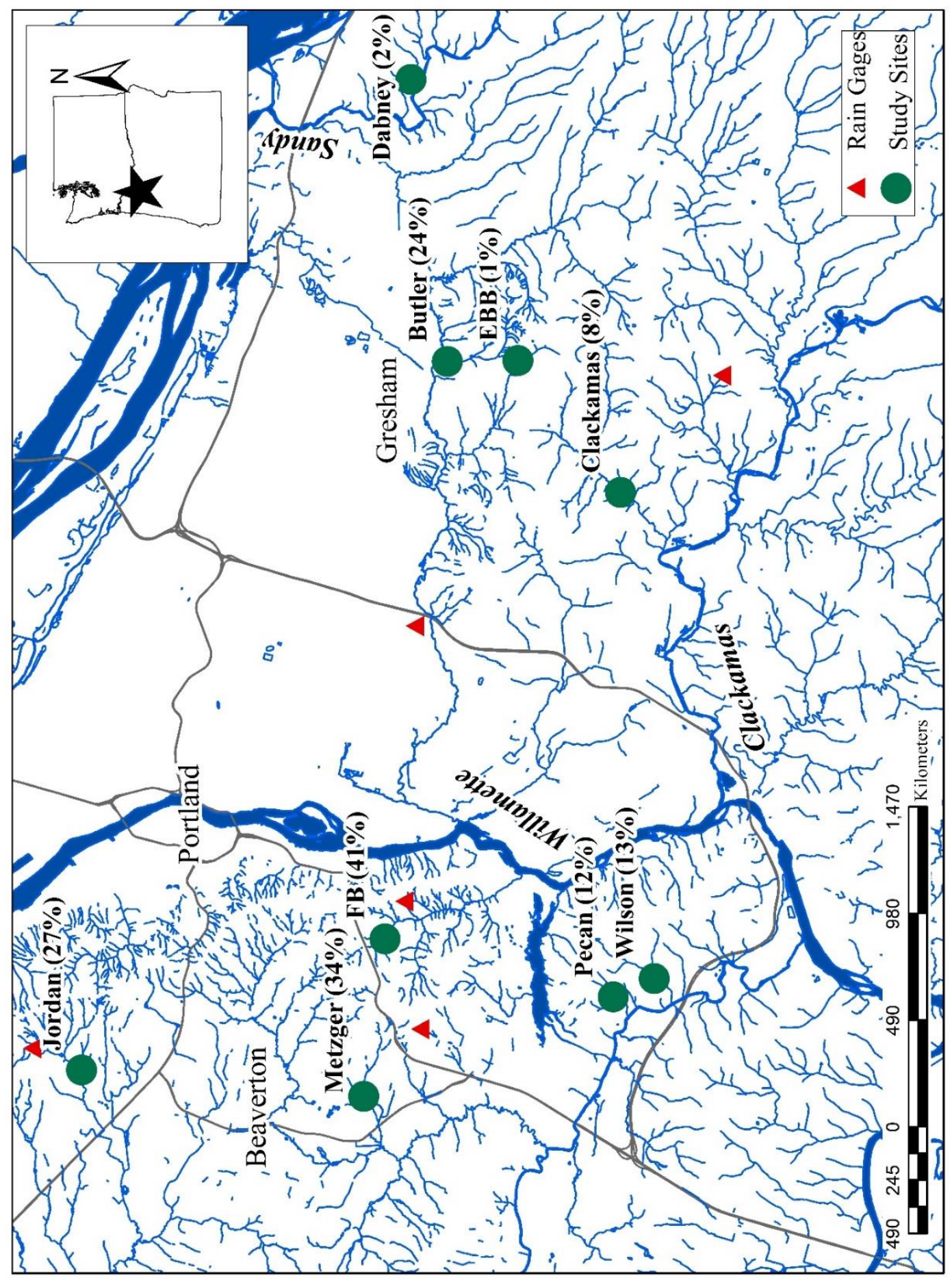

Figure 3.2: Nine study sites in the Portland, Oregon metropolitan area. The nine study sites ranged from $1 \%$ to $41 \%$ watershed TIA (shown in parentheses). Data from five HYDRA rain gages (or.water.usgs.gov/non-usgs/bes) were used to characterize rainfall patterns across the region. 
Table 3.1: Characteristics of nine study sites. The study sites were located on 9 different streams with 6 different land owners, all public agencies. The watersheds of study sites ranged from $1 \%$ TIA to $41 \%$; watershed area ranged from 154.8 ha to 1690.5 ha.

\begin{tabular}{|l|l|l|r|r|}
\hline Site Name & Site Owner & Stream & \multicolumn{1}{|c|}{$\begin{array}{l}\text { Watershed } \\
\text { TIA (\%) }\end{array}$} & $\begin{array}{l}\text { Watershed } \\
\text { Area (Ha) }\end{array}$ \\
\hline East Bliss Butte (EBB) & Metro & $\begin{array}{l}\text { Kelley } \\
\text { Creek }\end{array}$ & 1 & 172.0 \\
\hline Dabney State Rec Area & Oregon State Parks & $\begin{array}{l}\text { Bonnie } \\
\text { Brook }\end{array}$ & 2 & 132.6 \\
\hline Clackamas & $\begin{array}{l}\text { Clackamas County } \\
\text { Water Environment } \\
\text { Services }\end{array}$ & Rock Creek & 8 & 1690.7 \\
\hline Pecan Creek & Metro & $\begin{array}{l}\text { Pecan } \\
\text { Creek }\end{array}$ & 12 & 154.8 \\
\hline Wilson Creek & Metro & $\begin{array}{l}\text { Wilson } \\
\text { Creek }\end{array}$ & 13 & 490.0 \\
\hline Butler Creek Trail & City of Gresham & $\begin{array}{l}\text { Butler } \\
\text { Creek }\end{array}$ & 24 & 320.9 \\
\hline Jordan Woods & $\begin{array}{l}\text { Tualatin Hills Parks and } \\
\text { Recreation }\end{array}$ & $\begin{array}{l}\text { Cedar } \\
\text { Creek }\end{array}$ & 28 & 576.3 \\
\hline Metzger Park & City of Tigard & Ash Creek & 34 & 774.8 \\
\hline $\begin{array}{l}\text { FoleyBalmer Natural Area } \\
\text { (FB) }\end{array}$ & $\begin{array}{l}\text { Portland Parks and } \\
\text { Recreation }\end{array}$ & $\begin{array}{l}\text { Tryon } \\
\text { Creek }\end{array}$ & 41 & 372.8 \\
\hline
\end{tabular}

\section{Study Site Design}

In each riparian site, a study area was established adjacent to a $100 \mathrm{~m}$ stream reach on one side of the stream. This study area extended a minimum of $25 \mathrm{~m}$ and a maximum of $60 \mathrm{~m}$ upslope from the stream, depending on the size of the forest patch. Because dispersal dynamics were expected differ in the region immediately adjacent to the stream and the region farther up the bank into the forest patch, in each study area two sampling regions were established. The near-stream area extended from the stream edge $5 \mathrm{~m}$ up the stream bank, and the forest interior extended beyond the near-stream area to the edge of the study area (Figure 3.3). Seed deposition by wind was measured in both the near- 
stream area and forest interior. Deposition by water was measured in the near-stream

area.

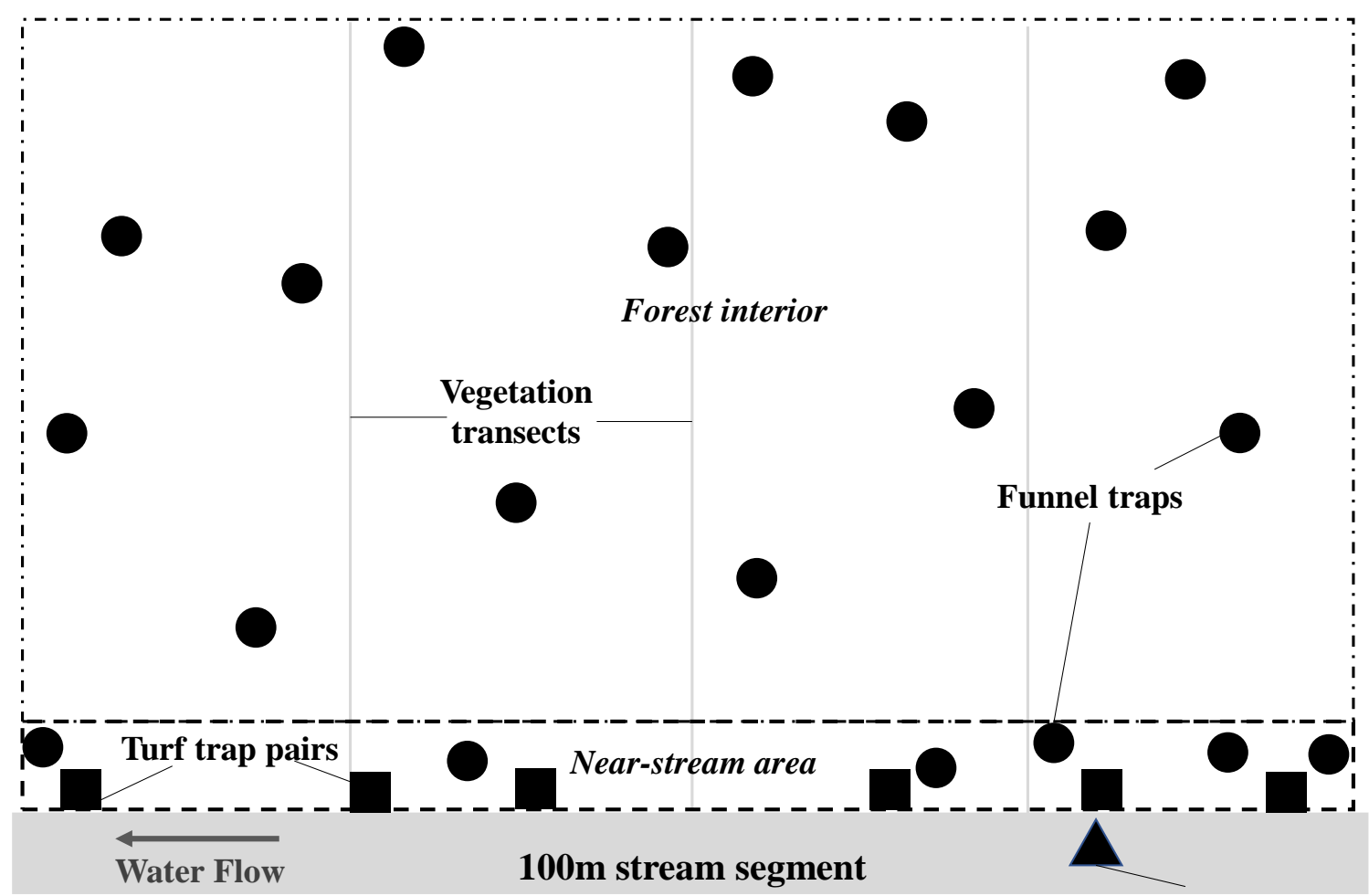

Water level data logger

Figure 3.3: Riparian site study design. Each study site was set up adjacent to a $100 \mathrm{~m}$ stream reach. Six pairs of turf mats were installed in random locations on the stream bank to collect seeds deposited by the stream. Six funnel traps, to collect seeds deposited by wind and gravity, were installed in the near-stream area (within $5 \mathrm{~m}$ of the stream), and 14 funnel traps were installed in the forest interior (beyond $5 \mathrm{~m}$ from stream).

Water depth was measured in each stream for the duration of the seed sampling periods. One OnSet $\mathrm{HOBO}$ water-level data logger was installed in the stream at each site in a PVC well. At each site the logger was placed in the location where it could best be secured, and position along the $100 \mathrm{~m}$ transect varied by site. A t-post was pounded as far as possible into the stream bed, and a 1m-long PVC tube attached to the t-post with hose clamps. The HOBO data logger was attached with waterproof tape to an aluminum 
rod, which fit snuggly inside the PVC tube. The logger was positioned at the bottom of the PVC tube, touching the stream bed. Loggers recorded pressure readings every 15 minutes. Daily atmospheric pressure data measured at the Portland airport were downloaded from the National Oceanic and Atmospheric Administration (www.ncdc.noaa.gov) and used to convert pressure measurements from the HOBO data loggers to water depth.

\section{Seed Rain Sampling}

Seed traps were installed in nine of the original 10 sites in December 2014. One of these sites was lost, leaving eight sites. Traps were installed in the $9^{\text {th }}$ site (Dabney) in March 2015. In the near-stream area, turf mats with $3.81 \mathrm{~cm}$-long "grass" blades were used to sample seeds deposited by the stream (as in Wolters et al. 2004). Six pairs of 20 x $20 \mathrm{~cm}$ turf mats were fixed to the stream bank (Figure 3.4). Surfaces with slope less than $30^{\circ}$ were determined to be suitable for seed deposition. Depositional areas along the $100 \mathrm{~m}$ stream transect were randomly selected for trap placement. In each pair the mats were placed at two elevations to collect seeds deposited in regular rain events, as well as those deposited during larger storms. In each pair, one mat sat just below the high water mark, with other up to $50 \mathrm{~cm}$ below, closer to the stream. At all sites the stream bank topography varied among depositional sites. As a result, the exact distances between the turf traps in each pair was also variable, ranging from 5 to $50 \mathrm{~cm}$.

Funnel traps were placed in randomly-selected locations to sample seeds deposited by wind (Figure 3.5). Six traps were placed in the near-stream area and 14 in 
the forest interior. Each trap consisted of a mesh bag secured to a $20 \mathrm{~cm}$ diameter funnel mounted on a PVC pipe. The end of the PVC pipe was buried, with the lip of the funnel about $8 \mathrm{~cm}$ off the ground.

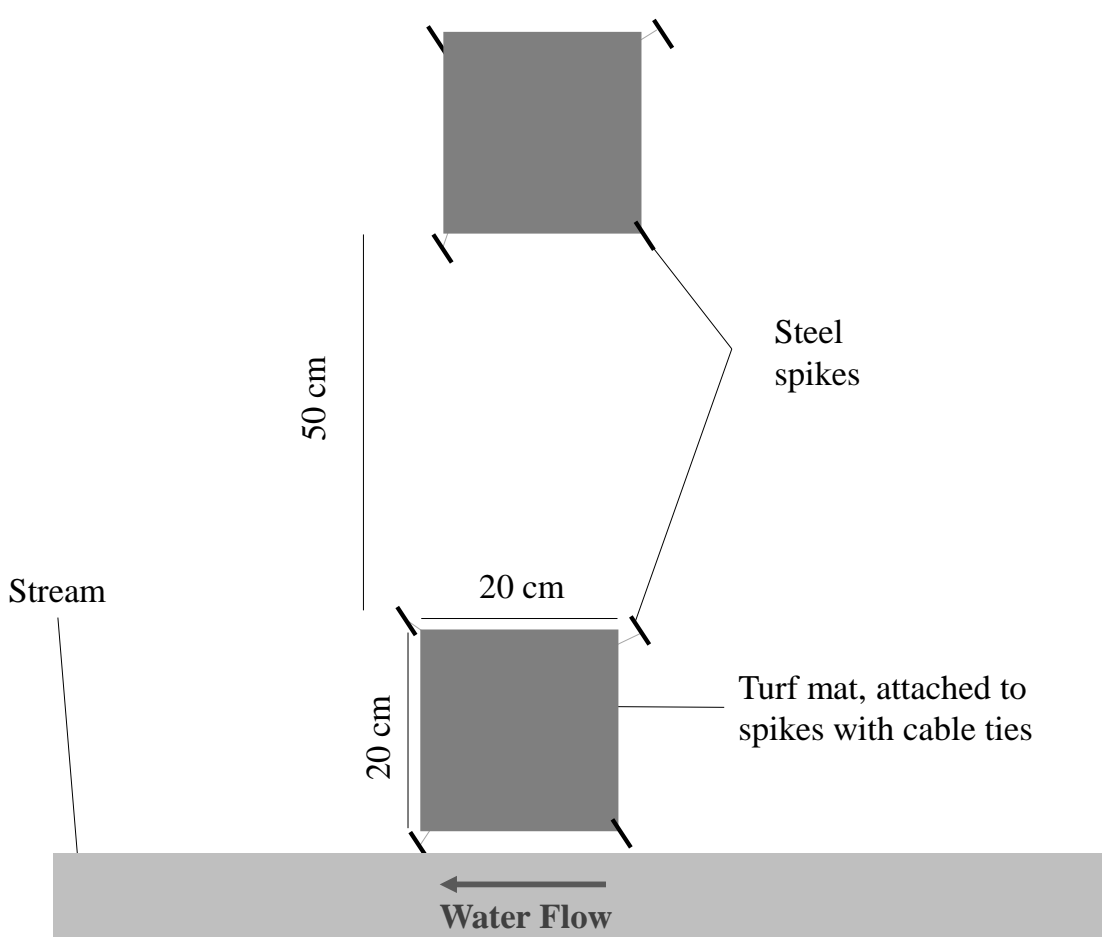

Figure 3.4: Turf trap pair: Turf mats, 20 x $20 \mathrm{~cm}$ each, were attached with cable ties to $1 \mathrm{ft}$ long steel spikes. Six pairs of mats were installed in each site. In each pair, the two mats were up to $50 \mathrm{~cm}$ apart. 


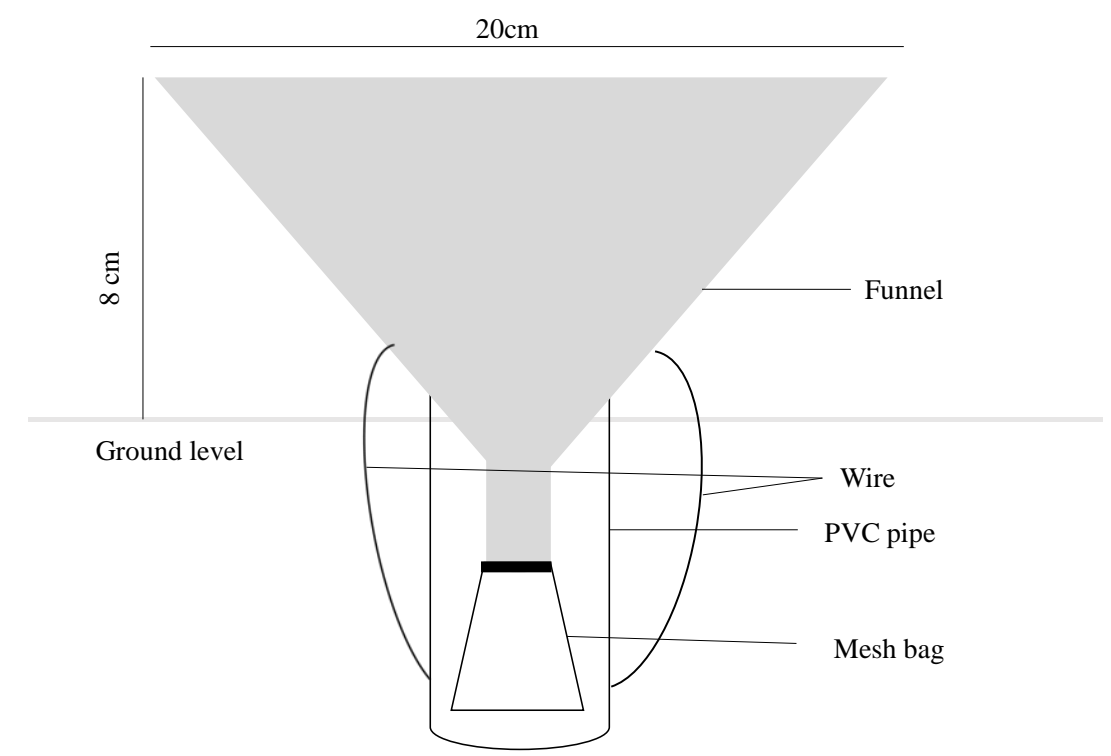

Figure 3.5: Funnel seed trap. Plastic funnels, PVC pipe, wire, and mesh bags were used to construct funnel traps. Twenty traps were installed in each site, six in the near-stream area (within $5 \mathrm{~m}$ of the stream), and 14 in the forest interior. The PVC pipe was buried, with the lip of the funnel 10cm above the ground.

Seed traps were left in study sites and contents collected after three (funnel; p1 through p3) or four (turf; p1 through p4) collection periods: January - March 2015 (p1), MarchJuly 2015 (p2), July - November 2015 (p3), and November 2015 - March 2016 (p4).

Between the $\mathrm{p} 3$ and $\mathrm{p} 4$ collection dates, large storms resulted in loss of most funnel traps through the inundation by streams, or destruction by debris falls and slides, leaving too few viable data points to warrant analysis for $\mathrm{p} 4$. To collect material from funnel traps, the mesh bag on each funnel was removed, in addition to any material stuck in the top of the funnel. The mesh bag was replaced at each sampling. Turf traps were removed from the stream bank and placed in plastic bags for transport. Clean turf mats were put down to replace those that were removed. 


\section{Sample Processing}

The seed extraction method was used to identify and count seeds caught in seed traps. This method was selected because it has been found to allow for a wider range of forest taxa to be identified than the commonly-used seedling emergence method (Brown 1992). First, turf traps were rinsed in tubs of water to remove seeds and sediment. Small paint brushes were used to gently scrub between blades to be sure that all contents were removed from mats. The water and turf contents were poured from tubs through two sieves: a $2 \mathrm{~mm}$ mesh sieve (\#10) stacked on top of a $0.125 \mathrm{~mm}$ mesh sieve (\#120), trapping any particles large enough to be seeds. Most of the material trapped in the $2 \mathrm{~mm}$ mesh sieve was organic matter and was kept for analysis. When a substantial amount of fine sediment was trapped in the $0.125 \mathrm{~mm}$ mesh sieve (more than about $100 \mathrm{~g}$ ), an additional step was used to extract organic material to facilitate searching for seeds under the microscope. A chemical extraction method was used to separate seeds in the sample from inorganic particles (Malone 1967). To disaggregate the sample, approximately $100 \mathrm{~g}$ sediment was added to a solution of $200 \mathrm{~mL}$ water, $40 \mathrm{~g}$ sodium hexametaphosphate, $20 \mathrm{~g}$ magnesium sulfate, and 100g sodium bicarbonate. The material was thoroughly stirred into the solution and left to rest for several minutes, allowing the organic matter to float to the surface. This separated organic material was decanted into a $0.125 \mathrm{~mm}$ mesh sieve and stored. Each $100 \mathrm{~g}$ soil sample was mixed in the solution and decanted three times, ensuring the maximum amount of organic possible was removed and preserved. If less than $100 \mathrm{~g}$ of material was collected in the $0.125 \mathrm{~mm}$ mesh sieve when poured from the tub, as was common in the lighter, summer deposition months, all 
contents were kept. Organic material was placed in a soil drying oven at $65^{\circ} \mathrm{C}$ and left until thoroughly dry (usually 2 to 4 hours). The material was then examined under a dissecting microscope, and all seeds found were identified and counted. Seeds were identified by comparison with a collection of seeds with known identities, as well as with seed images from Cappers et al. (2006), USDA, NRCS (2018), and Bonner et al. (2008). Seeds were recorded as "complete" and considered to be potentially viable if they were complete and unbroken, and "incomplete" if they were broken or fragmented.

\section{Turf Trap Distance to Water}

The vertical distance between the lower edge of each turf trap and the surface of the water was measured twice, in the summer and winter of 2016 . In the summer, stream profiles were mapped at each turf trap and at the water-level data logger. In the winter survey, the vertical distance was measured by extending a rod with a bubble level horizontally from the bottom of each turf trap, and measuring the distance between the rod and the water level.

\section{Vegetation Sampling}

Vegetation was surveyed in all study sites during the summer of 2016. Canopy cover and woody vegetation taller than $1.5 \mathrm{~m}$ were mapped along 3 transects extending from the stream edge to the end of the sampling area. The three vegetation transects were located at the $25 \mathrm{~m}, 50 \mathrm{~m}$, and $75 \mathrm{~m}$ markers along the stream transect. Vegetation was mapped to the nearest decimeter. The percent cover of herbs, shrubs, and tree seedlings 
smaller than $1.5 \mathrm{~m}$ in height was estimated in $1 \mathrm{~m}^{2}$ quadrats. Quadrats were located around each funnel and turf seed trap, giving a minimum of 32 quadrats sampled per site. Species accumulation curves were used to visually verify adequate sampling effort in each site. Curves were constructed using the function "specaccum" in the R package "vegan" (Oksanen et al. 2012). After evaluating initial quadrat data, additional quadrats were established at random points in two sites to assure that the majority of species in the site was captured. Vegetation was identified to the species level using Hitchcock and Cronquist (1973) and Meyers et al. (2015).

\section{Landscape Analysis}

Landscape metrics were calculated for each site at three different scales using ArcGIS; within a $250 \mathrm{~m}$ upstream cone of the site, within a $500 \mathrm{~m}$ upstream cone of the site (similar to Sonoda et al. 2001), and within the entire watershed delineated from the site. To create $250 \mathrm{~m}$ and $500 \mathrm{~m}$ upstream cones, $250 \mathrm{~m}$ and $500 \mathrm{~m}$ buffer circles were created around each site, then clipped to watershed boundaries. Cover of all NLCD categories in the cones was calculated. Development was broken into four categories in the NLCD database: open development (typically lawns and golf courses), low-density development (single-family residential), medium-density development (higher density single-family residential), and high-density development (apartments, commercial/industrial). 


\section{Data Analysis}

To compare hydrology of the nine sites across the study, data from water level data loggers were used to construct a flashiness index based on high pulse count following the methods of Wenger et al. (2010). For each collection period, the number of high pulse occurrences, defined as a series of water depth readings greater than twice the mean water level for the collection period, was tabulated for each site. Additionally, the hydrographs for streams were visually compared for each collection period. Streams with higher numbers of high pulse counts, as well as tall, narrow peaks in hydrographs, were considered flashier streams.

Rainfall data from the City of Portland Bureau of Environmental Services HYDRA network (or.water.usgs.gov/non-usgs/bes) were analyzed to verify that rainfall was comparable across study sites. For each site, the nearest HYDRA rain gage was identified (Figure 3.1), and rainfall data spanning the entire study period were downloaded. The mean daily rainfall across rain gages was calculated. Then, for each site the percent difference from the daily mean was calculated.

To look at the relationships between vegetation and seed traits and seed deposition rates, taxa collected in seed traps were placed into functional groups related to seed dispersal and deposition, similar to the approach used by Hérault and Honnay (2005) and Fraaije et al. (2017). For plant and seed traits with continuous variables (seed weight and length, plant height, number of seeds produced), four to five classes were created based on natural breaks in the data, as well as metrics reported in the literature to be ecologically meaningful. There were three functional groups that were hypothesized to 
interact with stream flow and affect deposition by hydrochory: seed weight, seed length, and presence of an appendage that may assist in dispersal. For seed weights, average weights for each taxon reported in the Seed Information Database (Royal Botanic Garden, Kew, 2015) were used. The five weight classes created (Table 3.2) were similar to the 6 used by Vogt et al. (2004), with several categories below 5mg. Seed length was the length of the longest axis of a seed. For this metric, values reported in multiple sources were used (Table 3.2). For taxa identified only to the genus level, mean values of seed weight and length for species likely to be in the area (based on Christy et al. 2009) were calculated, and these values were used to place taxa into the appropriate classes. Seeds with dispersal appendages were those with hairs, beaks, hooks, wings, or other structure that may assist with dispersal by water. Only structures attached to the unit dispersed by water were included; fleshy fruits were not considered to be dispersal appendages for these purposes, because being primarily animal-dispersed, it was assumed that most seeds of these species reach streams after passing through the guts of animals, thus did not retain the fleshy fruit.

Additional functional groups were not expected to interact with streamflow patterns to result in seed sorting, but were expected to affect the likelihood of a seed reaching a stream or a riparian site by wind: growth habit, primary dispersal vector, maximum plant height, and seed output. Growth habits included graminoids, forbs, shrubs, and trees. For analysis, Rubus spp. (raspberry/blackberry) was classified as a shrub. Values from multiple sources were used for mature plant height and seed output 
(Table 3.2). For some taxa, seed output per individual plant was estimated based on reported number of seeds per fruit.

Three additional functional groups, species origin, shade tolerance, and wetland indicator status were not expected to be related to dispersal, but their presence in the landscape was expected to be related to human development and forest cover. These three categories are also of interest to restoration practitioners, so were included in analysis. 
Table 3.2: Functional groups of taxa found in seed traps. Nine functional groups describing taxa deposited in turf and funnel traps.

\begin{tabular}{|c|c|c|c|}
\hline Category & Class & Description & Source \\
\hline \multirow{5}{*}{ 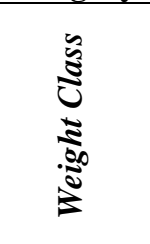 } & $\mathrm{Wt1}$ & $0-0.49 \mathrm{mg}$ & \multirow{5}{*}{$\begin{array}{l}\text { Royal Botanic Gardens, } \\
\text { Kew } 2017\end{array}$} \\
\hline & $\mathrm{Wt} 2$ & $0.5-0.99 \mathrm{mg}$ & \\
\hline & Wt3 & $1.0-2.9 \mathrm{mg}$ & \\
\hline & Wt4 & $3-4.9 \mathrm{mg}$ & \\
\hline & $\mathrm{Wt5}$ & $5+\mathrm{mg}$ & \\
\hline \multirow{4}{*}{ 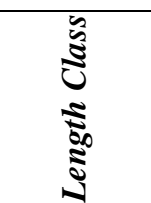 } & L1 & $0-1.9 \mathrm{~mm}$ & \multirow{4}{*}{$\begin{array}{l}\text { Bonner et al. 2008; } \\
\text { Cappers et al. 2006; } \\
\text { Wilson et al. 2014; } \\
\text { Klinkenberg 2017 }\end{array}$} \\
\hline & L2 & $2-4.9 \mathrm{~mm}$ & \\
\hline & L3 & $5-9.9 \mathrm{~mm}$ & \\
\hline & L4 & $10+\mathrm{mm}$ & \\
\hline \multirow{2}{*}{ 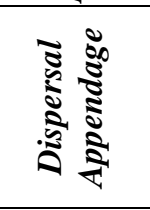 } & Present & $\begin{array}{l}\text { Presence of wing, hair, other structure } \\
\text { that may increase adhesion to water }\end{array}$ & \multirow{2}{*}{$\begin{array}{l}\text { Bonner et al. 2008; } \\
\text { Cappers et al. 2006; } \\
\text { Wilson et al. 2014; } \\
\text { WTU 2017; } \\
\text { Klinkenberg } 2017\end{array}$} \\
\hline & Absent & Absence of dispersal structure & \\
\hline \multirow{4}{*}{ 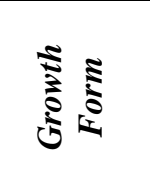 } & Tree & Woody, single stem & \multirow{4}{*}{$\begin{array}{l}\text { Oregon Flora Project } \\
\text { 2017; WTU 2017; } \\
\text { Klinkenberg } 2017\end{array}$} \\
\hline & Shrub & Woody, multiple stems & \\
\hline & Graminoid & Grasses, sedges, and rushes & \\
\hline & Forb & Non-graminoid herbaceous & \\
\hline \multirow{4}{*}{ 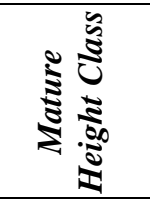 } & $\mathrm{H} 1$ & $0-0.99 \mathrm{~m}$ & \multirow{4}{*}{$\begin{array}{l}\text { Bonner et al. 2008; } \\
\text { Oregon Flora Project } \\
\text { 2017; WTU 2017; } \\
\text { Klinkenberg } 2017\end{array}$} \\
\hline & $\mathrm{H} 2$ & $1-4.99 \mathrm{~m}$ & \\
\hline & $\mathrm{H} 3$ & $5-14.99 \mathrm{~m}$ & \\
\hline & $\mathrm{H} 4$ & $15+\mathrm{m}$ & \\
\hline \multirow{5}{*}{ 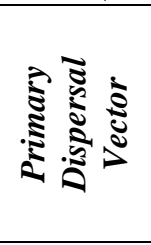 } & Animal & Internal or external animal dispersal & \multirow{5}{*}{$\begin{array}{l}\text { Royal Botanic Gardens } \\
\text { Kew, 2017; Bonner et } \\
\text { al. 2008; Wilson et al. } \\
\text { 2014; WTU 2017; } \\
\text { Klinkenberg } 2017\end{array}$} \\
\hline & Ballistic & Released by ballistic mechanism & \\
\hline & None & No adaptations for a specific method & \\
\hline & Water & Shape or structure for travel by water & \\
\hline & Wind & Shape structure, or size for wind travel & \\
\hline \multirow{5}{*}{ 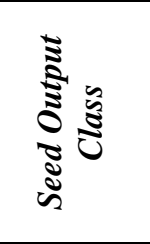 } & $\mathrm{O} 1$ & $1-499$ seeds/individual & \multirow{5}{*}{$\begin{array}{l}\text { Bonner et al. 2008; } \\
\text { Wilson et al. 2014; } \\
\text { Oregon Flora Project } \\
\text { 2017; WTU 2017; } \\
\text { Klinkenberg 2017 }\end{array}$} \\
\hline & $\mathrm{O} 2$ & 500-2,499 seeds/individual & \\
\hline & $\mathrm{O} 3$ & 2,500-4,999 seeds/individual & \\
\hline & $\mathrm{O} 4$ & $5,000-24,999$ seeds/individual & \\
\hline & O5 & $25,000+$ seeds/individual & \\
\hline \multirow{2}{*}{$\frac{5}{6}$} & Native & Native to the Pacific Northwest & \multirow{2}{*}{$\begin{array}{l}\text { Oregon Flora Project } \\
2017\end{array}$} \\
\hline & Non-native & Not native to the Pacific Northwest & \\
\hline \multirow{3}{*}{ क } & Tolerant & Tolerant of shade & \multirow{3}{*}{$\begin{array}{l}\text { Bonner et al. 2008; } \\
\text { Cappers et al. 2006; } \\
\text { WTU 2017; } \\
\text { Klinkenberg } 2017\end{array}$} \\
\hline & Intolerant & Not tolerant of shade & \\
\hline & Intermediate & Tolerant of low levels of shade & \\
\hline \multirow{5}{*}{ 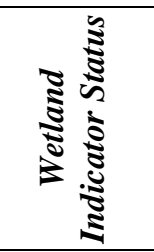 } & OBL & Almost exclusively in wetlands & \multirow[t]{5}{*}{ Licvar et al. 2016} \\
\hline & FACW & Usually in wetlands & \\
\hline & FAC & In wetlands and non-wetlands & \\
\hline & FACU & Usually not in wetlands & \\
\hline & NoWIS & No status listed & \\
\hline
\end{tabular}


In addition to investigating patterns in the entire dataset of potentially viable seeds collected, I created an additional dataset including only taxa that were potentially new species introductions to a trap microsite, similar to the approach by Moggridge et al. (2009). For each seed trap, I defined New herbaceous and shrub taxa as taxa that were found in the seed trap but were not present in the standing vegetation in the $1 \mathrm{~m}^{2}$ centered around the seed trap. Because of the greater distances seeds are typically able to travel when released from trees compared to herbs and shrubs, New tree taxa were defined as those caught in seed traps, but not identified in any vegetation transects in the site. The resulting dataset containing only seeds that potentially represented new species introductions (New dataset) was analyzed in parallel with the dataset containing all potentially viable seeds caught (Whole data).

To compare deposition patterns by wind and water, seed densities in turf traps were compared to densities in funnel traps across sites. Only complete, potentially viable seeds were used in analysis. For each functional group category, mean seed density in each type of seed trap was calculated for the different collection periods, as well as cumulatively for the entire study period. To avoid pseudoreplication, the mean densities per site of different functional groups were used in analysis, rather than including all individual traps. Mean turf and funnel densities of different categories were compared for the following functional groups: seed weight, seed length, growth form, primary dispersal vector, height class, and seed output class. Kruskal-Wallis tests and Wilcoxon rank-sum tests with the Bonferroni correction for multiple tests were used to compare differences in deposition rates between turf and funnel traps, and between collection periods. 
Nonparametric tests were used due to the non-normal nature of the count data. To allow for direct comparison of the density of seeds in turf and funnel traps, a trap size correction was applied to the turf data (number of seeds per turf were multiplied by 0.785), giving the aerial seed density.

In addition to nonparametric tests, generalized linear mixed models were used to explore the effects of trap position (upper or lower in a trap pair) and collection period on deposition of total number of seeds and of number of species in turf and funnel traps, following the recommendations of Bolker et al. (2008), and the example of Fraaije et al. (2017). The function "glmer" in the R package "Ime4" was used to run models using the Gauss-Hermite quadrature approach with a negative binomial residual distribution. Trap position, collection period, and the interaction between position and collection period were initially included as independent variables, with Site treated as a random effect. Forward selection was used to select final model variables, using AIC or quasi-AIC to evaluate model fit. Quasi-AIC was used for models that showed evidence of overdispersion, as suggested by Bolker et al. (2008). Variables were retained in models if their addition resulted in a decrease in AIC or QAIC of at least 2. For nested models within 2 AIC of QAIC, the simpler of the two models was retained. Wald F tests were used to test the null hypotheses of no model effect.

Linear mixed effects models were used to evaluate the relationship between vertical trap-to-water distance and total number of seeds and species caught in turf traps. The R function "Imer" was used to run models, with vertical distance as the fixed effect 
and Site included as a random effect. Total number of seeds and species were log- or square-root-transformed as needed to conform with the model assumption of normality.

Linear regression was used to analyze deposition patterns along the TIA gradient. When comparing deposition across multiple collection periods (for example seed totals in $\mathrm{p} 1$ through $\mathrm{p} 3$, or across the entire study, p1 through $\mathrm{p} 4)$, the sum of the means for each period was calculated for each site, giving the cumulative mean seed density across the study. In addition to total numbers of seeds, differences in deposition by water of all functional groups across the TIA gradient were examined.

I used nonmetric multidimensional scaling (NMDS) based on rank-similarity of sites using the Bray-Curtis index to explore relationships between other landscape variables and the assemblages of taxa deposited in turf traps at the nine sites. NMDS was chosen because of its compatibility and robustness with species data (Kenkel and Orlóci 1986; Minchin 1987). The function "envfit" in the R package "vegan" (Oksanen et al. 2012) was used to map landscape variables as vectors onto the ordination. Landscape variables that had a significant association with the ordination $(\mathrm{p}<0.05)$ were selected for further investigation of their relationships with seed deposition patterns. Two ordinations were conducted based on cumulative mean seed deposition in turf traps in each site from $\mathrm{p} 1$ through $\mathrm{p} 4$. For the first ordination the Whole seed data were used, and for the second ordination the New seed data were used, considering just taxa that may have been species introductions to trap microsites. All statistical analyses were conducted in $\mathrm{R}$ version 3.4.2 (R Development Core Team 2017). 


\section{Results}

\section{Land Use Composition of Study Watersheds}

Watersheds of the nine study sites ranged from $1 \%$ to $41 \%$ imperviousness and were covered from $5 \%$ to $94 \%$ with some level of urban development (Table 3.3; Figure 3.5). Total forest cover in the watersheds ranged from $6 \%$ to $62 \%$. Within a $500 \mathrm{~m}$ cone upstream from each study site, development ranged from $2 \%$ to $99 \%$ of the measured area. Within a 250m cone, development ranged from $0 \%$ to $100 \%$ (Figure 3.6).

\section{Rainfall and Stream Hydrology Across Study Sites}

Five rainfall gages from the HYDRA network were found to represent rainfall across the study region (Figure 3.2). A mean of $187 \mathrm{~cm}$ of rain fell across the entire study area over the study period (January 2015 - March 2016). The daily rainfall means at each of the five gages were found to be within $20 \%$ of the overall daily rainfall mean. Four of the five sites were within $10 \%$ of the overall daily mean.

Analysis of hydrographs and high pulse counts showed a general relationship between watershed TIA and stream flashiness (Figures 3.7 - 3.10; Table 3.4). The number of high pulse events per collection period generally increased with increasing watershed TIA, but there were some exceptions and variations across collection periods. Foley-Balmer (FB), the site with the highest watershed TIA (41\%), only had the highest number of high pulse events during one collection period, p1. Additionally, hydrographs for this site showed peaks that were not as high and narrow as for some of the other sites. Hydrology, based on both hydrograph patterns and high pulse count, was flashier at 
Butler and Metzger, sites that had lower watershed TIA than Foley-Balmer, but that had higher development within a $250 \mathrm{~m}$ cone. The least- and most-flashy streams were not the same across collection periods. Additionally, the season with the most high-pulse events varied across sites. Jordan had the highest number of high-pulse events in $\mathrm{p} 3$ when overall water depths were at their lowest, but had very few events during p2 and p4. Generally, the five lower TIA sites had fewer high pulse events than the four higher TIA; there was only one collection period (p3) where one of the five lower TIA sites had a greater number of high pulse events than one of the four higher TIA sites. 


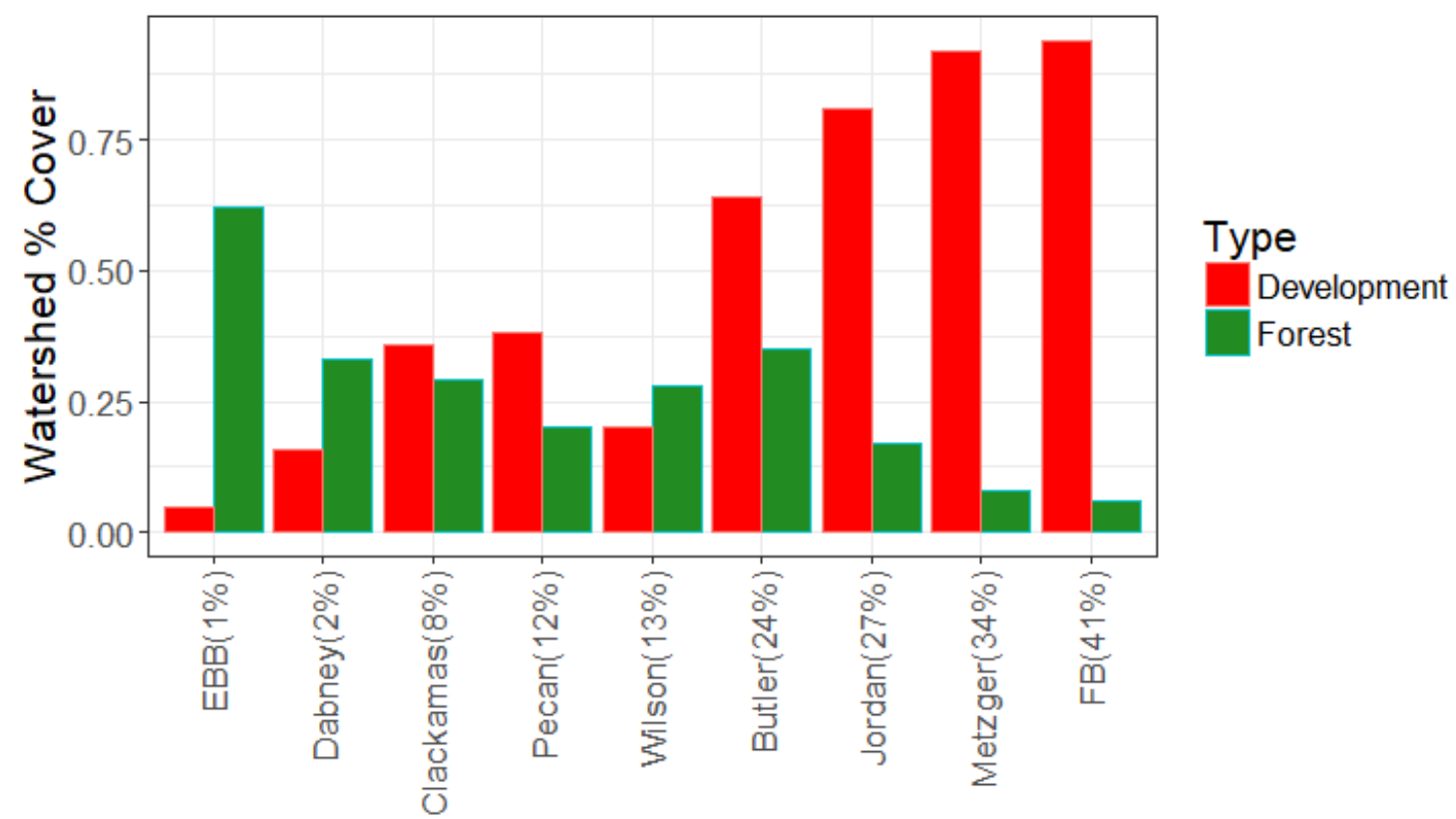

Site

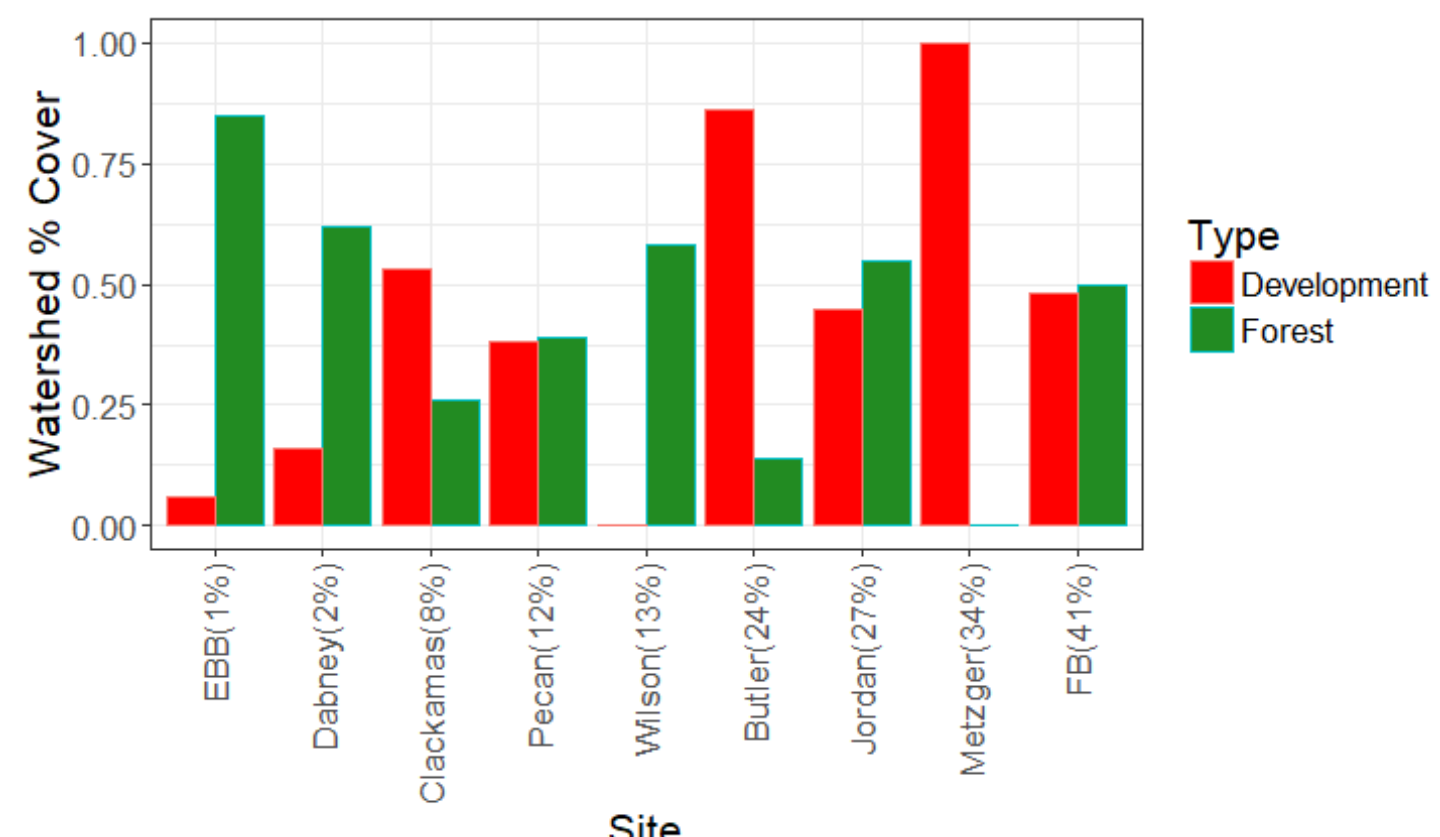

Figure 3.6: Cover by total development and forest in watersheds of study sites (top) and within a $250 \mathrm{~m}$ cone from each site (bottom). Sites are shown in ascending order of watershed TIA on the $\mathrm{x}$ axis. At the watershed scale, development generally increases with watershed TIA while watershed forest cover decreases. Within $250 \mathrm{~m}$ upstream of each site, development and forest cover do not change as regularly with watershed TIA. The sites with highest development cover at this scale (Metzger and Butler) are not the sites with the highest watershed TIA or development cover at the watershed scale. EBB still has the highest forest cover at the $250 \mathrm{~m}$ scale, but has higher development cover than Wilson, which has higher TIA and development at the watershed scale. 
Table 3.3: Landscape cover by four development densities and forest at three spatial scales from each site. $250 \mathrm{~m}$ and $500 \mathrm{~m}$ cones were created by clipping $250 \mathrm{~m}$ or $500 \mathrm{~m}$ buffer circles to delineated watersheds. Total development ranged from $5 \%$ to $94 \%$ in the watershed, from $2 \%$ to $99 \%$ within $500 \mathrm{~m}$, and from $0 \%$ to $100 \%$ within $250 \mathrm{~m}$.

\begin{tabular}{|c|c|c|c|c|c|c|c|}
\hline \multicolumn{8}{|c|}{ Watershed scale } \\
\hline \multirow[b]{2}{*}{ Site } & \multirow[b]{2}{*}{$\begin{array}{c}\text { Watershed } \\
\text { TIA }(\%)\end{array}$} & \multicolumn{5}{|c|}{ Development Density } & \multirow{2}{*}{$\begin{array}{c}\text { All } \\
\text { Forest } \\
(\%) \\
\end{array}$} \\
\hline & & $\begin{array}{c}\text { Open } \\
(\%)\end{array}$ & $\begin{array}{l}\text { Low } \\
(\%)\end{array}$ & $\begin{array}{l}\text { Medium } \\
(\%)\end{array}$ & $\begin{array}{c}\text { High } \\
(\%)\end{array}$ & All (\%) & \\
\hline EBB & 1 & 4 & 1 & 0 & 0 & 5 & 62 \\
\hline Dabney & 2 & 12 & 4 & 0 & 0 & 16 & 33 \\
\hline Clackamas & 8 & 16 & 17 & 3 & 0 & 36 & 29 \\
\hline Pecan & 12 & 14 & 20 & 4 & 1 & 38 & 20 \\
\hline Wilson & 13 & 9 & 11 & 1 & 0 & 20 & 28 \\
\hline Butler & 24 & 14 & 27 & 22 & 1 & 64 & 35 \\
\hline Jordan & 27 & 22 & 37 & 21 & 1 & 81 & 17 \\
\hline Metzger & 34 & 13 & 61 & 17 & 2 & 92 & 8 \\
\hline FB & 41 & 8 & 54 & 25 & 7 & 94 & 6 \\
\hline
\end{tabular}

$500 m$ upstream buffer

\begin{tabular}{|c|c|c|c|c|c|c|c|}
\hline \multirow[b]{2}{*}{ Site } & \multirow[b]{2}{*}{$\begin{array}{c}\text { Watershed } \\
\text { TIA }(\%) \\
\end{array}$} & \multicolumn{5}{|c|}{ Development Density } & \multirow{2}{*}{$\begin{array}{c}\text { All } \\
\text { Forest } \\
(\%)\end{array}$} \\
\hline & & $\begin{array}{c}\text { Open } \\
(\%)\end{array}$ & $\begin{array}{l}\text { Low } \\
(\%)\end{array}$ & $\begin{array}{c}\text { Medium } \\
(\%)\end{array}$ & $\begin{array}{c}\text { High } \\
(\%)\end{array}$ & All (\%) & \\
\hline EBB & 1 & 4 & 0 & 0 & 0 & 4 & 78 \\
\hline Dabney & 2 & 17 & 4 & 0 & 0 & 21 & 42 \\
\hline Clackamas & 8 & 18 & 16 & 8 & 9 & 51 & 17 \\
\hline Pecan & 12 & 17 & 12 & 1 & 0 & 30 & 24 \\
\hline Wilson & 13 & 2 & 0 & 0 & 0 & 2 & 58 \\
\hline Butler & 24 & 8 & 40 & 46 & 0 & 94 & 5 \\
\hline Jordan & 27 & 10 & 30 & 13 & 2 & 55 & 44 \\
\hline Metzger & 34 & 13 & 68 & 18 & 0 & 99 & 0 \\
\hline FB & 41 & 7 & 54 & 10 & 0 & 71 & 29 \\
\hline
\end{tabular}

250m upstream buffer

\begin{tabular}{|c|c|c|c|c|c|c|c|}
\hline \multirow[b]{2}{*}{ Site } & \multirow[b]{2}{*}{$\begin{array}{c}\text { Watershed } \\
\text { TIA }(\%)\end{array}$} & \multicolumn{5}{|c|}{ Development Density } & \multirow{2}{*}{$\begin{array}{c}\text { All } \\
\text { Forest } \\
(\%)\end{array}$} \\
\hline & & $\begin{array}{c}\text { Open } \\
(\%)\end{array}$ & $\begin{array}{l}\text { Low } \\
(\%)\end{array}$ & $\begin{array}{c}\text { Medium } \\
(\%)\end{array}$ & $\begin{array}{c}\text { High } \\
(\%)\end{array}$ & All (\%) & \\
\hline EBB & 1 & 6 & 0 & 0 & 0 & 6 & 85 \\
\hline Dabney & 2 & 16 & 0 & 0 & 0 & 16 & 62 \\
\hline Clackamas & 8 & 21 & 15 & 9 & 8 & 53 & 26 \\
\hline Pecan & 12 & 21 & 17 & 0 & 0 & 38 & 39 \\
\hline Wilson & 13 & 0 & 0 & 0 & 0 & 0 & 58 \\
\hline Butler & 24 & 2 & 34 & 50 & 0 & 86 & 14 \\
\hline Jordan & 27 & 15 & 26 & 4 & 0 & 45 & 55 \\
\hline Metzger & 34 & 23 & 52 & 25 & 0 & 100 & 0 \\
\hline FB & 41 & 8 & 37 & 4 & 0 & 48 & 50 \\
\hline
\end{tabular}



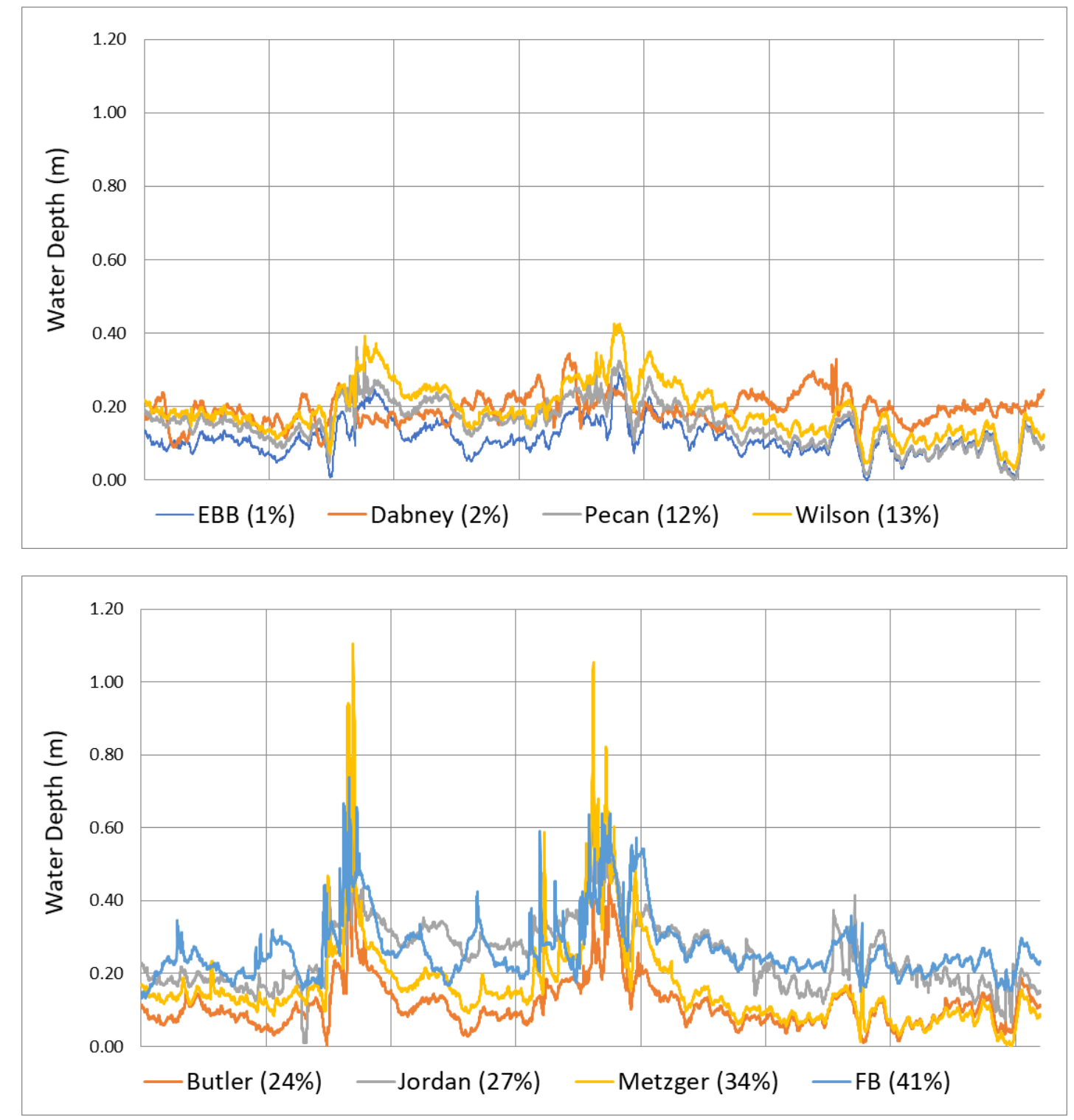

Figure 3.7: Water depth measured in study sites during p1 (January - March 2015). Hydrographs for sites with $0-13 \%$ TIA are shown in the upper plot, sites with $24-41 \%$ TIA are shown in the lower plot. Water level was recorded by data loggers every 15 minutes. There were no useable data collected from Clackamas ( $8 \%$ ) during this period. The four higher TIA sites have higher, narrower peaks than the four lower TIA sites. 

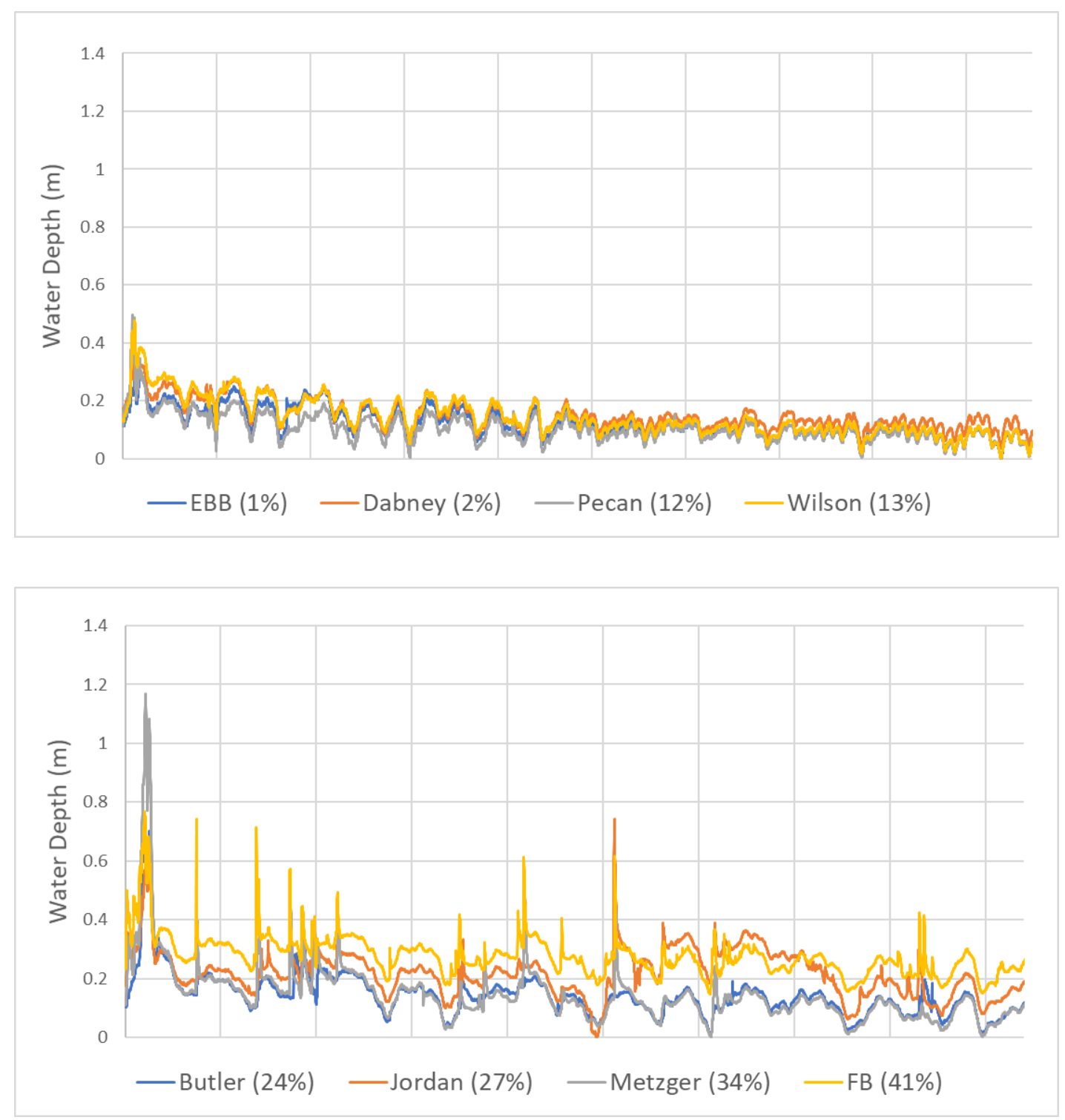

Figure 3.8: Water depth measured in study sites during p2 (March - July 2015). Hydrographs for sites with $0-13 \%$ TIA are shown in the upper plot, sites with $24-41 \%$ TIA are shown in the lower plot. Water level was recorded by data loggers every 15 minutes. There were no useable data collected from Clackamas (8\%) during this period. The four higher TIA sites have higher, narrower peaks than the four lower TIA sites. 

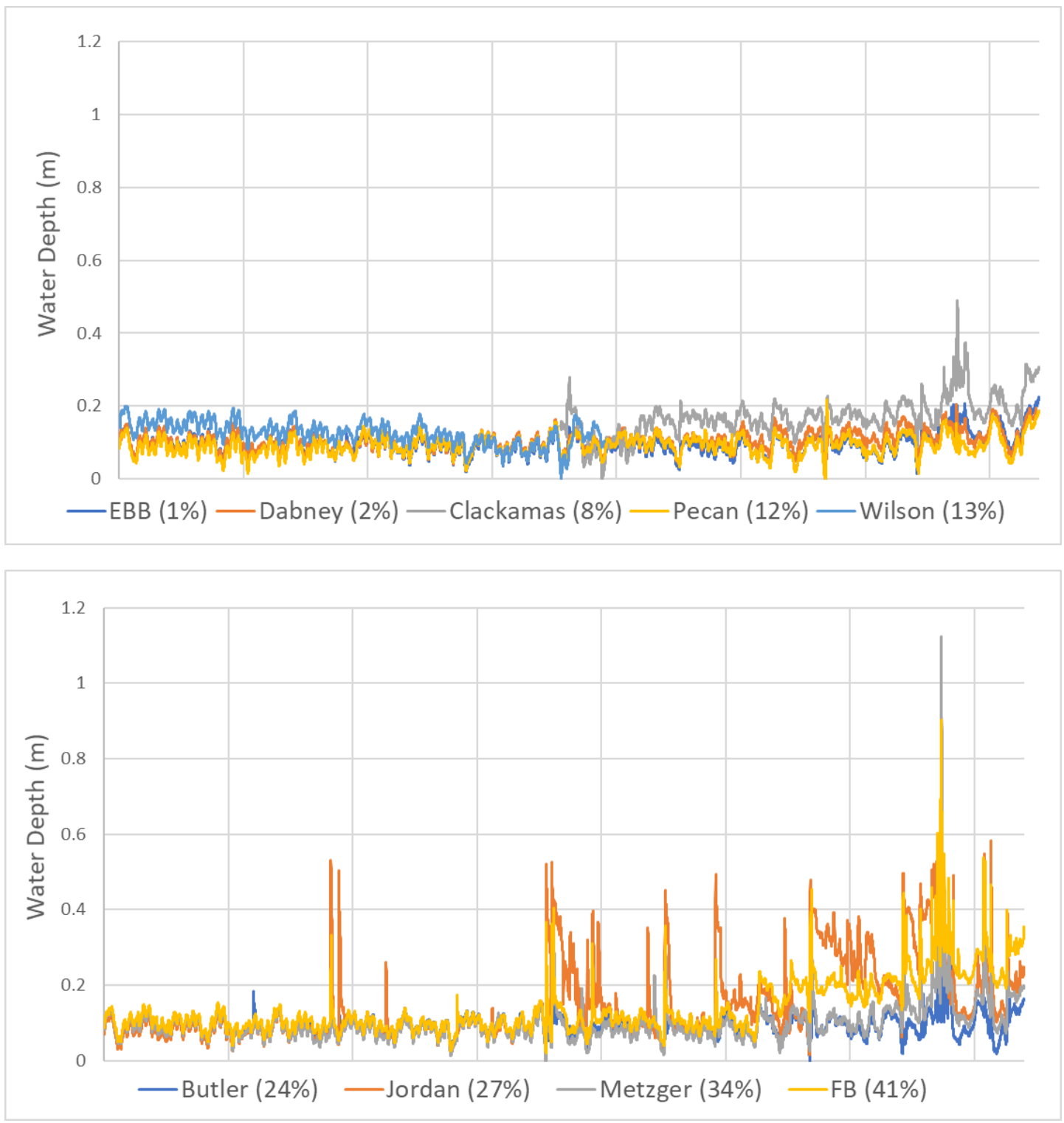

Figure 3.9: Water depth measured in study sites during p3 (July - November 2015). Hydrographs for sites with $0-13 \%$ TIA are shown in the upper plot, sites with $24-41 \%$ TIA are shown in the lower plot. Water level was recorded by data loggers every 15 minutes. The four higher TIA sites have higher, narrower peaks during storms than the five lower TIA sites. 

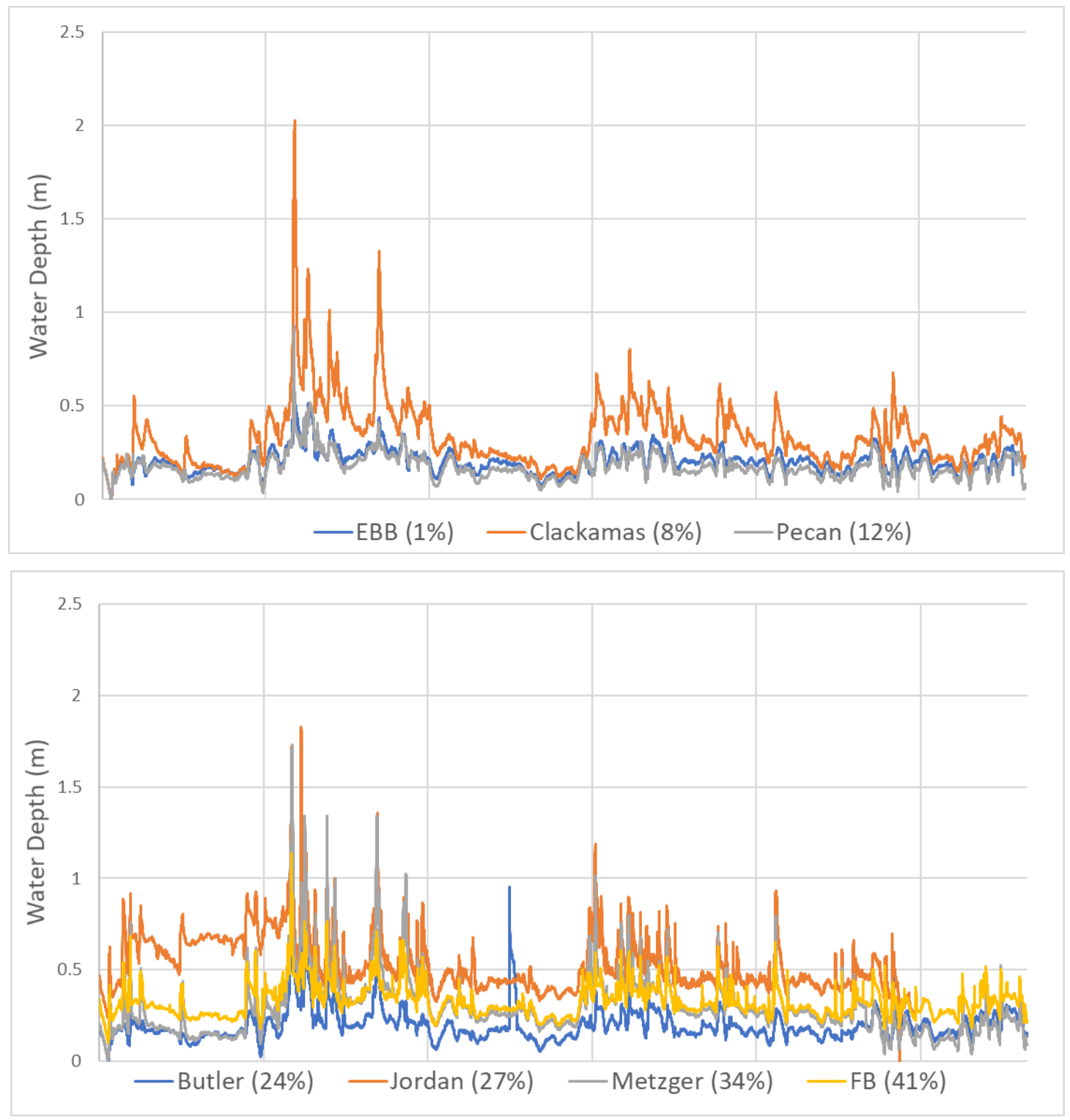

Figure 3.10: Water depth measured in study sites during p4 (November 2015 - March 2016).

Hydrographs for sites with $0-13 \%$ TIA are shown in the upper plot, sites with $24-41 \%$ TIA are shown in the lower plot. There were no useable data collected from Dabney (2\%) or Wilson (13\%) for this collection period. Water level was recorded by data loggers every 15 minutes. The four higher TIA sites have higher, narrower peaks during storms than two of the three lower TIA sites with data for this period, although Clackamas (8\%) also had high, narrow peaks during p4. 
Table 3.4: High pulse events during four collection periods at each site. A high pulse event was an occurrence of a series of water-level data points greater than twice the mean water level over the entire collection period. "N/a" indicates that no water level data were available for that period. Metzger had the most high pulse events in p2 and p4, Jordan had the most in p3, and FB had the most in p1. EBB, Dabney, Wilson, and Jordan all had the lowest number of events in different seasons (two sites were tied in $\mathrm{p} 3$ and p4).

\begin{tabular}{|c|c|c|c|c|c|}
\hline \multirow[b]{2}{*}{ Site } & \multirow[b]{2}{*}{$\begin{array}{l}\text { TIA } \\
(\%) \\
\end{array}$} & \multicolumn{4}{|c|}{ Number of high pulse events } \\
\hline & & p1 & p2 & p3 & p4 \\
\hline EBB & 1 & 8 & 6 & 10 & 6 \\
\hline Dabney & 2 & 0 & 3 & 0 & $\mathrm{n} / \mathrm{a}$ \\
\hline Clackamas & 8 & $\mathrm{n} / \mathrm{a}$ & $\mathrm{n} / \mathrm{a}$ & 2 & 11 \\
\hline Pecan & 12 & 7 & 4 & 4 & 12 \\
\hline Wilson & 13 & 3 & 2 & 0 & $\mathrm{n} / \mathrm{a}$ \\
\hline Butler & 24 & 13 & 13 & 9 & 11 \\
\hline Jordan & 27 & 13 & 6 & 34 & 6 \\
\hline Metzger & 34 & 8 & 16 & 22 & 27 \\
\hline FB & 41 & 19 & 10 & 23 & 10 \\
\hline
\end{tabular}

\section{Site Standing Vegetation}

All nine study sites had mixed conifer and hardwood canopy. Across all study sites, 113 species were identified in the standing vegetation. The relative canopy cover was over $95 \%$ for all sites, as measured along vegetation transects. Absolute cover by tree taxa ranged from $106 \%$ to $202 \%$ of the transect length sampled. Shrub cover measured in quadrats around seed traps ranged from $22 \%$ to $73 \%$ (Figure 3.11; Table 3.5), with Rubus spp. cover ranging from $2 \%$ to $30 \%$ (including $R$. spectabilis, R. bifrons, and $R$. parviflora; Figure 3.12; Table 3.5). Herbaceous understory cover measured in quadrats around seed traps ranged from $17 \%$ to $42 \%$ (Figure 3.11; Table 3.5). The sites varied in species richness and Shannon diversity in the understory, shrub, and canopy 
layers, but all had the highest richness in the understory layer, and eight of the nine sites had the lowest richness in the shrub layer (Table 3.5). 


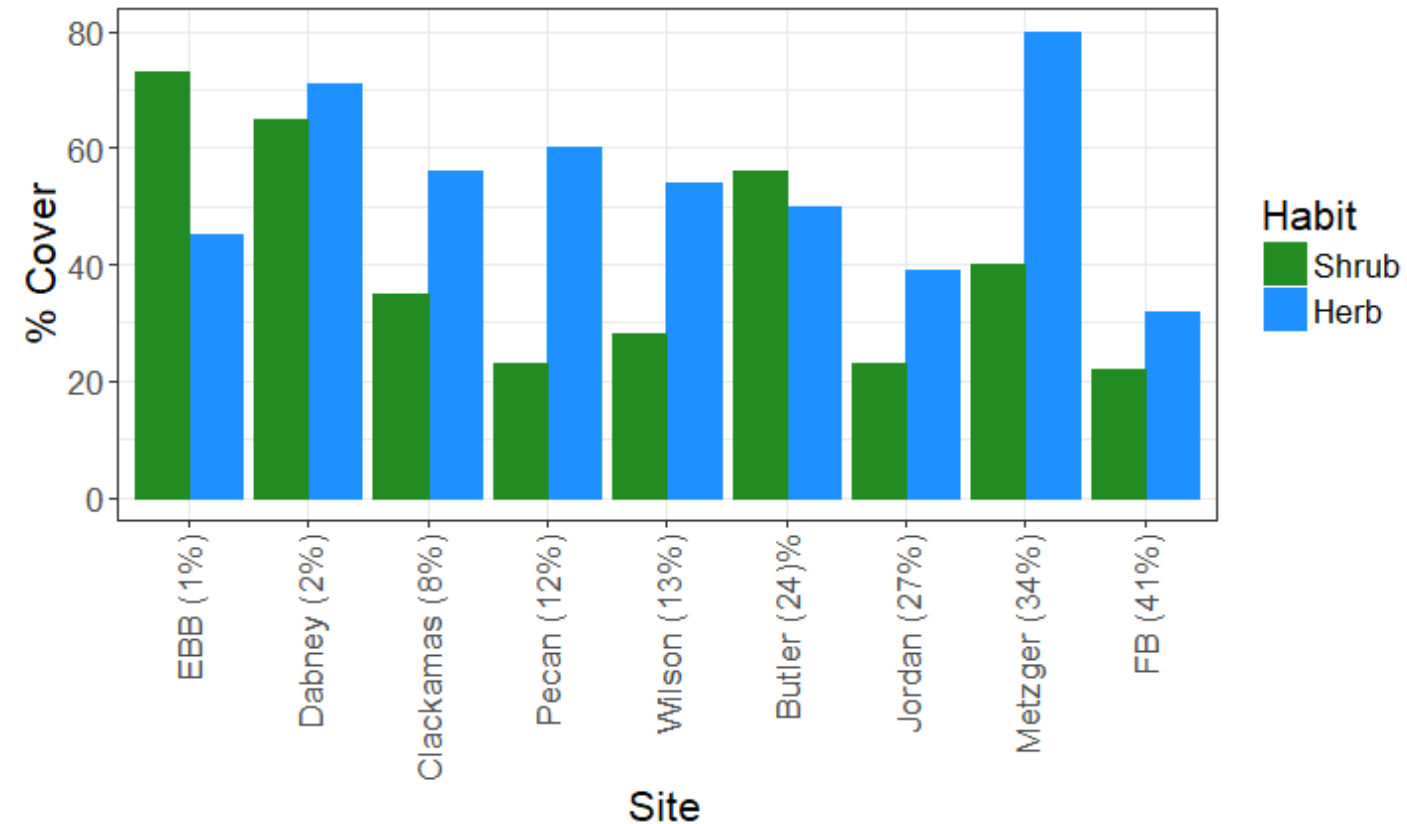

Figure 3.11: Shrub and herbaceous cover in the understory at nine study sites. Understory cover was measured in $1 \mathrm{~m}^{2}$ plots centered around each turf trap. Two sites (EBB and Butler) had higher shrub than herbaceous cover in the understory, the other seven sites had higher herbaceous cover.

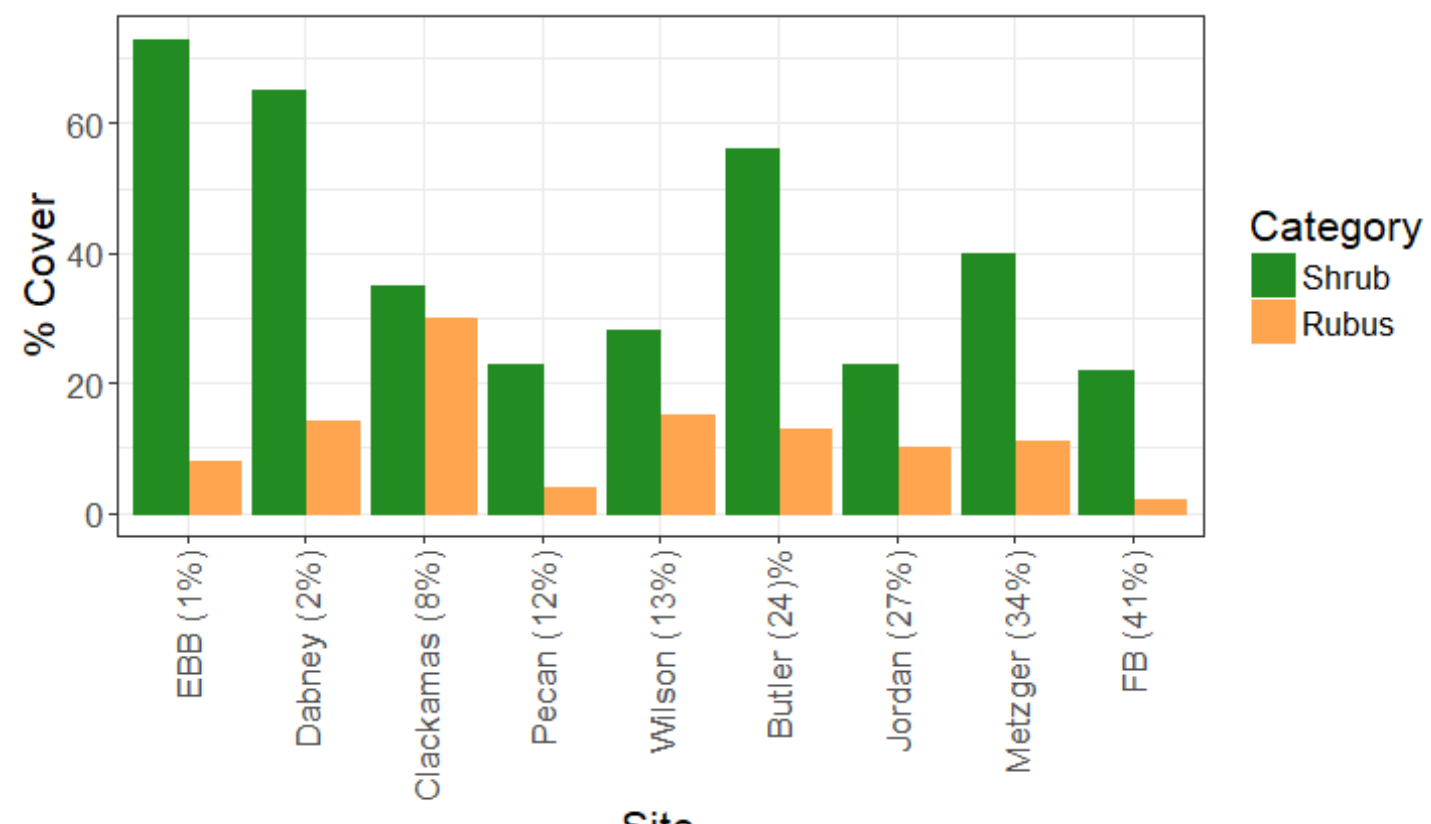

Figure 3.12: Cover by all shrub species and by Rubus spp. at nine study sites. Rubus species included $R$. spectabilis, $R$. bifrons, $R$. ursinus, and $R$. parviflorus. At Clackamas nearly all shrub cover consisted of Rubus spp., and at Wilson half the shrub cover was Rubus spp. At the other seven sites Rubus spp. made up less than half of total shrub cover. 
Table 3.5: Vegetation metrics in three strata across the nine study sites. Cover of shrub and herbaceous vegetation was measured in $1 \mathrm{~m}^{2}$ quadrats centered around each seed trap; tree cover was measured along three transects perpendicular to the stream. All sites had a mix of coniferous and deciduous cover in the canopy layer. Two of the nine sites, Butler and Jordan, had more conifer than hardwood cover, the other seven had greater hardwood than conifer cover. Clackamas had the highest herbaceous understory richness and Metzger the highest cover. Two sites, Clackamas and Wilson, had only one species detected in the shrub layer in transect surveys.

\begin{tabular}{|l|r|r|r|r|r|r|r|r|r|}
\cline { 2 - 11 } \multicolumn{1}{l|}{} & \multicolumn{1}{c|}{ EBB } & Dabney & Clackamas & Pecan & Wilson & Butler & Jordan & Metzger & FB \\
\hline TIA & 1 & 2 & 8 & 12 & 13 & 24 & 27 & 34 & 41 \\
\hline \% Conifer & 29 & 40 & 21 & 32 & 43 & 59 & 63 & 34 & 47 \\
\hline $\begin{array}{l}\text { \% } \\
\text { Hardwood }\end{array}$ & 71 & 60 & 79 & 68 & 57 & 41 & 37 & 66 & 53 \\
\hline $\begin{array}{l}\text { Tree } \\
\text { Richness }\end{array}$ & 8 & 5 & 6 & 6 & 6 & 9 & 5 & 12 & 7 \\
\hline $\begin{array}{l}\text { Shrub } \\
\text { Cover (\%) }\end{array}$ & 73 & 65 & 35 & 23 & 28 & 56 & 23 & 40 & 22 \\
\hline $\begin{array}{l}\text { Shrub } \\
\text { Richness }\end{array}$ & 5 & 5 & 1 & 3 & 1 & 7 & 6 & 5 & 2 \\
\hline $\begin{array}{l}\text { Herbaceous } \\
\text { Cover (\%) }\end{array}$ & 45 & 71 & 56 & 60 & 54 & 50 & 39 & 80 & 32 \\
\hline $\begin{array}{l}\text { Herbaceous } \\
\text { Richness }\end{array}$ & 17 & 35 & 42 & 33 & 33 & 30 & 35 & 40 & 29 \\
\hline $\begin{array}{l}\text { Rubus spp. } \\
\text { cover (\%) }\end{array}$ & 8 & 14 & 30 & 4 & 15 & 13 & 10 & 11 & 2 \\
\hline
\end{tabular}

\section{Deposition Patterns in Turf and Funnel Traps}

Seed traps were occasionally lost due to vandalism or damage by animals or large storms. The seed trap recovery rate varied by site and collection period, but over the entire study averaged $87 \%$ for turf traps and $88 \%$ for funnel traps (Table 3.6). Over the entire study, 15,668 potentially viable seeds from 78 taxa (Appendix A) were identified in the seed traps. Of the 78 taxa found, 67 were present in turf traps, and 39 were present in funnel traps. A total 4,418 seeds (Whole seeds) were found in funnel traps in p1 through p3 (January - November 2015), 1,478 (33\%) of which were New taxa to the microsite (New seeds). In turf traps, 11,250 Whole seeds were found in $\mathrm{p} 1$ through $\mathrm{p} 4$, 
4,267 (38\%) of which were New seeds. Across sites, cumulatively across all three periods where both turf and funnel collections were made (p1 through $\mathrm{p} 3$ ), there was significantly higher aerial seed density (in turf traps, density was multiplied by a trap size correction for comparison to funnel traps) in turf traps than in the near-stream funnel traps or forest interior funnel traps $(\mathrm{p}<0.001$; Table 3.7; Figure 3.13), for both Whole and New seeds. The highest aerial densities overall were in turf traps in the winter months, $\mathrm{p} 1$ and $\mathrm{p} 4$ in most sites, followed by the spring, $\mathrm{p} 2$. GLMM results showed that for both Whole and New seeds, collection period was a significant predictor of total seed deposition in turf traps ( $\mathrm{p}<0.01$; Table 3.8; Table 3.9). For both Whole and New seeds, GLMM results indicated that there were significantly fewer seeds deposited in turf traps during $\mathrm{p} 3$ than $\mathrm{p} 1(\mathrm{p}<0.001$; Table 3.9). Additionally, Wilcoxon rank-sum tests using site mean trap densities indicated that for both Whole seeds and New seeds, there was significantly lower seed density in turf traps during $\mathrm{p} 3$ than during all other collection periods $(\mathrm{p}<0.001)$. For New seeds, but not Whole seeds, Wilcoxon tests also showed that there was also significantly higher turf seed density in $\mathrm{p} 4$ than in $\mathrm{p} 2(\mathrm{p}<0.05)$. Wilcoxon tests showed that for both Whole and New seeds, there was no significant difference between lower turf traps and upper turf traps in mean seed density in any collection period. Consistent with results from Wilcoxon tests, inclusion of turf position in GLMM results did not significantly improve model fit, as indicated by AIC (Table $3.8)$.

In funnels, the highest seed densities across all traps were found during $\mathrm{p} 2$ and $\mathrm{p} 3$, with lower density during $\mathrm{p} 1$ in most sites. However, Wilcoxon tests showed that there 
were no significant differences among collection periods in mean funnel seed density.

There also were no significant differences between the near-stream and forest interior funnels in aerial seed density in any collection period, for either Whole seeds or New seeds. For GLMM results for both Whole and New seeds, there were no variables that improved QAIC by at least 2, and the null models, including only random effects, were retained (Table 3.8).

Table 3.6: Turf and funnel traps recovered in each site during the four collection periods. Turf traps were collected in p1 through p4 and funnel traps in p1 through p3. In each site a total of 12 turf traps and 20 funnel traps were installed. Loss of traps occurred due to vandalism, destruction by animals, and destruction by the stream in extreme high-water events. All funnel traps were considered lost in p4 because of inundation and destruction from extreme weather.

\begin{tabular}{|c|c|c|c|c|c|}
\hline \multicolumn{6}{|c|}{ Turf Traps } \\
\hline Site & TIA (\%) & p1 & p2 & p3 & p4 \\
\hline EBB & 1 & 12 & 12 & 12 & 5 \\
\hline Dabney & 2 & $\mathrm{n} / \mathrm{a}$ & 12 & 11 & 8 \\
\hline Clackamas & 8 & 12 & 10 & 10 & 12 \\
\hline Pecan & 12 & 9 & 10 & 12 & 10 \\
\hline Wilson & 13 & 12 & 12 & 12 & 8 \\
\hline Butler & 24 & 10 & 10 & 10 & 8 \\
\hline Jordan & 27 & 11 & 11 & 12 & 9 \\
\hline Metzger & 34 & 12 & 7 & 8 & 12 \\
\hline FB & 41 & 12 & 12 & 12 & 9 \\
\hline \multicolumn{6}{|c|}{ Funnel Traps } \\
\hline Site & TIA (\%) & p1 & p2 & p3 & \\
\hline EBB & 1 & 17 & 17 & 18 & \\
\hline Dabney & 2 & $\mathrm{n} / \mathrm{a}$ & 19 & 18 & \\
\hline Clackamas & 8 & 18 & 13 & 19 & \\
\hline Pecan & 12 & 16 & 19 & 18 & \\
\hline Wilson & 13 & 20 & 18 & 20 & \\
\hline Butler & 24 & 19 & 12 & 18 & \\
\hline Jordan & 27 & 20 & 10 & 17 & \\
\hline Metzger & 34 & 20 & 17 & 18 & \\
\hline FB & 41 & 20 & 18 & 20 & \\
\hline
\end{tabular}




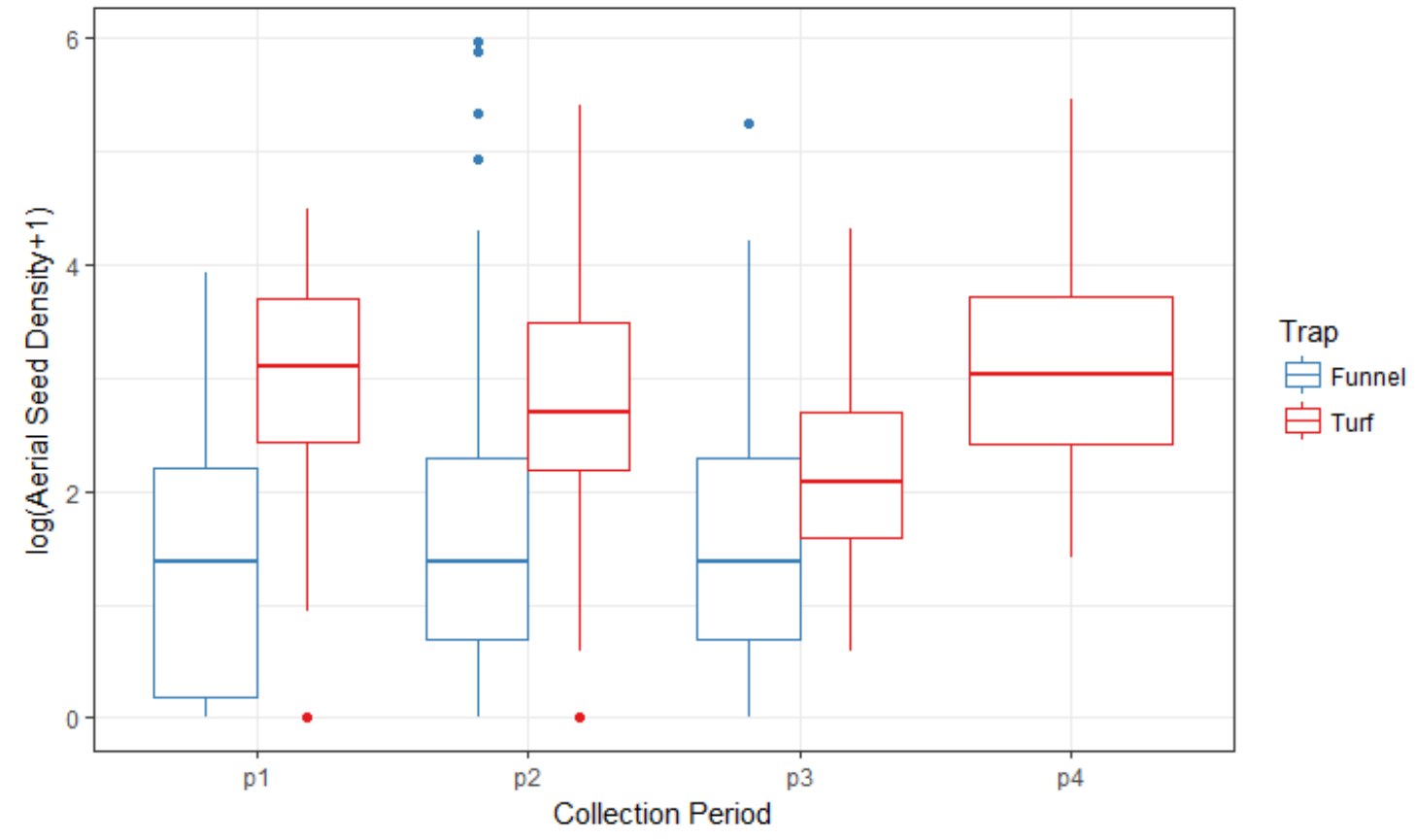

Figure 3.13: Aerial density of Whole seeds in turf and funnel traps on a log scale across four collection periods. GLMM results and Wilcoxon rank-sum tests showed that in turf traps, there were significantly more seeds deposited during $\mathrm{p} 1, \mathrm{p} 2$, and $\mathrm{p} 4$ than during $\mathrm{p} 3(\mathrm{p}<0.05)$. There were no significant differences among collection periods in deposition in funnel traps. Cumulatively, across $\mathrm{p} 1$ to $\mathrm{p} 3$, there was a significantly higher mean density of seeds in turf traps than in funnel traps $(\mathrm{p}<0.001)$. 
Table 3.7: Average aerial density of seeds per trap in each collection period across sites. Cumulatively across the entire study period, and in $\mathrm{p} 1$, there was a higher average number of seeds deposited per trap area in turf traps than in funnel traps. In $\mathrm{p} 2$, there were more seeds per trap in funnels than in turf at Pecan, all other sites had more seeds in turfs than funnels. In $\mathrm{p} 3$ there were more seeds in funnels in three of the sites.

\begin{tabular}{|c|c|c|c|c|c|c|c|c|c|}
\hline & $\begin{array}{l}\text { EBB } \\
(1 \%)\end{array}$ & $\begin{array}{c}\text { Dabney } \\
(2 \%)\end{array}$ & $\begin{array}{c}\text { Clackamas } \\
(8 \%)\end{array}$ & $\begin{array}{l}\text { Pecan } \\
(12 \%)\end{array}$ & $\begin{array}{l}\text { Wilson } \\
(13 \%)\end{array}$ & $\begin{array}{l}\text { Butler } \\
(13 \%)\end{array}$ & $\begin{array}{c}\text { Jordan } \\
(24 \%)\end{array}$ & $\begin{array}{c}\text { Metzger } \\
(27 \%)\end{array}$ & $\begin{array}{c}\text { FB } \\
(41 \%)\end{array}$ \\
\hline \multicolumn{10}{|l|}{ Turf } \\
\hline p1 & 35.72 & $\mathrm{n} / \mathrm{a}$ & 28.06 & 41.95 & 25.51 & 25.98 & 12.99 & 24.40 & 24.66 \\
\hline p2 & 33.10 & 7.07 & 53.22 & 37.84 & 43.50 & 19.86 & 10.92 & 27.03 & 14.92 \\
\hline p3 & 10.14 & 5.14 & 8.79 & 5.95 & 10.73 & 13.03 & 15.11 & 13.74 & 11.25 \\
\hline p4 & 3595 & 1773 & 1328 & 17898 & 4749 & 2438 & 925 & 18.32 & 3.84 \\
\hline $\begin{array}{l}\text { All } \\
\text { turf }\end{array}$ & 114.91 & .93 & 103.36 & 264.72 & 127.24 & 83.25 & 48.26 & 83.48 & 54.67 \\
\hline \multicolumn{10}{|l|}{ Funnel } \\
\hline p1 & 10.71 & $\mathrm{n} / \mathrm{a}$ & 4.61 & 3.06 & 1.80 & 12.16 & 2.65 & 3.25 & 9.15 \\
\hline p2 & 7.55 & 16.63 & 3.62 & 55.53 & 18.39 & 12.08 & 0.80 & 5.59 & 1.80 \\
\hline p3 & 21.11 & 8.17 & 2.84 & 11.56 & 4.40 & 11.61 & 2.92 & 9.28 & 3.70 \\
\hline $\begin{array}{l}\text { All } \\
\text { funnel }\end{array}$ & 39.36 & $\mathrm{n} / \mathrm{a}$ & 11.07 & 70.14 & 24.59 & 35.85 & 6.37 & 18.12 & 14.65 \\
\hline
\end{tabular}

Table 3.8: Forward selection of fixed effects in GLMM results explaining total number of seeds and species caught in seed traps. Values shown are AIC for turf models, and QAIC for funnel models, which showed signs of overdispersion. Best-fitting models are shown in bold text. Variables were retained when their addition to the model resulted in a drop of AIC or QAIC of at least 2. For nested models within 2 AIC or QAIC, the simpler model was kept.

\begin{tabular}{|c|c|c|c|c|}
\hline \multicolumn{5}{|l|}{ Total Number of Seeds } \\
\hline Fixed Effects & $\begin{array}{l}\text { All } \\
\text { Turf }\end{array}$ & $\begin{array}{l}\text { New } \\
\text { Turf }\end{array}$ & $\begin{array}{l}\text { All } \\
\text { Funnel }\end{array}$ & $\begin{array}{l}\text { New } \\
\text { Funnel }\end{array}$ \\
\hline Period+Position+Period:Position & 351.1 & 516.0 & 482.4 & 492.8 \\
\hline Period+Position & 345.7 & 512.4 & 480.5 & 490.4 \\
\hline Period & 344.1 & 511.0 & 479.6 & 489.3 \\
\hline Position & 391.1 & 568.0 & 479.6 & 487.5 \\
\hline none & 390.7 & 566.4 & 478.7 & 486.4 \\
\hline \multicolumn{5}{|l|}{ Total Number of Species } \\
\hline Fixed Effects & $\begin{array}{l}\text { All } \\
\text { Turf }\end{array}$ & $\begin{array}{l}\text { New } \\
\text { Turf }\end{array}$ & $\begin{array}{l}\text { All } \\
\text { Funnel }\end{array}$ & $\begin{array}{l}\text { New } \\
\text { Funnel }\end{array}$ \\
\hline Period+Position+Period:Position & 118.3 & 221.4 & 257.5 & 492.8 \\
\hline Period+Position & 112.4 & 215.9 & 256.0 & 490.4 \\
\hline Period & 110.4 & 214.0 & 254.1 & 489.3 \\
\hline Position & 127.3 & 245.6 & 254.9 & 487.5 \\
\hline none & 125.3 & 243.6 & 253.0 & 486.4 \\
\hline
\end{tabular}


Table 3.9: Parameters for selected models explaining total number of seeds caught in turf and funnel traps. Final GLMM's were selected based on AIC for turf models and QAIC for funnel models. Significance levels: $* \mathrm{p}<0.05 ; * * \mathrm{p}<0.01 ; * * \mathrm{p}<0.001$.

\begin{tabular}{|c|c|c|c|c|c|}
\hline \multirow[t]{6}{*}{ Whole Turf } & \multicolumn{5}{|c|}{$\begin{array}{l}\text { Model: Total } \sim \text { Period }+1 \mid \text { Site } \\
\text { Degrees of freedom: } 360 \\
\text { AIC: } 344.1\end{array}$} \\
\hline & Fixed Effects & Estimate & Standard Error & $\begin{array}{c}\begin{array}{c}\mathrm{z}- \\
\text { value }\end{array} \\
\end{array}$ & p-value \\
\hline & p1 (intercept) & 3.493 & 0.132 & 26.372 & $2 \mathrm{e}-16^{* * * *}$ \\
\hline & $\mathrm{p} 2$ & -0.017 & 0.150 & -0.113 & 0.910 \\
\hline & $\mathrm{p} 3$ & -0.895 & 0.153 & -5.840 & $5.23 \mathrm{e}-9 * * *$ \\
\hline & $\mathrm{p} 4$ & 0.252 & 0.158 & 1.592 & 0.111 \\
\hline \multirow[t]{6}{*}{ New Turf } & \multicolumn{5}{|c|}{$\begin{array}{l}\text { Model: Total } \sim \text { Period }+1 \mid \text { Site } \\
\text { Degrees of freedom: } 360 \\
\text { AIC: } 511.0\end{array}$} \\
\hline & Fixed Effects & Estimate & Standard Error & $\begin{array}{c}z- \\
\text { value }\end{array}$ & p-value \\
\hline & p1 (intercept) & 2.432 & 0.196 & 12.389 & $2 \mathrm{e}-16^{* * *}$ \\
\hline & $\mathrm{p} 2$ & -0.107 & 0.157 & -0.683 & 0.495 \\
\hline & p3 & -0.941 & 0.162 & -5.806 & $6.4 \mathrm{e}-9 * * *$ \\
\hline & $\mathrm{p} 4$ & 0.338 & 0.163 & 2.076 & $0.038 *$ \\
\hline \multirow[t]{3}{*}{$\begin{array}{l}\text { Whole } \\
\text { Funnel }\end{array}$} & \multicolumn{5}{|c|}{$\begin{array}{l}\text { Model: Total } \sim 1 \mid \text { Site } \\
\text { Degrees of freedom: } 452 \\
\text { QAIC: } 478.7\end{array}$} \\
\hline & Fixed Effects & Estimate & Standard Error & $\begin{array}{c}\text { z- } \\
\text { value }\end{array}$ & p-value \\
\hline & intercept & 2.075 & 0.222 & 9.340 & $2 \mathrm{e}-16^{* * *}$ \\
\hline \multirow[t]{3}{*}{ New Funnel } & \multicolumn{5}{|c|}{$\begin{array}{l}\text { Model: Total } \sim 1 \mid \text { Site } \\
\text { Degrees of freedom: } 456 \\
\text { QAIC: } 486.4\end{array}$} \\
\hline & Fixed Effects & Estimate & Standard Error & $\begin{array}{c}z- \\
\text { value }\end{array}$ & p-value \\
\hline & intercept & -0.148 & 0.646 & -0.229 & 0.819 \\
\hline
\end{tabular}


Table 3.10: Parameters for selected models explaining species richness in turf and funnel traps. Final GLMM's were selected based on AIC for turf models and QAIC for funnel models. Significance levels: * $p$ $<0.05 ; * * \mathrm{p}<0.01 ; * * * \mathrm{p}<0.001$.

\begin{tabular}{|c|c|c|c|c|c|}
\hline \multirow[t]{6}{*}{ Whole Turf } & \multicolumn{5}{|c|}{$\begin{array}{l}\text { Model: Richness } \sim \text { Period }+1 \mid \text { Site } \\
\text { Degrees of freedom: } 360 \\
\text { AIC: } 110.4\end{array}$} \\
\hline & Fixed Effects & Estimate & Standard Error & $\begin{array}{c}\mathrm{z}- \\
\text { value }\end{array}$ & p-value \\
\hline & p1 (intercept) & 1.865 & 0.113 & 16.463 & $2 \mathrm{e}-16^{* * * *}$ \\
\hline & p2 & -0.193 & 0.159 & -1.215 & 0.224 \\
\hline & p3 & -0.517 & 0.160 & -3.236 & $0.001 * *$ \\
\hline & $\mathrm{p} 4$ & 0.197 & 0.164 & 1.207 & 0.227 \\
\hline \multirow[t]{6}{*}{ New Turf } & \multicolumn{5}{|c|}{$\begin{array}{l}\text { Model: Richness } \sim \text { Period }+1 \mid \text { Site } \\
\text { Degrees of freedom: } 360 \\
\text { AIC: } 214.0\end{array}$} \\
\hline & Fixed Effects & Estimate & Standard Error & $\begin{array}{c}\mathrm{z}- \\
\text { value }\end{array}$ & p-value \\
\hline & p1 (intercept) & 1.269 & 0.125 & 10.172 & $2 \mathrm{e}-16 * * *$ \\
\hline & $\mathrm{p} 2$ & -0.191 & 0.168 & -1.131 & 0.258 \\
\hline & p3 & -0.698 & 0.174 & -4.017 & $5.89 \mathrm{e}-5 * * *$ \\
\hline & $\mathrm{p} 4$ & 0.330 & 0.172 & 1.918 & 0.0551 \\
\hline \multirow[t]{3}{*}{$\begin{array}{l}\text { Whole } \\
\text { Funnel }\end{array}$} & \multicolumn{5}{|c|}{$\begin{array}{l}\text { Model: Total } \sim 1 \mid \text { Site } \\
\text { Degrees of freedom: } 452 \\
\text { QAIC: } 253.0\end{array}$} \\
\hline & Fixed Effects & Estimate & Standard Error & $\begin{array}{c}\mathrm{z}- \\
\text { value }\end{array}$ & p-value \\
\hline & intercept & 0.372 & 0.085 & 4.368 & $1.25 \mathrm{e}-5 * * *$ \\
\hline \multirow[t]{3}{*}{ New Funnel } & \multicolumn{5}{|c|}{$\begin{array}{l}\text { Model: Total } \sim 1 \mid \text { Site } \\
\text { Degrees of freedom: } 456 \\
\text { QAIC: } 486.4\end{array}$} \\
\hline & Fixed Effects & Estimate & Standard Error & $\begin{array}{c}\mathrm{z}- \\
\text { value }\end{array}$ & p-value \\
\hline & intercept & -0.148 & 0.646 & -0.229 & 0.819 \\
\hline
\end{tabular}

For both Whole and New seeds, there were seasonal patterns in the species richness of seeds deposited in turf traps. As for total number of seeds, GLMM results indicated that collection period was a significant predictor of number of distinct taxa per 
trap ( $\mathrm{p}<0.01$; Table 3.8; Table 3.10). For Whole seeds in turf traps, the model showed that there were significantly fewer species deposited in p3 (July - November 2015) than in p1 (January - March 2015; p <0.01; Table 3.10; Figure 3.14). Additionally, Wilcoxon rank-sum tests suggested that there were significantly fewer species deposited during p3 than during p2 (March - July 2015) or p4 (November 2015 - March 2016; p < 0.05). Similarly, for New seeds, the GLMM showed that there were significantly fewer species deposited in turf traps in $\mathrm{p} 3$ than in $\mathrm{p} 1$ ( $\mathrm{p}<0.001$; Table 3.10). Additionally, the difference between $\mathrm{p} 1$ and $\mathrm{p} 4$ in New species richness was nearly significant $(0.05<\mathrm{p}<$ 1). Wilcoxon tests, considering mean richness across each site, did indicate significantly more species in $\mathrm{p} 4$ than $\mathrm{p} 1(\mathrm{p}<0.05)$. Wilcoxon tests also indicated that significantly fewer species were deposited in turf traps in $\mathrm{p} 3$ than in $\mathrm{p} 2$ or $\mathrm{p} 4(\mathrm{p}<0.05)$.

Unlike for turf traps, for funnel traps GLMM results indicated that collection period was not a significant predictor of species richness in funnel traps. As for total number of seeds in funnel traps, the null model, including only study site as a random effect, was the best predictor of funnel species richness (Table 3.8); addition of collection period and trap position as model parameters did not significantly improve QAIC values. 


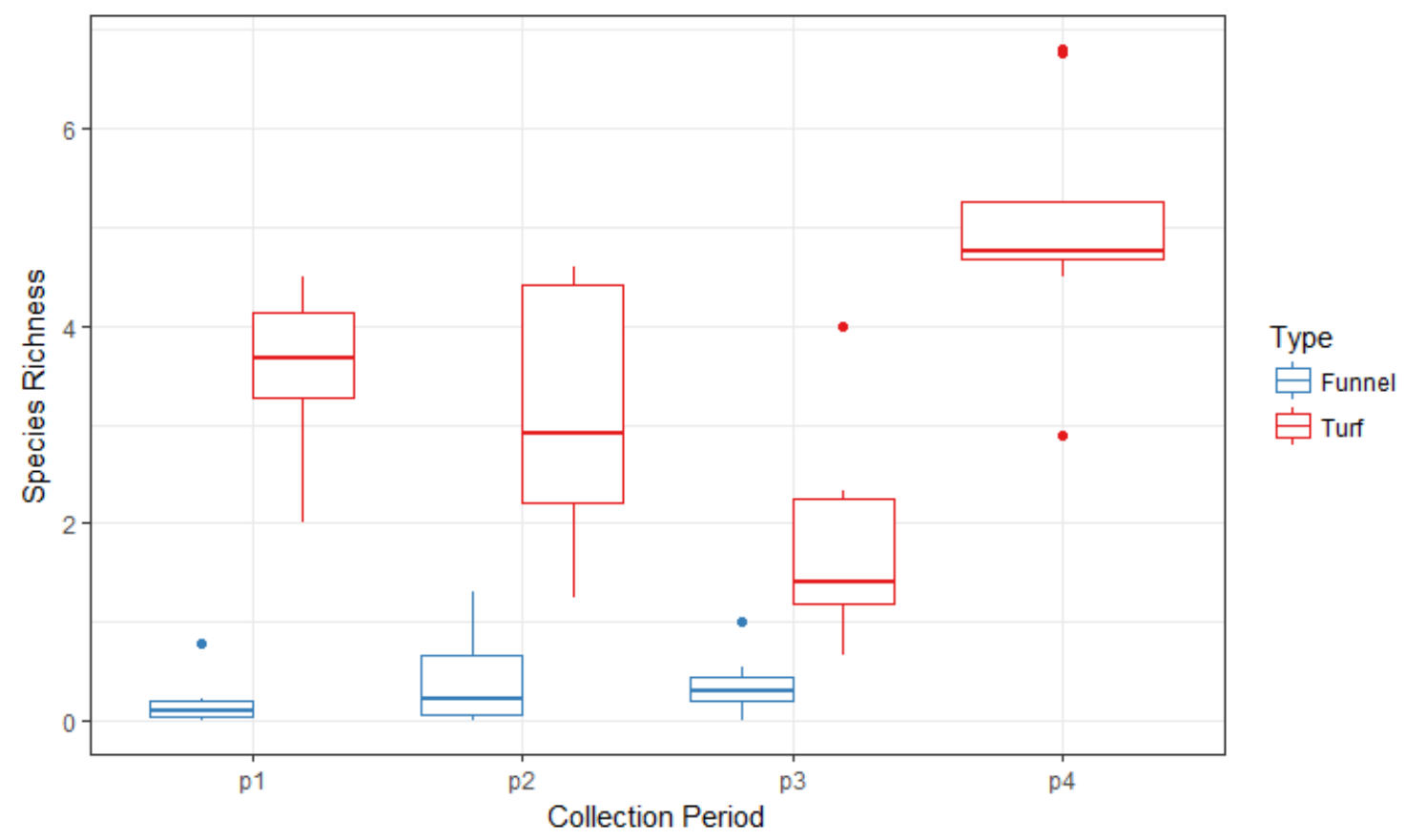

Figure 3.14: Species richness of Whole seeds in turf and funnel traps across four collection periods. In turf traps, there were significantly fewer taxa deposited during $\mathrm{p} 3$ than $\mathrm{p} 1$, as indicated by GLMM results and Wilcoxon rank-sum tests $(\mathrm{p}<0.05)$. Wilcoxon tests also indicated that there were significantly fewer species in $\mathrm{p} 3$ than in $\mathrm{p} 2$ or $\mathrm{p} 4$ in turf traps $(\mathrm{p}<0.05)$, and significantly more species in $\mathrm{p} 4$ than in $\mathrm{p} 1$. GLMM results and Wilcoxon tests showed that there were no significant differences among collection periods in species richness of seeds in funnel traps.

Rubus spp. (Figure 3.15) was the taxon most represented across the entire study, with a total of 3,634 potentially viable seeds ( $23 \%$ of total seeds) identified. Rubus spp. was found in turf traps at all nine study sites, and it was also in the standing vegetation at all sites. The species of Rubus could not be determined from seed, but it is likely that much of the seed caught was Rubus spectabilis (salmonberry), as this species was present in all nine sites in the standing vegetation, and dominant near the stream in several sites. Rubus spp. was present in turf traps as a new taxon at five of the nine sites. For Whole seeds, the highest turf densities of Rubus spp. were found in p4 (November 2015 - March 2016), followed by p1 (January - March 2015) and p2 (March - July 2015), with the 
lowest densities in p3 (July - November 2015) Figure 3.16). There were significantly higher densities of Whole Rubus spp. seeds in $\mathrm{p} 1$, $\mathrm{p} 2$, and $\mathrm{p} 4$ than in $\mathrm{p} 3(\mathrm{p}<0.05)$. For New seeds, the highest mean turf densities of Rubus spp. occurred in $\mathrm{p} 2$, and the lowest in $\mathrm{p} 3$, but there were no statistically significant differences among collection periods. There was no relationship found between density of Rubus spp. seeds caught in turf traps at a site and cover by Rubus spp. in the standing vegetation in trap microsites. Compared to turf traps, there were very few Rubus spp. seeds caught in funnel traps (61 seeds total, compared to 2,023 in turf traps from $\mathrm{p} 1$ through $\mathrm{p} 3$ ). The highest funnel densities of Rubus spp. seeds were found in $\mathrm{p} 3$, but there were no statistically significant differences among collection periods, for either Whole or New seeds.

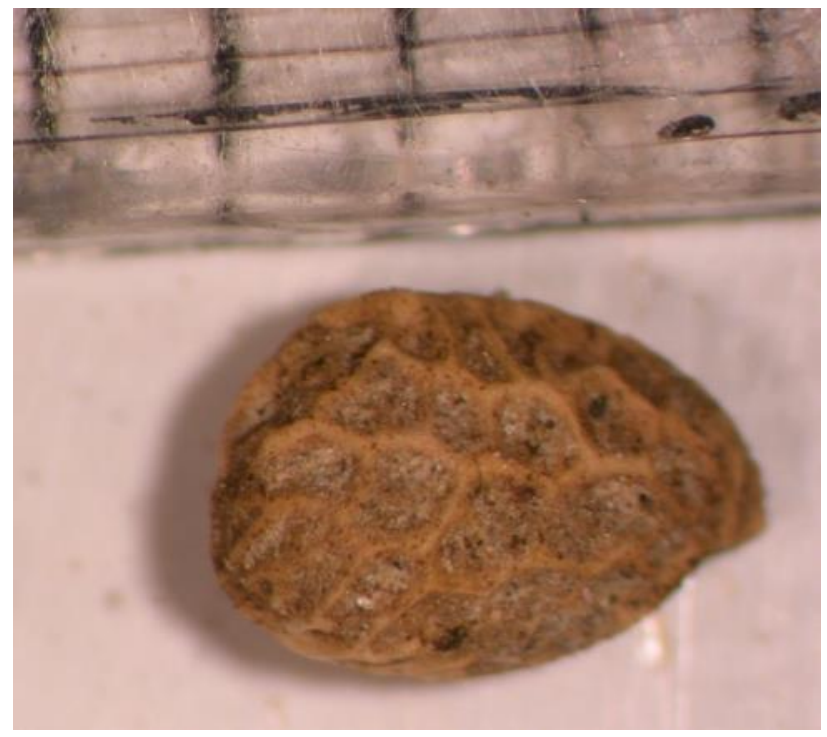

Figure 3.15: Rubus spp. seed caught in turf trap. Scale is in mm. More seeds of Rubus were collected throughout the study than seeds of any other taxa. No seeds were found with any fleshy fruit still attached. From seed, Rubus could not be identified to the species level. Most seeds were likely R. spectabilis (salmonberry), but seeds from $R$. bifrons (Himalayan blackberry), R. parviflorus, (thimbleberry), and $R$. ursinus (trailing blackberry) were likely also present in seed samples in some amount. 


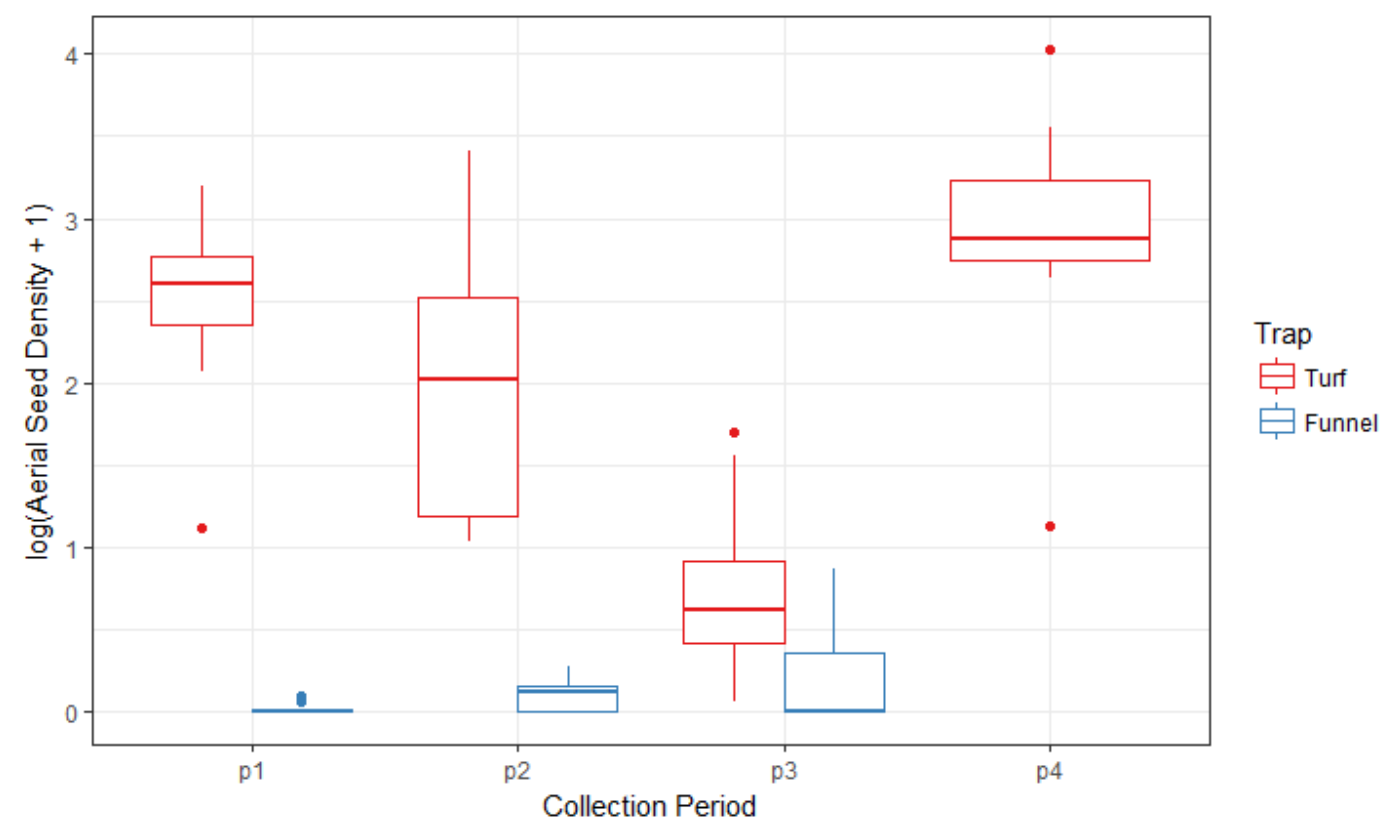

Figure 3.16: Whole Rubus spp. seeds caught in turf and funnel traps across four collection periods. A total of 3,643 Rubus spp. seeds were caught in turf traps during the study, with the highest trap density occurring during $\mathrm{p} 4$. There was significantly higher seed density in turf traps during $\mathrm{p} 1, \mathrm{p} 2$, and $\mathrm{p} 4$ than in $\mathrm{p} 3$ ( $\mathrm{p}<0.05)$. There was significantly higher Rubus spp. aerial density in turf traps than in funnel traps in all collection periods, as well as cumulatively across $\mathrm{p} 1$ through $\mathrm{p} 3(\mathrm{p}<0.05)$.

Alnus rubra (red alder; Figure 3.17) was the second-most represented taxon in seed traps overall, with 3,232 seeds captured. This was also the taxon with the most seeds caught in funnel traps. In all collection periods there was higher mean density of Alnus rubra in turf traps than funnel traps, but the cumulative aerial density across $\mathrm{p} 1$ through p3 was not significantly different in turf and funnel traps. 


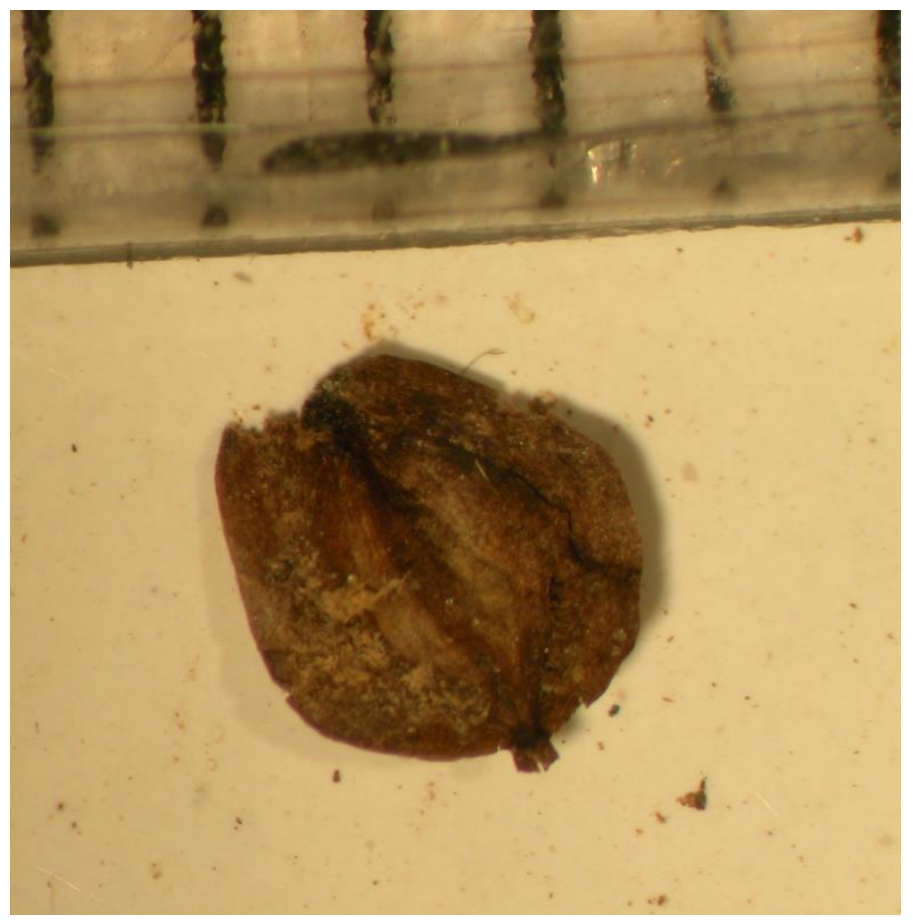

Figure 3.17: Alnus rubra seed caught in funnel trap. Scale is in $\mathrm{mm}$. Alnus rubra was the most-caught taxon in funnel traps and the second-most in turf traps.

In turf traps, Tellima grandiflora (fringecup) was the most collected forb species, and Carex leptopoda (slender-foot sedge; Figure 3.18) was the most collected graminoid. In funnel traps, Claytonia spp. (springbeauty) was the most-collected forb species. Carex leptopoda was also the most-collected graminoid species in funnel traps, but with many fewer seeds collected overall than in turf traps. Figures 3.19 and 3.20 show the top 20 taxa captured in turf traps and in funnel traps across the study. 


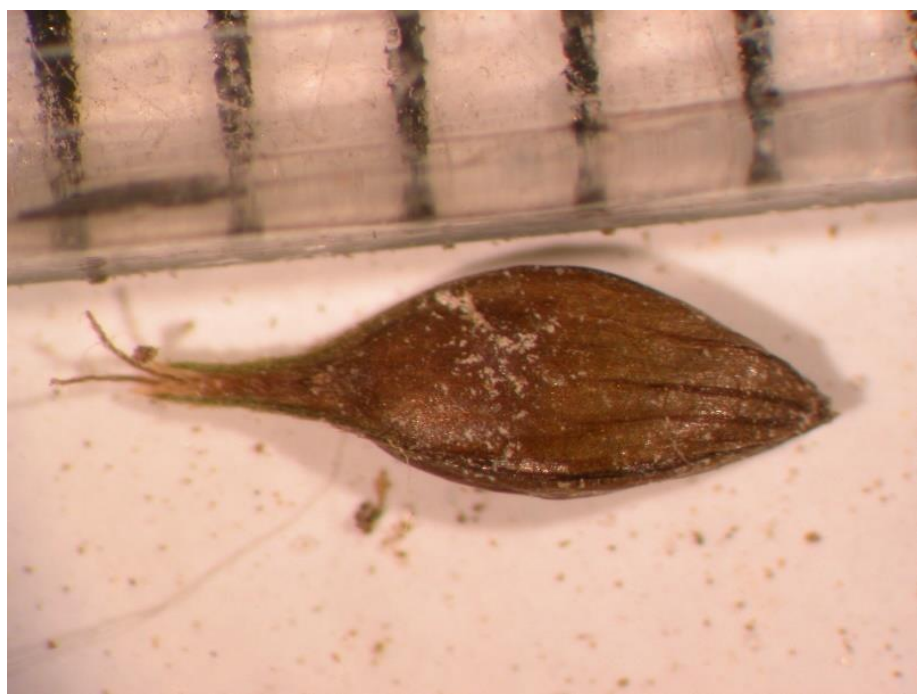

Figure 3.18: Carex leptopoda seed taught in turf trap. Scale is in $\mathrm{mm}$. Carex leptopoda was the most common graminoid species caught in both turf and funnel traps.

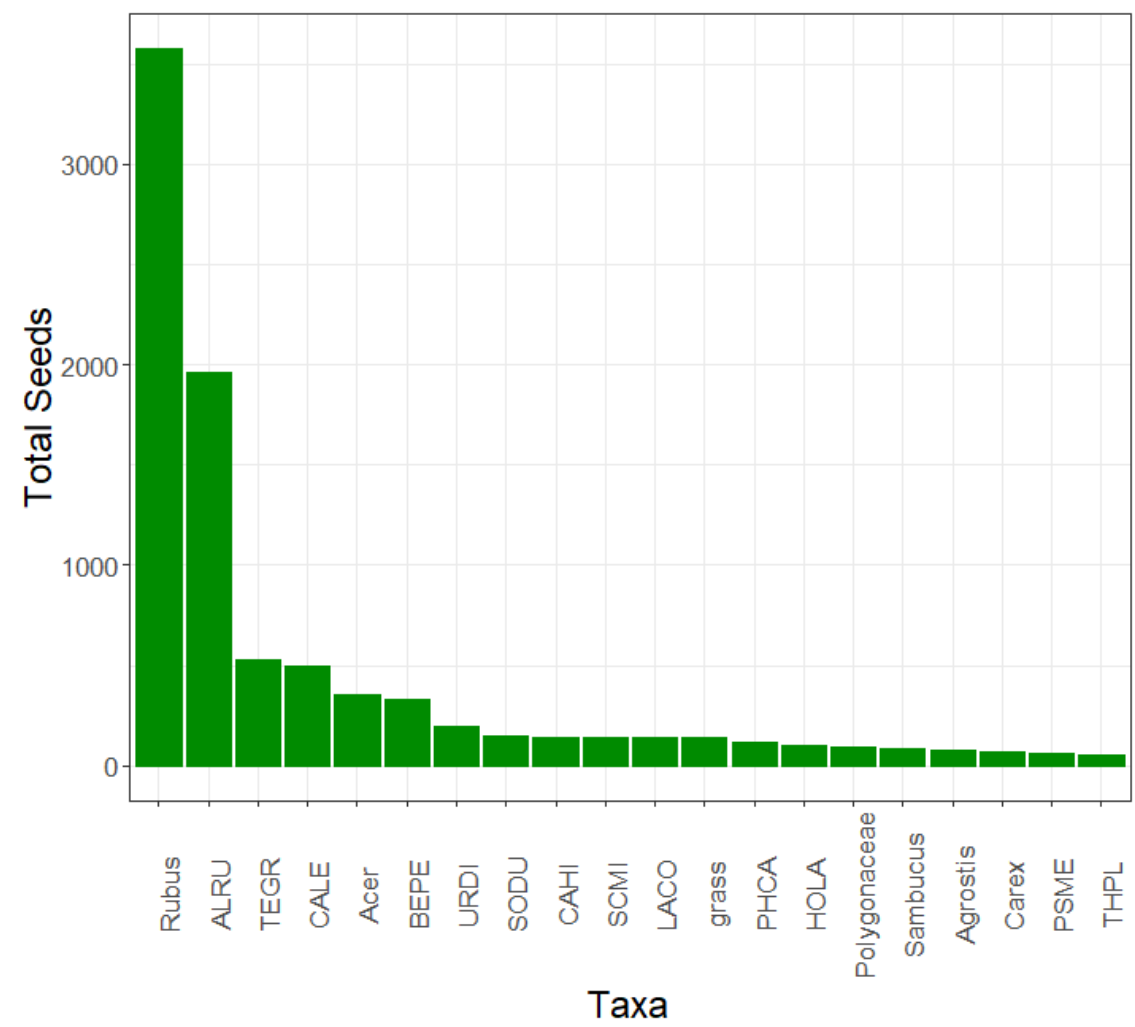

Figure 3.19 Top 20 taxa found in turf traps across the study period. Taxa identified to the species level are represented by the first 2 letters of the genus and the first 2 letters of the specific epithet. Rubus spp. was by far the most represented taxon in turf traps, followed by Alnus rubra. 


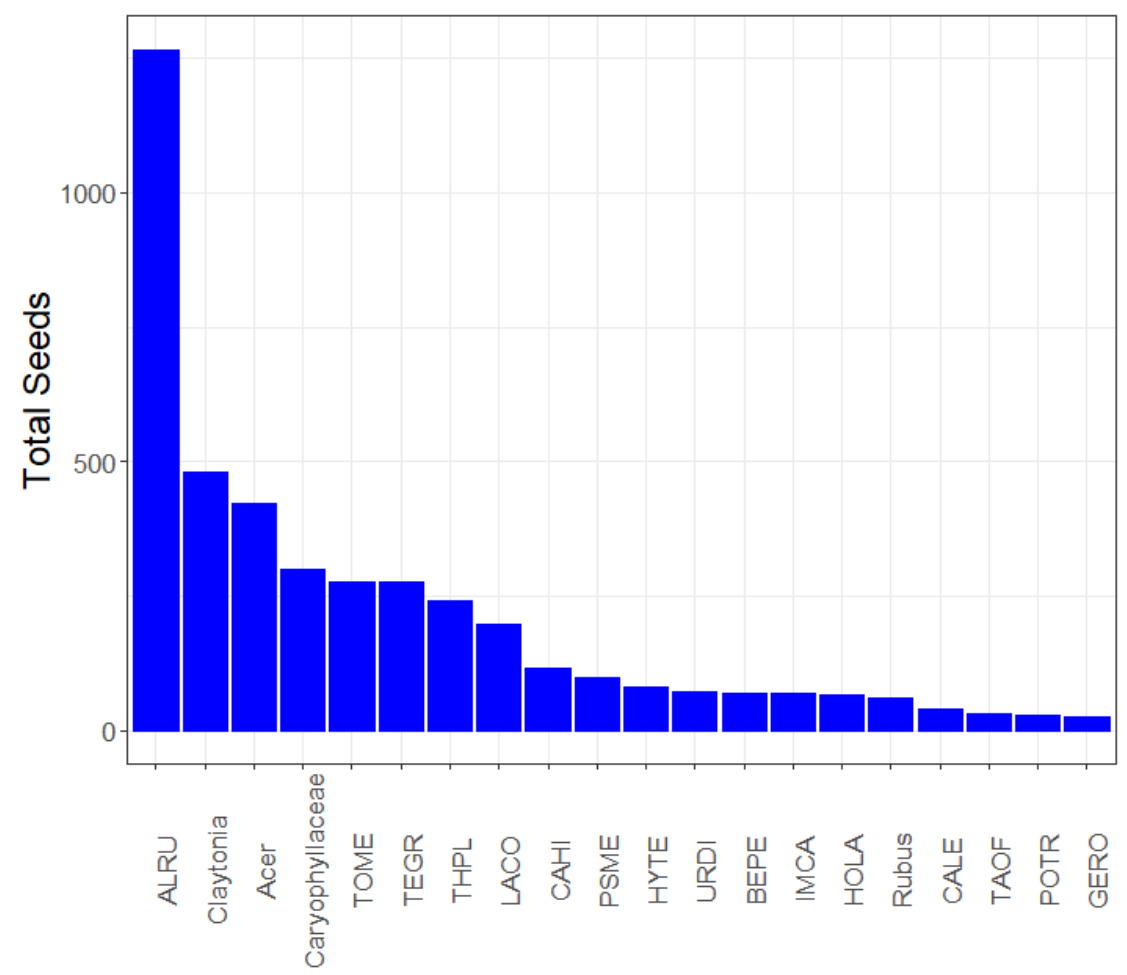

Taxa

Figure 3.20: Top 20 taxa found in funnel traps across the study period. Taxa identified to the species level are represented by the first 2 letters of the genus and the first 2 letters of the specific epithet. Alnus rubra was the most represented taxon in funnel traps, followed by Claytonia spp. and Acer spp.

\section{Functional Group Patterns in Turf and Funnel Traps}

Weight Class: There were differences among the five weight classes in deposition patterns in turf and funnel traps for both Whole (Figure 3.21) and New seeds (Figure 3.22). For Whole seeds in turf traps in p1 (January - March 2015), p2 (March July 2015), and p4 (November 2015 - March 2016), weight class 3 (1.0 - 2.9mg) and 4 $(3-4.9 \mathrm{mg})$ seeds had the highest density, class $2(0.5-0.99 \mathrm{mg})$ and $5(5.0+\mathrm{mg})$ seeds the lowest, and class $1(0-0.49 \mathrm{mg})$ seeds were intermediate (Table 3.11). Across the entire study, there was a significantly higher cumulative density of both class 3 and class 4 seeds than either class 2 or class 5 seeds $(\mathrm{p}<0.05)$. Rubus spp. seeds caught in turf 
traps composed a majority of the weight class 4 seeds. The differences among weight classes were not statistically significant when New seeds alone were evaluated (Figure 3.22). There was, however, a similar trend for New seeds in turf traps; weight class 5 made up the lowest density in turf traps across all four collection periods, while class 4 had the highest, followed by class 1 (Table 3.11). During p3 (July - November 2015; Figure 3.22), there is a visible pattern of decreased deposition of New seeds in turf traps with increasing weight class.

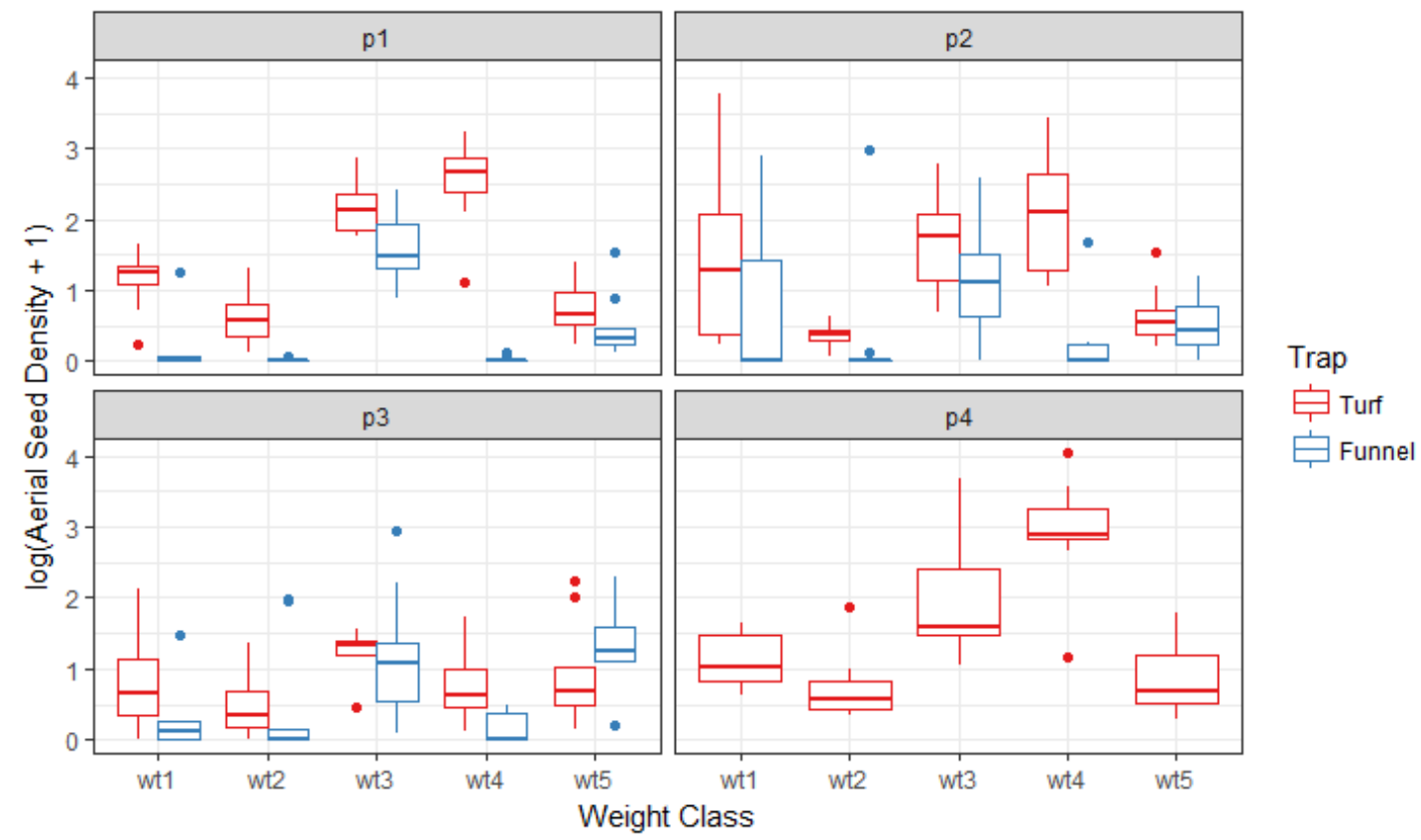

Figure 3.21: Density of Whole seeds by weight class on a log scale across all collection periods.

Cumulatively across collection periods, weight classes $3(1.0-2.9 \mathrm{mg})$ and $4(3-4.9 \mathrm{mg})$ had the highest aerial seed densities in turf traps, significantly higher than classes $2(0.5-0.99 \mathrm{mg})$ and $5(5+\mathrm{mg} ; \mathrm{p}<$ 0.05). The lowest deposition rates in turf traps occurred in $\mathrm{p} 3$ for seeds of all weight classes. Class 3 seeds had significantly higher density in $\mathrm{p} 1$ than $\mathrm{p} 3$ ( $\mathrm{p}<0.05)$, and class 4 seeds had significantly higher density in $\mathrm{p} 1, \mathrm{p} 2$, and $\mathrm{p} 4$ than in $\mathrm{p} 3(\mathrm{p}<0.05)$. Cumulatively, weight class 4 seeds had the lowest density in funnel traps, and significantly lower than classes 3 and $5(\mathrm{p}<0.05)$. There were no significant seasonal patterns of weight classes of seeds caught in funnel traps. 


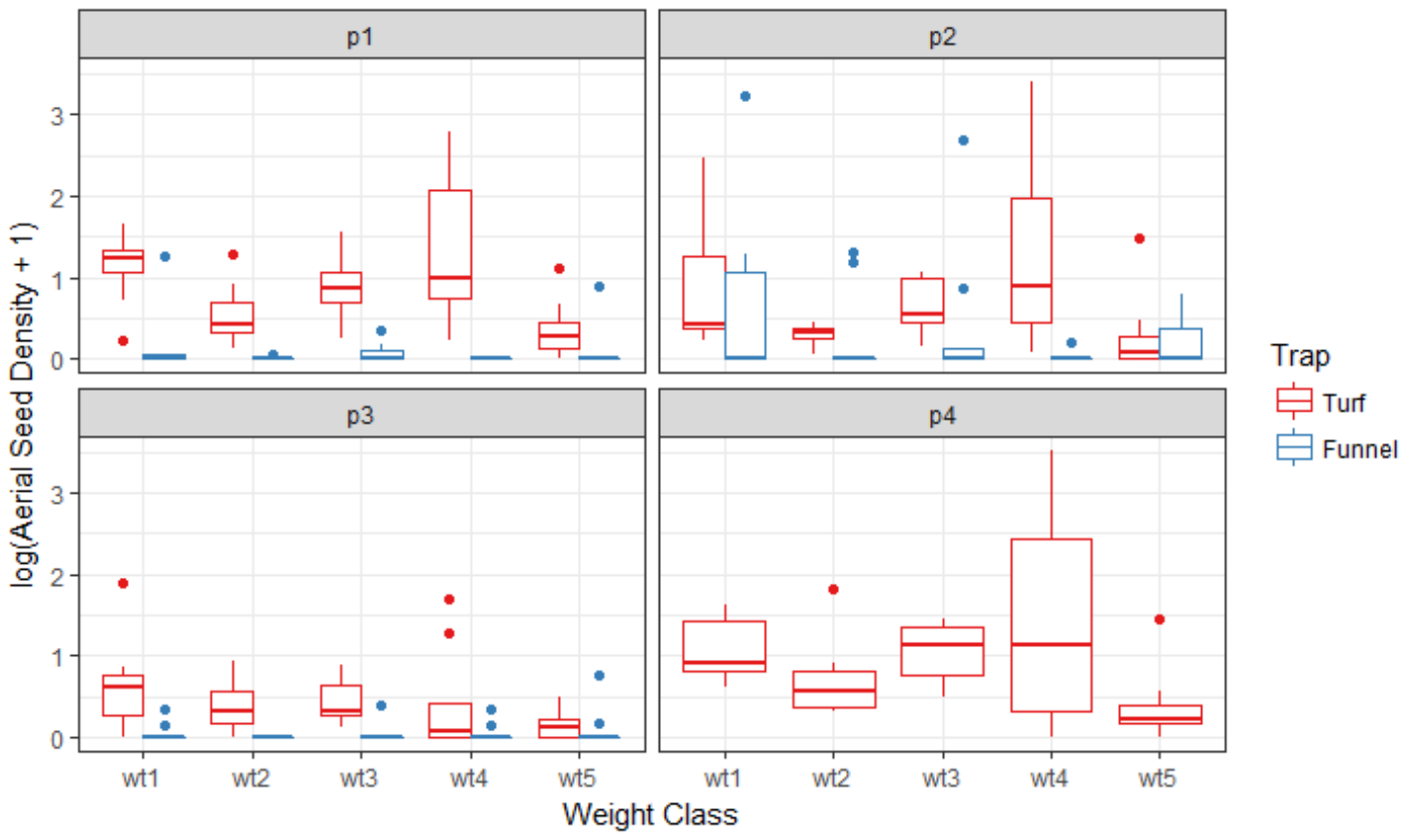

Figure 3.22: Density of New seeds by weight class on a log scale across all collection periods. There were no significant differences among weight classes of seed densities in either turf or funnel traps. Weight class $3(1.0-2.9 \mathrm{mg})$ had significantly higher turf density in $\mathrm{p} 4$ than in $\mathrm{p} 3$, but there were no other seasonal differences. There was a significantly higher cumulative aerial density of seeds in turf traps than near-stream funnel traps for weight classes 1 through 4.

For Whole seeds (Figure 3.21), there were seasonal differences in deposition patterns of weight class 3 and 4 seeds in turf traps. For weight class 3 , there was a significantly higher seed density in $\mathrm{p} 1$ than in $\mathrm{p} 3$. For weight class 4 , there were significantly higher densities in $\mathrm{p} 1, \mathrm{p} 2$, and $\mathrm{p} 4$ than in $\mathrm{p} 3$. For New seeds, there was a significantly higher density of weight class 3 seeds in $\mathrm{p} 4$ than in $\mathrm{p} 3$, but there were no other seasonal differences in the deposition of different weight classes.

In funnel traps, for Whole seeds across the entire study period (Figure 3.21), there was a significantly lower density of weight class 4 seeds than class 3 or class 5 seeds ( $<$ 0.05), but there were no other significant differences among weight classes (Table 3.12). 
There were no significant differences among periods in deposition of seeds in funnel traps for any weight class for either Whole or New seeds.

For Whole seeds, there was a significantly higher cumulative aerial density of weight class 2 and weight class 4 seeds in turf traps than in both near-stream and forest interior funnel traps $(\mathrm{p}<0.05)$ across $\mathrm{p} 1$ through $\mathrm{p} 3$, the periods when there were collections from both turf and funnel traps. For weight classes 1, 3, and 5, there were no significant differences between turf and funnel traps. For New seeds, there was a significantly higher aerial density of seeds in weight classes 1 through 4 in turfs than in near-stream funnels $(\mathrm{p}<0.05)$. For weight class 4 only, there were also significantly more seeds in turf traps than forest interior funnels. There were no significant differences between the near-stream and forest interior funnel traps in cumulative density of any weight class across periods 1 through 3 .

Length Class: For Whole seeds, length class $2(2-4.9 \mathrm{~mm})$ had a significantly higher aerial density in turf traps than all other length classes $(\mathrm{p}<0.05)$, and class $1(0-$ $1.9 \mathrm{~mm})$ had a significantly higher density than class $3(5-9.9 \mathrm{~mm} ; \mathrm{p}<0.05)$, but not than class 4 (10+mm; Figure 3.23; Table 3.11). There were some seasonal differences in deposition for length classes 2 and 3 for Whole seeds. There were significantly higher densities of class 2 seeds in p2 (March - July 2015) and p4 (November 2015 - March 2016) than in $\mathrm{p} 3$ (July - November 2015; $\mathrm{p}<0.05$ ). There was also a significantly higher density of length class 3 seeds in $\mathrm{p} 4$ than in $\mathrm{p} 3(\mathrm{p}<0.05)$, but there were no other differences among seasons for this class. 


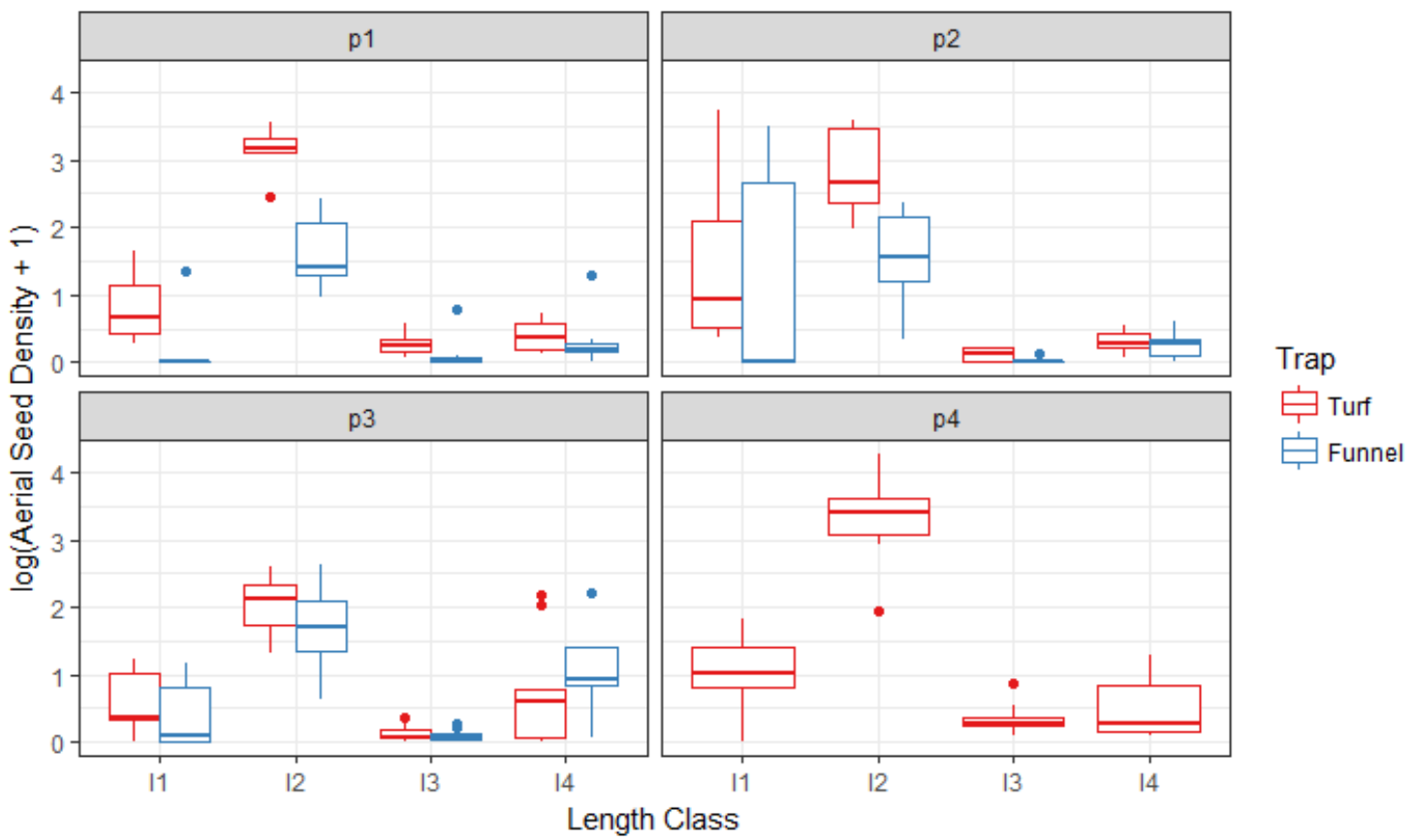

Figure 3.23: Density of Whole seeds by length class on a log scale across all collection periods. Length class $2(2-4.9 \mathrm{~mm})$ seeds had the highest densities of the four length classes in both turf and funnel traps. In funnel traps, there was a significantly higher density of length class 2 seeds than of all other weight classes ( $\mathrm{p}<0.05)$. P2 and p4 were the most important seasons for deposition of class 2 seeds in turf traps, with significantly higher turf densities in these periods than in $\mathrm{p} 3(\mathrm{p}<0.05)$. In funnel traps there was a significantly higher density of class 2 seeds than class $3(5-9.9 \mathrm{~mm})$ or $4(10+\mathrm{mm})$ seeds, and a higher density of class 4 than class 3 seeds ( $p<0.05)$. There were higher cumulative densities of class $1(0-$ $1.99 \mathrm{~mm}$ ), 2, and 3 seeds ( $<<0.05$ ), but not class 4 seeds, in turf traps than in funnel traps.

For New seeds, all four length classes differed significantly from each other in cumulative density in turf traps over the entire study period $(\mathrm{p}<0.05$; Figure 3.24 , Table 3.11). Length class 2, which included Rubus spp. and Alnus rubra, had the highest density, followed by classes 1,3 , and then 4 . For New seeds, there were no seasonal differences in deposition for any classes except class 1 , which had higher density in turfs in $\mathrm{p} 4$ than $\mathrm{p} 3(\mathrm{p}<0.05)$. 


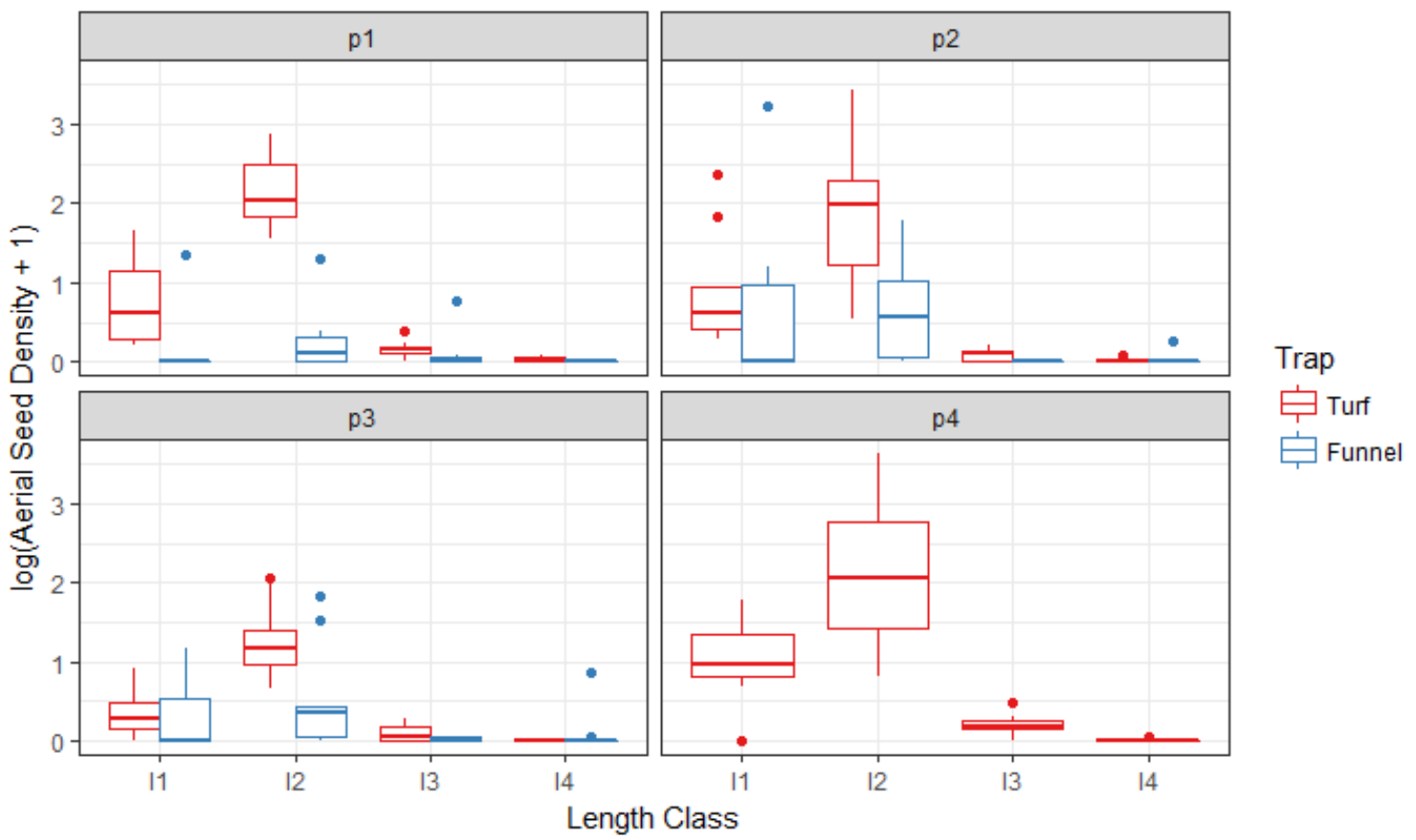

Figure 3.24: Density of New seeds by length class on a log scale across all collection periods.

Cumulatively over all four collection periods all length classes differed in mean density in turf traps ( $\mathrm{p}<$ 0.05). Length class $1(0-1.99 \mathrm{~mm})$ seeds had higher turf density in $\mathrm{p} 4$ than in $\mathrm{p} 3$, but there were no other seasonal differences in funnel traps. There were no significant differences among length classes in density in funnel traps. Cumulatively in p1 through p3, there were significantly more length class $2(2-4.9 \mathrm{~mm})$ seeds in turf than near-stream funnel traps $(\mathrm{p}<0.05)$, but no other significant differences among trap types.

Length class 2 seeds also had the highest Whole seed density in funnels, significantly higher than length classes 3 and 4 ( $\mathrm{p}<0.05$; Figure 3.23; Table 3.12). There was also a significantly higher density of class 4 seeds than class 3 seeds $(\mathrm{p}<0.05)$. For New seeds, there were no differences among length classes in seed density in funnel traps (Table 3.12). For both Whole and New seeds, there were no statistically significant seasonal differences in deposition in funnel traps for any seed length class.

For Whole seeds, there were significantly higher cumulative aerial densities of length class 1, 2, and 3 seeds in turf traps than near-stream funnel traps across p1 through p3 $(\mathrm{p}<0.05)$. There was also higher cumulative seed density in turfs than forest interior 
funnels for length class 2, but not for any other length classes. For length class 4 , there was no significant difference between turf and near-stream funnel density. For New seeds, there was a higher cumulative aerial density of length class 2 seeds in turfs than near-stream funnels and forest interior funnels $(\mathrm{p}<0.05)$, but there were no significant differences among trap types for other length classes. There were also no significant differences between near-stream and forest interior funnels in deposition of any length classes for Whole or New seeds.

Growth Form: There were large differences between turf and funnel traps in the growth forms of taxa collected for Whole seeds (Figure 3.25; Table 3.11). Shrubs were the growth form with the highest aerial seed density in turf traps, and the lowest in both near-stream and forest interior funnel traps. Across the entire study, there was a significantly higher cumulative Whole seed density of shrub seeds than graminoid seeds in turf traps; there were no significant differences among any other growth forms. In each site, between $88 \%$ and $99 \%$ of the shrub seeds caught in turf traps were Rubus spp. When Rubus spp. was left out of analysis, shrub seeds had the lowest Whole seed density in turf traps of the four growth forms. Non-Rubus shrub species collected were Physocarpus capitatus (Pacific ninebark), Holodiscus discolor (oceanspray), and Sambucus spp (elderberry). Of these, only Sambucus spp. seeds were found in funnel traps in addition to turf traps. For New seeds, results of a Kruskal-Wallis test indicated that there were no significant differences in cumulative density among the four growth forms in turf traps. 


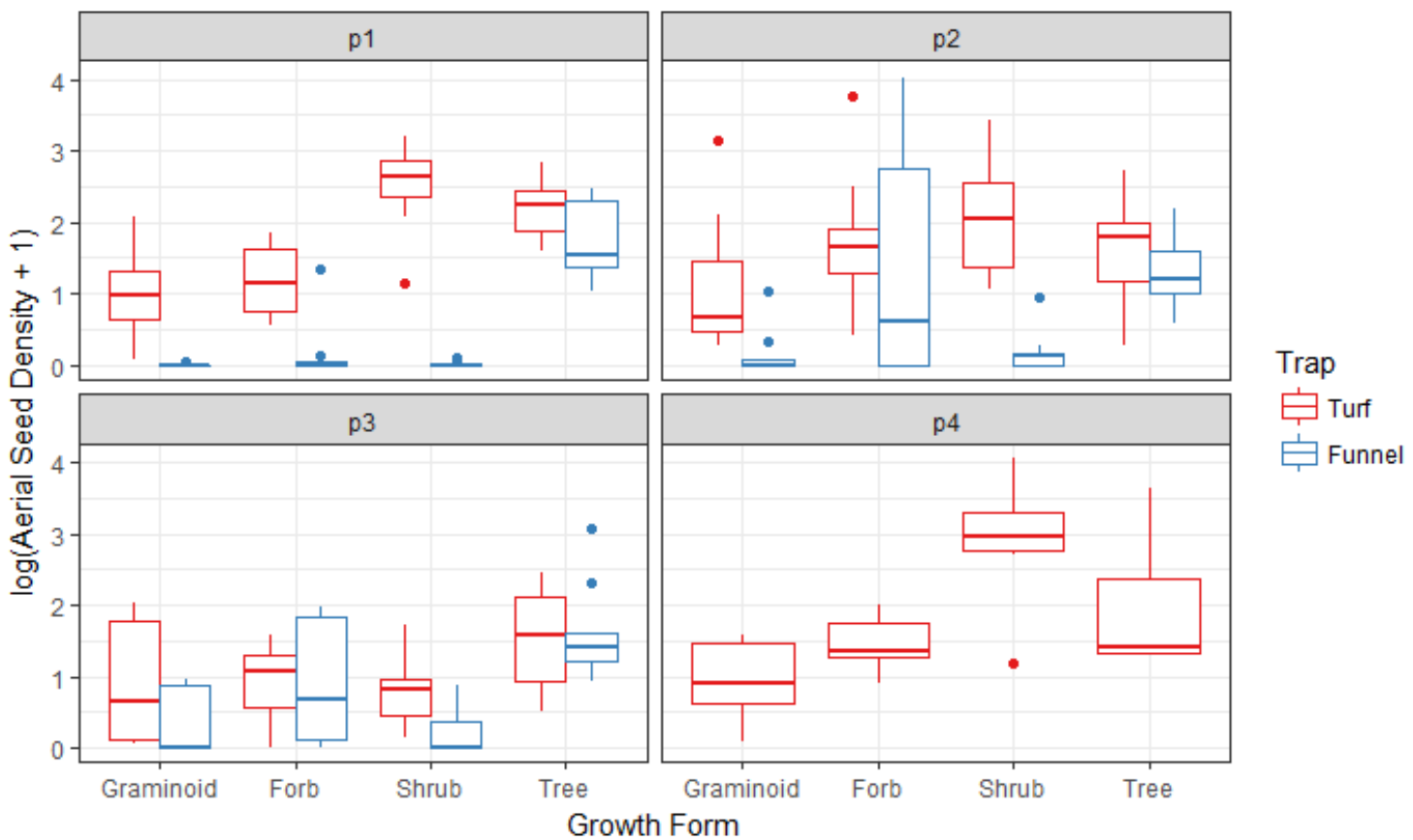

Figure 3.25: Density of Whole seeds by growth form on a log scale across all collection periods. Shrub seeds had the highest cumulative density in turf traps, and significantly higher than graminoid seeds $(\mathrm{p}<$ 0.05). Shrub seeds had the lowest density in funnel traps. There were significantly higher shrub seed densities in turf traps in p1, p2, and p4 than p3 ( $<0.05)$. There were significantly higher cumulative densities of tree, shrub, and graminoid seeds in turf traps than in near-stream funnel traps $(\mathrm{p}<0.05)$.

For Whole seeds, there were seasonal differences in deposition patterns for shrub seeds in turf traps, but not for any other growth forms (Figure 3.25). The seasonal deposition patterns for shrub seeds mirrored those for Rubus spp. alone; they showed a significantly higher seed density in p1 (January - March 2015), p2 (March - July 2015), and p4 (November 2015 - March 2016) than p3 (July - November 2015; p < 0.05), but no other significant differences among seasons. There were no significant seasonal differences in deposition of New seeds of any growth form in turf traps.

For Whole seeds in funnel traps (Figure 3.25; Table 3.12), there was a significantly higher cumulative density of tree seeds than graminoid or shrub seeds $(\mathrm{p}<$ 0.05), but not than forb seeds, across $\mathrm{p} 1$ through $\mathrm{p} 3$. For New seeds, there were no 
significant differences among growth forms in cumulative seed density in funnel traps. There were no significant differences among collection periods in density of seeds of any growth form in funnel traps, for either Whole or New seeds.

Across $\mathrm{p} 1$ through $\mathrm{p} 3$ there were significantly higher cumulative aerial densities of graminoid, shrub, and tree seeds in turf traps than near-stream funnel traps for Whole seeds ( $\mathrm{p}<0.05$; Figure 3.25). There was also a higher cumulative aerial density of shrub seeds in turf traps than forest interior funnels $(\mathrm{p}<0.05)$, but no other significant differences between turfs and forest interior funnels for Whole seeds. There were also no significant differences between turf traps and either location of funnel trap in cumulative density of forb seeds. For New seeds, there was a significantly higher density of graminoid and shrub seeds in turf traps than in both near-stream and forest interior funnel traps $(\mathrm{p}<0.05)$. For both Whole and New seeds, when Rubus spp. was omitted from analysis, there was still a significantly higher cumulative density of shrub seeds in turf traps than in both near-stream and forest interior funnel traps $(\mathrm{p}<0.05)$.

Primary Dispersal Vector: For Whole seeds in turf traps, animal- and winddispersed seeds (Figure 3.26; Table 3.11) had the highest cumulative densities across the entire study period. There was a significantly higher density of animal-dispersed seeds in turf traps than taxa with ballistic, water, or no specialized dispersal mechanism $(\mathrm{p}<0.05$; Figure 3.26). There was a significantly higher density of wind-dispersed seeds than taxa with water and no special dispersal mechanisms $(\mathrm{p}<0.05)$, but not than ballisticdispersed taxa. A majority of animal-dispersed Whole seeds in turf traps were Rubus spp. seeds. When Rubus spp. was removed from analysis, animal-dispersed seeds had the 
lowest cumulative mean seed density of the five dispersal groups. For New seeds in turf traps, there were no significant differences among dispersal groups in cumulative density (Table 3.11). For Whole seeds, deposition patterns of animal-dispersed seeds mirrored that of Rubus spp., with a significantly higher density in p1 (January - March 2015), p2 (March - July 2015), and p4 (November 2015 - March 2016) than in p3 (July November 2015). For seeds with no special dispersal mechanism, there was a significantly higher density of seeds in turfs in $\mathrm{p} 4$ than $\mathrm{p} 3$.

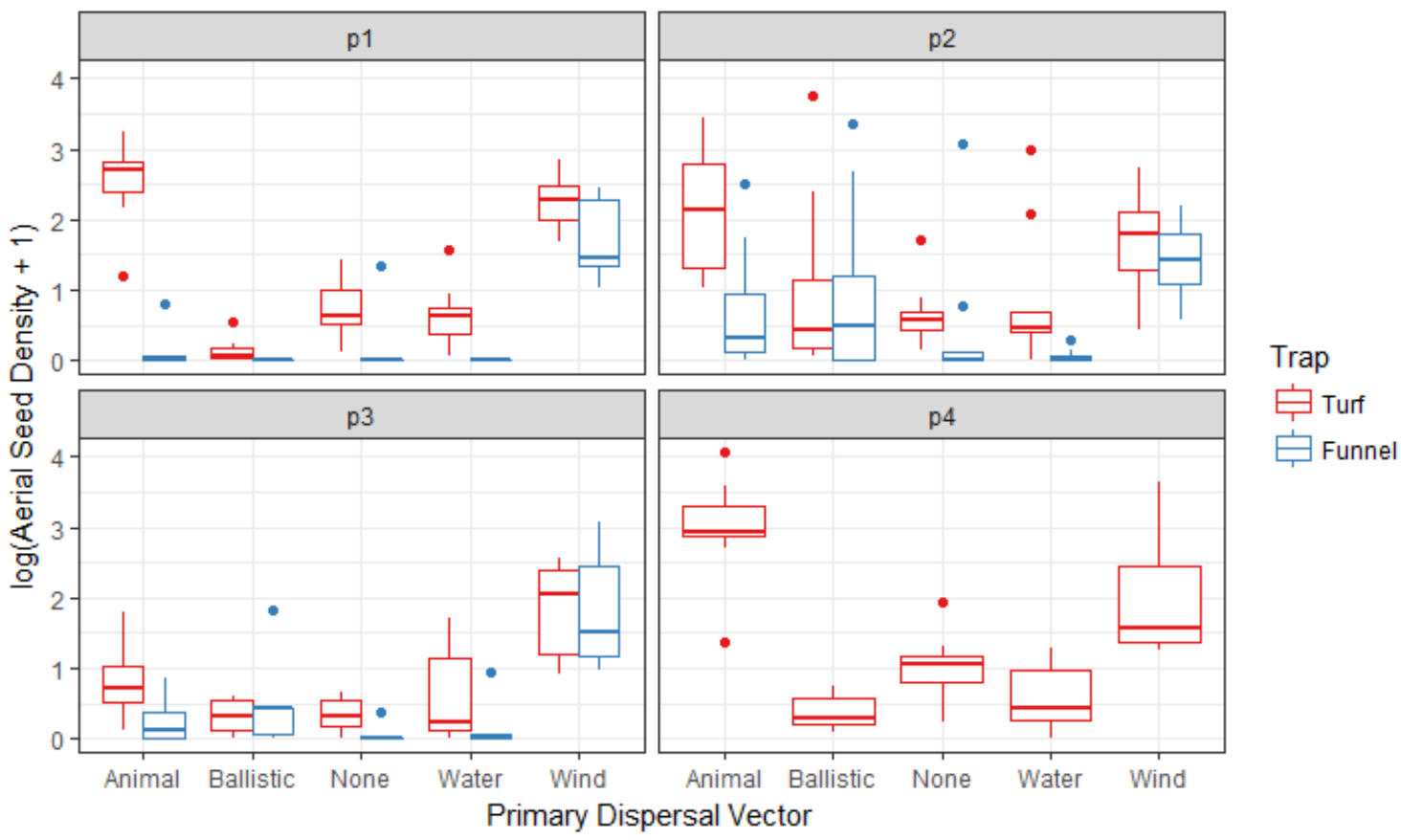

Figure 3.26: Density of Whole seeds by primary dispersal vector on a log scale across all collection periods. In turf traps, there was significantly higher cumulative density of animal-dispersed seeds than seeds with water, ballistic, or no special dispersal mechanism $(\mathrm{p}<0.05)$. Wind-dispersed seed had higher cumulative density than water-dispersed and no mechanism seeds in turf traps $(\mathrm{p}<0.05)$ and higher cumulative density than all other dispersal mechanisms in funnel traps $(\mathrm{p}<0.05)$. Density of winddispersed seeds was high in all collection periods for both turf and funnel traps; there were no significant differences among periods. Animal-dispersed seeds had a significantly higher density in turfs in p1, p2, and $\mathrm{p} 4$ than in $\mathrm{p} 3$. Ballistic-dispersed seeds had significantly higher density in funnels in $\mathrm{p} 3$ than in $\mathrm{p} 4$. 
Wind-dispersed seeds had a significantly higher Whole seed aerial density in funnel traps than other groups ( $\mathrm{p}<0.05$; Table 3.12), except for ballistic dispersal. For New seeds, there were no differences in among dispersal groups in cumulative seed density in funnel traps across the study. For both Whole and New seeds, there was a significantly higher density of ballistic seeds in $\mathrm{p} 3$ than $\mathrm{p} 1$. There were no other seasonal differences for dispersal categories for Whole or New seeds in funnel traps.

For Whole and New seeds, there was a significantly higher aerial density of seeds with animal, water, and no special dispersal mechanism in turf traps than in near-stream or forest interior funnel traps $(\mathrm{p}<0.05)$. There were no significant differences between trap types for ballistic or wind-dispersed seeds when Whole seeds were analyzed. For New seeds, there was a significantly higher aerial density of wind-dispersed seeds in turf traps than in near-stream funnels $(\mathrm{p}<0.05)$, but not significantly more than forest interior funnels.

Height Class: For Whole seeds, height class $3(5-14.99 m)$, which included Rubus spp., had the highest cumulative mean seed density in turf traps across the study (Table 3.11), as well as the highest density in periods p1 (January - March 2015), p2 (March - July 2015), and p4 (November 2015 - March 2016; Figure 3.27). The cumulative mean density of class 3 seeds, however, only differed significantly from that of height class $2(1-4.99 m)$ seeds $(p<0.05)$. Height class $4(15+m)$ had the second highest mean density of Whole seeds in turf traps across all four periods, but the cumulative mean density did not differ significantly from any other height class. For New seeds in turf traps, height classes 2 and 3 had the highest cumulative mean densities, 
but there were no significant differences among any groups (Table 3.11). There was a significantly higher density of Whole height class 2 seeds in turfs in p4 than in p3 (July November 2015; $\mathrm{p}<0.05)$, and a significantly higher density of class 3 seeds in $\mathrm{p} 1, \mathrm{p} 2$, and $\mathrm{p} 4$ than in $\mathrm{p} 3(\mathrm{p}<0.05)$. For New seeds, there was a significantly higher density of seeds of height class 2 taxa in $\mathrm{p} 4$ than in $\mathrm{p} 3(\mathrm{p}<0.05)$, but there were no other significant seasonal differences among height classes for New seeds in turf traps.

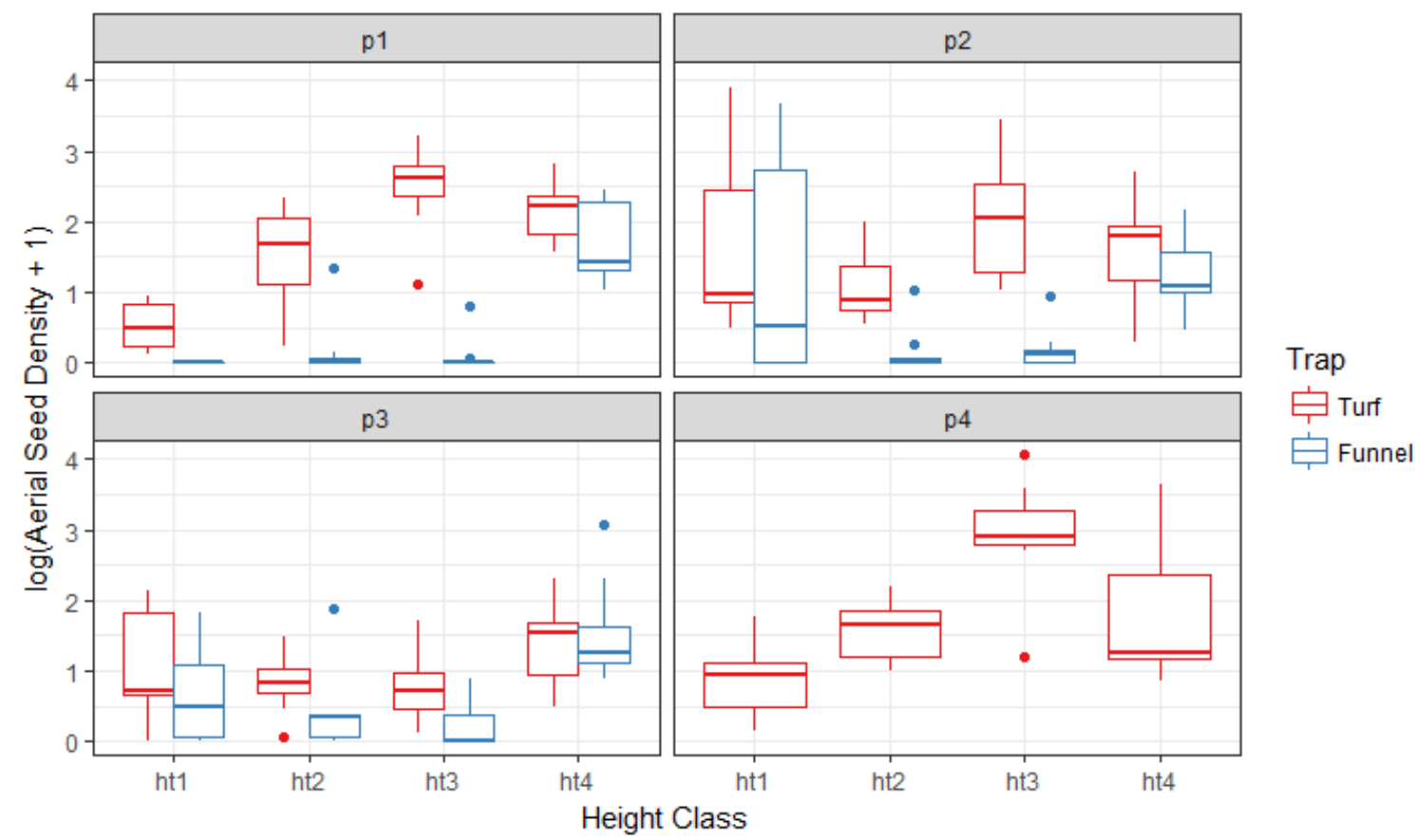

Figure 3.27: Density of Whole seeds by height class on a log scale across all collection periods. In turf traps, height class $3(5-14.99 \mathrm{~m})$ seeds had the highest cumulative mean density of the four height classes. There was significantly higher class 3 density in turf traps in $\mathrm{p} 1$, p2, and p4 than in $\mathrm{p} 3$ ( $\mathrm{p}<0.05)$. Class 4 $(15+\mathrm{m})$ seeds had the highest cumulative mean density in funnel traps, significantly higher than density of class $2(1-4.99 m)$ or class 3 seeds $(\mathrm{p}<0.05)$. There were seasonal differences in deposition for height class $1(0-0.99 \mathrm{~m})$ seeds in funnels, with significantly higher seed density in $\mathrm{p} 2$ than in $\mathrm{p} 1$ or $\mathrm{p} 3(\mathrm{p}<0.05)$.

In funnel traps, height class 4 had the highest cumulative mean seed density for Whole seeds (Figure 3.27; Table 3.12). There was a significantly higher mean density of class 4 seeds than of classes 2 or $3(p<0.05)$, but class 4 density was not significantly different from class $1(0-0.99 \mathrm{~m})$ density. For Whole seeds, there were significant 
seasonal differences in density of height class 1 seeds in funnel traps, with significantly higher density in $\mathrm{p} 2$ than in $\mathrm{p} 1$ or $\mathrm{p} 3(\mathrm{p}<0.05)$. For New seeds only, there were significantly higher densities of height class 1 seeds in $\mathrm{p} 2$ and $\mathrm{p} 3$ than in $\mathrm{p} 1(\mathrm{p}<0.05)$, but $\mathrm{p} 2$ and $\mathrm{p} 3$ did not differ significantly from each other.

Cumulatively across $\mathrm{p} 1$ through $\mathrm{p} 3$, there was a significantly higher aerial density of Whole seeds from height classes 2 and 3 in turf traps than near-stream funnel traps ( $p$ $<0.05$; Figure 3.27). There were no significant differences between turfs and nearstream funnels in density of class 1 or 4 for Whole seeds. Turf traps also had a significantly higher density of height class 3 seeds than forest interior funnels $(\mathrm{p}<0.05)$ for Whole seeds, but there was no difference between these two trap types in density of class 2 seeds. For New height class 1 seeds, the highest cumulative mean seed densities occurred in forest interior traps, due to a very high density in one site, but it did not differ significantly from density in near-stream funnel or turf traps. There was a significantly higher cumulative mean density of height class 1 seeds in turf traps than near-stream funnel traps across $\mathrm{p} 1$ through $\mathrm{p} 3(\mathrm{p}<0.05)$. There were also higher cumulative mean seed densities of New class 2 and 3 seeds in turf traps than either type of funnel trap ( $p<$ 0.05), but no significant differences between turf and funnel traps in density of New class 4 seeds.

Seed Output Class: For Whole seeds in turf traps, there was a general trend of higher density of seeds from higher seed output classes (number of seeds produced per individual plant; Table 3.2), especially in p1 (January - March 2015) and p4 (November 2015 - March 2016; Figure 3.19). 


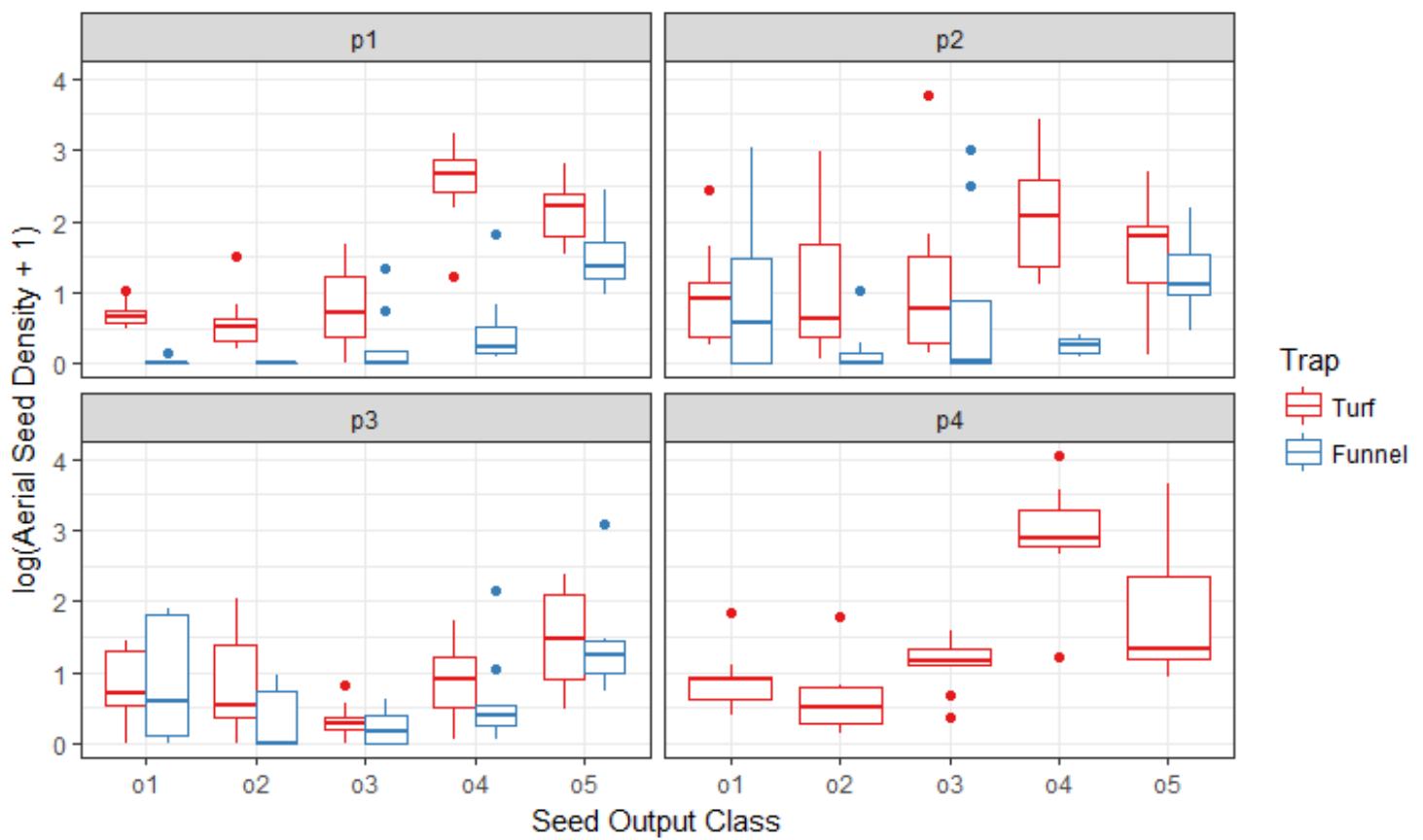

Figure 3.28: Density of Whole seeds by seed output class on a log scale across all collection periods. In turf traps, class $4(5,000-24,999$ seeds per individual $)$ seeds had significantly higher cumulative density that classes 1 ( 1 - 499 seeds per individual), 2 (500 - 2,499 seeds per individual), and 3 (2,500 - 4,999 seeds per individual). P4 was the most important season for deposition of class 3 and 4 seeds in turf traps. Class 5 (25,000+ seeds per individual) seeds had the highest cumulative density in funnel traps.

Output class $4(5,000-24,999$ seeds per individual) had the highest cumulative mean seed density across the entire study, significantly higher than classes 1 ( 1 - 499 seeds per individual), 2 (500 - 2,499 seeds per individual), and 3 (2,500 - 4,999 seeds per individual), but not compared with class $5(25,000+$ seeds per individual; $\mathrm{p}<0.05$; Table 3.11). Class 4 was the class that contained Rubus spp. seeds. Class 5 had significantly higher density in turf traps than class $1(\mathrm{p}<0.05)$, but not than any other output classes. For New seeds, there were no significant differences among seed output classes in cumulative density in turf traps (Table 3.11). For Whole seeds, there were seasonal differences in deposition for seeds from output classes 3 and 4. For output class 3 there was a significantly higher density in p4 than in p3 (July - November 2015; p < 0.05). 
For output class 4, p3 had significantly lower density in turf traps than all other periods ( $\mathrm{p}$ $<0.05$ ). Like for Whole seeds, for New seeds, there was a significantly higher density of class 3 seeds in turf traps in $\mathrm{p} 4$ than in $\mathrm{p} 3(\mathrm{p}<0.05)$, but there were no other seasonal differences.

For Whole seeds in funnel traps (Figure 3.28), output class 5 had the highest cumulative seed density, but it only differed significantly from the densities of classes 2 and 4 ( $\mathrm{p}<0.05$; Table 3.12). For New seeds, there were no significant differences among output classes in seed density in funnel traps (Table 3.12). For both Whole and New seeds, there were significantly more output class 1 seeds in funnel traps during $\mathrm{p} 2$ than $\mathrm{p} 1$ $(\mathrm{p}<0.05)$. There were no other seasonal differences among output classes in funnels. Across $\mathrm{p} 1$ through $\mathrm{p} 3$, the highest cumulative density of Whole output class 4 seeds occurred in turf traps, with significantly higher density than in either near-stream and forest interior funnel traps ( $\mathrm{p}<0.05$; Figure 3.28). For output class 2 , there was a significantly higher seed density in turf traps than in near-stream funnel traps $(\mathrm{p}<0.05)$, but not than forest interior funnel traps. For New seeds, there was a significantly higher density of seeds in turf traps than near-stream funnel traps for output classes 1 through 4 $(\mathrm{p}<0.05)$, but not for class 5 . There were also significantly more New seeds of output class 4 in turf traps than in forest interior funnel traps $(\mathrm{p}<0.05)$, but no other significant turf-forest interior funnel differences. 
Table 3.11: Deposition patterns of different functional groups in turf traps. For each category, deposition of the 4 or 5 classes are ranked from highest trap density (1) to lowest trap density (4 or 5). Bold numbers indicate that seed density of that class differs significantly $(p<0.05)$ from at least one other class in the category.

\begin{tabular}{|c|c|c|c|c|c|c|}
\hline & \multicolumn{3}{|c|}{ Whole Seeds } & \multicolumn{3}{|c|}{ New Seeds } \\
\hline & Category & $\begin{array}{c}\text { Overall } \\
\text { rank }\end{array}$ & $\begin{array}{c}\begin{array}{c}\text { Highest } \\
\text { period }\end{array} \\
\end{array}$ & Category & $\begin{array}{c}\text { Overall } \\
\text { rank }\end{array}$ & $\begin{array}{c}\begin{array}{c}\text { Highest } \\
\text { period }\end{array} \\
\end{array}$ \\
\hline \multirow{5}{*}{ 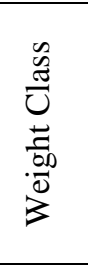 } & Wt1: $0.0-0.49 \mathrm{mg}$ & 3 & $\mathrm{p} 2$ & Wt $10.0-0.49 \mathrm{mg}$ & 3 & $\mathrm{p} 4$ \\
\hline & Wt2: $0.5-0.99 \mathrm{mg}$ & 5 & $\mathrm{p} 4$ & Wt2: $0.5-0.99 \mathrm{mg}$ & 4 & $\mathrm{p} 4$ \\
\hline & $\mathrm{Wt} 3: 1.0-2.9 \mathrm{mg}$ & 2 & $\mathrm{p} 4$ & $\mathrm{Wt} 3: 1.0-2.9 \mathrm{mg}$ & 2 & $\mathrm{p} 4$ \\
\hline & $\mathrm{Wt} 4: 3.0-4.9 \mathrm{mg}$ & 1 & $\mathrm{p} 4$ & $\mathrm{Wt} 4: 3.0-4.9 \mathrm{mg}$ & 1 & $\mathrm{p} 4$ \\
\hline & Wt5: $5.0+\mathrm{mg}$ & 4 & p3 & Wt5: $5.0+\mathrm{mg}$ & 5 & $\mathrm{p} 1$ \\
\hline \multirow{4}{*}{ 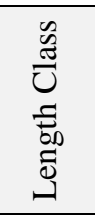 } & L1: $0.0-1.9 \mathrm{~mm}$ & 2 & $\mathrm{p} 2$ & L1: $0.0-1.9 \mathrm{~mm}$ & 2 & $\mathrm{p} 4$ \\
\hline & $\mathrm{L} 2: 2.0-4.9 \mathrm{~mm}$ & 1 & $\mathrm{p} 4$ & $\mathrm{~L} 2: 2.0-4.9 \mathrm{~mm}$ & 1 & $\mathrm{p} 4$ \\
\hline & L3: $5.0-9.9 \mathrm{~mm}$ & 4 & $\mathrm{p} 4$ & L3: $5.0-9.9 \mathrm{~mm}$ & 3 & $\mathrm{p} 4$ \\
\hline & $\mathrm{L} 4: 10.0+\mathrm{mm}$ & 3 & p3 & $\mathrm{L} 4: 10.0+\mathrm{mm}$ & 4 & $\mathrm{p} 1$ \\
\hline \multirow{4}{*}{$\begin{array}{l}\Xi \\
\vdots \\
0 \\
5 \\
0 \\
0 \\
0 \\
0\end{array}$} & Tree & 2 & $\mathrm{p} 4$ & Tree & 4 & $\mathrm{p} 1$ \\
\hline & Shrub & 1 & $\mathrm{p} 4$ & Shrub & 1 & $\mathrm{p} 4$ \\
\hline & Graminoid & 4 & $\mathrm{p} 1$ & Graminoid & 3 & $\mathrm{p} 1$ \\
\hline & Forb & 3 & $\mathrm{p} 2$ & Forb & 2 & p2 \\
\hline \multirow{5}{*}{ 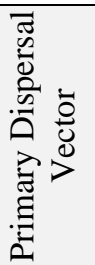 } & Animal & 1 & $\mathrm{p} 4$ & Animal & 1 & $\mathrm{p} 4$ \\
\hline & Ballistic & 3 & $\mathrm{p} 2$ & Ballistic & 5 & $\mathrm{p} 2$ \\
\hline & None & 5 & $\mathrm{p} 4$ & None & 3 & $\mathrm{p} 4$ \\
\hline & Water & 4 & $\mathrm{p} 2$ & Water & 4 & $\mathrm{p} 2$ \\
\hline & Wind & 2 & $\mathrm{p} 1$ & Wind & 2 & $\mathrm{p} 1$ \\
\hline \multirow{4}{*}{ 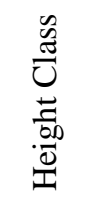 } & $\mathrm{H} 1: 0.0-0.99 \mathrm{~m}$ & 3 & $\mathrm{p} 2$ & $\mathrm{H} 1: 0.0-0.99 \mathrm{~m}$ & 3 & $\mathrm{p} 2$ \\
\hline & $\mathrm{H} 2: 1.0-4.99 \mathrm{~m}$ & 4 & $\mathrm{p} 4$ & $\mathrm{H} 2: 1.0-4.99 \mathrm{~m}$ & 2 & $\mathrm{p} 4$ \\
\hline & $\mathrm{H} 3: 5.0-14.99 \mathrm{~m}$ & 1 & $\mathrm{p} 4$ & $\mathrm{H} 3: 5.0-14.99 \mathrm{~m}$ & 1 & $\mathrm{p} 4$ \\
\hline & $\mathrm{H} 4: 15.0+\mathrm{m}$ & 2 & $\mathrm{p} 1$ & $\mathrm{H} 4: 15.0+\mathrm{m}$ & 4 & $\mathrm{p} 1$ \\
\hline \multirow{5}{*}{ 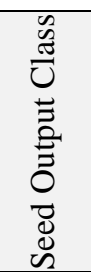 } & O1: 1-499 seeds & 5 & $\mathrm{p} 2$ & O1: 1-499 seeds & 3 & $\mathrm{p} 2$ \\
\hline & O2: $500-2,499$ seeds & 2 & $\mathrm{p} 2$ & O2: $500-2,499$ seeds & 5 & p2 \\
\hline & O3: 2,500-4,999 seeds & 3 & $\mathrm{p} 4$ & O3: 2,500-4,999 seeds & 2 & $\mathrm{p} 4$ \\
\hline & O4: 5,000-24,999 seeds & 1 & $\mathrm{p} 4$ & O4: 5,000-24,999 seeds & 1 & $\mathrm{p} 4$ \\
\hline & O5: $25,000+$ seeds & 2 & $\mathrm{p} 1$ & O5: $25,000+$ seeds & 4 & $\mathrm{p} 1$ \\
\hline
\end{tabular}


Table 3.12: Deposition patterns of different functional groups in funnel traps. For each category, deposition of the 4 or 5 classes are ranked from highest trap density (1) to lowest trap density (4 or 5). Bold numbers indicate that seed density of that class differs significantly $(\mathrm{p}<0.05)$ from at least one other class in the category.

\begin{tabular}{|c|c|c|c|c|c|c|}
\hline & \multicolumn{3}{|c|}{ Whole Seeds } & \multicolumn{3}{|c|}{ New Seeds } \\
\hline & Category & $\begin{array}{c}\text { Overall } \\
\text { rank }\end{array}$ & $\begin{array}{c}\text { Highest } \\
\text { period }\end{array}$ & Category & $\begin{array}{c}\text { Overall } \\
\text { rank }\end{array}$ & $\begin{array}{c}\text { Highest } \\
\text { period }\end{array}$ \\
\hline \multirow{5}{*}{ 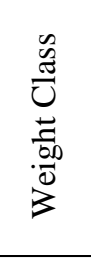 } & Wt1: $0.0-0.49 \mathrm{mg}$ & 3 & $\mathrm{p} 2$ & $\mathrm{Wt} 1: 0.0-0.49 \mathrm{mg}$ & 1 & $\mathrm{p} 2$ \\
\hline & Wt2: $0.5-0.99 \mathrm{mg}$ & 4 & p3 & Wt2: $0.5-0.99 \mathrm{mg}$ & 4 & $\mathrm{p} 2$ \\
\hline & $\mathrm{Wt} 3: 1.0-2.9 \mathrm{mg}$ & 1 & p1 & Wt3: $1.0-2.9 \mathrm{mg}$ & 2 & p2 \\
\hline & $\mathrm{Wt} 4: 3.0-4.9 \mathrm{mg}$ & 5 & p3 & $\mathrm{Wt} 4: 3.0-4.9 \mathrm{mg}$ & 5 & p3 \\
\hline & Wt5: $5.0+\mathrm{mg}$ & 2 & p3 & Wt5: $5.0+\mathrm{mg}$ & 3 & $\mathrm{p} 2$ \\
\hline \multirow{4}{*}{ 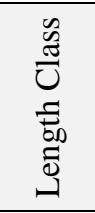 } & L1: $0.0-1.9 \mathrm{~mm}$ & 2 & $\mathrm{p} 2$ & $\mathrm{~L} 1: 0.0-1.9 \mathrm{~mm}$ & 1 & p2 \\
\hline & $\mathrm{L} 2: 2.0-4.9 \mathrm{~mm}$ & 1 & p3 & L2: $2.0-4.9 \mathrm{~mm}$ & 2 & p3 \\
\hline & L3: $5.0-9.9 \mathrm{~mm}$ & 2 & p3 & L3: $5.0-9.9 \mathrm{~mm}$ & 4 & p3 \\
\hline & L4: $10.0+\mathrm{mm}$ & 3 & p3 & L4: $10.0+\mathrm{mm}$ & 3 & p3 \\
\hline \multirow{4}{*}{$\begin{array}{l}\text { E } \\
0 \\
5 \\
0 \\
0 \\
0 \\
0\end{array}$} & Tree & 1 & $\mathrm{p} 1$ & Tree & 2 & $\mathrm{p} 1$ \\
\hline & Shrub & 4 & p3 & Shrub & 2 & p3 \\
\hline & Graminoid & 3 & p3 & Graminoid & 3 & p3 \\
\hline & Forb & 2 & p2 & Forb & 1 & p2 \\
\hline \multirow{5}{*}{ 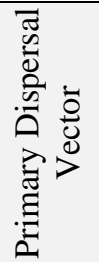 } & Animal & 4 & $\mathrm{p} 2$ & Animal & 4 & p2 \\
\hline & Ballistic & 2 & p2 & Ballistic & 1 & p2 \\
\hline & None & 3 & $\mathrm{p} 2$ & None & 3 & $\mathrm{p} 2$ \\
\hline & Water & 5 & p2 & Water & 5 & p2 \\
\hline & Wind & 1 & p3 & Wind & 2 & p3 \\
\hline \multirow{4}{*}{ 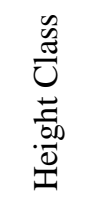 } & $\mathrm{H} 1: 0.0-0.99 \mathrm{~m}$ & 2 & $\mathrm{p} 2$ & $\mathrm{H} 1: 0.0-0.99 \mathrm{~m}$ & 1 & $\mathrm{p} 2$ \\
\hline & $\mathrm{H} 2: 1.0-4.99 \mathrm{~m}$ & 3 & p3 & $\mathrm{H} 2: 1.0-4.99 \mathrm{~m}$ & 3 & p3 \\
\hline & H3: $5.0-14.99 \mathrm{~m}$ & 4 & $\mathrm{p} 2$ & H3: $5.0-14.99 \mathrm{~m}$ & 4 & $\mathrm{p} 2$ \\
\hline & $\mathrm{H} 4: 15.0+\mathrm{m}$ & 1 & p3 & $\mathrm{H} 4: 15.0+\mathrm{m}$ & 2 & p3 \\
\hline \multirow{5}{*}{ 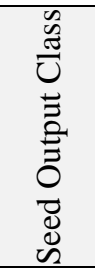 } & O1: 1-499 seeds & 3 & $\mathrm{p} 2$ & O1: 1-499 seeds & 1 & p2 \\
\hline & O2: $500-2,499$ seeds & 5 & p3 & O2: $500-2,499$ seeds & 4 & p3 \\
\hline & O3: 2,500-4,999 seeds & 2 & p3 & O3: 2,500-4,999 seeds & 3 & p3 \\
\hline & O4: 5,000-24,999 seeds & 4 & p3 & O4: $5,000-24,999$ seeds & 5 & p3 \\
\hline & O5: $25,000+$ seeds & 1 & $\mathrm{p} 1$ & O5: $25,000+$ seeds & 2 & $\mathrm{p} 1$ \\
\hline
\end{tabular}

Lower vs. upper turf traps: For both Whole and New seeds, there were no significant differences between upper and lower turf traps in total seed density or species richness across the entire study, or in any individual collection period. There were also 
no significant differences between upper and lower traps in deposition of seeds of different functional groups, for either Whole or New seeds.

Water-to-turf distance: There was no relationship found between distance from the water level to the lower edge of the turf trap, measured in either summer or winter, and total number of seeds in any collection period. Scatter plots suggested that there might be a relationship between distance and total deposition of Whole seeds in $\mathrm{p} 1$ and p4 (Appendix B), but linear mixed models showed that there was no significant effect of distance once differences attributable to study site were accounted (Table B.1).

\section{Differences Across the TIA Gradient: Deposition in Funnel Traps}

For Whole and New seeds, there was no relationship between TIA and total number of seeds deposited in funnel traps, in either near-stream funnels or forest interior funnels. There were also no relationships found between TIA and any functional groups of seeds deposited in funnel traps.

\section{Differences Across the TIA Gradient: Deposition in Turf Traps}

Total seeds collected: For Whole seeds in turf traps, seed density changed along the watershed TIA gradient. In p1 (January - March 2015), p2 (March - July 2015), and p4 (November 2015 - March 2016), there was a negative relationship between TIA and

mean seed density (Figure 3.29), though the relationship was only statistically significant in $\mathrm{p} 4\left(\mathrm{y}=-1.28 \mathrm{x}+70.11\right.$; adjusted $\left.\mathrm{R}^{2}=0.42 ; \mathrm{p}<0.05\right)$, as well as cumulatively across the entire study $\left(y=-2.87 x+191.95\right.$; adjusted $R^{2}=0.74 ; p<0.01$; Figure 3.30). 


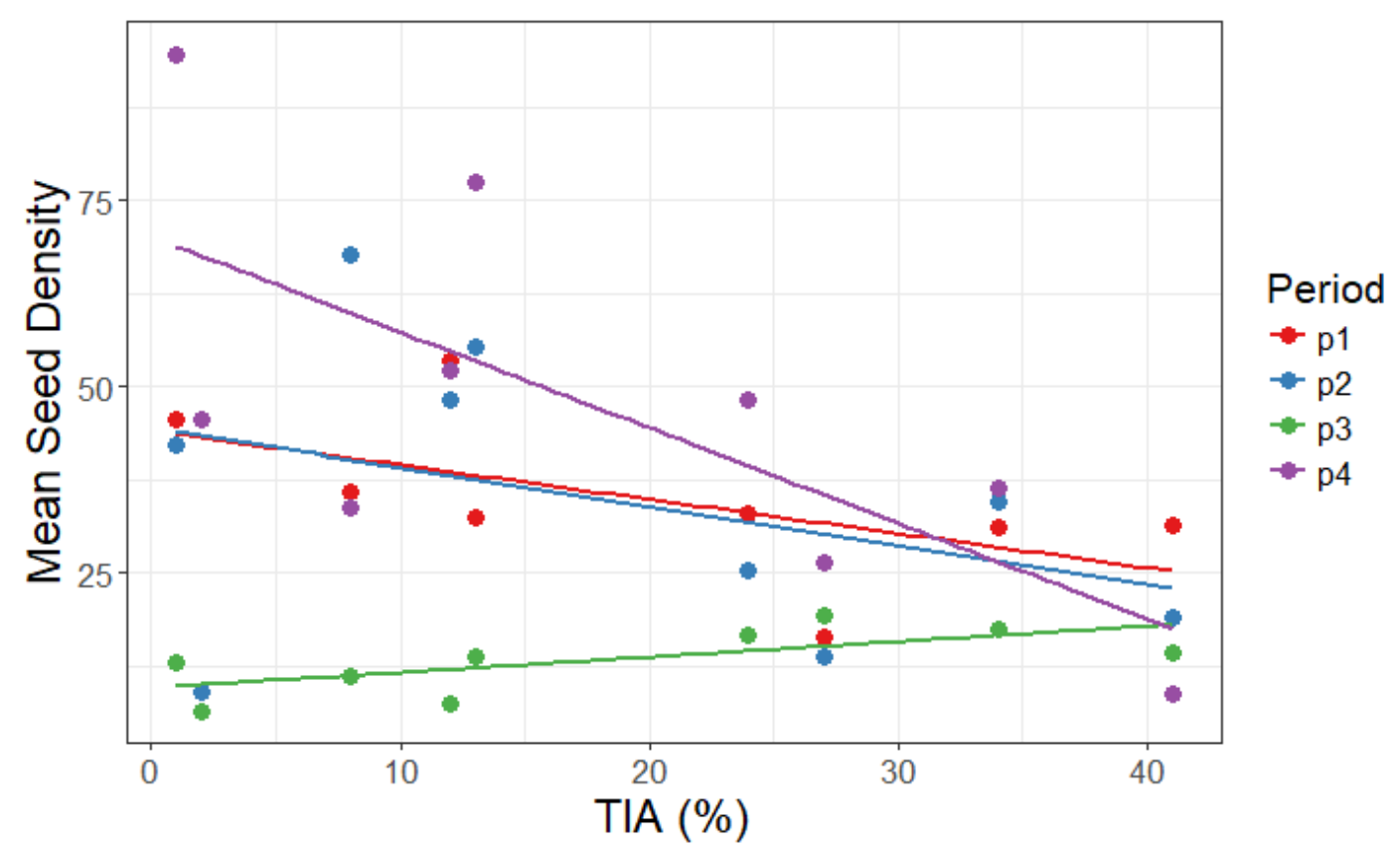

Figure 3.29: Mean Whole seed density in turf traps in four collection periods across the TIA gradient. For $\mathrm{p} 3$ and $\mathrm{p} 4$, there was a linear relationship between TIA and mean seed density that was significantly different from 0. P3: $\mathrm{y}=0.21 \mathrm{x}+9.57$; adjusted $\mathrm{R}^{2}=0.39 ; \mathrm{p}<0.05$. $\mathrm{P} 4: \mathrm{y}=-1.28 \mathrm{x}+70.11$; adjusted $\mathrm{R}^{2}=$ $0.42 ; \mathrm{p}<0.05$. P3 was the only collection period when seed density increased with TIA. In $\mathrm{p} 1$ and $\mathrm{p} 2$, the total number of seeds appears to decrease as in $\mathrm{p} 4$, but the relationship between TIA and mean seed density was not statistically significant for these time periods.

In $\mathrm{p} 1$, while there was no significant linear relationship between TIA and turf seed density, there was a nearly significant $(0.05<\mathrm{p}<0.1)$ difference between the four sites below 15\% TIA and the four sites above 15\% TIA in density of whole seeds. In p3 (July - November 2015), there was a significant and positive relationship between TIA and total seeds collected $\left(y=0.21 x+9.57\right.$; adjusted $R^{2}=0.39 ; p<0.05$; Figure 3.29). P3 was also the collection period with the fewest total seeds overall collected at seven of the nine study sites. Across the entire period of the study, p1 through p4, there was a significant negative relationship between TIA and the cumulative mean number of seeds caught per turf trap $\left(y=-2.87+191.95\right.$; adjusted $\mathrm{R}^{2}=0.74 ; \mathrm{p}<0.01$; Figure 3.30). For 
New seeds, there was no detectable relationship between TIA and total seed deposition in any of the four collection periods, or cumulatively across the study.

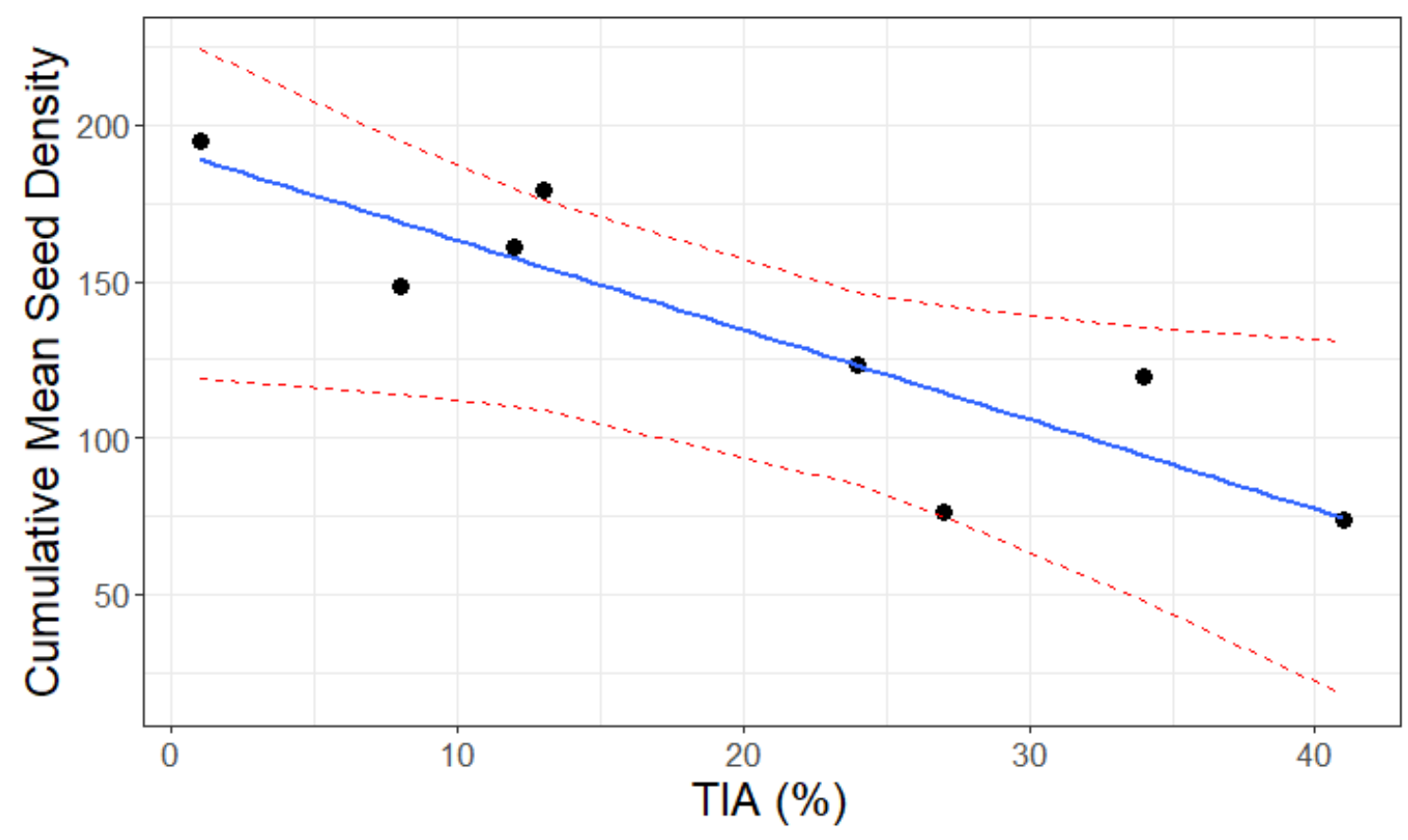

Figure 3.30: Cumulative Whole seed density in turf traps across the TIA gradient. $y=-2.87 x+$ 191.95; adjusted $\mathrm{R}^{2}=0.74 ; \mathrm{p}<0.01$. Dashed lines indicate the $95 \%$ confidence interval. Across all four collection periods, there was a significant decrease in cumulative mean number of seeds deposited as TIA increased.

Species Richness: For both Whole and New seeds, there was a general trend of increasing species richness with TIA in $\mathrm{p} 1$ through $\mathrm{p} 3$ and decreasing richness with increasing TIA in p4 (Whole seeds Figure 3.31). The relationship between TIA and mean trap richness was significant for both Whole and New seeds in $\mathrm{p} 3$ (Whole: adjusted $\mathrm{R}^{2}=0.89 ; \mathrm{p}<0.001$, New: adjusted $\left.\mathrm{R}^{2}=0.81 ; \mathrm{p}<0.001\right)$. Cumulatively across $\mathrm{p} 1$ to $\mathrm{p} 4$, there was no significant relationship between TIA and species richness. 


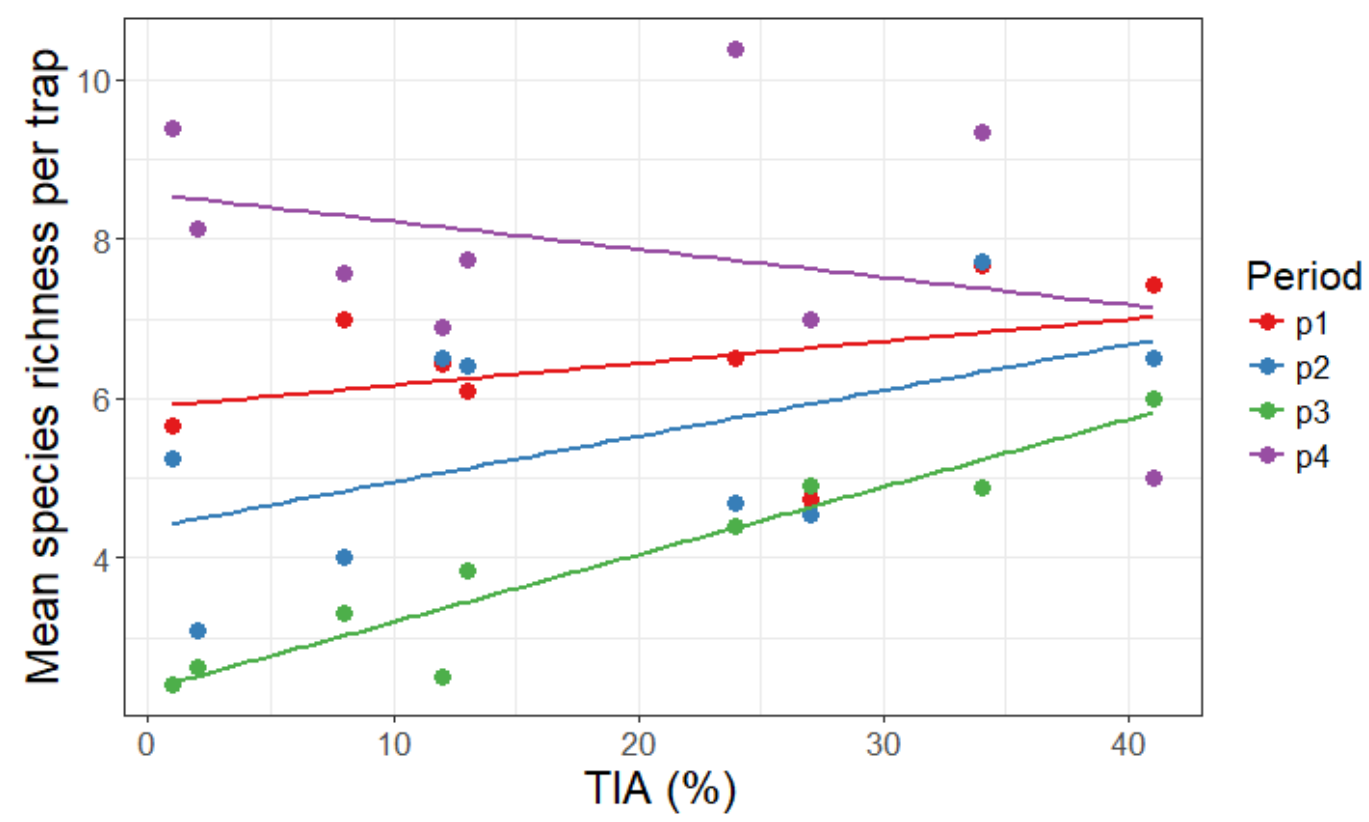

Figure 3.31: Mean species richness of Whole seeds in turf traps in four collection periods across the TIA gradient. In $\mathrm{p} 3$ there was a significant, positive relationship between TIA and mean trap species richness $\left(y=0.08 x+2.4\right.$; adjusted $\left.\mathrm{R}^{2}=0.89 ; \mathrm{p}<0.001\right)$. Richness also increased with TIA in $\mathrm{p} 1$ and $\mathrm{p} 2$, and decreased with TIA in $\mathrm{p} 4$, though the relationships in these collection periods were not statistically significant.

Rubus spp. seeds: For Whole seeds, the deposition pattern of Rubus spp. seeds in turf traps mirrored the pattern of total seed deposition (Figure 3.32). Similarly, in p4 there was a significant, negative relationship between TIA and number of Rubus spp. seeds collected $\left(y=6.83 x-0.11\right.$; adjusted $\left.R^{2}=0.60 ; p<0.01\right)$, after data were squareroot transformed to reduce heteroskedasticity. During $\mathrm{p} 1$, the relationship between TIA and Rubus spp. seeds was more of a threshold response, there was no significant linear relationship, between TIA and Rubus spp. density, but a Wilcoxon rank-sum test showed that there were significantly more Rubus spp. seeds in the four low TIA sites than the four high TIA sites $(\mathrm{p}<0.05$, Figure 3.33). For New seeds, there were no similar relationships between TIA and total Rubus spp. deposition. 


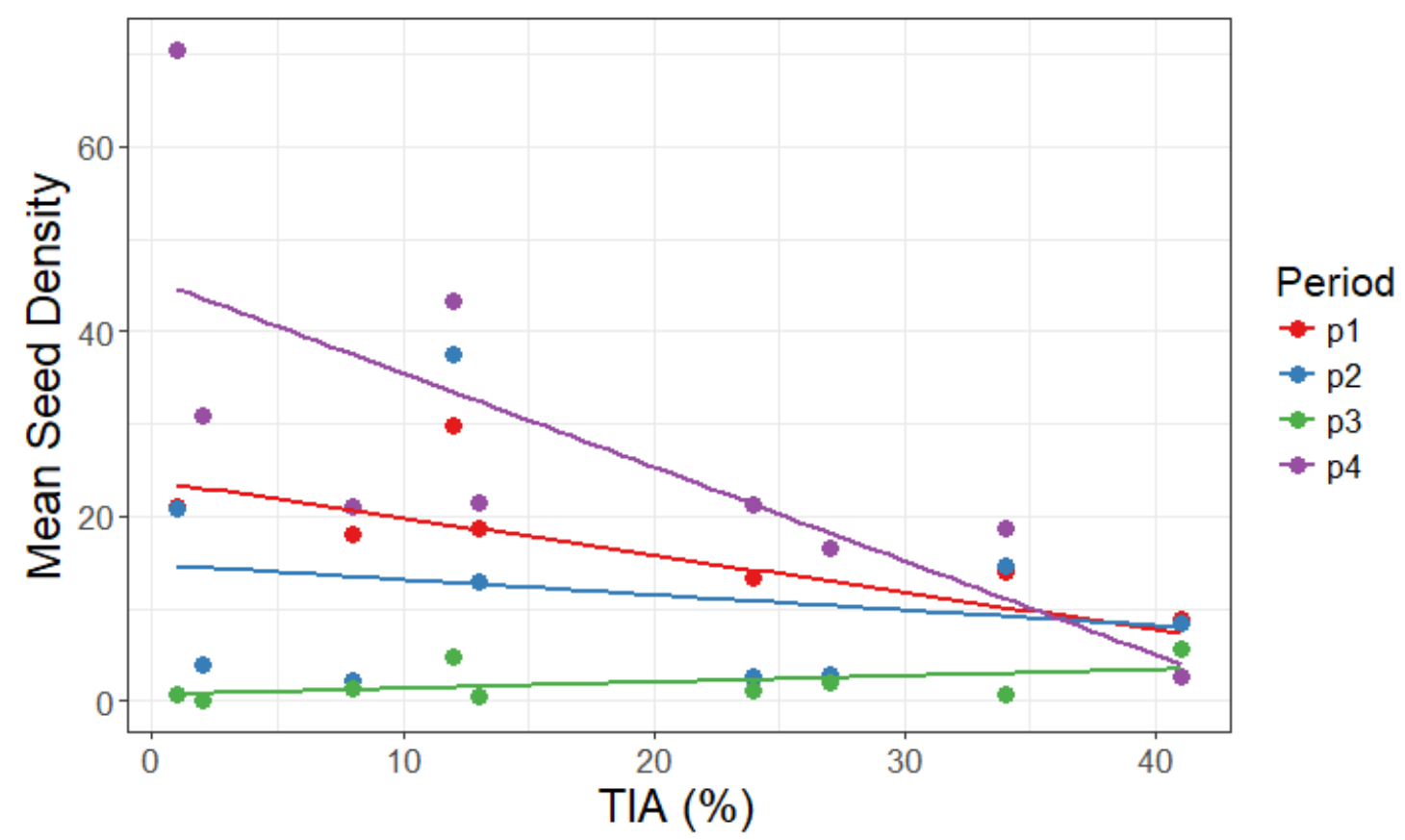

Figure 3.32: Density of Whole Rubus spp. seeds in turf traps in four collection periods across the TIA gradient. There was a significant, negative relationship between TIA and Rubus spp. seed density in turf traps during $\mathrm{p} 4$ after square root transformation: $\mathrm{y}=6.83 \mathrm{x}-0.11$; adjusted $\mathrm{R}^{2}=0.60 ; \mathrm{p}<0.01$.

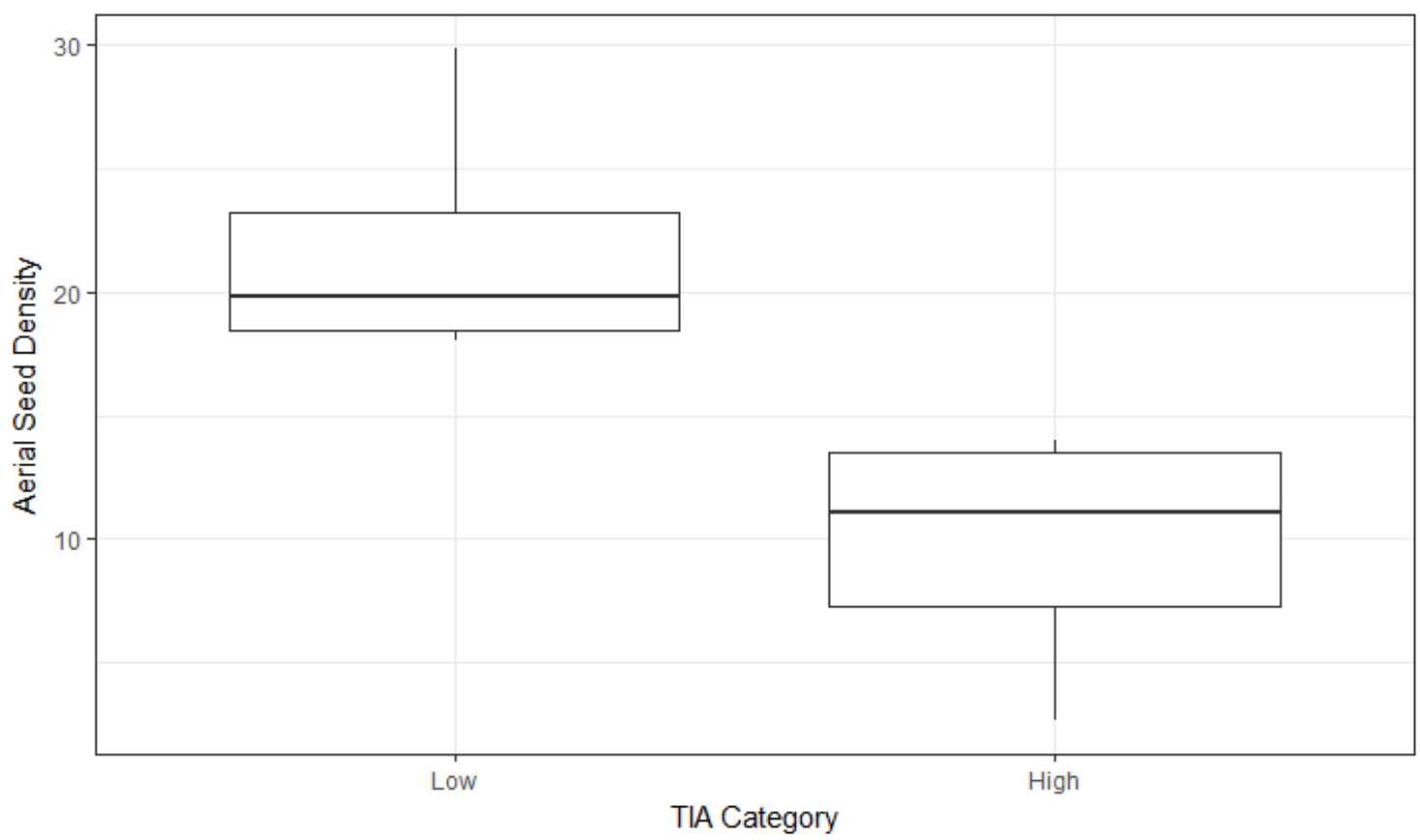

Figure 3.33: Whole Rubus spp. seeds per trap in the four high TIA and four low TIA sites during p1. There was a significantly higher density of Rubus spp. seeds in turf traps in the four sites below $15 \%$ TIA than the 4 sites above: $\mathrm{W}=16 ; \mathrm{p}<0.05$. 
Seeds Weight and Length Classes: There were no significant relationships found between watershed TIA and deposition of seeds of any weight or length class for New or Whole seeds, for any collection period or cumulatively across the study.

Dispersal Appendage: For Whole seeds, across all four study periods, there was a significant negative relationship between TIA and deposition of seeds with no dispersal appendage in turf traps $\left(y=-1.97 x+120.69\right.$; adjusted $\left.R^{2}=0.49 ; p<0.05\right)$. The No Appendage category contained the dominant Rubus spp., and the significant relationship was not maintained when Rubus spp. was removed from analysis. However, the relationship between TIA and cumulative Rubus spp. density alone over the entire study was also not quite statistically significant $(0.05<\mathrm{p}<0.1)$, indicating that Rubus spp. alone cannot entirely account for the significant relationship between TIA and seeds lacking a dispersal appendage. There was no significant relationship between TIA and deposition of seeds with a dispersal appendage for Whole seeds. For New seeds, there was no significant relationship between TIA and deposition of seeds with or without an appendage over all four collection periods.

Mature Plant Height and Seed Output Class: There was no significant relationship found between watershed TIA and turf trap density of taxa of different height classes, for either Whole or New seeds. For the lowest seed output classes, 1 and 2, as well as the highest, 5, there was no relationship between TIA and seed deposition in turf traps, for either Whole or New seeds. For output classes 3 and 4, there were relationships between TIA and seed density that were close to statistically significant $(0.05<\mathrm{p}<0.1)$. In p4 (November 2015 - March 2016), for both Whole and New seeds, the density of 
class 3 seeds in turf traps decreased as TIA increased. For Whole seeds, there was a nearly significant and positive relationship between TIA and class 4 seeds deposited during p3 (July - October 2015). In contrast, there was a nearly-significant and negative relationship between TIA and class 4 seeds deposited during p4 (Figure 3.34).

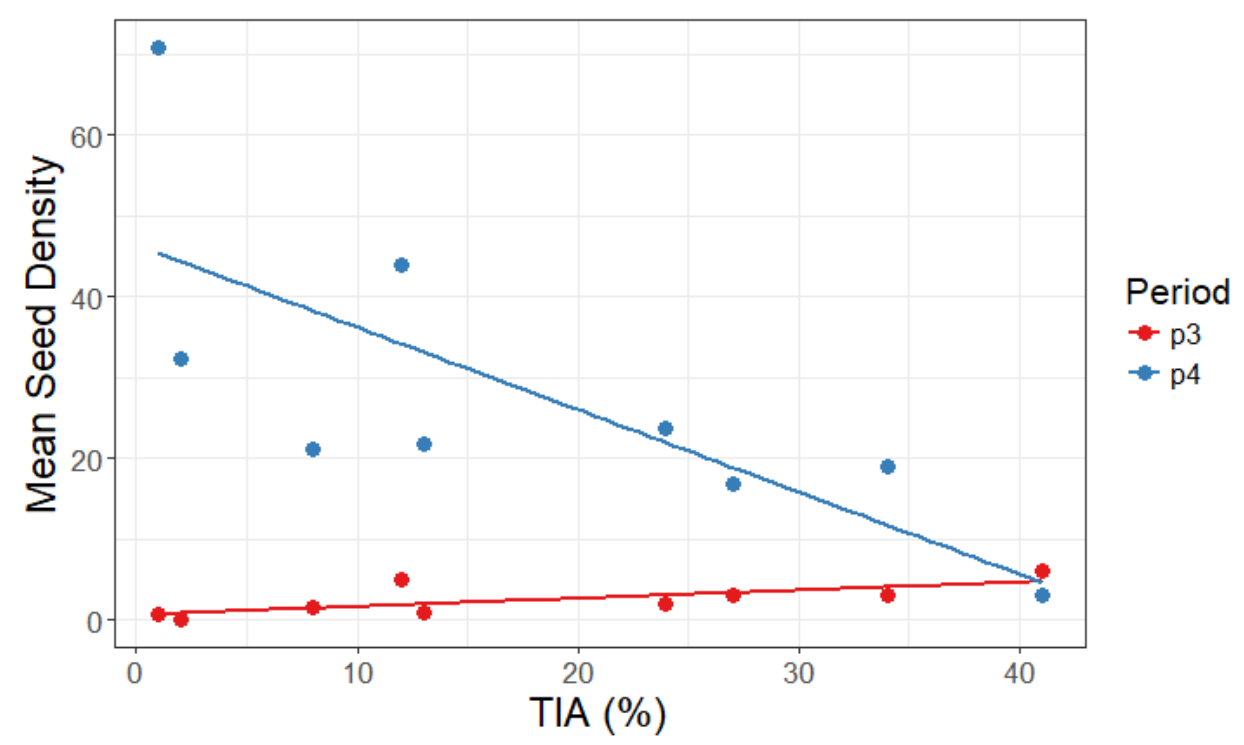

Figure 3.34: Mean Whole seed density of output class 4 seeds in turf traps during p3 and p4. During p3 there was a nearly-significant $(0.05<\mathrm{p}<0.1)$ positive relationship between TIA and density of output class 4 seeds. During p4, there was a nearly-significant negative relationship between TIA and density of output class 4 seeds.

Shade Tolerance: For both Whole seeds and New seeds, during p4 there was a negative relationship between TIA and deposition of shade-tolerant seeds that was nearly significant $(0.05<\mathrm{p}<0.1)$. For New seeds, there was a similar pattern during $\mathrm{p} 1$, as well as cumulatively across the entire study, but the relationship was also not statistically significant across these time periods. There was no relationship seen between TIA and deposition of shade-intolerant taxa, or of taxa with intermediate shade tolerance. 
Wetland Indicator Status: There were no significant relationships between TIA and density of seeds of any wetland indicator status, either for Whole or New seeds.

Species Origin: For native species, there was a significant relationship with TIA for New seeds in $\mathrm{p} 4$. In this period, deposition of native seeds decreased significantly as TIA increased $\left(\mathrm{y}=-0.11 \mathrm{x}+5.46\right.$; adjusted $\left.\mathrm{R}^{2}=0.55 ; \mathrm{p}<0.05\right)$. There were no significant relationships between TIA and native seed deposition for other collection periods or cumulatively across the study. For non-native species, there was a significant, positive relationship between TIA and seed density for New seeds during $\mathrm{p} 1$ and $\mathrm{p} 2$ (p1: $\mathrm{y}=0.12 \mathrm{x}+0.66 ;$ adjusted $\mathrm{R}^{2}=0.79 ; \mathrm{p}<0.01 ; \mathrm{p} 2: \mathrm{y}=0.10 \mathrm{x}+0.12 ;$ adjusted $\mathrm{R}^{2}=0.56 ; \mathrm{p}$ $<0.05$; Figure 3.35).

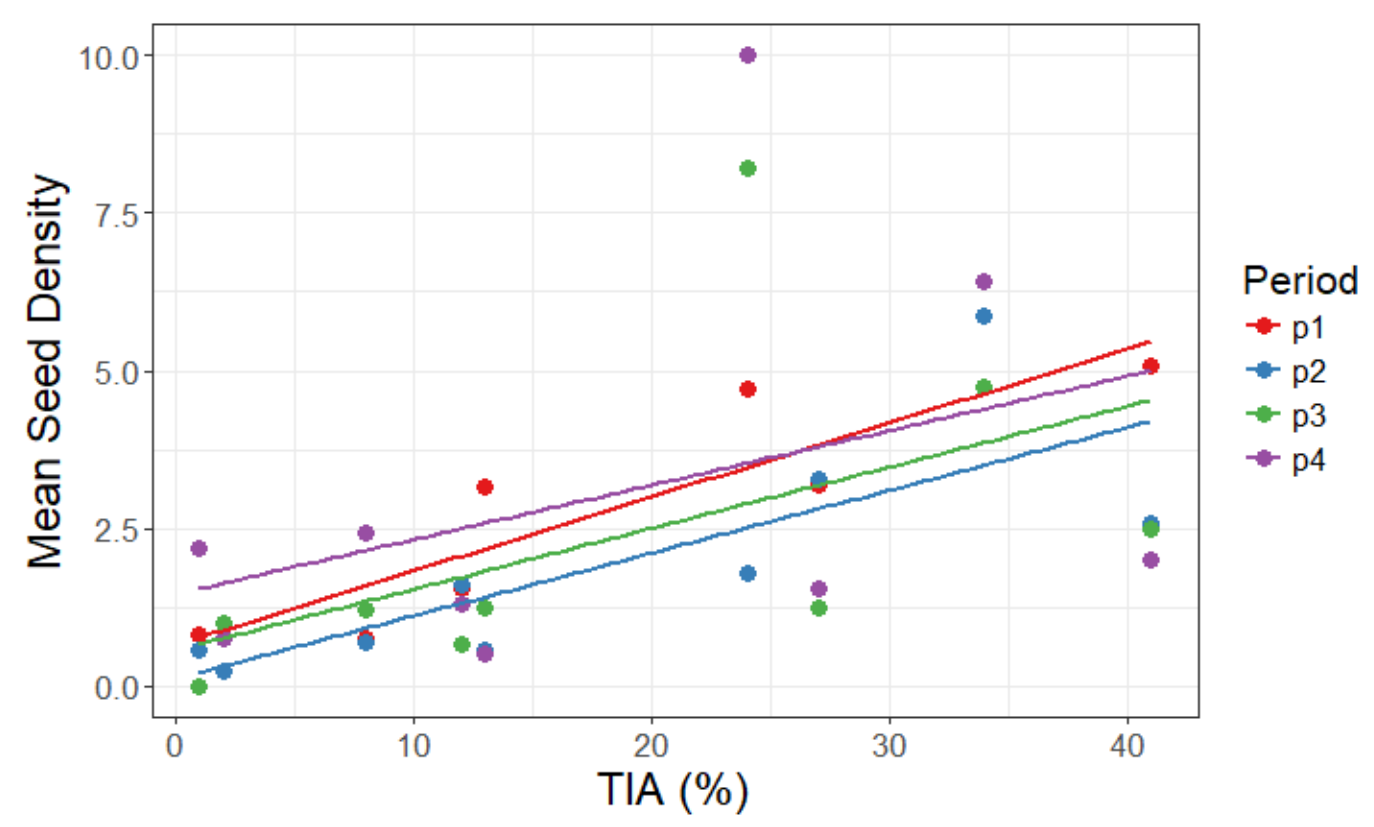

Figure 3.35: New non-native seeds in turf traps in four collection periods across the TIA gradient. During $\mathrm{p} 1$ and $\mathrm{p} 2$ there was a significant increase in density of non-native seeds in turf traps as TIA increased. $\mathrm{P} 1: \mathrm{y}=0.12 \mathrm{x}+0.66$; adjusted $\mathrm{R}^{2}=0.79 ; \mathrm{p}<0.01$. $\mathrm{P} 2: \mathrm{y}=0.1 \mathrm{x}+0.12$; adjusted $\mathrm{R}^{2}=0.62 ; \mathrm{p}<$ 0.05 . 


\section{NMDS Results}

Arrangement of sites and taxa: Ordinations using Whole seed data and New seed data produced very different arrangements of sites and taxa in ordination space. When Whole data were used (Figure 3.36), all eight study sites included were somewhat evenly distributed in ordination space, with no obvious grouping of sites. Seven taxa had higher density than overall mean per-taxon density, but there were no clear relationships between any of these taxa watershed TIA of study sites.

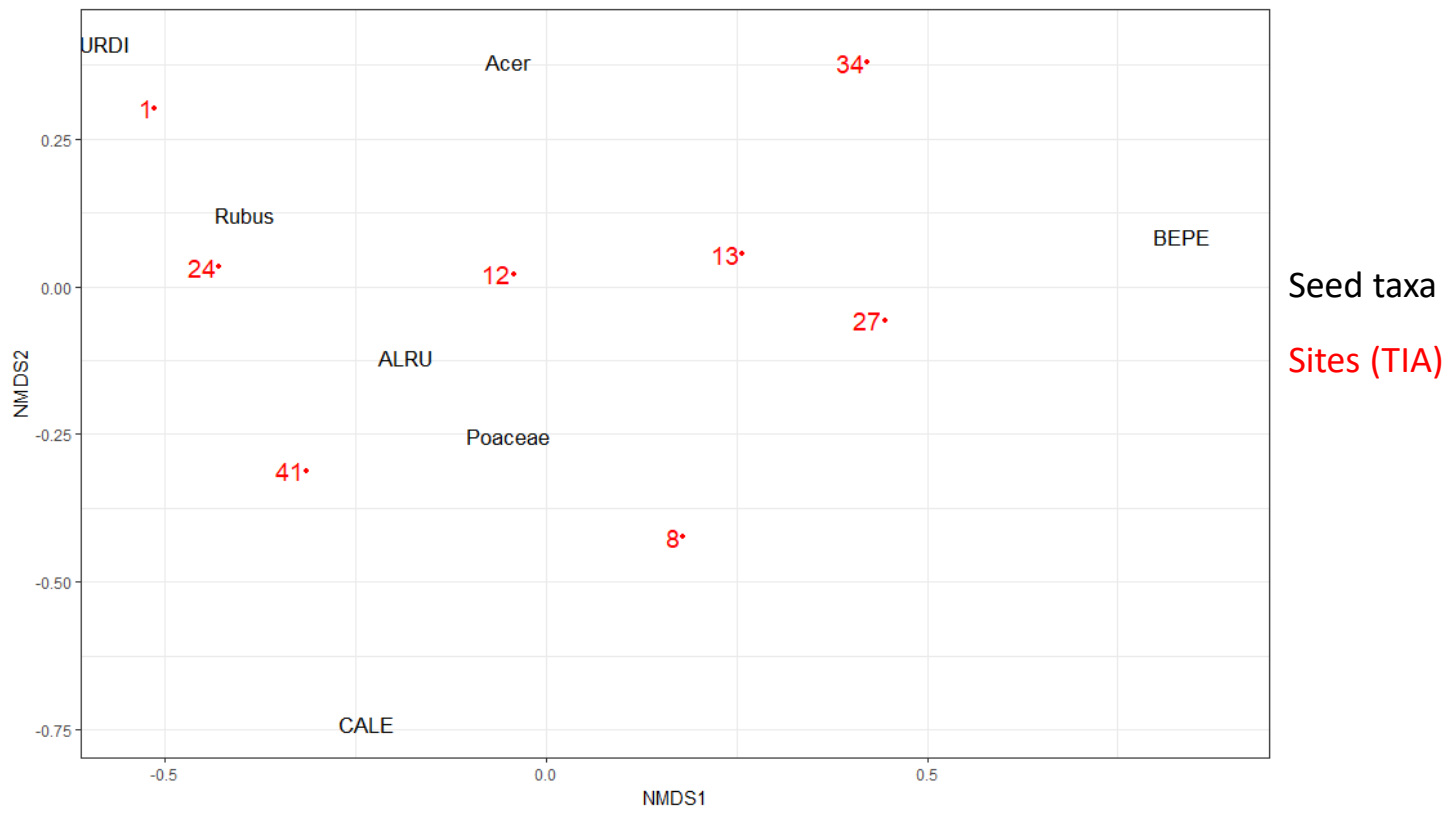

Figure 3.36: NMDS of sites based on composition of Whole taxa in turf traps, p1 through p4. NMDS stress $=0.06$. Sites are labeled with watershed TIA. Taxa shown are those with higher density across the study than the overall mean taxon density. There was no grouping of sites in ordination space, and no landscape variables were significantly associated with the ordination. Acer $=$ Acer spp., ALRU $=$ Alnus rubra, $\mathrm{BEPE}=$ Betula pendula, $\mathrm{CALE}=$ Carex leptopoda, Poaceae $=$ grasses, Rubus $=$ Rubus $\mathrm{spp}, \mathrm{URDI}=$ Urtica dioica.

When New data were used in the ordination, there were two pairs of sites that were mapped very close together in ordination space (Figure 3.37). The $27 \%$ and $41 \%$ sites (Jordan and FB) were very close to each other, as were the $1 \%$ and $12 \%$ sites (EBB and 
Pecan). Other sites were more evenly spaced. While the low- and high-TIA sites did not cluster together in ordination space, the four sites below 15\% TIA were all located at negative positions on the NMDS2 axis, and the four sites above $15 \%$ were at positive positions. Eleven taxa had higher trap density than the overall per-taxon density. Rubus spp., Scirpus microcarpus (small-fruited bulrush), Carex leptopoda (slender-foot sedge), and Urtica dioica (stinging nettle) were also mapped at negative positions on the NMDS 2 axis, near the four below 15\% TIA sites. Solanum dulcamara (climbing nightshade), Cardamine hirsuta (hairy bittercress), Betula pendula (European birch), and Polygonaceae were mapped closer to the four sites above 15\% TIA, at positive positions on the NMDS2 axis. The three graminoid taxa mapped in ordination space (Poaceae, Scirpus microcarpus, and Carex leptopoda) were each located in negative positions on both NMDS axes, closest to the 8\% (Clackamas), 13\% (Wilson), and 34\% (Metzger) TIA sites. There were no other similar groupings of taxa based on growth form, or other functional group. 


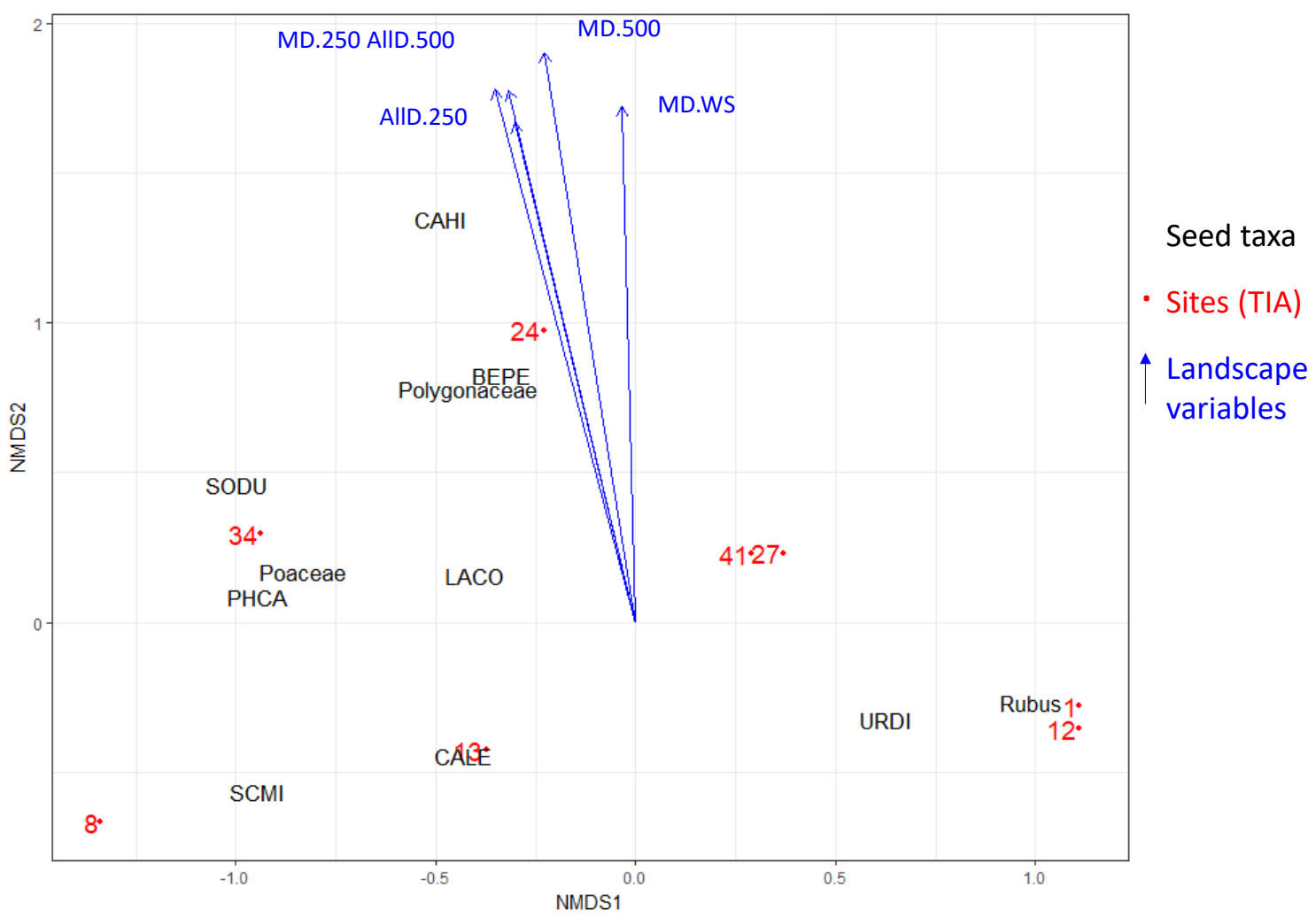

Figure 3.37: NMDS of sites based on composition of New taxa in turf traps, p1 through p4. NMDS stress $=0.03$. Sites are labeled with watershed TIA. Taxa shown are those with higher density across the study than the overall per taxon mean density. All sites below $15 \%$ watershed TIA were mapped at negative positions on the NMDS2 axis, and all sites above 15\% TIA mapped at positive positions on this axis. There were five landscape variables significantly associated with the ordination $(\mathrm{p}<0.05)$ : mediumdensity development (250m), all development (250m), medium-density development (500m), all development $(500 \mathrm{~m})$, and medium-density development (watershed). BEPE $=$ Betula pendula, $\mathrm{CAHI}=$ Cardamine hirsuta, CALE = Carex leptopoda, $\mathrm{LACO}=$ Lapsana communis, $\mathrm{PHCA}=$ Physocarpus capitatus, Poaceae $=$ grasses, Polygonaceae $=$ buckwheat family species, Rubus = Rubus spp., SCMI = Scirpus microcarpus, URDI = Urtica dioica.

Landscape Variables: No landscape variables were found to be significantly associated with the ordination of sites when Whole seed data were used. In contrast, five development variables were significantly associated with the ordination of sites when New data were used $(\mathrm{p}<0.05)$, indicating a relationship with vegetation composition in the study sites: medium-density development and all development within a $250 \mathrm{~m}$ cone, medium-density development and all development within a 500m cone, and medium- 
density development within the entire watershed. The mapped landscape vectors show a positive relationship with the non-native species included, and a negative relationship with the native taxa. No landscape variables related to forest cover, or other types of vegetation cover, were found to be significantly associated with the ordination.

Landscape variables as predictors of functional group deposition: The five significant landscape variables identified through ordination and vector fitting were highly correlated with each other (correlation coefficient 0.79 and higher). All development within a 500m cone had the highest correlation with other development variables, so it was selected for further analysis with seed deposition data. Unlike watershed TIA, there was no relationship found between total seed density in turf traps and all development within a 500m cone, for either Whole or New seeds. For functional groups that had no relationship with watershed TIA, there was also no relationship found with all development within a 500m cone. For some functional groups with deposition partially explained by TIA, all development within a 500m cone provided additional explanation.

For New non-native seeds, there was a strong relationship between TIA and turf seed density in $\mathrm{p} 1$ and $\mathrm{p} 2$ ( $\mathrm{p}<0.05$; Figure 3.23), but there was no significant relationship between TIA and cumulative density of non-native seeds. In contrast, there was a significant, positive relationship between all development within a 500m cone and cumulative density of non-native seeds in turf traps $\left(y=16.47 x+4.23\right.$; adjusted $R^{2}=$ $0.47 ; \mathrm{p}<0.05)$ 
For New shade-tolerant taxa, there was a nearly-significant relationship with TIA during $\mathrm{p} 4$. During this period there was a significant, negative relationship between all development within 500m and density of New shade-tolerant taxa in turf traps $(y=-1.3 x$ +2.6 ; adjusted $\left.\mathrm{R}^{2}=0.55 ; \mathrm{p}<0.05\right)$. There was also a significant relationship between all development within a 500m cone and deposition of New shade-tolerant taxa across the entire study when seed deposition was log-transformed ( $\mathrm{p}<0.05$; Figure 3.38).

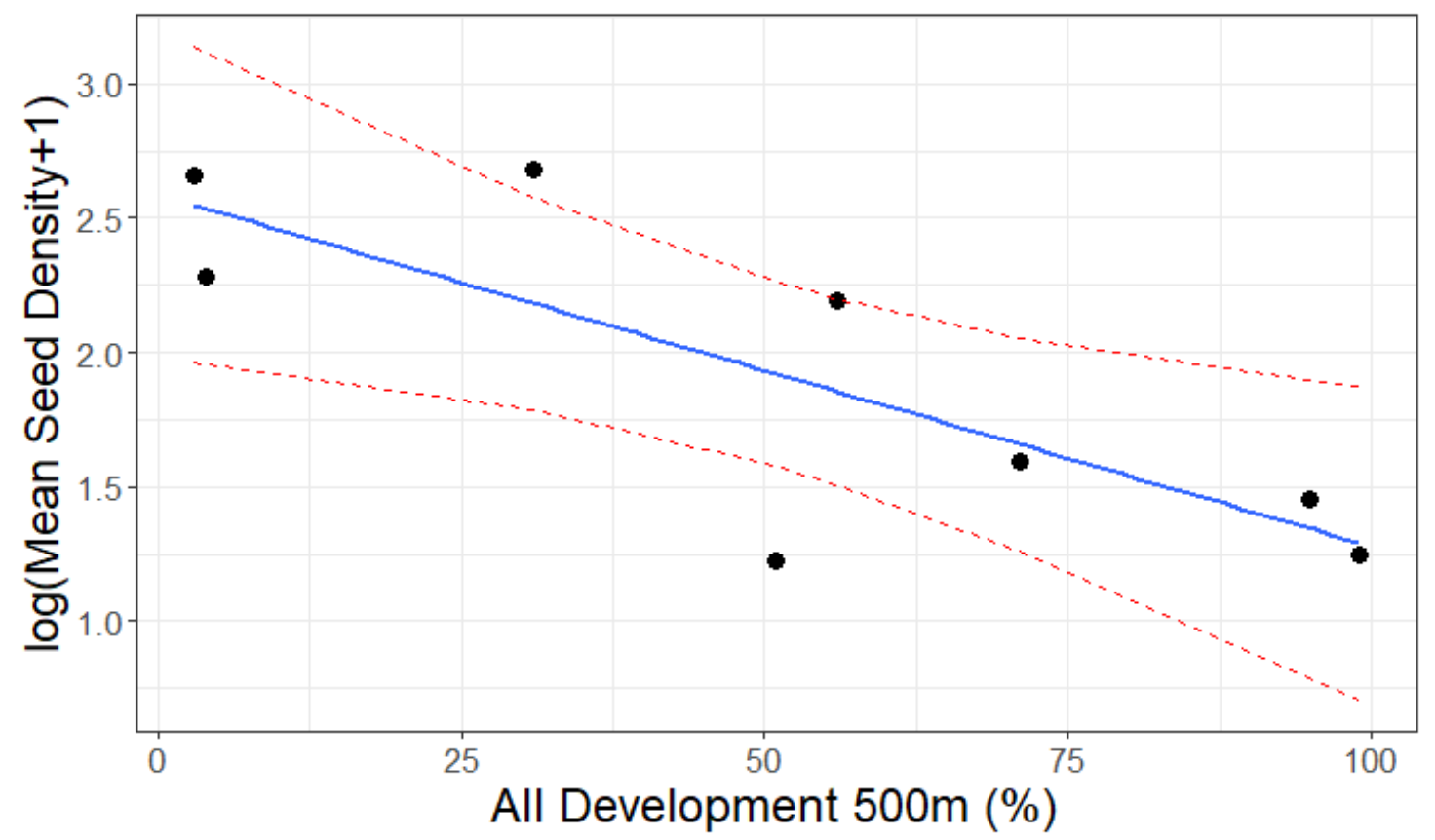

Figure 3.38: Cumulative mean density of New shade-tolerant taxa in turf traps along a gradient of development within a 500m cone, on a log scale. $y=-1.3 x+2.6$; adjusted $R^{2}=0.57 ; p<0.05$. Dashed lines indicate $95 \%$ confidence interval. Density of New shade-tolerant taxa decreased in turf traps as development within $500 \mathrm{~m}$ increased. 


\section{Discussion}

TIA, Land Use Patterns, and Hydrology

Results demonstrate, consistently with findings from other studies (e.g. Arnold and Gibbons 1996; Morse et al. 2003; Chadwick et al. 2006), that stream hydrology changed with watershed TIA. Hydrographs showed an evident increase in stream flashiness as watershed TIA increased (Figure 3.5). Results also indicate other landscape factors measured at finer scales contributed to stream hydrology responses. Factors were present both at the near-stream and whole-watershed scales. For example, although the very flashiest stream in this study did not have the highest watershed TIA, it had the highest overall development cover within a 250m cone. For the study of seed dispersal patterns, watershed TIA is not a sufficient metric to provide explanations on the mechanisms of deposition at the microsite scale.

Seed Deposition by Different Vectors in Urban Riparian Areas

Results support my first hypothesis, that more seeds overall would be deposited in riparian areas by streams than by wind and gravity. This finding is consistent with the results of other studies (e.g. Jansson et al. 2005; Hérault and Honnay 2005; Moggridge and Gurnell 2010), but to my knowledge this is the first time that this pattern has been demonstrated across a broad urban region. It is not surprising that the highest deposition of seeds by streams occurred during high-water periods, particularly p1 (January - March 2015) and p4 (November 2015 - March 2016). Other dispersal studies in regions with high winter rainfall have also found winter to be the most important season for dispersal 
by hydrochory (e.g. Moggridge and Gurnell 2010; Fraaije et al. 2017). The periods p2 (March - July 2015) and p3 (July - November 2015) were the most important times for wind dispersal, consistent with the fruiting times of most taxa encountered.

Results suggest that hydrochory primarily works to increase the deposition of seeds of species with certain plant and seed traits in forested urban riparian areas. For any of these species that are dispersal-limited by wind or animal vectors due to urban forest fragmentation, connection by streams may help overcome dispersal limitation. The significantly higher density of weight class 1 through 4 seeds (New seeds; $\mathrm{p}<0.05$ ) and length class 1 through 3 seeds (Whole seeds, $\mathrm{p}<0.05$ ) in turf traps than in funnel traps suggests that hydrochory increases delivery of small- to mid-sized seeds to urban riparian areas. In contrast, the lack of a significant difference between turf and funnel traps in density of the largest weight or length classes, for both Whole and New seeds, suggests that hydrochory does not increase seed deposition for large seeds over aerial vectors. This finding is somewhat surprising, as others have reported that large seeds and other particles are more readily deposited on stream banks than smaller particles (Gurnell et al. 2007; Samuel and Kowarik 2013). It is likely that the lack of a difference between turf and funnel traps in density of large seeds reflects particularly effective deposition of these species by wind, as opposed to ineffective deposition by water. Acer spp. (maple) was in the highest weight and length categories, and was prominent in funnel traps. Other winddispersed tree seeds were in these categories, including Pseudotsuga menziesii (Douglas fir) and Tsuga heterphylla (Western hemlock). Even in urban areas, these species are 
common, produce many seeds that are effectively dispersed by wind, and are not likely to be dispersal-limited in riparian forests.

The prevalence of shrub seeds and animal-dispersed seeds in turf traps, as well as their small numbers in funnel traps, suggests that hydrochory plays an important role in the seed ecology of these taxa in urban riparian areas. As seed traps were not placed in targeted locations to sample seed deposition by birds and other animals, results do not conclusively indicate whether these species are limited in dispersal by animals; however, other studies have found animal-dispersed species to be seed limited in urban areas (e.g. McEuen and Curran 2004; Alados et al. 2010). The very high density of seeds from these taxa in turf traps does suggest that hydrochory may allow these species to overcome dispersal limitation in areas where it does exist due to habitat fragmentation. Hydrochory appears to be particularly important for dispersal of Rubus spp. (raspberry/blackberry), which made up a majority of shrub seeds caught in all sites. As Rubus spp. are known to spread prolifically through vegetative means (Bonner et al. 2008), it is unclear what role seed deposition by streams may play in the population dynamics of established patches. Hydrochory could be an important vector for colonization of new patches by Rubus spp. and other riparian shrubs.

In contrast to Cadenasso and Pickett (2001) and Takahashi and Kaminati (2004), there was no evidence in this study that wind-dispersed species are dispersal-limited in urban riparian forests. There were no significant differences found between turf and funnel traps in density of wind-dispersed seeds. In funnel traps, wind dispersed seeds had the highest density of any dispersal group. This finding supports the conclusions of 
McEuen and Curran (2004) and Lin et al. (2006) that wind-dispersed species can be effective colonizers of forest patches.

Not surprisingly, results suggest that species that are primarily water-dispersed are dispersal-limited by aerial vectors. There were very few water-dispersed seeds found overall in funnel traps, and a significantly greater density of these taxa in turf traps ( $<$ < $0.05)$. Given that many of the graminoid species observed in this study are primarily water-dispersed, including Carex species (sedges), Scirpus microcarpus (small-fruited bulrush), and Leersia oryzoides (rice cutgrass), it is also not surprising that there was a significantly higher density of graminoid seeds in turf traps than in funnel traps.

Consistent with findings of other studies (e.g. Muller-Landau et al. 2008; Thomson et al. 2011), results suggest that short plants are dispersal-limited in riparian forest patches compared to taller plants. In funnel traps, there was significantly higher New seed density of height class 4 seeds $(15+\mathrm{m})$ than height class 2 or 3 seeds. It is interesting that there was no significant difference between density of class 4 and class 1 $(0-0.99 \mathrm{~m})$ seeds. The mean density of class 1 seeds, however, was driven by a very high density of Tellima grandiflora (fringecup) in a single trap during p3, and of Claytonia spp. (springbeauty) in three traps during p2. Both these taxa, while not recorded in the $1 \mathrm{~m}^{2}$ centered around those traps, had high cover across the site where these traps were located. It is likely that had a broader vegetation survey area been used to exclude taxa from the New seed dataset, a difference between seed densities of height classes 1 and 4 may have been observed in funnel traps. 
Results also suggest that in urban riparian areas, hydrochory can help shorter plants to overcome dispersal limitation experienced by aerial dispersal vectors. For height classes 1,2, and 3 (all taxa below 15m tall), there were significantly more seeds found in turf traps than in funnel traps $(\mathrm{p}<0.05)$. There were no significant differences between densities in turf and funnel traps only for the tallest species, in height class 4 .

It is somewhat surprising that in funnel traps there few differences among densities of seeds with different output classes (number of seeds produced per individual plant). Others have suggested that dispersal limitation decreases for a species as number of seeds produced per individual increases (e.g. Nathan and Muller-Landau 2000). Results do suggest, however, that for species with low seed output, hydrochory can increase deposition in urban riparian areas. For output classes 1 through 4 (fewer than 25,000 seeds produced per individual), there was a significantly higher seed density in turf traps than in funnel traps $(\mathrm{p}<0.05)$. This result suggests that in situations where low seed-producing species are seed-limited, hydrochory may be able to help overcome that limitation.

Given the relationships between stream bank elevation and seed deposition seen in other studies, it is surprising that there were not differences found between lower and upper turf traps in terms of overall seed density or classes of seeds. Fraaije et al. (2017) found a gradual decrease in the number of seeds deposited by the stream as bank elevation increased, and Gurnell et al. (2008) found changes in species composition along an elevational gradient. The lack of a difference between upper and lower traps suggests that for these small headwater streams, most seed deposition occurred during high flows 
that inundated both upper and lower traps. It is also possible that lower traps were inundated more frequently than upper traps, but scouring flows removed any additional seeds that were deposited, over what was deposited in upper traps. Merritt and Wohl (2002) found that in storm events, seeds were scoured from stream banks during the ascending limb of the hydrograph and deposited during the descending limb. It is possible that in this study, a balance of scouring and depositing flows left lower seed traps with similar numbers of seeds as upper traps, even if they were more frequently inundated.

For some of the taxa found to be deposited effectively by water, hydrochory may be an important mechanism of long-distance dispersal. Some taxa, including Carex stipata (awl-fruit sedge) and Scirpus microcarpus, were found only in turf traps. The absence of these species in the standing vegetation surveyed at these sites suggests that they may have travelled from upstream of the study sites. While they were not found in the standing vegetation at any study site, both these species are common regionally (Christy et al. 2009), and readily dispersed by water, so their presence in turf traps in multiple sites is not surprising.

For a majority of taxa found to be deposited by water, hydrochory likely serves as means of redistribution of seeds within a small area, as well as a potential vector for longdistance dispersal. The large density of Whole seeds in traps compared to the density of New seeds suggests that most seeds traveled to traps from nearby sources. This finding concurs with Boedeltje et al. (2003), who found that occurrence in the local species pool was a significant predictor of presence of seeds in their in-stream seed traps. This 
redistribution by the stream could serve as a means of evening out the distribution of seeds across a landscape, as well as increasing the availability of different microhabitats for certain species. For example, New height class 1 seeds were very patchy in funnels, found in only $9 \%$ of traps, but they were in $44 \%$ of turf traps (twice as many turf traps as funnel traps), illustrating the capacity of streams to spread seeds over a wider range than wind and gravity may do alone, even if they are not new species introductions for the site.

Overall, with the high density of seeds and large number of distinct taxa found in turf traps compared to funnel traps, as well as the detection of some taxa in turf traps that were potentially new introductions to the entire site, results suggest that even across an urban landscape, streams can increase the connectivity of vegetation patches. Seed deposition appears to be increased by hydrochory more for some functional groups than for others. For taxa with small- to mid-sized seeds, shrub species, taxa with primary dispersal by animals or water, and species below $15 \mathrm{~m}$ at maturity hydrochory appears to substantially increase seed delivery over aerial vectors.

\section{Changes in Seed Deposition by Hydrochory Across an Urban Gradient}

Results provided strong support for my second hypothesis, that the total number of seeds deposited by streams would decrease as urbanization increased. There was a strong relationship between TIA and cumulative Whole seed density in turf traps (adjusted $\mathrm{R}^{2}=0.74 ; \mathrm{p}<0.05$; Figure 3.21 ). The relationship between TIA and deposition varied across collection periods, and in p3 (July - November 2015) seed density increased significantly with TIA (adjusted $\mathrm{R}^{2}=0.39 ; \mathrm{p}<0.05$ ). It is important to note, 
however, that $\mathrm{p} 3$ had significantly lower overall deposition by streams than all other collection periods $(\mathrm{p}<0.05)$. It is interesting that the one individual season where there was a significant negative linear relationship between watershed TIA and turf seed density (adjusted $\mathrm{R}^{2}=0.42 ; \mathrm{p}<0.05$ ) was the winter season with heavy storms and the highest stream flows (p4; November 2015 - March 2016). During p1 (January - March 2015), there appeared to be a more of a threshold response, where in sites above $15 \%$ TIA there was reduced seed deposition. However, the difference between the low and high TIA sites was not statistically significant. Together, these results indicate that the relationship between TIA and seed deposition by streams is not constant, but suggest that riparian sites with high watershed TIA are likely to have lower seed deposition from hydrochory, at least in some winter seasons, than riparian sites with lower watershed TIA.

Beyond changes in total number of seeds, I hypothesized that changes in stream morphology and hydrology across the TIA gradient would result in shifts in the types of species deposited in riparian areas. While TIA and other watershed land use features appear to affect the total number of seeds deposited in a riparian area, there was little evidence that seeds are differentially affected in their delivery based on seed size. For Whole seeds, there was a negative relationship between TIA and deposition of seeds with no dispersal appendage $(\mathrm{p}<0.05)$, suggesting that an appendage could assist with deposition, although the pattern did not hold for New taxa. I expected small seeds to become more limited as TIA increased, but there was no evidence to support this hypothesis. It is possible that a study on the interactions of hydrology and seed size and 
morphology, involving more intense sampling at the site level, would be able to identify taxa and seed morphologies whose deposition patterns are affected by urban hydrological changes. It is also possible that, while altered urban hydrology affects seed deposition in general, as illustrated by the decline in deposition of total Whole seeds along the TIA gradient, hydrological change does not lead to seed sorting based on seed size and morphology. In a flume study, Chambert and James (2009) found that seed travel patterns were affected by hydrological changes induced from morphological alterations to the channel. As with the present study, however, they found that different types of seeds were not differentially affected by these changes; all taxa studied responded in similar ways to the hydrological changes. Their study only considered seed travel patterns however, not deposition, which can provide a separate opportunity for seed sorting. There was similarly little evidence from this study to suggest that dispersal by hydrochory of taxa with different mature heights or seed production rates are differentially affected by watershed development.

While there was little evidence that plant traits related to deposition by streams or to long-distance dispersal are differentially affected by watershed TIA, there were relationships found between watershed TIA and species origin and between watershed TIA and shade tolerance. The reduction in native seeds, and possibly of shade-tolerant taxa as TIA increases (Whole seeds), as well as the increase in non-native seeds (New seeds), likely reflects the prominence of these species in source pools of the different watersheds, rather than any difference in seed dispersal ability. It is well-established that non-native plants are associated with human development (Chapter 2; Cadenasso and 
Pickett 2001; Duguay et al. 2007). Shifts from shade-tolerant to shade-intolerant taxa with increasing urbanization have also been documented (Metzger 2000; Burton et al. 2009). It is not surprising that a reduction in shade tolerance and nativity in the seed rain would follow increased TIA, a general measure of urban development. Development at a finer scale than the entire watershed seems to be a more important driver of deposition of shade-tolerant taxa than watershed TIA, and is also strongly related to species origin. While the relationship between watershed TIA and density of shade-tolerant taxa was not quite statistically significant for either Whole or New species, all development within a $500 \mathrm{~m}$ cone was significantly related to New shade-tolerant seed density in p1, as well as to cumulative density across the entire study period $(\mathrm{p}<0.05)$. Other studies have linked a decrease in prevalence of shade tolerance to increasing forest fragmentation and loss of connectivity, and hypothesized that increased dispersal limitation is a mechanism for this transition (Metzger 2000; Burton et al. 2009). The finding of decreased deposition by streams of shade-tolerant species as development within a 500m cone increases provides support for this hypothesis for sites that receive seed delivery from streams.

It is somewhat surprising that there was no relationship found between deposition of seeds of any wetland indicator status and either watershed TIA or development within a 500m cone. Numerous studies have found a shift from wetland and riparian specialists to assemblages dominated by upland species in urban areas (e.g. Groffman et al. 2008; Burton and Samuelson 2008; Turner et al. 2015), although such a relationship was not found in Chapter 2. It may be that these previously reported findings of declines in wetland and riparian specialists reflect an inability of these species to tolerate altered 
hydrological conditions in urban areas, rather than dispersal limitation by wetland species, or rather than by an increase in propagule pressure by upland species in more urban watersheds.

It is interesting that there were several differences between Whole and New seed data in relationships with landscape variables. For total number of seeds and seeds with no dispersal appendage, there was a relationship between TIA and seed deposition for Whole seeds only, but not for New seeds. For species origin and shade-tolerance, there were relationships between all development within $500 \mathrm{~m}$ for New seeds, but not for Whole seeds. Additionally, the ordinations based on Whole and New seed data produced very different arrangements of sites in ordination space, and there were significant relationships between the ordination and landscape variables for New seed data, but not for Whole seed data. Together, these findings suggest that there are different drivers of deposition patterns for locally derived seeds and for new arrivals. For total numbers of seeds deposited, the relationship with TIA for Whole seeds primarily indicates that during winter high-flow events, additional seeds in low TIA sites were coming from local sources and not travelling long distances. For the most part, however, these seeds were not likely dropped directly from parent plants, as they were deposited in the largest numbers outside of the fruiting season (for Rubus spp. in particular). Rather, these seeds were likely present on the ground near the turf traps, having been initially deposited the previous spring and summer, and remobilized any number of times by rain events, animals, or wind. During large winter storms, these seeds on the ground could have been remobilized by stream overbank flows, and then deposited close by in the turf traps when 
water receded. Similarly, Gurnell et al. (2008) found that there were strong trends in winter deposition along an elevational gradient when all seeds collected were considered, but the trend was absent when only new seeds were used in analysis. They concluded that the pattern was generated by seeds that fell from plants in the standing vegetation in spring and summer, and then were remobilized and deposited in traps by high stream flows in the winter season (Gurnell et al. 2008). In this study, it is possible that, with higher peak flows in the high TIA sites, seeds near turf traps were picked up by overbank flows, with many were carried away from the riparian area by the stream instead of being immediately deposited again in turf traps. In contrast, for low TIA sites with lower peak flows, it would be more likely that seeds would remain deposited on or near turf traps than being carried away. This process could also explain the relationship between TIA and taxa with no dispersal appendage, as well as between TIA and Rubus spp. seeds, which, as with total seeds, existed for Whole but not New taxa. With higher peak flows picking up local seeds in high TIA sites, lack of a dispersal appendage could inhibit immediate deposition more than it does in low TIA sites where peak flows are not as high, making deposition more likely. There was no relationship between Rubus spp. cover in the standing vegetation and TIA that might explain the trend of more Rubus spp. seeds in lower TIA sites, suggesting that differences in turf density along the TIA gradient may have been related to differences in hydrology. While further study is needed to determine the exact mechanisms behind these relationships, the finding of lower total seed deposition in higher TIA sites, even if in only some winters, could have important implications for riparian restoration and management. 
To my knowledge, this is the first study to show that for urban riparian forests, urban streams may contribute significantly to seed delivery over what wind and gravity alone deposit. Additionally, this study has demonstrated some of the ways in which seed deposition by hydrochory in forested riparian areas may change as watershed urbanization increases. These findings could have important implications for urban riparian conservation and restoration. Overall, results suggest that both plant traits and characteristics of the surrounding landscape contribute to the likelihood of a seed being deposited in a forested riparian area in an urban region. Similarly, Brederveld et al. (2011) found that both plant traits related to seed dispersal and nearby source populations determined the presence of species in newly restored riparian areas. They concluded that for the passive restoration of fragmented stream segments to be successful, welldeveloped vegetation communities in the vicinity are crucial. Though in this study I did not quantify potential source populations near the study sites, results for native and shade-tolerant categories in the New seed data suggest that the presence of nearby source populations is likely an important predictor of deposition in downstream riparian areas. For understory species, in particular, increased watershed development is likely to lead to increased dispersal limitation, which will decrease the likelihood of a successful outcome from a passive approach to riparian forest restoration. In addition to vicinity of source populations, the differences in Whole seed and New seed deposition along the TIA gradient suggest that landscape factors could affect seed deposition patterns through hydrological mechanisms. Though further research will be necessary to fully understand these mechanisms, results of this study suggest that an overall reduction in seed 
deposition by streams can be expected to accompany an increase in watershed urban development. 


\section{Chapter 4: Conclusions and Management Implications}

With rapidly expanding urban development across the globe, the protection of riparian areas and their functions is more important than ever. The overall objective of this dissertation was to improve knowledge of how landscape-level features contribute to forested riparian vegetation patterns in regions with Mediterranean climate through their influence on seed dispersal dynamics. This knowledge is crucial for improving management practices to maintain the critical ecosystem functions performed by these communities. Moreover, this knowledge can improve the decisions about when to make use of passive restoration approaches.

A major finding in this dissertation is that diverse, native understory communities can persist in in urban riparian forests if at least $15 \%$ watershed forest cover is maintained. Several studies have reported a shift from shade-tolerant to shade-intolerant herbaceous species, as well as an increase in cover by shrub species as urbanization increases (e.g. Burton et al. 2009; Brice et al. 2016). Results of this study add significantly to the understanding of these patterns by demonstrating a potential threshold level of forest cover that allows for the persistence of these species. Even within an urban context, sufficiently forested watersheds may be able to provide refuges for understory plant species, as well as for other taxa that rely on understory habitats, such as amphibians.

Results of the dispersal study in this dissertation add significantly to the understanding of dispersal dynamics of vegetation in urban riparian forests. By 
characterizing seed deposition patterns along nine streams, this study allows for broader conclusions to be drawn about riparian dispersal patterns than has been possible from other similar studies, which have typically studied two to three streams (e.g. Merritt and Wohl 2002; Gurnell et al. 2008; Moggridge and Gurnell 2010; Fraaije et al. 2017). Results suggest that across urban regions, for some species with traits that make them likely to be dispersal-limited by wind and animal vectors, hydrochory may serve as a means for overcoming dispersal limitation. Others have suggested that species below $15 \mathrm{~m}$ in height, animal-dispersed species, and shrub species are likely to be limited in fragmented urban forest patches (Nathan and Muller-Landau 2000; McEuen and Curran 2004; Alados et al. 2010), and results from deposition in funnel traps in this study support those findings. Additionally, results indicate that for species with these traits, hydrochory may significantly increase seed delivery to riparian areas. Previous studies have shown that streams can connect otherwise fragmented plant populations by acting as seed dispersal vectors (Honnay et al. 2001, Merritt et al. 2010, Moggridge and Gurnell 2010, Nilsson et al. 2010, Fraaije et al. 2015), but to my knowledge this is the first study to demonstrate that the capabilities of streams to connect fragmented populations are maintained across an urban region.

This study also demonstrated that alteration of dispersal patterns is likely one mechanism through which urbanization alters forested riparian vegetation communities. Results suggest that an overall reduction in seed delivery by hydrochory can be expected to follow from an increase in urban development, which could potentially have major consequences for vegetation communities. Though further study will be needed to 
elucidate the precise mechanisms behind the relationship between urban development and seed deposition, results suggest that flashy urban hydrology plays a prominent role.

Findings from this work can also provide insight on the drivers of some commonly-reported changes to riparian vegetation communities with urbanization. For the frequently observed shifts from native- to non-native dominated communities (e.g. Cadenasso and Pickett 2001; Duguay et al. 2007), and from shade tolerance to increasing shade intolerance (e.g. Moffatt et al. 2009), findings suggest that dispersal dynamics may be an important driver. Development within the watershed, as well as development within $500 \mathrm{~m}$ of a riparian area likely decrease the availability of seeds of shade-tolerant species in the source pool, precluding their delivery to riparian forests. Simultaneously, these development factors likely increase non-native species in the source pool, increasing the availability of their seeds for deposition in riparian areas. For other commonly observed shifts in riparian vegetation communities, particularly flood tolerance (e.g. Groffman et al. 2003; Turner et al. 2015), results suggest that other mechanisms, besides dispersal, are the main drivers of change in urban areas. It is likely that these shifts are primarily due to altered hydrological regimes that make many urban riparian areas unsuitable habitats for these species, as suggested by Turner et al. (2015).

Results of these two studies suggest that the consideration of landscape context could provide important insight on appropriate management approaches for urban riparian forests. Though it has become increasingly clear that a "one size fits all" approach to restoration is not likely to be successful, these two studies provide further evidence of the importance of considering landscape context for conservation and 
restoration. Results suggest that within an urban setting, the persistence of riparian forests with diverse understory communities maintained by sufficient seed delivery is only likely to be possible in watersheds with sufficient forest cover (at least 15\%), and with low cover by urban development closer to the stream. Similarly, Dietrich (2012) found that high surrounding forest cover and low development cover were necessary for persistence of amphibian populations. Together, these findings suggest that for maintaining highly functional riparian areas, conservation of remaining urban forest cover should be a high priority.

Consideration of the landscape context could also help to determine the most appropriate restoration techniques for a given riparian site. Historically, a very passive approach has been taken for the restoration of forest understories. Trees and shrubs are routinely planted to increase shade and structural complexity at the beginning of a restoration project, but herbaceous understory species are often not actively introduced, but instead allowed to colonize a site on their own (Gilliam 2007). While sometimes effective, very often restoration goals are not met with this approach (Hilderbrand et al. 2005). Results from this work suggest that a passive approach to riparian understory restoration in urban areas only has the potential to be successful in locations with high forest cover and low development cover both within the entire watershed, and in the nearstream area. To effectively restore the understory in highly urban sites, these findings suggest that actively seeding or planting plugs may be necessary.

As the value of small streams and their riparian areas are increasingly realized, urban riparian conservation and restoration efforts continue to expand. Improved 
knowledge of the dynamics of riparian forest vegetation communities in the urban landscape will continue to make these efforts more effective. Incorporation of the information on relationships among vegetation, seed dispersal, and watershed cover patterns provided in these studies can help land managers to reach their conservation and restoration goals. 


\section{Literature Cited}

Alados, C.L., T. Navarro, B. Komac, V. Pascual., and M. Rietkerk. 2010. Dispersal abilities and spatial patterns in fragmented landscapes. Biological Journal of the Linnean Society 100:935-947.

Allan, J.D. 2004. Landscapes and riverscapes: The influence of land use on stream ecosystems. Annual Review of Ecology, Evolution, and Systematics 35:257-284.

Allan. J.D., D. Erickson and J. Fay. 1997. The influence of catchment land use on stream integrity across multiple spatial scales. Freshwater Biology 37:149-161.

Angiolini, C, A. Nucci, F. Frignani and M. Landi. 2011. Using multivariate analyses to assess effects of fluvial type on plant species distribution in a Mediterranean river. Wetlands 31:167-177.

Arnold, C.L. and C.J. Gibbons. 1996. Impervious surface coverage: the emergence of a key environmental indicator. Journal of the American Planning Association 62:243-258.

Baker, M.E. and M.J. Wiley. 2009. Multiscale control of flooding and riparian forest composition in lower Michigan, U.S.A. Ecology 90:145-159.

Banville, M.J. and H.L. Bateman. 2012. Urban and wildland herpetofauna communities and riparian microhabitats along the Salt River, Arizona. Urban Ecosystems 15:473-488.

Benda, L., M.A. Hassan, M. Church and C.L. May. 2005. Geomorphology of steepland headwaters: the transition from hillslopes to channels. Journal of the American Water Resources Association 41:835-851.

Bennett, A.F., D.G. Nimmo and J.Q. Radford. 2014. Riparian vegetation has disproportionate benefits for landscape-scale conservation of woodland birds in highly modified environments. Journal of Applied Ecology 51:514-523.

Boedeltje, G., J.P. Bakker, R.M. Bekker, J.M. Van Groenendael, and M. Soesbergen. 2003. Plant dispersal in a lowland stream in relation to occurrence and three specific lifehistory traits of the species in the species pool. Journal of Ecology 91:855-866.

Bolker, B.M., M.E. Brooks, C.J. Clark, S.W. Geange, J.R. Poulsen, M.H.H. Stevens and J.S. White. 2008. Generalized linear mixed models: a practical guide for ecology and evolution. Trends in Ecology and Evolution 24:127-135.

Bonner, F.T., R.P. Karrfalt and R.G. Nisley (eds.). 2008. The woody plant seed manual. USDA Forest Service Agriculture Handbook 727. 
Booth, D.B., D. Hartley, \& R. Jackson. 2002. Forest cover, impervious-surface area, and the mitigation of stormwater impacts. Journal of the American Water Resources Association 38:835-845.

Brederveld, R.J., S.C. Jahnig, A.W. Lorenz, S. Brunzel and M.B. Soons. 2011. Dispersal as a limiting factor in the colonization of restored mountain streams by plants and macroinvertebrates. Journal of Applied Ecology 48:1241-1250.

Brice, M.H., S. Pellerin and M. Poulin. 2016. Environmental filtering and spatial processes in urban riparian forests. Journal of Vegetation Science 27:1023-1035.

Brice, M.H., S. Pellerin and M. Poulin. 2017. Does urbanization lead to taxonomic and functional homogenization in riparian forests? Diversity and Distributions 23:828-840.

Briggs, M.K. 1992. An evaluation of riparian revegetation efforts in Arizona. Masters Thesis, The University of Arizona.

Brown, D. 1992. Estimating the composition of a forest seed bank: a comparison of seed extraction and seedling emergence methods. Canadian Journal of Botany 70:1603-1612.

Brunet J. and G. Von Oheimb. 1998. Migration of vascular plants to secondary woodlands in Southern Sweden. Journal of Ecology 86:429-438.

Burton, J.I., A. Ares, D.H. Olson, and K.J. Puettmann. 2013. Management trade-off between aboveground carbon storage and understory plant species richness in temperate forests. Ecological Applications 23:1297-1310.

Burton, M.L. and L.J. Samuelson. 2008. Influence of urbanization on riparian forest diversity and structure in the Georgia Piedmont, US. Plant Ecology 195:99-115.

Burton, M.L., L.J. Samuelson and M.D. Mackenzie. 2009. Riparian woody plant traits across an urban-rural land use gradient and implications for watershed function with urbanization. Landscape and Urban Planning 90:42-55.

Cadenasso, M.L. and S.T.A. Pickett. 2001. Effect of edge structure on the flux of species into forest interiors. Conservation Biology 15:91-97.

Cappers, R.T.J., Bekker, R.M. and J.E.A. Jans. 2006. Digital Seed Atlas of the Netherlands. Groningen Archaeological Studies 4, Barkhuis Publishing, Eelde, The Netherlands. www.plantatlas.eu.

Chadwick, M.A., D.R. Dobberfuhl, A.C. Benke, A.D. Huryn, K. Suberkropp and J.E. Thiele. 2006. Urbanization affects stream ecosystem function by altering hydrology, chemistry, and biotic richness. Ecological Applications 16:1796-1807. 
Chambert, S. and C.S. James. 2009. Sorting of seeds by hydrochory. River Research and Applications 25:48-61.

Christy, J.A., A. Kimpo, V. Marttala, P.K. Gaddis and N.L. Christy. 2009. Urbanizing flora of Portland, Oregon, 1806-2008. Native Plant Society of Oregon Occasional Paper 3.

Cooper, S.D., P.S. Lake, S. Sabater, J.M. Melack and J.L. Sabo. 2013. The effects of land use changes on streams and rivers in Mediterranean climates. Hydrobiologia 719:383425 .

Cunnings, A., E. Johnson and Y. Martin. 2015. Fluvial seed dispersal of riparian trees: transport and depositional processes. Earth Surface Processes and Landforms 41:615625.

Dalling, J.W., H.C. Muller-Landau, S.J. Wright, and S.P. Hubbell. 2002. Role of dispersal in the recruitment limitation of neotropical pioneer species. Journal of Ecology 90:714-727.

Dietrich, A.E. 2012. Stream-associated amphibian habitat assessment in the PortlandVancouver metropolitan region. Masters Thesis, Portland State University, Portland, Oregon. PDXScholar Dissertations and Theses Paper 604.

Dlugosch, K. 2005. Understory community changes associated with English ivy invasions in Seattle's urban parks. Northwest Science 79:53-60.

Downing, J.A., J.J. Cole, C.M. Duarte, J.J. Middleburg, J.M. Melack, Y.T. Prairie, P. Kortelainen, R.G. Strigel, W.H. McDowell and L.J. Tranvik. 2012. Global abundance and size distribution of streams and rivers. Inland Waters 2:229-236.

Dufrêne, M. and P. Legendre. 1997. Species assemblages and indicator species: the need for a flexible asymmetrical approach. Ecological Monographs 67:345-366.

Duguay, S., F. Eigenbrod and L. Fahrig. 2007. Effects of surrounding urbanization on non-native flora in small forest patches. Landscape Ecology 22:589-599.

Ehrlen, J and O. Erikkson, 2000. Dispersal limitation and patch occupancy in forest herbs. Ecology, 81:1667-1674.

Engstrom, J., C. Nilsson and R. Jansson. 2009. Effects of stream restoration on dispersal of plant propagules. Journal of Applied Ecology 46:397-405.

Erikkson, O. and J. Ehrlen. 1992. Seed and microsite limitation of recruitment in plant populations. Oecologia 91:360-364. 
ESRI, 2009. ArcGIS Desktop version 9.3.1. Redlands, CA.

ESRI, 2014. ArcGIS Desktop version 10.4. Redlands, CA.

Ettinger, A.K., B.R. Lee and S. Montgomery. 2017. Seed limitation and lack of downed wood, not invasive species, threaten conifer regeneration in an urban forest. Urban Ecosystems 20:877-887.

Everson, D.A. and B.H. Boucher. 1998. Tree species-richness and topographic complexity along the riparian edge of the Potomac River. Forest Ecology and Management 109:305-314.

Fernandes, M.R., F.C. Aguiar and M.T. Ferreira. 2011. Assessing riparian vegetation structure and the influence of land use using landscape metrics and geostatistical tools. Landscape and Urban Planning 99:166-177.

Fetherston, K.L., R.J. Naiman and R.E. Bilby. 1995. Large woody debris, physical processes, and riparian forest development in montane river networks of the Pacific Northwest. Geomorphology 13:133-144.

Ficetola, G.F., L. Marziali, B. Rossaro, F. De Bernardi and E. Padoa-Schioppa. 2011. Landscape-stream interactions and habitat conservation for amphibians. Ecological Applications 21:1272-1282.

Fraaije, R.G.A., S. Moinier, I. van Gogh, R. Timmers, J.J. van Deelen, J.T.A. Verhoeven and M.B. Soons. 2017. Spatial patterns of water-dispersed seed deposition along stream riparian gradients. Plos One 12:e185247.

Fraaije, R.B.A., C.J.F. ter Braak, B. Verduyen, J.T.A. Verhoeven and M.B. Soons. 2015. Dispersal versus environmental filtering in a dynamic system: drivers of vegetation patterns and diversity along stream riparian gradients. Journal of Ecology 103:1634-1646.

Fry, J., G. Xian, S. Jin, J. Dewitz, C. Homer, L. Yang, C. Barnes, N. Herold and J. Wickham. 2011. Completion of the 2006 National Land Cover Database for the conterminous United States. Photogrammetric Engineering \& Remote Sensing 77:858864.

Giesbrecht, I.J.W., S.C. Saunders, A. MacKinnon and K.P. Lertzman. 2017. Overstory structure drives fine-scale coupling of understory light and vegetation in two temperate rainforest floodplains. Canadian Journal of Forest Research 47:1244-1256.

Gilliam, F.S. 2007. The ecological significance of the herbaceous layer in temperate forest ecosystems. BioScience 10:845-858. 
Gold, A.J., P.M. Groffman, K. Addy, D.Q. Kellogg, M Stolt and A.E. Rosenblatt. 2001. Landscape attributes as controls on ground water nitrate removal capacity of riparian zones. Journal of the American Water Resources Association 37:1457-1464.

Gomi, T., R.D. Sidle, and J.H. Richardson. 2002. Understanding processes and downstream linkages of headwater systems. BioScience:905-916.

Goodson, J.M., A.M. Gurnell, P.G. Angold and I.P. Morrissey. 2003. Evidence for hydrochory and the deposition of viable seeds within winter flow-deposited sediments: the River Dove, Derbyshire, UK. River Research and Applications 19:317-334.

Gornish, E.S., M.S. Lennox, D. Lewis, K.W. Tate, and R.D. Jackson. 2017. Comparing herbaceous plant communities in active and passive riparian restoration. Plos One 4:e0176338.

Gregory S.V., F.J. Swanson, W.A. McKee and K.W. Cummins. 1991. An ecosystem perspective of riparian zones. BioScience 41:540-551.

Groffman, P.M., D.J. Bain, L.E. Band, K.T. Belt, G.S. Brush, J.M. Grove, R.V. Pouyat, I.C. Yesilonis and W.C. Zipperer. 2003. Down by the riverside: urban riparian ecology. Frontiers in Ecology and the Environment 6:315-321.

Guntenspergen, G.R. and J.B. Levenson 1997. Understory plant species composition in remnant stands along an urban-to-rural land use gradient. Urban Ecosystems 1:155-169.

Gurnell, A.M., K. Thompson, J. Goodson, and H. Moggridge. 2008. Propagule deposition along river margins: linking hydrology and ecology. Journal of Ecology 96:553-565.

Hanzlik, K. and B. Gerowitt. 2011. The importance of climate, site and management on weed vegetation in oilseed rape in Germany. Agriculture, Ecosystems \& Environment 141:323-331.

Henshaw, P.C. and D.B. Booth. 2000. Natural restabilization of stream channels in urban watersheds. Journal of the American Water Resources Association 36:1219-1236.

Herault, B. and O. Honnay. 2005. The relative importance of local, regional and historical factors determining the distribution of plants in fragmented riverine forests: an emergent group approach. Journal of Biogeography 12:2069-2081.

Herberg, E.R. and J.M. Sarneel. 2017. Recruitment of riparian plants after restoration of geomorphic complexity in northern Sweden. Applied Vegetation Science 20:435-445.

Hibbs, D.E. and A.L. Bower. 2001. Riparian forests in the Oregon Coast Range. Forest Ecology and Management 154:201-213. 
Hilderbrand, R.H., A.C. Watts and A.M. Randle. 2005. The myths of restoration ecology. Ecology and Society 10:19.

Hitchcock, C.L. \& A. Cronquist. 1973. Flora of the Pacific Northwest. University of Washington Press, Seattle.

Homer, C.G., J.A. Dewitz, L. Yang, S. Jin, P. Danielson, G. Xian, J. Coulston, N.D. Herold, J.D. Whickham and K. Megown. 2015. Completion of the 2011 National Land Cover Database for the coterminous United States - Representing a decade of land cover change information. Photogrammetric Engineering and Remote Sensing 81:345-354.

Honnay, O., W. Verheyen, J. Butaye, H. Jacquemyn, B. Bossuyt and M. Hermy. 2002. Possible effects of habitat fragmentation and climate change on the range of forest plant species. Ecological Letters 5:525-530.

Honnay, O., W. Verheyen, and M. Hermy. 2001. Plant community assembly along dendritic networks of small forest streams. Ecology 82:1691-1702.

Houser, J.N., P.J. Mulholland and K.O. Maloney. 2005. Catchment disturbance and stream metabolism: patterns in ecosystem respiration and gross primary production along a gradient of upland soil and vegetation disturbance. Journal of the North American Benthological Society 24:538-552.

Hughes, J.W. and T.J. Fahey. 1988. Seed dispersal and colonization in a disturbed northern hardwood forest. Bulletin of the Torrey Botanical Club 115:89-99.

Hutmacher, A.M., G.N. Zaines, J. Martin and D.M. Green. 2013. Vegetation structure along urban ephemeral streams in southeastern Arizona. Urban Ecosystems doi: 10.1007/s11252-013-0293-4.

Irwin, E.G. and N.E. Bockstael. 2007. The evolution of urban sprawl: Evidence of spatial heterogeneity and increasing land fragmentation. Proceedings of the National Academy of Sciences USA 104:20672-20677.

Jansson, R., U. Zinko, D.M. Merritt and C. Merritt. 2005. Hydrochory increases riparian plant species richness: a comparison between a free-flowing and a regulated river. Journal of Ecology 93:1094-1103.

Johnson, S.L. and J.A. Jones. 2000. Stream temperature responses to forest harvest and debris flows in western Cascades, Oregon. Canadian Journal of Fisheries and Aquatic Sciences 57:30-39.

Kaufman, L. and P.J. Rousseeuw. 1990. Finding Groups in Data: An Introduction to Cluster Analysis. John Wiley \& Sons, New York. 
Kenkel, N.C. and L. Orlóci. 1986. Applying metric and nonmetric multidimensional scaling to ecological studies: some new results. Ecology 67:919-928.

King, K.W., P.C. Smiley Jr. and N.R. Fausey. 2009. Hydrology of channelized and natural headwater streams. Hydrological Sciences 54:929-948.

Klinkenberg, B. (ed.), 2017. E-Flora BC: Electronic Atlas of the Flora of British Columbia. Lab for Advanced Spatial Analysis, Department of Geography, University of British Columbia, Vancouver. http://ibis.geog.ubc.ca/biodiversity/eflora/index.shtml.

Kolb, A. and M. Diekmann. 2005. Effects of life-history traits on responses of plant species to forest fragmentation. Conservation Biology 19:929-938.

Konrad, C.P. and D.B. Booth. 2005. Hydrologic changes in urban streams and their ecological significance. American Fisheries Society Symposium 47:157-177.

Lecerf, A., C. Evangelista, J. Cucherousset and A Boiché. 2016. Riparian overstoryunderstory interactions and their potential implications for forest-stream linkages. Forest Ecology and Management 367:112-119.

Lin, L., M. Cao, Y. He, J. Baskin and C. Baskin. 2006. Nonconstituent species in soil seed banks as indicators of anthropogenic disturbance in forest fragments. Canadian Journal of Forest Research 36:2300-2316.

Loewenstein, N. and E.F. Loewenstein. 2005. Non-native plants in the understory of riparian forests across a land use gradient in the Southeast. Urban Ecosystems 8:79-91.

Lorenz. A.W. and C.K. Feld. 2013. Upstream river morphology and riparian land use overrule local restoration effects on ecological status assessment. Hydrobiologia 704:489501.

Magee, T.K, P.L. Ringold and M.A. Bollman. 2008. Alien species importance in native vegetation along wadeable streams, John Day River basin, Oregon, USA. Plant Ecology 195:287-307.

Malone, C.R. 1967. A rapid method for enumeration of viable seeds in soil. Weeds 15:381-382.

Matzek, V., S. Warren and C. Fisher. 2016. Incomplete recovery of ecosystem processes after two decades of riparian forest restoration. Restoration Ecology 24:637-645.

May, C.W. and R.R. Horner. 2000. The cumulative impacts of watershed urbanization on stream-riparian ecosystems. Proceedings of the American Water Resources Association 
International Conference on riparian ecology and management in multi-land use watersheds, Portland, Ore. 281-286.

Licvar, R.W., D.L. Banks, W.N. Kirchner and N.C. Melvin. 2016. The National Wetland Plant List: 2016 wetland ratings. Phytoneuron 2016-30:1-17.

McEuen A.B. and L.M. Curran 2004. Seed dispersal and recruitment limitation across spatial scales in temperate forest fragments. Ecology 85:507-518.

McKinney M.L. 2008. Effects of urbanization on species richness: A review of plants and animals. Urban Ecosystems 11:161-176.

Meek, C.S., D.M. Richardson, and L. Mucina. 2010. A river runs through it: Land-use and the composition of vegetation along a riparian corridor in the Cape Floristic Region, South Africa. Biological Conservation 143:156-164.

Mendoza, I., L. Gómez-Aparicio, R. Zamora and L. Matías. 2009. Recruitment limitation of forest communities in a degraded Mediterranean landscape. Journal of Vegetation Science 20:367-376.

Merritt, D.M., C. Nillson, and R. Jansson. 2010. Consequences of propagule dispersal and river fragmentation for riparian plant community diversity and turnover. Ecological Monographs 80:609-626.

Merritt, D.M. and E.E. Wohl. 2002. Processes governing hydrochory along rivers: Hydraulics, hydrology, and dispersal phenology. Ecological Applications 12:1071-1087.

Metro. Welcome to Metro. Online [URL] www.oregonmetro.gov (Accessed on 19 August 2013).

Metro Data Resource Center. RLIS Discovery. Online [URL]

rlisdiscovery.oregonmetro.gov (Accessed on 19 August 2013).

Metzger, J.P. 2000. Tree functional group richness and landscape structure in a Brazilian tropical fragmented landscape. Ecological Applications 10:1147-1161.

Meyers, S.C., T. Jaster, K.E. Mitchell and L.K. Hardison. 2015. Flora of Oregon. Volume 1: Pteridophytes, Gymnosperms, and Monocots. Botanical Research Institute of Texas, Fort Worth, Texas, U.S.A.

Miller, J.N., R.P. Brooks and M.J. Croonquist. 1997. Effects of landscape patterns on biotic communities. Landscape Ecology 12:137-153.

Minchin, P.R. 1987. An evaluation of the relative robustness of techniques for ecological ordination. Vegetatio 69:89-107. 
Moffatt, S.F. and S.M. McLachlan 2004. Understorey indicators of disturbance for riparian forests along an urban-rural gradient in Manitoba. Ecological Indicators 4:1-16.

Moffatt, S.F., S,M. McLachlan, and N.C. Kenkel 2004. Impacts of land use on riparian forest along an urban-rural gradient in southern Manitoba. Plant Ecology 174:119-135.

Moggridge, H.L., A.M. Gurnell, and J.O. Mountford. 2009. Propagule input, transport and deposition in riparian environments: the importance of connectivity for diversity. Journal of Vegetation Science 20:465-474.

Moggridge, H.L. and A.M. Gurnell. 2010. Hydrological controls on the transport and deposition of plant propagules within riparian zones. River Research and Applications 26:512-527.

Montgomery, D.R. and J.M. Buffington. 1998. Channel-reach morphology in mountain drainage basins. Geological Society of America Bulletin 109:596-611.

Morse, C.C., A.D. Huryn, and C. Cronan. 2003. Impervious surface area as a predictor of the effects of urbanization on stream insect communities. Environmental Monitoring and Assessment 89:95-127.

Muller-Landau, H.C., J.S. Wright, O. Calderon, R. Condit, and S.P. Hubbell. 2008. Interspecific variation in primary seed dispersal in a tropical forest. Journal of Ecology 96:653-667.

Münzbergová, Z. and T. Herben. 2005. Seed, dispersal, microsite, habitat, and recruitment limitation: identification of terms and concepts in studies of limitations. Oecologia 145:1-8.

Naiman, R., R.E. Bilby and P.A. Bisson. 2000. Riparian ecology and management in the Pacific coastal rain forest. BioScience:996-1011.

Naiman, R., H. Decamps, and M. Pollock. 1993. The role of riparian corridors in maintaining regional biodiversity. Ecological Applications 3:209-212.

Naiman, R. and H. Decamps. 1997. The ecology of interfaces: Riparian zones. Annual Review of Ecology and Systematics 28:621-658.

Naiman, R., H. Decamps and M.E. McClain. 2005. Riparia: Ecology, conservation, and management of streamside communities. Oxford, Elsevier Academic.

Nakano, S. and M. Murakami. 2001. Reciprocal subsidies: Dynamic interdependence between terrestrial and aquatic food webs. Proceedings of the National Academy of Sciences of the United States of America 98:166-170. 
Nathan, R. and H.C. Muller-Landau. 2000. Spatial patterns of seed dispersal, their determinants and consequences for recruitment. Trends in Ecology and Evolution 7:278285.

Newham, M.J., C.S. Fellows and F. Sheldon. 2011. Functions of riparian forest in urban catchments: a case study from sub-tropical Brisbane, Australia. Urban Ecosystems 14:165-180.

Nierenberg, T.R., and D.E. Hibbs. 2000. A characterization of unmanaged riparian areas in the central Coast Range of western Oregon. Forest Ecology and Management 129:195206.

Nilsson, C., R.L. Brown, R. Jansson, and D.M. Merritt. 2010. The role of hydrochory in structuring riparian and wetland vegetation. Biological Reviews 85:837858.

Nucci, A., C. Angiolini, M. Landi and G. Bacchetta 2012. Regional and local patterns of riparian flora: Comparison between insular and continental Mediterranean rivers. Ecoscience 19:213-224.

Oksanen, J., F.G. Blanchet, R. Kindt, P. Legendre, P.R. Minchin, R.B. O’Hara, G.L. Simpson, P. Solymos, M.H.H. Stevens and H. Wagner. 2012. Vegan: Community Ecology Package. R Package Version 2.0-5. Online. [URL] http://cran.rproject.org/package=vegan (Accessed on 19 August 2013).

Oneal, A.S. and J.T. Rotenberry. 2008. Riparian plant composition in an urbanizing landscape in southern California, USA. Landscape Ecology 23:553-567.

Ozawa, C.P. and J.A. Yeakley. 2007. Performance of management strategies in the protection of riparian vegetation in three Oregon cities. Journal of Environmental Planning and Management 50:803-822.

Pabst, R.J. and T.A. Spies. 1998. Structure and composition of unmanaged riparian forests in the coastal mountains of Oregon, U.S.A. Canadian Journal of Forest Research 29:1557-1573.

Pabst, R.J. and T.A. Spies. 1999. Distribution of herbs and shrubs in relation to landform and canopy cover in riparian forests of coastal Oregon. Canadian Journal of Botany 76:298-315.

Parendes, L.A. and J.A. Jones. 2000. Role of light availability and dispersal in exotic plant invasion along roads and streams in the H.J. Andrews Experimental Forest, Oregon. Conservation Biology 14:64-75. 
Parker, K., L. Head, L.A. Chisholm and N. Fenely. 2008. A conceptual model of ecological connectivity in the Shellharbour Local Government Area, New South Wales, Australia. Landscape and Urban Planning 86:47-59.

Pätel, M., M. Zobel, K. Zobel and E. van der Maarel. 1996. The species pool and its relation to species richness: Evidence from Estonian plant communities. Oikos 75:111117.

Paul, M.J. and J.L. Meyer. 2001. Streams in the urban landscape. Annual Review of Ecology and Systematics 32:333-365.

Pearson, R.G. and T.P. Dawson. 2005. Long-distance plant dispersal and habitat fragmentation: identifying conservation targets for spatial landscape planning under climate change. Biological Conservation 123:389-401.

Pennington, D.N., J.R. Hansel and D.L. Gorchov. 2010. Urbanization and riparian forest woody communities: Diversity, composition, and structure within a metropolitan landscape. Biological Conservation 143:182-194.

Poff, N.L., B.D. Bledsoe and C.O. Cuhaciyan. 2006. Hydrologic variation with land use across the contiguous United States: Geomorphic and ecological consequences for stream ecosystems. Geomorphology 79:264-285.

Pojar, J and A. MacKinnon. 1994. Plants of the Pacific Northwest Coast, Revised Edition. Lone Pine Publishing, Vancouver, British Columbia.

Porter, E.E., B.R. Forschner and R.B. Blair RB 2001. Woody vegetation and canopy fragmentation along a forest-to-urban gradient. Urban Ecosystems 5:131-151.

Puşcaş, M. and P. Choler, 2012. A biogeographic delineation of the European alpine system based on a cluster analysis of Carex curvula-dominated grasslands. Flora 207:168-178.

R Development Core Team. 2017. R: A language and environment for statistical computing. R Foundation for Statistical Computing, Vienna, Austria.

Randhir, T. and P. Ekness. 2009. Urbanization effects on watershed habitat potential: a multivariate assessment of thresholds and interactions. Ecohydrology 2:88-101.

Richardson, J.S. and R.J. Danehy. 2007. A synthesis of the ecology of headwater streams and their riparian zones in temperate forests. Forest Science 53:131-147. 
Richardson, J.S., R.J. Naiman and P.A. Bisson. 2012. How did fixed-width buffers become standard practice for protecting freshwaters and their riparian areas from forest harvest practices? Freshwater Science 31:232-238.

Richardson, J.S., R.J. Naiman, F.J. Swanson, \& D.E. Hibbs. 2005. Riparian communities associated with Pacific Northwest headwater streams: Assemblages, processes, and uniqueness. Journal of the American Water Resources Association 41:935-947.

Rockey, C. 2012. Portland climate normal (1981-2010), means and extremes. National Oceanic and Atmospheric Administration National Weather Service Forecast Office, Portland, OR. Online [URL] www.wrh.noaa.gov/pqr/pdxclimate/pg121.pdf (Accessed on 27 January 2014).

Roy, A.H., A.L. Dybas, K.M. Fritz, and H.R. Lubbers. 2009. Urbanization affects the extent and hydrologic permanence of headwater streams in a Midwestern US metropolitan area. Journal of the North American Benthological Society 28:911-928.

Roy, D.B., M.O. Hill and P. Rothery. 1999. Effects of urban land cover on the local species pool in Britain. Ecography 22:507-515.

Royal Botanic Gardens, Kew. 2018. Seed Information Database (SID). Version 7.1. http://data.kew.org/sid/

Salinas, M.J. and J.J. Casas. 2007. Riparian vegetation of two semi-arid Mediterranean rivers: Basin-scale responses of woody and herbaceous plants to environmental gradients. Wetlands 27:831-845.

Samuel, I. and I. Kowarik. 2010. Urban rivers as dispersal corridors for primarily winddispersed invasive tree species. Landscape and Urban Planning 94:244-249.

Samuel, I. and I. Kowarik. 2013. Propagule morphology and river characteristics shape secondary water dispersal in tree species. Plant Ecology 214:1257-1272.

Sarr, D.A. and D.E. Hibbs. 2007. Woody riparian plant distributions in western Oregon, USA: Comparing landscape and local scale factors. Plant Ecology 190:291-311.

Schwoertzig, E., D. Ertlen and M. Tremolieres. 2016a. Are plant communities mainly determined by anthropogenic land cover along urban riparian corridors? Urban Ecosystems 19:1767-1786.

Schwoertzig, E., N. Poulin, L. Harion and M. Tremolieres. 2016b. Plant ecological traits highlight the effects of landscape on riparian plant communities along an urban-rural gradient. Ecological Indicators 61:568-576. 
Shannon, C.E. and W. Weaver. 1949. The mathematical theory of communication. University of Illinois Press, Urbana.

Sonoda, K., J.A. Yeakley and C.E. Walker. 2001. Near-stream landuse effects on streamwater nutrient distribution in an urbanizing watershed. Journal of the American Water Resources Association 37:1517-1532.

Stanfield, L.W. and D.A. Jackson. 2011. Understanding the factors that influence headwater stream flows in response to storm events. Journal of the American Water Resources Association 47:315-336.

Strohbach, M., V. Audorff and C. Beierkuhnlein. 2009. Drivers of plant species composition in siliceous spring ecosystems: groundwater chemistry, catchment traits, or spatial factors? Journal of Limnology 68:375-384.

Suding, K.N., K.L. Gross, and G.R. Houseman. 2004. Alternative states and positive feedbacks in restoration ecology. Trends in Ecology and Evolution 19:46-53.

Sun, N., J. Yearsley, N. Voisin and D.P. Lettenmaier. 2015. A spatially distributed model for the assessment of land use impacts on stream temperature in small urban watersheds. Hydrological Processes 29:2331-2345.

Sweeney, B.W., T.L. Bott, L.A. Kaplan, J.D. Newbold, L.J. Standley, W.C. Hession, R.J. Horwitz and M.G. Wolman. 2004. Riparian deforestation, stream narrowing, and loss of stream ecosystem services. Proceedings of the National Academy of Sciences of the United States of America 101:14132-14137.

Tabacchi, E., D.L. Correll, R.Hauer, G. Pinay, A. Planty-Tabacchi and R.C. Wissmar. 1998. Development, maintenance and role of riparian vegetation in the river landscape. Freshwater Biology 40:497-516.

Tabacchi, E., L. Lambs, H. Guilloy, A. Planty-Tabacchi, E. Muller E and H. Decamps. 2000. Impacts of riparian vegetation on hydrological processes. Hydrological Processes 14:2959-2976.

Tabacchi, E. and A. Planty-Tabacchi. 2005. Exotic and native plant community distributions within complex riparian landscapes: a positive correlation. Ecoscience 12:412-423.

Takahashi, K. and T. Kamitani. 2004. Effect of dispersal capacity on forest plant migration at a landscape scale. Journal of Ecology 92:778-785.

Therneau, T., B. Atkinson and B. Ripley. 2012. rpart: Recursive Partitioning. R Package Version 3.1-55. Online [URL] http://cran.r-project.org/package=rpart (Accessed on 19 August 2013). 
Thomson, F.J., A.T. Moles, T.D. Auld, and R.T. Kingsford. 2011. Seed dispersal distance is more strongly correlated with plant height than with seed mass. Journal of Ecology 99:1299-1307.

Turner, I.P., E.F. Brantley, J.N. Shaw, C.J. Anderson and B.S. Helms. 2015. Floristic composition of Alabama Piedmont floodplains across a gradient of stream channel incision. American Midland Naturalist 174:238-253.

USDA, NRCS. 2018. The PLANTS Database. National Plant Data Team, Greensboro, NC 27401-4901, USA. http://plants.usda.gov.

USDA, NRCS, USGS, EPA. Watershed Boundary Dataset for HUC 2-17. Online [URL] nhd.usgs.gov (Accessed 19 August 2013).

Vidra, R.L., T.H. Shear and T.R. Wentworth. 2006. Testing the paradigms of exotic species invasion in urban riparian forests. Natural Areas Journal 26:339-350.Wim

Vogt, K., L. Rasran and K. Jensen. 2004. Water-borne seed transport and seed deposition during flooding in a small river-valley in Northern Germany. Flora 199:377388.

Walsh, C.J., A.H. Roy, J.W. Feminella, P.D. Cottingham, P.M. Groffman and P.M. Raymond II, 2005. The urban stream syndrome: Current knowledge and the search for a cure. Journal of the North American Benthological Society 24:706-723.

Wania, A., I. Kuhn and S. Klotz. 2006. Plant richness patterns in agricultural and urban landscapes in Central Germany - spatial gradients of species richness. Landscape and Urban Planning 75:97-110.

Wenger, S.J., C.H. Luce, A.F. Hamlet, D.J. Isaak and H.M. Neville. 2010. Macroscale hydrologic modeling of ecologically relevant flow metrics. Water Resources Research 46:W09513.

White, M.D. and K.A. Greer. 2006. The effects of watershed urbanization on the stream hydrology and riparian vegetation of Los Peñasquitos Creek, California. Landscape and Urban Planning 74:125-138.

Willson, M.F. and A. Travaset. 2000. The ecology of seed dispersal. In: Fenner (ed.). Seeds, the ecology of regeneration in plant communities, $2^{\text {nd }}$ ed. CABI, Wallingford, UK.

Wilson, B.L., R. Brainerd, D. Lytjen, B. Newhouse and N. Otting. 2014. The Field Guide to the Sedges of the Pacific Northwest, $2^{\text {nd }}$ ed. Oregon State University Press. 
Wimberly, M.C. and T.A. Spies. 2001. Influences of environment and disturbance of forest patterns in coastal Oregon watersheds. Ecology 85:1443-1459.

Wohl, E. 2017. The significance of small streams. Frontiers in Earth Science 11:447-456.

Wolters, M., J. Geertsema, E.R. Chang, R.M. Veeneklaas, P.D. Carey, and J.P. Bakker. 2004. Astroturf seed traps for studying hydrochory. Functional Ecology 18:141-147.

WTU Image Collection: Plants of Washington. 2018. Burke Museum of Natural History and Culture. University of Washington.

http://biology.burke.washington.edu/herbarium/imagecollection.php.

Yeakley, J.A. 2014a. Introduction to Wild Salmonids in the Urbanizing Pacific Northwest. In: Yeakley, J.A., K.G. Maas-Hebner and R.M.Hughes (eds.). 2014. Wild Salmonids in the Urbanizing Pacific Northwest. Springer Science + Business Media, New York.

Yeakley, J.A. 2014b. Urban Hydrology in the Pacific Northwest. In: Yeakley, J.A., K.G. Maas-Hebner and R.M.Hughes (eds.). 2014. Wild Salmonids in the Urbanizing Pacific Northwest. Springer Science + Business Media, New York. 


\section{Appendix A: Functional groups of taxa found in seed traps}

Table A.1: Functional groups of taxa found in seed traps. Taxa were classified into as many of the 12 functional groups as possible, given the level of identification. Abbreviations: Gram $=$ Graminoid; Nat $=$ Native Non $=$ Non-native; Inter $=$ Intermediate Intol $=$ Intolerant $;$ Tol $=$ Tolerant .

\begin{tabular}{|c|c|c|c|c|c|c|c|c|c|c|c|c|}
\hline 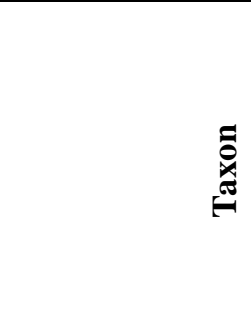 & 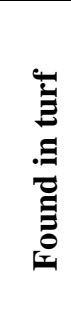 & 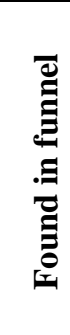 & $\begin{array}{l}0 \\
0 \\
0 \\
0\end{array}$ & 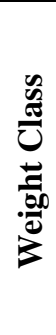 & 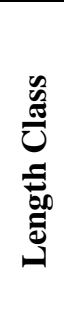 & 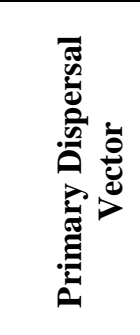 & 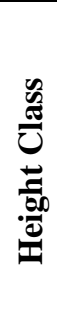 & 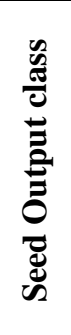 & 葛 & 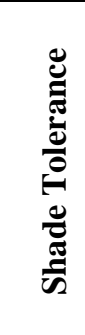 & 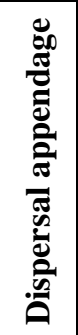 & 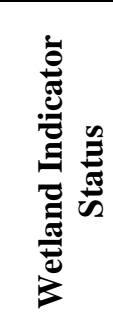 \\
\hline $\begin{array}{l}\text { Acer } \\
\text { macrophyllum }\end{array}$ & Yes & Yes & Tree & 5 & 4 & Wind & 4 & 5 & Nat & Inter & Yes & FAC \\
\hline Acer spp. & Yes & Yes & Tree & 5 & 4 & Wind & $\mathrm{n} / \mathrm{a}$ & 5 & $\mathrm{n} / \mathrm{a}$ & Intol & Yes & $\mathrm{n} / \mathrm{a}$ \\
\hline $\begin{array}{l}\text { Achillea } \\
\text { millefolium }\end{array}$ & Yes & No & Herb & 1 & 1 & Wind & 1 & 4 & Nat & Inter & No & FACU \\
\hline Agrostis spp. & Yes & Yes & Gram & 1 & 1 & Wind & 1 & 1 & $\mathrm{n} / \mathrm{a}$ & Intol & No & FAC \\
\hline Alnus rubra & Yes & Yes & Tree & 3 & 2 & Wind & 4 & 5 & Nat & Intol & Yes & FAC \\
\hline Apiaceae & Yes & No & Herb & $\mathrm{n} / \mathrm{a}$ & $\mathrm{n} / \mathrm{a}$ & $\mathrm{n} / \mathrm{a}$ & $\mathrm{n} / \mathrm{a}$ & $\mathrm{n} / \mathrm{a}$ & $\mathrm{n} / \mathrm{a}$ & $\mathrm{n} / \mathrm{a}$ & $\mathrm{n} / \mathrm{a}$ & $\mathrm{n} / \mathrm{a}$ \\
\hline Asteraceae & Yes & No & Herb & $\mathrm{n} / \mathrm{a}$ & $\mathrm{n} / \mathrm{a}$ & Wind & $\mathrm{n} / \mathrm{a}$ & $\mathrm{n} / \mathrm{a}$ & $\mathrm{n} / \mathrm{a}$ & $\mathrm{n} / \mathrm{a}$ & $\mathrm{n} / \mathrm{a}$ & $\mathrm{n} / \mathrm{a}$ \\
\hline Betua pendula & Yes & Yes & & 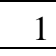 & 2 & & 4 & 5 & Non & Intol & Yes & FACU \\
\hline $\begin{array}{l}\text { Brachypodium } \\
\text { sylvaticum }\end{array}$ & Yes & No & Gram & 4 & 3 & Wind & 2 & 2 & Non & Inter & No & none \\
\hline $\begin{array}{l}\text { Cardamine } \\
\text { hirsuta }\end{array}$ & Yes & Yes & Herb & 1 & 1 & Ballistic & 1 & 1 & $\mathrm{n} / \mathrm{a}$ & Inter & Yes & FACU \\
\hline Carex leptopoda & Yes & Yes & Gram & $\mathrm{n} / \mathrm{a}$ & 2 & Water & 1 & 2 & Nat & Tol & No & FAC \\
\hline Carex pendula & Yes & No & Gram & 2 & 1 & Water & 2 & 2 & Non & Inter & Yes & FAC \\
\hline Carex spp. & Yes & Yes & Gram & 3 & 1 & Water & 2 & 2 & $\mathrm{n} / \mathrm{a}$ & $\mathrm{n} / \mathrm{a}$ & Yes & $\mathrm{n} / \mathrm{a}$ \\
\hline Carex stipata & Yes & No & Gram & 2 & 1 & Water & 2 & 2 & Nat & Tol & $\mathrm{n} / \mathrm{a}$ & OBL \\
\hline Caryophyllaceae & No & Yes & Herb & $\mathrm{n} / \mathrm{a}$ & $\mathrm{n} / \mathrm{a}$ & None & $\mathrm{n} / \mathrm{a}$ & $\mathrm{n} / \mathrm{a}$ & $\mathrm{n} / \mathrm{a}$ & $\mathrm{n} / \mathrm{a}$ & Yes & $\mathrm{n} / \mathrm{a}$ \\
\hline Cirsium spp. & No & Yes & Herb & $\mathrm{n} / \mathrm{a}$ & $\mathrm{n} / \mathrm{a}$ & Wind & $\mathrm{n} / \mathrm{a}$ & 3 & Non & $\mathrm{n} / \mathrm{a}$ & Yes & $\mathrm{n} / \mathrm{a}$ \\
\hline Claytonia spp. & Yes & Yes & Herb & - & 1 & Ballistic & 1 & 1 & Nat & Tol & No & FAC \\
\hline Clematis vitalba & Yes & Yes & Herb & 3 & 2 & Wind & 1 & 2 & Non & Tol & Yes & FAC \\
\hline $\begin{array}{l}\text { Conium } \\
\text { maculatum }\end{array}$ & Yes & No & Herb & 4 & 2 & ind & 2 & 3 & Non & Tol & Yes & FAC \\
\hline $\begin{array}{l}\text { Crataegus } \\
\text { douglassiana }\end{array}$ & Yes & No & ee & 5 & 3 & $11 \mathrm{mal}$ & 3 & 3 & Nat & ter & No & CRDO \\
\hline $\begin{array}{l}\text { Crataegus } \\
\text { monogyna }\end{array}$ & Yes & Yes & Tree & 5 & 3 & Animal & 3 & 3 & Non & Inter & No & CRMO \\
\hline Cyperaceae & Yes & No & Gram & 3 & 2 & Wind & 2 & $\mathrm{n} / \mathrm{a}$ & $\mathrm{n} / \mathrm{a}$ & $\mathrm{n} / \mathrm{a}$ & Yes & $\mathrm{n} / \mathrm{a}$ \\
\hline $\begin{array}{l}\text { Dicentra } \\
\text { formosa }\end{array}$ & es & No & Herb & 3 & 2 & Animal & 1 & $\mathrm{n} / \mathrm{a}$ & Nat & Tol & No & FACU \\
\hline
\end{tabular}




\begin{tabular}{|c|c|c|c|c|c|c|c|c|c|c|c|c|}
\hline $\begin{array}{l}\text { Digitaria } \\
\text { sanguinalis }\end{array}$ & Yes & No & Gram & 2 & 2 & None & 1 & 1 & Non & Intol & No & FACU \\
\hline $\begin{array}{l}\text { Dipsacus } \\
\text { fullonum }\end{array}$ & Yes & No & Herb & 4 & 3 & None & 2 & 3 & Non & Intol & No & FAC \\
\hline $\begin{array}{l}\text { Echinochloa } \\
\text { crus-galli }\end{array}$ & Yes & No & Gram & 3 & 2 & Water & 2 & 5 & Non & Inter & No & FAC \\
\hline Fabaceae & Yes & No & $\mathrm{n} / \mathrm{a}$ & $\mathrm{n} / \mathrm{a}$ & $\mathrm{n} / \mathrm{a}$ & $\mathrm{n} / \mathrm{a}$ & $\mathrm{n} / \mathrm{a}$ & $\mathrm{n} / \mathrm{a}$ & $\mathrm{n} / \mathrm{a}$ & $\mathrm{n} / \mathrm{a}$ & $\mathrm{n} / \mathrm{a}$ & $\mathrm{n} / \mathrm{a}$ \\
\hline $\begin{array}{l}\text { Frangula } \\
\text { purshiana }\end{array}$ & Yes & No & Tree & 5 & 3 & Animal & 4 & 3 & Nat & Tol & Yes & FAC \\
\hline $\begin{array}{l}\text { Fraxinus } \\
\text { latifolia } \\
\end{array}$ & Yes & Yes & Tree & 5 & 2 & Wind & 4 & 3 & Nat & Inter & No & FACW \\
\hline Galium aparine & No & Yes & Herb & 5 & 2 & Animal & 1 & 1 & Nat & Tol & Yes & FACU \\
\hline $\begin{array}{l}\text { Geranium } \\
\text { robertianum }\end{array}$ & Yes & Yes & Herb & 3 & 2 & Ballistic & 1 & 1 & Non & Tol & No & FACU \\
\hline Geranium spp. & Yes & No & Herb & $\mathrm{n} / \mathrm{a}$ & $\mathrm{n} / \mathrm{a}$ & Ballistic & 1 & 1 & $\mathrm{n} / \mathrm{a}$ & $\mathrm{n} / \mathrm{a}$ & No & $\mathrm{n} / \mathrm{a}$ \\
\hline Geum spp. & Yes & Yes & Herb & 3 & 3 & Animal & 1 & 2 & $\mathrm{n} / \mathrm{a}$ & Tol & Yes & $\mathrm{n} / \mathrm{a}$ \\
\hline $\begin{array}{l}\text { Glechoma } \\
\text { hederacea }\end{array}$ & Yes & No & Herb & 2 & 1 & None & 1 & 1 & Non & Tol & No & FACU \\
\hline Holcus lanatus & Yes & Yes & Gram & 1 & 2 & Find & 1 & 2 & Non & Inter & $\mathrm{n} / \mathrm{a}$ & FAC \\
\hline $\begin{array}{l}\text { Holodiscus } \\
\text { discolor }\end{array}$ & Yes & No & Shrub & 1 & 1 & ind & 2 & 3 & Nat & Intol & Yes & FACU \\
\hline $\begin{array}{l}\text { Hydrophyllum } \\
\text { tenuipes }\end{array}$ & No & Yes & Herb & 5 & 2 & None & 1 & 1 & Nat & Tol & No & FAC \\
\hline $\begin{array}{l}\text { Hypochaeris } \\
\text { radicata }\end{array}$ & Yes & No & Herb & 2 & 3 & $1 \mathrm{Iu}$ & 1 & 1 & Non & Inter & Yes & FACU \\
\hline Ilex aquifolium & Yes & Yes & Tree & 5 & 3 & Ial & 2 & 3 & Non & Tol & No & FACU \\
\hline $\begin{array}{l}\text { Impatiens } \\
\text { capensis }\end{array}$ & Yes & Yes & Herb & 5 & 2 & Ballistic & 1 & 1 & Non & Tol & No & FACW \\
\hline Juncaceae & Yes & No & Gram & $\mathrm{n} / \mathrm{a}$ & $\mathrm{n} / \mathrm{a}$ & $\mathrm{n} / \mathrm{a}$ & $\mathrm{n} / \mathrm{a}$ & $\mathrm{n} / \mathrm{a}$ & $\mathrm{n} / \mathrm{a}$ & $\mathrm{n} / \mathrm{a}$ & $\mathrm{No}$ & $\mathrm{n} / \mathrm{a}$ \\
\hline Lactuce & Yes & Yes & Herb & 2 & 3 & Wind & 2 & 1 & Non & Intol & Yes & FACU \\
\hline Lamiaceae & Yes & Yes & Herb & 3 & 2 & $\mathrm{n} / \mathrm{a}$ & 1 & $\mathrm{n} / \mathrm{a}$ & $\mathrm{n} / \mathrm{a}$ & $\mathrm{n} / \mathrm{a}$ & No & $\mathrm{n} / \mathrm{a}$ \\
\hline $\begin{array}{l}\text { Lapsana } \\
\text { communis }\end{array}$ & Yes & Yes & erb & 2 & 2 & & 2 & 1 & Non & ater & No & FACU \\
\hline $\begin{array}{l}\text { Leersia } \\
\text { oryzoides }\end{array}$ & Yes & No & Gram & 3 & 2 & er & 2 & 1 & Nat & Intol & Yes & OBL \\
\hline $\begin{array}{l}\text { Leucanthemum } \\
\text { vulgare }\end{array}$ & Yes & No & erb & 1 & 2 & one & 1 & 2 & Non & nter & Yes & FACU \\
\hline $\begin{array}{l}\text { Matricaria } \\
\text { discoidea }\end{array}$ & Yes & No & Herb & 1 & 1 & None & 1 & 2 & Nat & Intol & No & FACU \\
\hline $\begin{array}{l}\text { Melissa } \\
\text { officinalis }\end{array}$ & Yes & No & Herb & 2 & 1 & & 1 & 1 & Non & Inter & No & FACU \\
\hline Mentha spp. & Yes & No & Herb & $\mathrm{n} / \mathrm{a}$ & 1 & Water & 1 & 1 & $\mathrm{n} / \mathrm{a}$ & Intol & No & $\mathrm{n} / \mathrm{a}$ \\
\hline
\end{tabular}




\begin{tabular}{|c|c|c|c|c|c|c|c|c|c|c|c|c|}
\hline $\begin{array}{l}\text { Oenanthe } \\
\text { sarmentosa }\end{array}$ & Ies & No & Herb & 3 & 1 & Water & 1 & 2 & Nat & Tol & No & OBL \\
\hline Oxalis spp. & Yes & Yes & Herb & 3 & 2 & Ballistic & 1 & 1 & $\mathrm{n} / \mathrm{a}$ & $\mathrm{n} / \mathrm{a}$ & $\mathrm{No}$ & FACU \\
\hline Panicum spp. & Yes & No & Gram & 3 & 1 & Wind & 1 & 1 & Non & Inter & No & $\mathrm{n} / \mathrm{a}$ \\
\hline Persicaria spp. & Yes & No & Herb & $\mathrm{n} / \mathrm{a}$ & 2 & Water & 1 & 1 & $\mathrm{n} / \mathrm{a}$ & $\mathrm{n} / \mathrm{a}$ & No & $\mathrm{n} / \mathrm{a}$ \\
\hline $\begin{array}{l}\text { Phalaris } \\
\text { arundinacea }\end{array}$ & Yes & No & Gram & 2 & 2 & None & 2 & 2 & Non & Intol & No & FACW \\
\hline $\begin{array}{l}\text { Physocarpus } \\
\text { capitatus }\end{array}$ & Yes & No & Shrub & 2 & 2 & None & 2 & 4 & Nat & Intol & No & FACW \\
\hline Poaceae & Yes & Yes & Gram & 4 & 2 & $\mathrm{n} / \mathrm{a}$ & 2 & $\mathrm{n} / \mathrm{a}$ & $\mathrm{n} / \mathrm{a}$ & $\mathrm{n} / \mathrm{a}$ & No & $\mathrm{n} / \mathrm{a}$ \\
\hline Polygonaceae & Yes & No & Herb & 3 & 2 & $\mathrm{n} / \mathrm{a}$ & 2 & $\mathrm{n} / \mathrm{a}$ & $\mathrm{n} / \mathrm{a}$ & $\mathrm{n} / \mathrm{a}$ & No & $\mathrm{n} / \mathrm{a}$ \\
\hline $\begin{array}{l}\text { Populus } \\
\text { trichocarpa }\end{array}$ & Yes & Yes & Tree & 1 & 2 & Wind & 4 & 5 & Nat & Intol & Yes & FAC \\
\hline $\begin{array}{l}\text { Prunella } \\
\text { vulgaris }\end{array}$ & Yes & No & Herb & 3 & 2 & None & 1 & 1 & Nat & Inter & No & FACU \\
\hline Prunus avium & Yes & Yes & Tree & 5 & 3 & Animal & 4 & 3 & Nat & Tol & No & FACW \\
\hline $\begin{array}{l}\text { Prunus } \\
\text { laurocerasus }\end{array}$ & Yes & No & Shrub & 1 & 4 & Animal & 3 & 2 & Non & Tol & No & none \\
\hline Prunus spp. & Yes & No & Tree & 5 & 3 & Animal & $\mathrm{n} / \mathrm{a}$ & $\mathrm{n} / \mathrm{a}$ & $\mathrm{n} / \mathrm{a}$ & Tol & No & $\mathrm{n} / \mathrm{a}$ \\
\hline $\begin{array}{l}\text { Pseudotsuga } \\
\text { menziesii }\end{array}$ & Yes & Yes & Tree & 5 & 4 & Wind & 4 & 4 & Nat & Inter & Yes & FACU \\
\hline Quercus spp. & Yes & Yes & Tree & 5 & 4 & Animal & 4 & 4 & $\mathrm{n} / \mathrm{a}$ & Inter & No & $\mathrm{n} / \mathrm{a}$ \\
\hline $\begin{array}{l}\text { Ranunculus } \\
\text { repens }\end{array}$ & Yes & Yes & Herb & 3 & 2 & None & 1 & 1 & Non & Tol & Yes & FAC \\
\hline $\begin{array}{l}\text { Robinia } \\
\text { pseudoacacia }\end{array}$ & Yes & No & Tree & 5 & 3 & None & 4 & 4 & Non & Intol & No & FACU \\
\hline Rubus spp. & Yes & Yes & Shrub & 4 & 2 & Animal & 3 & 4 & $\mathrm{n} / \mathrm{a}$ & $\mathrm{n} / \mathrm{a}$ & No & $\mathrm{n} / \mathrm{a}$ \\
\hline $\begin{array}{l}\text { Rumex } \\
\text { obtusifolius }\end{array}$ & Yes & Yes & Herb & 3 & 1 & V & 2 & 1 & Non & Inter & Yes & FAC \\
\hline Rumex spp. & Yes & Yes & Herb & 3 & 2 & Wind & 2 & 1 & $\mathrm{n} / \mathrm{a}$ & $\mathrm{n} / \mathrm{a}$ & Yes & $\mathrm{n} / \mathrm{a}$ \\
\hline Sambucus spp. & Yes & Yes & Shrub & 3 & 2 & Animal & 3 & 3 & Nat & Tol & Yes & $\mathrm{n} / \mathrm{a}$ \\
\hline $\begin{array}{l}\text { Scirpus } \\
\text { microcarpus }\end{array}$ & Yes & No & Gram & 1 & 1 & Water & 2 & 3 & Nat & Intol & Yes & OBL \\
\hline Scirpus spp. & Yes & No & Gram & 2 & 2 & $\mathrm{n} / \mathrm{a}$ & 2 & 3 & $\mathrm{n} / \mathrm{a}$ & $\mathrm{n} / \mathrm{a}$ & Yes & $\mathrm{n} / \mathrm{a}$ \\
\hline Senecio spp. & Yes & No & Herb & 1 & 2 & Wind & 1 & 2 & Non & Intol & Yes & FACU \\
\hline $\begin{array}{l}\text { Solanum } \\
\text { dulcamara }\end{array}$ & Yes & No & Herb & 5 & 2 & Animal & 2 & 2 & Non & Inter & Yes & FAC \\
\hline Sonchus asper & Yes & No & Herb & 1 & 2 & Wind & 1 & 2 & Non & Inter & No & FACU \\
\hline $\begin{array}{l}\text { Taraxacum } \\
\text { officinale }\end{array}$ & es & $\mathrm{Ye}$ & erb & 2 & 2 & Wind & 1 & 2 & Non & ater & Yes & FACU \\
\hline $\begin{array}{l}\text { Tellima } \\
\text { grandiflora }\end{array}$ & Yes & Yes & Herb & 1 & 1 & Ballistic & 1 & 3 & Nat & Tol & No & FACU \\
\hline Thuja plicata & Yes & Yes & Tree & 3 & 3 & Wind & 4 & 4 & Nat & Tol & Yes & FAC \\
\hline $\begin{array}{l}\text { Tolmiea } \\
\text { menziesii }\end{array}$ & Yes & Yes & Herb & 1 & 1 & Animal & 1 & 3 & Nat & Tol & Yes & FAC \\
\hline Trifolium spp. & Yes & No & Herb & 3 & 1 & None & 1 & 1 & Non & Intol & No & $\mathrm{n} / \mathrm{a}$ \\
\hline
\end{tabular}




\begin{tabular}{|l|l|l|l|l|l|l|l|l|l|l|l|l|} 
Tsuga & & & & & & & & & & & & \\
heterophylla & Yes & Yes & Tree & 3 & 3 & Wind & 4 & 4 & Nat & Tol & Yes & FACU \\
\hline Urtica dioica & Yes & Yes & Herb & 1 & 1 & None & 2 & 3 & Nat & Tol & No & FAC \\
\hline
\end{tabular}




\section{Appendix B: Water-to-Turf Distance and Total Seed Deposition}

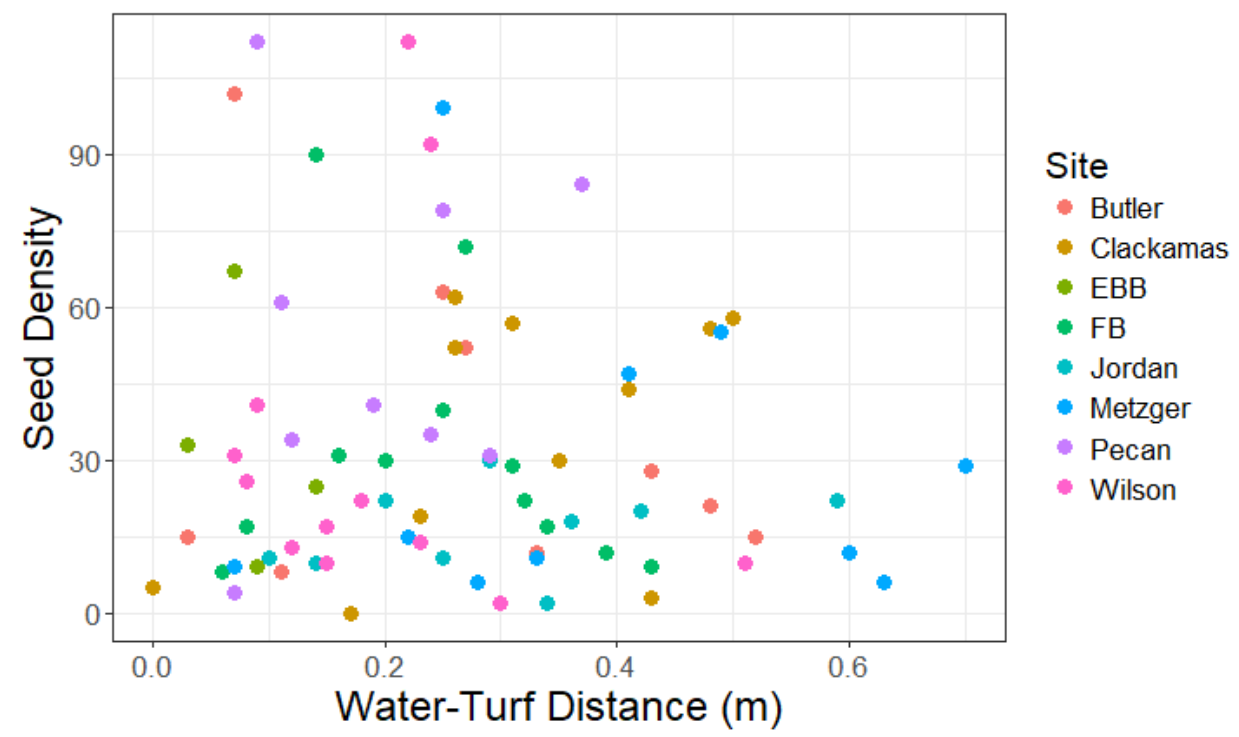

Figure B.1: Summer water-to-turf distance and p1 turf seed density. Linear mixed-effects models showed that there was no significant relationship between the vertical distance from the water surface to the bottom of the turf trap measured in summer, and total number of seeds collected per turf during p1.

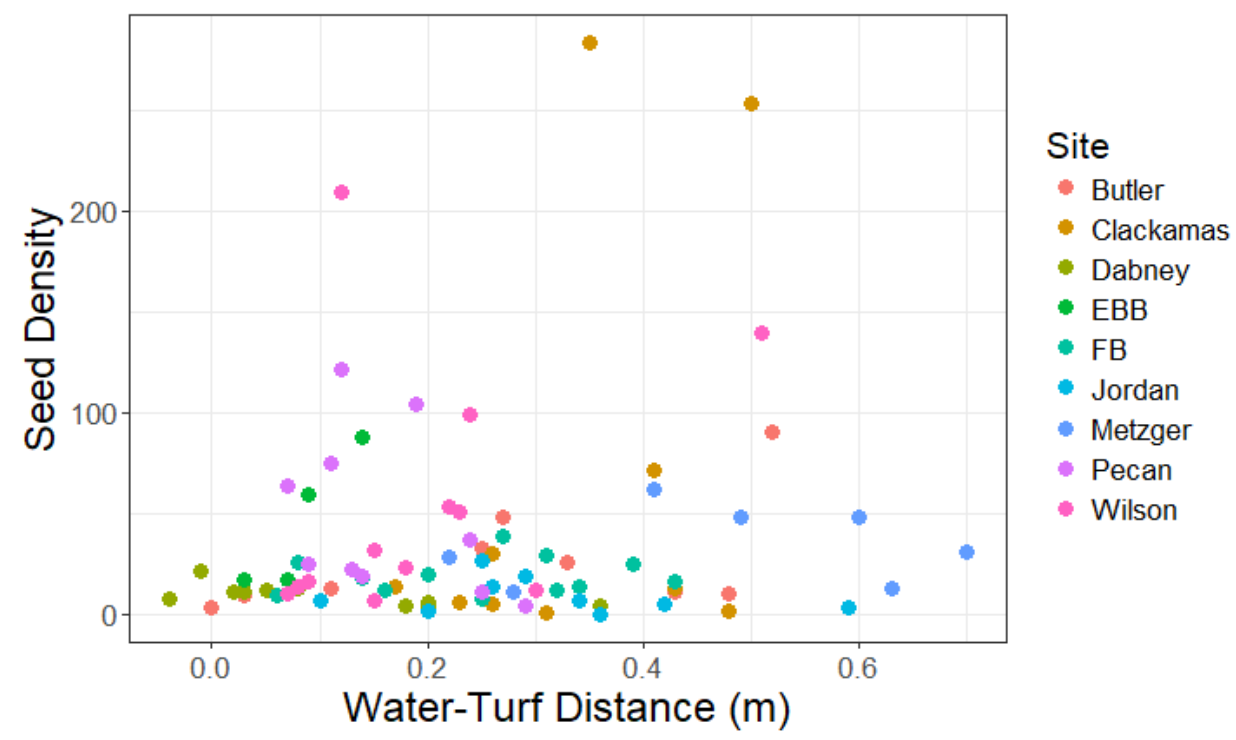

Figure B.2: Summer water-to-turf distance and p2 turf seed density. Linear mixed-effects models showed that there was no significant relationship between the vertical distance from the water surface to the bottom of the turf trap measured in summer, and total number of seeds collected per turf during p2. 


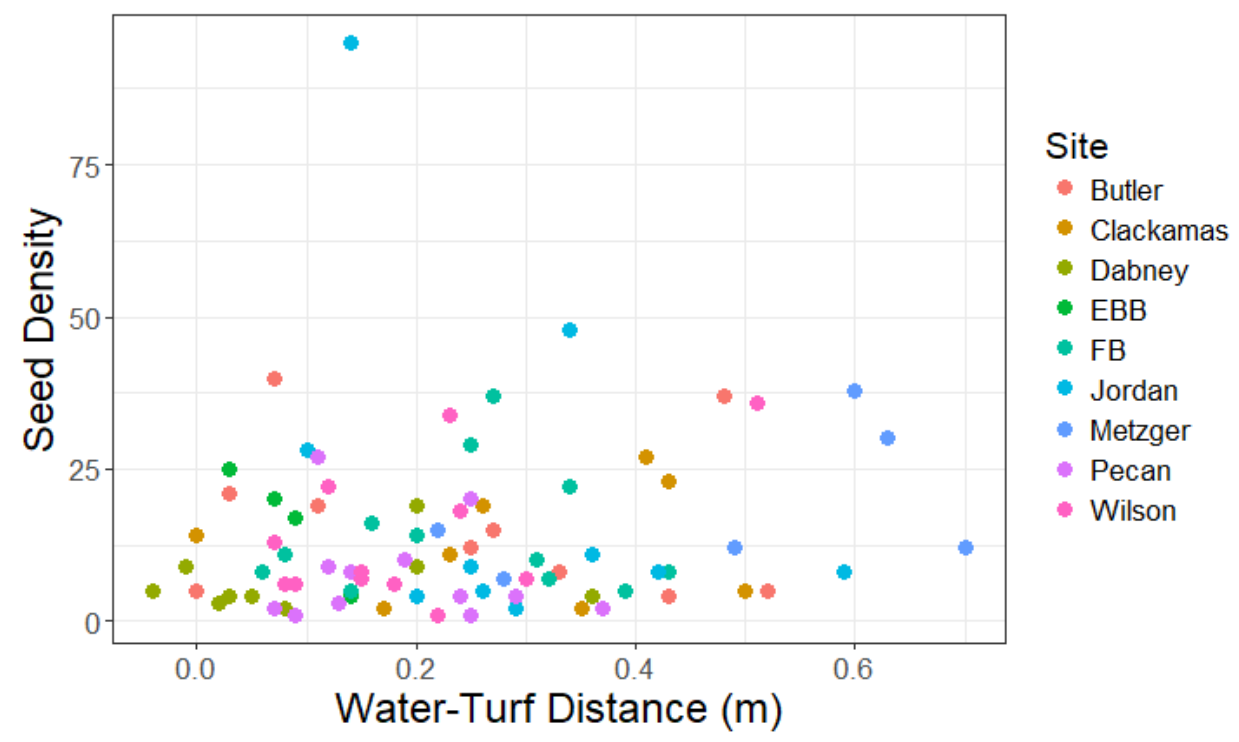

Figure B.3: Summer water-to-turf distance and p3 turf seed density. Linear mixed-effects models showed that there was no significant relationship between the vertical distance from the water surface to the bottom of the turf trap measured in summer, and total number of seeds collected per turf during p3.

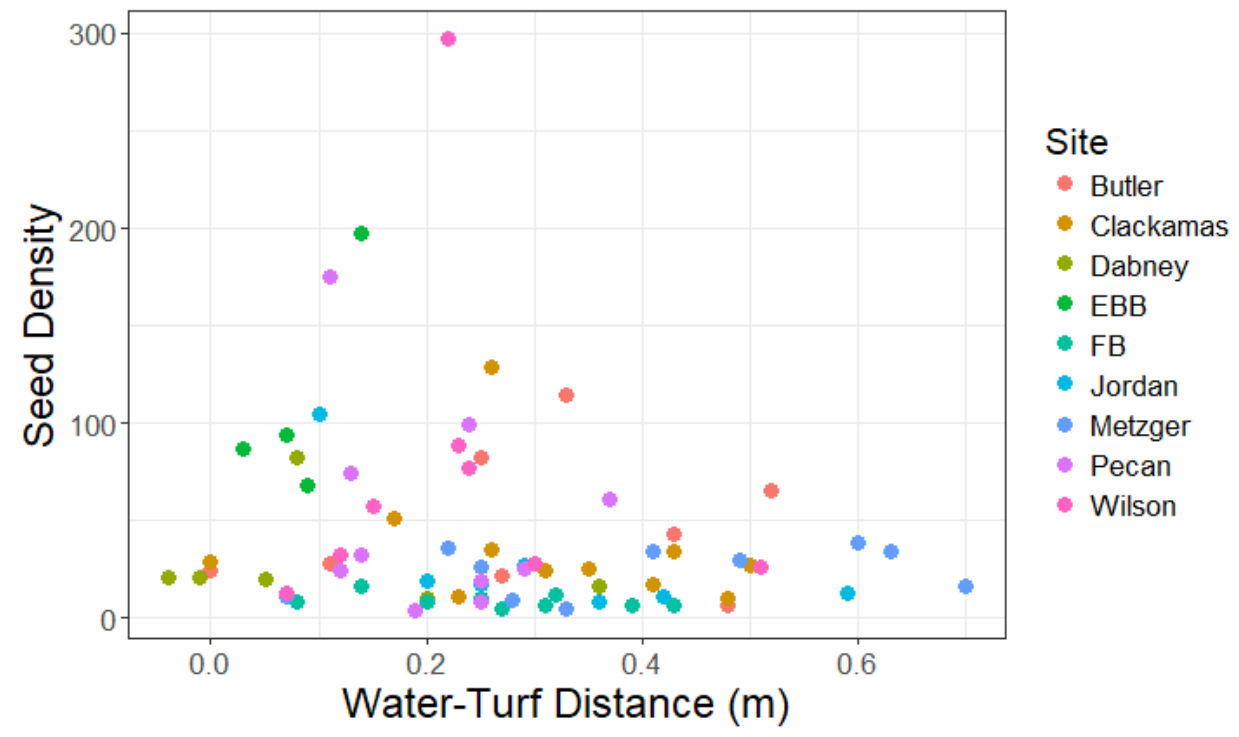

Figure B.4: Summer water-to-turf distance and p4 turf seed density. Linear mixed-effects models showed that there was no significant relationship between the vertical distance from the water surface to the bottom of the turf trap measured in summer, and total number of seeds collected per turf during p4. 


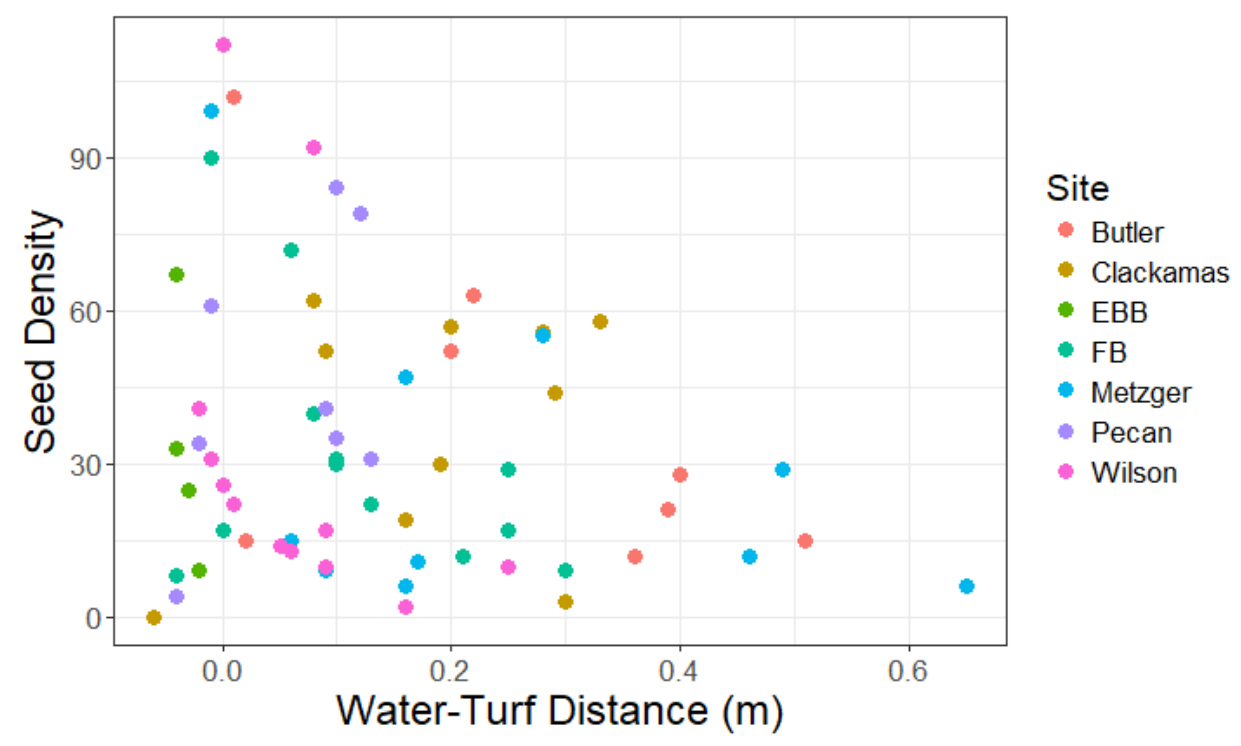

Figure B.5: Winter water-to-turf distance and p1 turf seed density. Linear mixed-effects models showed that there was no significant relationship between the vertical distance from the water surface to the bottom of the turf trap measured in winter, and total number of seeds collected per turf during p1.

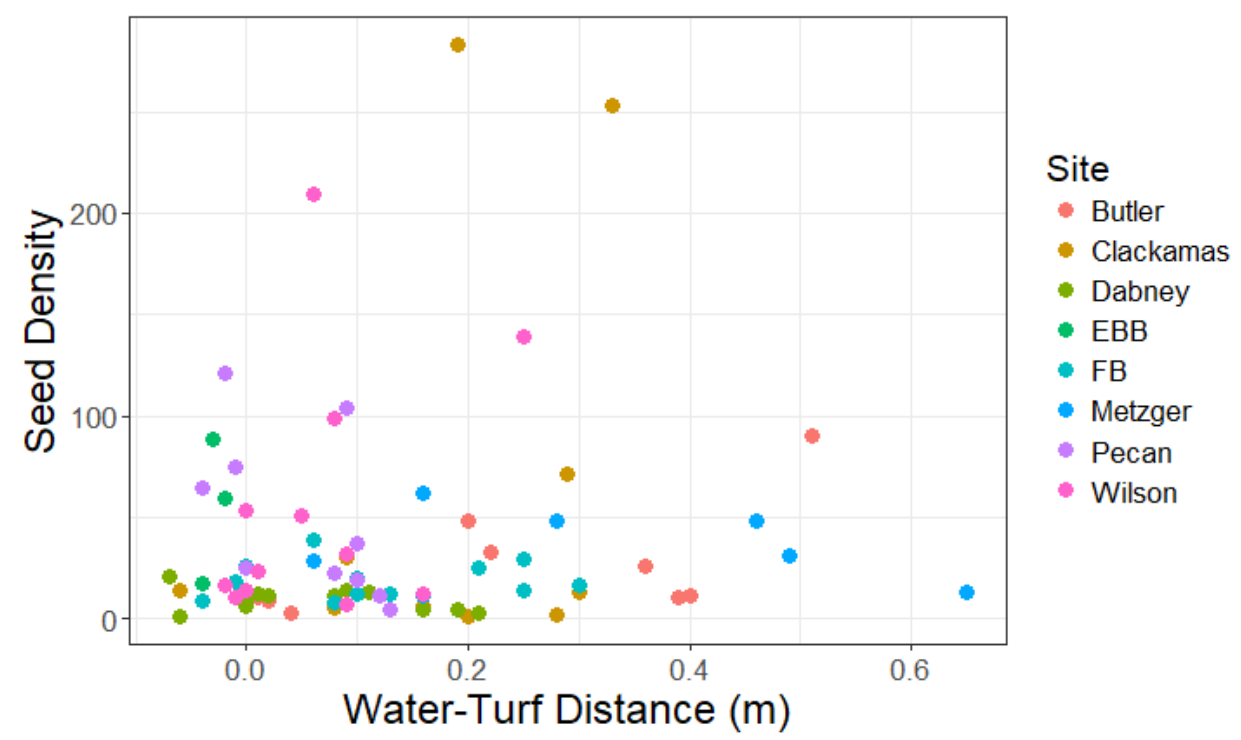

Figure B.6: Winter water-to-turf distance and p2 turf seed density. Linear mixed-effects models showed that there was no significant relationship between the vertical distance from the water surface to the bottom of the turf trap measured in winter, and total number of seeds collected per turf during p2. 


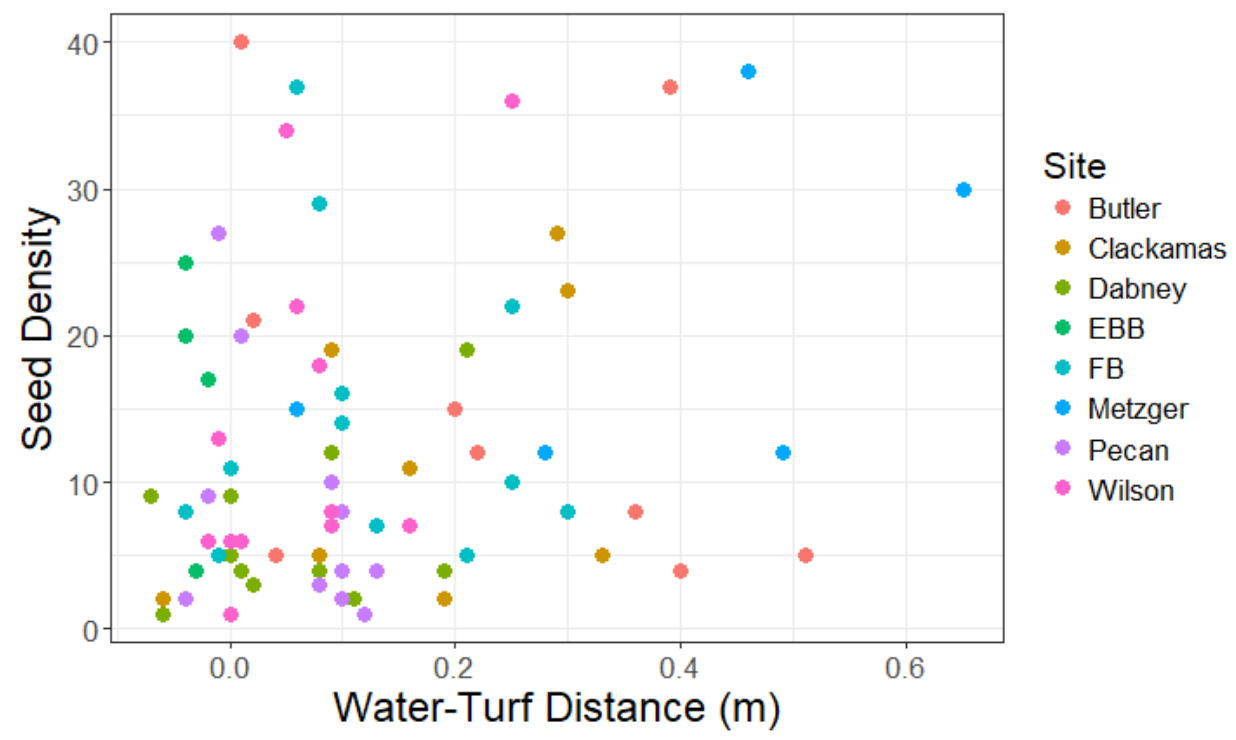

Figure B.7: Winter water-to-turf distance and p3 turf seed density. Linear mixed-effects models showed that there was no significant relationship between the vertical distance from the water surface to the bottom of the turf trap measured in winter, and total number of seeds collected per turf during p3.

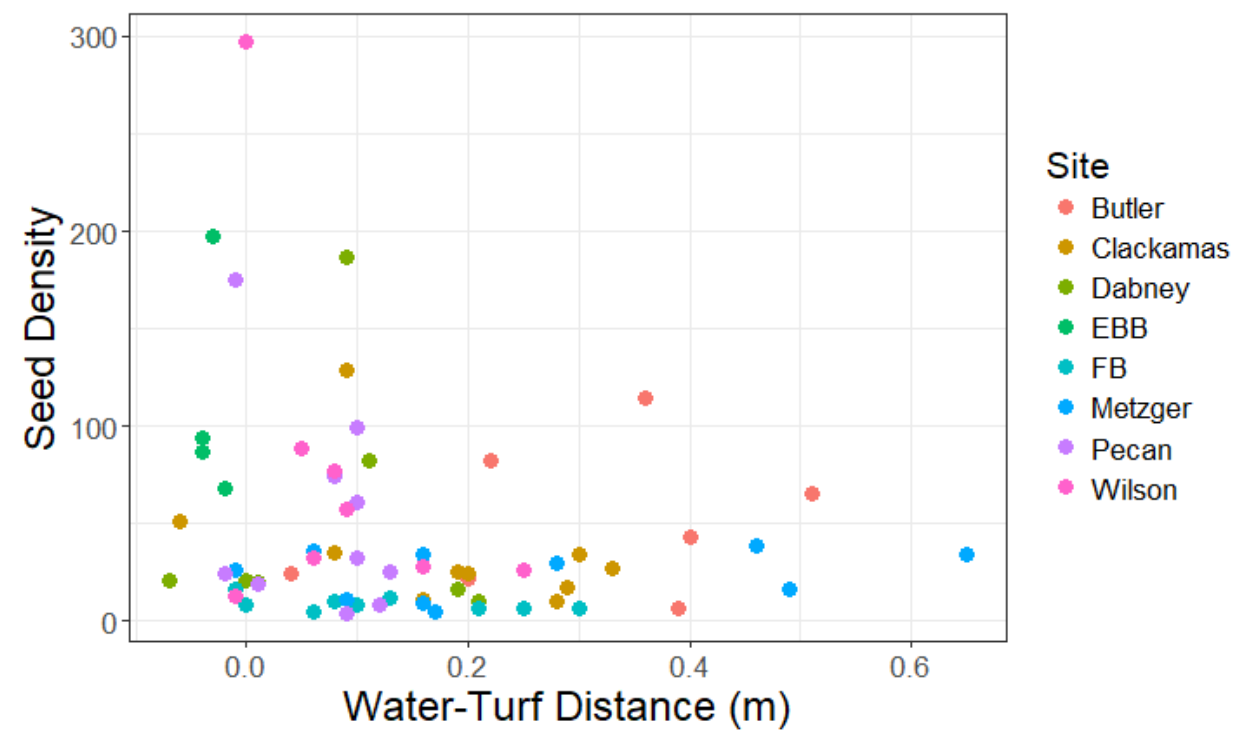

Figure B.8: Winter water-to-turf distance and p4 turf seed density. Linear mixed-effects models showed that there was no significant relationship between the vertical distance from the water surface to the bottom of the turf trap measured in winter, and total number of seeds collected per turf during $\mathrm{p} 4$. 
Table B.1: Linear mixed models investigating the effect of turf vertical distance from water and total seed deposition in four collection periods. Vertical distance between turf traps and stream water level was estimated in the winter of 2016. Total seed density was square root- or log-transformed to meet model assumption of normality. Vertical distance was not found to be a significant predictor of trap seed density in any collection period.

\begin{tabular}{|c|c|c|c|c|c|}
\hline \multirow[t]{4}{*}{ p1 } & \multicolumn{5}{|c|}{$\begin{array}{l}\text { Model: }(\text { VTotal }) \sim \text { Distance }+(1 \mid \text { Site }) \\
\text { Degrees of freedom: } 61 \\
\text { AIC: } 301.9\end{array}$} \\
\hline & Fixed Effects & Estimate & Standard Error & $\begin{array}{c}\text { t- } \\
\text { value }\end{array}$ & p-value \\
\hline & intercept & 5.981 & 0.400 & 14.949 & $2 \mathrm{e}-16^{* * *}$ \\
\hline & Distance & -3.347 & 1.925 & -1.739 & 0.087 \\
\hline \multirow[t]{4}{*}{ p2 } & \multicolumn{5}{|c|}{$\begin{array}{l}\text { Model: } \log (\text { Total }) \sim \text { Distance }+(1 \mid \text { Site }) \\
\text { Degrees of freedom: } 72 \\
\text { AIC: } 241.4\end{array}$} \\
\hline & Fixed Effects & Estimate & Standard Error & $\begin{array}{c}\mathrm{t}- \\
\text { value }\end{array}$ & p-value \\
\hline & intercept & 2.899 & 0.238 & 12.179 & $7.3 \mathrm{e}-8^{* * *}$ \\
\hline & Distance & 0.754 & 0.944 & 0.798 & 0.428 \\
\hline \multirow[t]{4}{*}{ p3 } & \multicolumn{5}{|c|}{$\begin{array}{l}\text { Model: } \log (\text { Total }) \sim \text { Distance }+(1 \mid \text { Site }) \\
\text { Degrees of freedom: } 70 \\
\text { AIC: } 205.8\end{array}$} \\
\hline & Fixed Effects & Estimate & Standard Error & $\begin{array}{c}\text { t- } \\
\text { value }\end{array}$ & p-value \\
\hline & intercept & 2.01 & 0.177 & 11.373 & $5.2 \mathrm{e}-7^{* * * *}$ \\
\hline & Distance & 1.232 & 0.762 & 1.616 & 0.112 \\
\hline \multirow[t]{4}{*}{ p4 } & \multicolumn{5}{|c|}{$\begin{array}{l}\text { Model: } \log (\text { Total }) \sim \text { Distance }+(1 \mid \text { Site }) \\
\text { Degrees of freedom: } 62 \\
\text { AIC: } 186.6\end{array}$} \\
\hline & Fixed Effects & Estimate & Standard Error & $\begin{array}{c}\mathrm{t}- \\
\text { value }\end{array}$ & p-value \\
\hline & intercept & 3.456 & 0.262 & 13.188 & $2.8 \mathrm{e}-7 * * *$ \\
\hline & Distance & -0.610 & 0.837 & -0.729 & 0.469 \\
\hline
\end{tabular}

